\title{
Jahwe unser Gott: Sprache, Aufbau und Erzähltechnik in der Berufung des Mose (Ex 3-4)
}

Fischer, Georg

\begin{abstract}
Die Berufung des Mose (Exodus 3,1-4,17) präsentiert einen Schnittpunkt göttlichen Zugehens auf die Menschen und menschlicher Annahme dieser Selbsterschliessung. Entscheidende Faktoren in diesem Dialog sind das Reden von Gott, die Einwände des Mose und das Einbeziehen vergangener und zukünftiger Geschichte. In Verbindung mit dem Zeitpunkt (Anfang der Volkswerdung und Beginn der Geschichte der Befreiung) erlauben Vokabular und Entwicklung eine Deutung von Ex 3-4 als Verdichtungs- und Wendepunkt: Noch einmal werden Themen aus der Gen aufgegriffen, und zugleich wird ein weiter und teils sehr präziser Ausblick in eine neue Zukunft gegeben. In diesen Wandel wird alles hineingerissen, der Gott der Väter, Mose der Hirte und die Söhne Israels in Ägypten. Die einzige Größe, die in dieser Verwandlung Halt geben kann - und sie dabei sogar selbst provoziert hat! -, ist die bleibende Identität Gottes, die in der Gleichsetzung des Vätergottes mit Jahwe zum Ausdruck kommt. Ihr entspricht das Bekenntnis „Jahwe unser Gott“. Diese am Päpstlichen Bibelinstitut in Rom entstandene Dissertation folgt dem in der Literaturwissenschaft üblichen Vorgehen. Nach Übersetzung, Abgrenzung, Untersuchung von Form und Gliederung kommt eine ausführliche Textanalyse. Als ein Ergebnis zeigt sich dabei, dass wir mit erzählerischer Einheitlichkeit des Textes rechnen müssen. Fünft Exkurse gehen auf besondere Texteigenheiten ein, wie z.B. den doppelten Namensanruf „Mose! Mose!“ oder Ex 3,14a „Ich werde sein, wer immer ich sein werde“. Das letzte Kapitel, eher theologisch, befasst sich u.a. mit der literarischen Konvention des Einsetzungsberichtes, mit den Personen der Erzählung, Jahwe und Mose, und mit dem Paradox des brennenden und nicht verbrennenden Dornbusches. Insgesamt zeigt sich die Berufung des Mose so als die aus monotheistischem Glauben heraus formulierte literarische Projektion eines einheitsstiftenden und identitätsbildenden Angelpunktes innerhalb des AT.
\end{abstract}

Posted at the Zurich Open Repository and Archive, University of Zurich

ZORA URL: https://doi.org/10.5167/uzh-151435

Monograph

Published Version

Originally published at:

Fischer, Georg (1989). Jahwe unser Gott: Sprache, Aufbau und Erzähltechnik in der Berufung des Mose (Ex 3-4). Freiburg, Switzerland / Göttingen, Germany: Universitätsverlag / Vandenhoeck Ruprecht. 
FISCHER - JAHWE UNSER GOTT 
Im Auftrag des Biblischen Instituts der Universität Freiburg Schweiz des Seminars für biblische Zeitgeschichte der Universität Münster i. W. und der Schweizerischen Gesellschaft für orientalische Altertumswissenschaft herausgegeben von Othmar Keel unter Mitarbeit von Erich Zenger und Albert de Pury

Georg Fischer, geb. 5. Juni 1954 in Feldkirch/Vorarlberg, trat 1972 in die Gesellschaft Jesu in Nürnberg ein. Die Ordensausbildung umfaßte u. a. Studien der Philosophie in München (1974-1976) und der Theologie in Innsbruck (19781981), zuletzt am Päpstlichen Bibelinstitut in Rom (1981-1987). Lehrtätigkeit in Rom (Gregoriana) von 1985 bis 1987 und seit März 1988 an der Theologischen Fakultät der Universität Innsbruck. 


\author{
GEORG FISCHER
}

\title{
JAHWE UNSER GOTT
}

SPRACHE, AUFBAU UND ERZÄHLTECHNIK IN DER BERUFUNG DES MOSE (EX 3-4) 
CIP-Titelaufnahme der Deutschen Bibliothek

Fischer, Georg:

Jahwe, unser Gott: Sprache, Aufbau und Erzähltechnik in der Berufung des Mose (Ex 3-4) / Georg Fischer. - Freiburg, Schweiz: Univ.-Verl.; Göttingen: Vandenhoeck u. Ruprecht, 1989

(Orbis biblicus et orientalis; 91)

ISBN 3-525-53721-2 (Vandenhoeck u. Ruprecht) Gb.

ISBN 3-7278-0646-X (Univ.-Verl.) Gb.

NE: GT

Die Druckvorlagen

wurden vom Herausgeber als reprofertige

Dokumente zur Verfügung gestellt

(C) 1989 by Universitätsverlag Freiburg Schweiz

Vandenhoeck \& Ruprecht Göttingen

Paulusdruckerei Freiburg Schweiz

ISBN 3-7278-0646-X (Universitätsverlag) ISBN 3-525-53721-2 (Vandenhoeck \& Ruprecht)

Digitalisat erstellt durch Florian Lippke, Departement für Biblische Studien, Universität Freiburg Schweiz 
Meinen Eltern, in Dankbarkeit und Freude 


\section{INHALTSVERZEICHNIS}

Einleitung 3

1. Kapitel: Übersetzung und Abgrenzung 7

1.1 Übersetzung 7

Erläuterungen zur Übersetzung: Ex $3 \ldots 11$

Ex $4 \ldots 18$

1.2 Abgrenzung 21

1.2.1 Bestimmung der textlichen Einheit 21

$\begin{array}{ll}1.2 .2 & \text { Die übergänge }\end{array}$

2. Kapitel: Form und Aufbau 37

$2.1 \quad$ Formale Gestaltung 37

2.1.1 Rede und Gegenrede 38

$\begin{array}{lll}\text { Exkurs 1: Wiederholte Redeeinleitungen } & 41-45 & \\ 2 \text { Das Berufungsschema } & & 47\end{array}$

$\begin{array}{lll}2.1 .2 & \text { Das Berufungsschema } & 47 \\ 2.1 .3 & \text { Der Bericht von der Sendung des Retters } & 53\end{array}$

2.1.4 Der Konflikt Begehren - Erfüllung 58

$\begin{array}{lll}2.1 .5 & \text { Ergebnis } & 65\end{array}$

2.2 Vier semantische Felder 67

2.2.1 Das semantische Feld des Sehens: Ex 3,1-9 69

2.2.2 Das semantische Feld der Sendung: Ex 3,10-22 72

2.2.3 Das sem. Feld der Glaubwürdigkeit: Ex 4,1-9 76

2.2.4 Das semantische Feld des Sprechens: Ex 4,10-17 79

2.2.5 Rückblick 81

2.3 Die sechs Bilder 83

2.3.1 1. Bild: Inszenierung Ex 3,1-6 85

2.3.2 2. Bild: Gottes Anliegen Ex 3,7-12 87

2.3.3 3. Bild: Der Name des Sendenden Ex 3,13-15 88

2.3.4 4. Bild: Jahwes Plan Ex 3,16-22 89

2.3.5 5. Bild: Jahwes Machterweis Ex 4,1-9 91

2.3.6 6. Bild: Mitbestellung Aarons Ex 4,10-17 93

2.3.7 Auswertung 94

3. Kapitel: Analyse der Entwicklung 99

3.1 Ex 3,1-6: Inszenierung 99

Exkurs 2: Doppelter Namensanruf 105-107 (Rüickblick 114)

Exkurs 3: Epiphanie- und Berufungselemente
in Ex 3,1-6

3.2 Ex 3,7-12: Gottes Anliegen 122 (Rückblick 133)

3.3 Ex 3,13-15: Der Name des Sendenden 134 (Rückblick 144)

Exkurs 4: Zum Verständnis von Ex 3,14a 147-154 
3.4 Ex 3,16-22: Jahwes Plan 154 (Rückblick 169)

$\begin{array}{lll}3.5 & \text { Ex 4,1-9: Jahwes Machterweis } & 171\end{array}$ (Rückblick 181)

3.6 Ex 4, 10-17: Mitbestellung Aarons 184 Exkurs 5: Moses Unfähigkeit zu sprechen 186-192 (Rückblick 200)

3.7 Auswertung der Analyse

4. Kapitel: Konventionen und Personen der Erzählung 205

4.1 Literarische Konventionen 205

4.1.1 Ex 3,15 - ein Einsetzungsbericht 205

4.1.2 Die Erzählung vom Anfang 210

4.1.3 Sichtbares Wort 212

4.2 Der Kontext von Gottesbild und Berufung 216

4.2.1 Jahwes Beziehung zum vätergott 216

4.2.2 Ex 3-4 im Vergleich mit anderen Berufungen 221

4.3 Jahwe und Mose 224

4.3.1 Die Präsentation Gottes durch den Erzähler 224

4.3.2 Gottes Reden über sich selbst 226

4.3.3 Die Einwände des Mose 228

$\begin{array}{ll}\text { 4.3.4 Die Verwandlung des Mose } & 230\end{array}$

$\begin{array}{lr}\text { Abkürzungsverzeichnis } & 235\end{array}$

Literaturverzeichnis $\quad 236$

$\begin{array}{ll}\text { Verzeichnis der Bibelstellen } & 251\end{array}$

$\begin{array}{lr}\text { Namenregister } & 255\end{array}$

$\begin{array}{ll}\text { Stichwortregister } & 258\end{array}$

SCHEMATA

Schema 1: Die Reden Gottes und Moses 40

Schema 2: Abfolge der Elemente des Berufungsschemas 50

Schema 3: Begehren - Erfüllung (2.Ebene) 61

Schema 4: Begehren - Erfüllung: 1.+ 2.Ebene 62

Schema 5: Sem. Felder und ihre Schlüsselwörter

Schema 6: Hauptmerkmale der sechs Bilder 95

Schema 7: אמן Hi und שמן in Ex 4,1-9 179

Schema 8: zeitformel mit mehrfachem a 187

$\begin{array}{ll}\text { Schema 9: Einsetzungsberichte } & 207\end{array}$ 
Man kann den höchsten Gott mit allen Namen nennen, man kann ihm wiederum nicht einen zuerkennen.

Angelus Silesius

\section{EINLEITUNG}

\section{Hinführung}

In der Literatur zu Exodus 3-4 begegnen wir zwei grundsätzlich verschiedenen Haltungen. Eine Gruppe von Autoren entdeckt im Text von Anfang an vielfache Spannungen und wiederholungen und rechnet deshalb sofort damit, daß der Text eine vorgeschichte hat. Sie aufzudecken und ursprüngliche Textgestalten zu gewinnen, wird zu ihrem Hauptinteresse. Die entwicklungsgeschichtlichen Rekonstruktionen sind im einzelnen verschieden. Meist rechnet man mit mehreren "Quellen" und hält, wie zumindest die Praxis zeigt, die Scheidung dieser Quellen und ihre getrennte Behandlung für die einzig mögliche Grundlage einer soliden Auslegung (z.B. H. GreBmann, w.Richter, P.Weimar, W.H.Schmidt). In einem solchen Fall ist es nicht nötig, ja sogar überflüssig, sich weiter um den Aufbau des vorliegenden Textes zu bemühen - gibt er ja doch nur die Organisation eines aus verschiedenen Quellen und Redaktionen zusammengesetzten Gemisches wieder.

Dieser ersten Gruppe steht eine zweite gegenüber, die annimmt, der uns überlieferte Text in seiner Letztgestalt mache Sinn, und die deswegen von der "Einheitlichkeit" des Textes ausgeht (B.Jacob, U.Cassuto, M.Greenberg, B.S.Childs). "Einheitlichkeit" wird dabei nicht notwendig gleichgesetzt mit "von einer Hand stammend" - die vertreter dieser Position nehmen teils selbst mehrere Quellen an! -, sondern verstanden als jene Eigenschaft des Textes, die ein kohärentes und sinnvolles Lesen des betreffenden Textes ermöglicht. Das bedeutet, daß der ganze Text von einem Gesichtspunkt aus gelesen und verstanden werden kann, ohne daß zu große spannungen zu widersprüchen führen. In der Sicht dieser zweiten Gruppe ist es zum Beispiel möglich und erwünscht, eine Gliederung des Textes herauszuarbeiten. 
Die Position des Autors liegt in der Nähe der zweiten Gruppe, allerdings mit dem zusatz, daB er sich um den Aufweis dieser "Einheitlichkeit" bemühen möchte. Wenn wir mit der "Einheitlichkeit" eines Textes - bei Beibehaltung der Verwendung verschiedener Quellen - argumentieren, müssen wir den Nachweis dieser Einheitlichkeit leisten. Die vorliegende Arbeit möchte dieser Forderung wenigstens teilweise nachkommen.

Als Weg zu diesem ziel wird der Ansatz der Literaturwissenschaft verwendet, wie er in den standardwerken von E.Lämmert, $J$. Vogt, D.Gutzen, F.K.Stanzel u.a. beschrieben ist. Dieser zugang von manchen auch als "synchron" bezeichnet - ist in der englischund französischsprachigen Bibelwissenschaft verbreitet und gewinnt neuerdings, nach w.Richter und etwas anders als er, auch verstärkt Einfluß auf die deutsche Exegese. Das Methodenbuch von w.Egger mag als Zeugnis dafür dienen.

Da Studien mit diesem Ansatz unter den neueren bibelwissenschaftlichen Publikationen deutscher sprache eher selten sind, muB der Weg erst gebahnt werden. Der Autor bittet den Leser deswegen um Geduld bei den vielleicht fremden Begriffen und bei vorläufig scheinbar wenig ertragreichen Untersuchungen (vor allem in c1 und 2). Wer gleich Ergebnisse sehen möchte, wende sich zur Analyse der Verse (c3) oder zum folgenden Kapitel (c4) und schlage nur dann zuvor nach, wenn es Verweise gibt oder wenn er es wünscht; die Untersuchungen von $c 1$ und 2 sind, gerade unter dem Gesichtspunkt der Einheitlichkeit, in vielem die Basis für die später gemachten Beobachtungen.

\section{Schritte der Arbeit und Überblick}

Den Anfang jeder literaturwissenschaftlichen Untersuchung stellt eine gesicherte Textbasis dar. Der massoretische Text von Ex 3-4 weist wenige textkritische Probleme auf. Deswegen kann am Beginn der Arbeit eine übersetzung mit nachfolgenden Erläuterungen (1.1) stehen, wobei die getroffene Abgrenzung ausführlich begründet wird $(1.2)$. 
Ein Text ist normalerweise ein gegliedertes Ganzes. So wird im 2.Kapitel unsere Erzählung unter formalen Gesichtspunkten untersucht; zusätzlich sollen zwei mögliche Gliederungen vorgestellt werden. In beiden Fällen erweist sich unser Text als einheitlich: Unter den verschiedenen Formen zeigt sich ein zwar komplexer, aber zusammengehöriger Text. Und bei den Gliederungen bestehen dieselben Merkmale in allen Teilen der Erzählung, zeichen einer einheitlichen Durchgestaltung.

"Text als ProzeB" nennt C.Conroy einen seiner Untersuchungsschritte. In einer Analyse Vers für Vers (c3) wird die Entwicklung der Erzählung abzutasten versucht und gleichzeitig auf wichtige Ausdrücke oder Besonderheiten eingegangen. Auch in erzählerischer und inhaltlicher Hinsicht erweist sich Ex 3,1-4,17 dabei als eine Einheit, was die im vorhergehenden Kapitel (besonders durch die Gliederungen) sich nahelegende Auffassung bestätigt und verstärkt.

Am Ende der Arbeit, in c4, weitet sich der Blick auf andere Texte und umfassendere Aspekte (z.B. die Frage des Monotheismus oder der Berufung), u.a. auch auf die Beziehungen zu verwandten Texten. Das Interesse gilt dabei vor allem den literarischen Konventionen und den Personen unserer Erzählung, Gott und Mose. Dieses letzte Kapitel greift in größeren zusammenhängen, eher theologisch, wesentliche Gesichtspunkte der Untersuchung nochmals aus anderer Perspektive auf und möchte so die Arbeit abrunden. An Stelle einer Wiederholung am SchluB wurde versucht, bei allen Unterpunkten von 2.1 bis 3.6 sowie bei der Analyse aller längeren Verse in c3 jeweils am Ende einen Rückblick zu halten. Besondere Bedeutung als Zusammenfassung kommt dabei der Auswertung $3.7 \mathrm{zu}$.

Der etwas unübliche Titel der Arbeit "Jahwe unser Gott" für Ex 3-4, sonst als Berufung des Mose bezeichnet, führt sich auf mehreres zurück: Einmal redet Gott in unserem Text sehr viel und in entscheidender Weise von sich. Er steht damit wenigstens ebenso im zentrum wie Mose. Dann kommt diese Formel "Jahwe unser Gott" hier zum ersten Mal vor, ist also neu für den von Gen 1 herkommenden Leser. Schließlich - das soll die Analyse von Ex 3,18 zeigen - ist diese Formel eine Art Programm. Sie möchte Menschen zum Bekenntnis des einen Gottes zusammenschlieBen. 


\section{Anerkennung}

Viele haben dazu beigetragen, daß diese Untersuchung so entstanden ist. Mein Dank gilt in erster Linie meinen Eltern, die die voraussetzungen gelegt haben $\mathrm{zu}$ solchem Arbeiten und mich immer unterstützten. Danken möchte ich auch meinem Orden, der Gesellschaft Jesu, und hier besonders den Oberen der Österreichischen Provinz, die mich für dieses studium bestimmt und freigestellt haben, sowie all denen, die mich durch ihr Lehren beschenkt haben: Unter vielen möchte ich Gebhard Jäger, Arnold Gamper und Klemens Stock erwähnen.

Die vorliegende Arbeit ist als Dissertation am Päpstlichen Bibelinstitut in Rom geschrieben und dort am 29.4.1988 verteidigt worden. Im Juni 1983 hatte Dennis J.McCarthy das Thema und mein Arbeiten mit ihm akzeptiert; zwei Monate später starb er in Salamanca. Sein Andenken ist mir unvergeBlich. Im am Bibelinstitut üblichen "annus ad doctoratum" haben mich Norbert Lohfink und Bob Lawton begleitet und geführt. Beiden bin ich sehr dankbar. Die Doktorarbeit ist von Jean Louis Ska und Horacio Simian-Yofre als erstem und zweitem Lektor betreut worden, die durch ihre Genauigkeit und Kritik das Wachsen dieser studie gefördert haben und denen ich dafür danke. Nicht vergessen möchte ich all die Freunde und Mitstudent(inn)en in Rom, die mir dort während des Lizentiats- und Doktoratsstudiums treue Weggefährten waren.

Die Aufnahme in die Reihe "Orbis Biblicus et Orientalis" verdanke ich Erich Zenger und othmar Keel. Ersterem sei herzlich gedankt für sein wohlwollen und vertrauen, letzterem für die ausgezeichnete und prompte Betreuung der Drucklegung. In diesem Zusammenhang auch einen besonderen Dank an die jungen Mitbrüder in Frankfurt, die das Programm wP-Plus entworfen und mir bei der Ausarbeitung der Druckvorlage geholfen haben. In großzügiger Weise haben meine Eltern, die Gesellschaft Jesu und die Vorarlberger Landesregierung die Druckkosten übernommen. 


\section{KAPITEL: ÜBERSETZUNG UND ABGRENZUNG}

\section{1 ÜBERSETZUNG (Ex 3,1-4,17)}

Hochgestellte Buchstaben verweisen auf die Erläuterungen, die am Ende der übersetzung folgen. Das Zeichen / zeigt den übergang von Versteil a zu Versteil b an (entspricht also dem massoretischen Atnach).

Der Erzähltext steht ohne Anführungszeichen und füllt die ganze zeile. Jahwerede ist eingerückt linksbündig, Moserede rechtsbündig wiedergegeben. Alle Reden stehen in Anführungszeichen.

3,1 Mose aber ${ }^{A}$ war dabei ${ }^{B}$, die Schafe Jitros, seines Schwiegervaters, des Priesters von Midian, zu hüten./ Und er führte die Schafe an den Rand der steppe ${ }^{C}$ und kam zum Gottesberg, zum Horeb.

3,2 Da erschien ihm Jahwes Bote als ${ }^{D}$ Feuersflamme mitten aus einem $^{E}$ Dornbusch heraus ${ }^{F}$./ Und er sah, und da: Der Dornbusch brannte lodernd ${ }^{G}$, aber der Dornbusch wurde nicht aufgezehrt.

Da sagte sich $^{\mathrm{H}}$ Mose:

"Ich will doch abbiegen, um diese großartige Erscheinung zu sehen!/ warum verbrennt ${ }^{J}$ der Dornbusch nicht?"

3,4 Und Jahwe sah, daB er abgebogen war, um zu sehen./ Da rief ihn Gott mitten aus dem Dornbusch heraus und sagte:

"Mose! Mose!"

Und er sagte: "Siehe mich!"K

3,5 Und er sagte:

"Nähere dich nicht hierher!/ Zieh deine Sandalen von deinen Füßen, denn das Gebiet, auf dem du stehst, ist heiliger Boden."

3,6 Und er sagte:

"Ich bin der Gott deines Vaters, der Gott Abrahams, der Gott Isaaks und der Gott Jakobs."/

Da verbarg Mose sein Gesicht, denn er fürchtete sich, den Gott anzublicken. 
3,7 Und Jahwe sagte:

"Sicherlich" habe ich das Elend meines Volkes gesehen, das in Ägypten ist ${ }^{M}$, / und ihr $^{N}$ Schreien habe ich gehört, vor seinen Antreibern; ja ${ }^{0}$, ich kenne seine Schmerzen.

3,8 So bin ich heruntergestiegen, um es aus der Hand der Ägypter herauszureißen und es hinaufzuführen von diesem Land in ein gutes und weites Land, in ein Land fließend von Milch und Honig,/ in das Gebiet des Kanaaniters, Hetiters, Amoriters, Perisiters, Hiwiters und Jebusiters.

3,9 Und nun, siehe: Das Geschrei der Israeliten ${ }^{P}$ ist zu mir gekommen, / und ich habe auch die Bedrückung gesehen, wie die Ägypter sie unterdrücken.

3,10 Und nun geh! Ich will dich zum Pharao senden,/ damit $^{Q}$ du mein Volk, die Israeliten, aus Ägypten herausführst!"

3,11

Und Mose sagte zu dem Gott:

"Wer bin ich, daß ich zum Pharao gehe/

und daß ich die Israeliten aus Ägypten herausführe?"

3,12 Und er sagte:

"Ich ${ }^{R}$ werde mit dir sein, und dies wird" dir das Zeichen sein, daß ich $^{\mathrm{T}}$ dich sende ${ }^{\mathrm{U}} \mathrm{V}^{\mathrm{V}} / \mathrm{Wenn}^{\mathrm{W}}$ du das Volk aus Ägypten herausführst, werdet ihr den Gott auf diesem Berg verehren."

3,13

Und Mose sagte zu dem Gott: "Wenn" ich zu den Israeliten komme und ihnen sage": >Der Gott eurer väter hat mich zu euch gesandt.</ und sie mich fragen ${ }^{Y}$ : was ist ${ }^{Z}$ sein Name?<, was soll ich ihnen antworten ${ }^{\prime}$ "

3,14 Und Gott sagte zu Mose:

"Ich werde sein, wer immer ich sein werde."a/

Und er sagte:

"So sollst du den Israeliten sagen: >"Ich-werdesein"b hat mich zu euch gesandt. <"

3,15 Und weiter sagte Gott zu Mose:

"So sollst du zu den Israeliten sagen: >Jahwe, der Gott eurer väter, der Gott Abrahams, der Gott Isaaks und der Gott Jakobs, hat mich zu euch gesandt./ Das wird ${ }^{C}$ mein Name auf ewig, und das 
meine Anrufung von Geschlecht zu Geschlecht ${ }^{d}$ sein!<

3,16 Geh und versammle die Ältesten Israels und sag zu ihnen: >Jahwe, der Gott eurer väter, ist mir erschienen, der Gott Abrahams, Isaaks und Jakobs, und hat gesagt:/ > $\mathbf{e}^{\text {GewiB }^{\mathbf{f}}}$ habe ich euch und das, was euch in Ägypten angetan worden ist, überprüft ${ }^{g}$,

3,17 und ich sagte $(\operatorname{mir})^{h}$ : $\gg>$ Ich will euch hinaufführen aus dem Elend Ägyptens in das Land des Kanaaniters, Hetiters, Amoriters, Perisiters, Hiwiters und Jebusiters, / in ein Land fließend von Milch und Honig. $<<<<$

3,18 Und sie werden auf deine stimme hören./ Und $\mathrm{du}^{i}$ sollst mit den Ältesten Israels zum König Ägyptens kommen, und ihr sollt ihm sagen: >Jahwe, der Gott der Hebräer, ist uns begegnet. Und nun wollen ${ }^{j}$ wir drei Tagreisen in die wüste ${ }^{k}$ gehen und Jahwe, unserem Gott, opfern.<

3,19 Ich aber ${ }^{1}$ weiß, daß der könig Ägyptens euch nicht gehen lassen wird,/ es sei denn ${ }^{m}$, wegen einer starken Hand.

3,20 So werde ich meine Hand ausstrecken und Ägypten mit all meinen Wundertaten schlagen, die ich in seiner Mitte tun werde./ Und danach wird er euch entlassen.

3,21 Und ich werde diesem Volk ${ }^{\circ}$ in den Augen der Ägypter Gunst verschaffen, / und es wird sein: Wenn ihr geht, geht ihr nicht leer.

3,22 Und es soll jede $\mathrm{p}^{\mathrm{p}}$ von ihrer Nachbarin und von ihrer Hausgenossin Gegenstände aus silber und Gegenstände aus Gold und Mäntel erbitten, / und ihr werdet sie euren Söhnen und euren Töchtern anlegen. So werdet ihr Ägypten frei machenq."

Und Mose antwortete und sagte:

"Aber wenn ${ }^{A}$ sie mir nicht glauben und nicht auf meine stimme hören, / sondern sagen: >Nicht ist dir Jahwe erschienen.< ?"

4,2 Und es sagte zu ihm Jahwe:

"Was ist das in deiner Hand?"/ 
Und er sagte:

"Ein Stab"

4,3 Und er sagte:

"Wirf ihn zur Erde!"

Und er warf ihn zur Erde, und er wurde zu einer Schlange./ Da fuhr $^{B}$ Mose vor ihr zurück.

4,4 Und Jahwe sagte zu Mose:

"streck deine Hand aus und erfasse ihren Schwanz!"/

Und er streckte seine Hand aus und ergriff ihn, und sie wurde zum Stab in seiner Hand $C$.

4,5 " Damit sie glauben, daß dir erschienen ist Jahwe, der Gott ihrer väter,/ der Gott Abrahams, der Gott Isaaks und der Gott Jakobs."

4,6 Und Jahwe sagte ihm weiter:

"Steck doch deine Hand in deinen Gewandbausch!"

Und er steckte seine Hand in seinen Gewandbausch./ Und er zog sie heraus, und da: Seine Hand war aussätzig, wie Schnee.

4,7 Und er sagte:

"steck deine Hand wieder in ${ }^{\mathrm{D}}$ deinen Gewandbausch!"

Und er steckte seine Hand wieder in seinen Gewandbausch./

Und er zog sie aus seinem Gewandbausch heraus, und da: Sie war wieder wie sein Fleisch.

4,8 "Und es wird sein: Wenn sie dir nicht glauben und nicht auf die Sprache ${ }^{E}$ des ersten zeichens hören,/ werden sie der Sprache des anderen Zeichens glauben.

4,9 Und es wird sein: Wenn sie auch diesen beiden zeichen nicht glauben und nicht auf deine stimme hören, so sollst du vom Wasser des Nil nehmen und auf das Trockene gießen./ Und es wird das Wasser, das du aus dem Nil nimmst, ${ }^{-F}$ es wird zu Blut auf dem Trockenen!"

"Bitte, mein Herr, kein Mann von Worten bin ich, weder seit gestern noch seit vorgestern noch seit du zu deinem Knecht sprichst;/ ungeschickt ${ }^{G}$ mit dem Mund und ungeschickt mit der zunge bin ich." 
4,11 Und Jahwe sagte $\mathrm{zu}$ ihm:

"Wer hat dem Menschen einen Mund gemacht? Oder wer macht stumm? Oder taub, oder sehend, oder blind?/ Nicht ich, Jahwe?

4,12 Und nun: Geh!/ Ich selbst ${ }^{\mathrm{H}}$ werde mit deinem Mund sein und dich lehren, was du reden sollst."

4,13

Und er sagte:

"Bitte, mein Herr, / sende doch, wen $^{I}$ du senden willst $\mathrm{J}_{\text {!" }}$

4,14 Da entbrannte der Zorn Jahwes gegen Mose und er sagte:

"Ist da nicht Aaron, dein Bruder, der Levit" $\mathrm{K}_{\text {? }}$ Ich weiB, daB er sehr gut ${ }^{L}$ reden kann./ AuBerdem ${ }^{M}$, siehe, er zieht gerade heraus, dir entgegen: Wenn er dich sieht, wird er sich von Herzen freuen.

4,15 Und du sollst $z u$ ihm reden und die Worte in seinen Mund legen./ Ich selbst ${ }^{N}$ aber werde mit deinem Mund und mit seinem Mund sein und euch lehren, was ihr tun sollt ${ }^{0}$.

4,16 Und reden wird er $^{P}$ für dich zum Volk/ und es wird sein: Er $^{P}$ wird dir Mund sein, und $d^{P}$ wirst ihm Gott sein.

4,17 Diesen Stab aber nimm in deine Hand!/ Mit ihm sollst du die zeichen tun."

ERLÄUTERUNGEN ZUR ÜBERSETZUNG

Die Übersetzung versuchte, den hebräischen Text möglichst wortgetreu wiederzugeben. Die folgenden Erläuterungen sollen einige für die deutsche Wiedergabe getroffene Entscheidungen genauer begründen bzw. auf Texteigentümlichkeiten aufmerksam machen.

\section{Erläuterungen zu Exodus 3}

A Der Subjektwechsel gegenüber 2,25 ist durch das Abgehen von dem für Erzählungen charakteristischen Imperfekt consecutivum markiert. Statt dessen steht $l+$ neues Subjekt am Beginn des Satzes. Dieses Vorgehen dient häufig zur Einleitung neuer Abschnitte (siehe unter 1.2.1 Anm.5 und 6). 
B היה + Partizip (= Durativ II) dient zur Bezeichnung einer in der Vergangenheit andauernden oder sich wiederholenden Handlung (vgl. R.MEYER, Hebräische Grammatik III 57, und W.H.SCHMIDT, Exodus 102).

C אחר המרבר, wörtlich: "hinter die wüste". eigentlich "hinter, jenseits", könnte auch eine Himmelsrichtung konnotieren, nämlich "nach Westen" (siehe Ges.B. zu אחור). מדבר bedeutet sowohl die wasserlose wüste wie die Steppe, die den Schafen Weideland bietet.

D Nach Ges.K. \$119i ist die Präposition $\beth$ als beth essentiae (Übersetzung: "als") zu verstehen. Andere vertreten ein lokales Verständnis ("in einer Feuersflamme").

E Der Gebrauch des Artikels zur Bezeichnung einer unbestimmten Sache ist im Hebräischen häufig. Deswegen muß der hebräische Artikel manchmal mit "ein" oder "ein gewisser" übersetzt werden: P.JoüON, Grammaire $\$ 137 \mathrm{~m} .0$, führt als erstes Beispiel Ex 3,2 an und gibt mit "un buisson" wieder. So auch Ges.K. \$126 q.r; anders jedoch E. KöNIG, Syntax \$299, und w.H.SCHMIDT, Exodus 103.

F Nach P.JoüoN, Grammaire $\$ 133$ b Anm.2, betont נראה אל das Heraustreten der Erscheinung aus einem Gegenstand zum Sehenden hin.

G wörtlich: als Feuer.

H אמר kann im Hebräischen auch "denken, sich sagen" bedeuten. Vgl. auch die Erläuterungen $Y \mathrm{zu} 3,13$ und $\mathrm{h} z \mathrm{zu}, 17$.

I Die Folge von Kohortativ und $1+$ Präformativkonjugation (Es ist unsicher, ob ואראה auch als Kohortativ gedacht ist, denn von der Form her ist der Kohortativ bei Verben $\underline{l^{\prime \prime} h}$ nicht zu unterscheiden: P.Joüon, Grammaire $\$ 79$ o.) läBt offen, ob der zweite Ausdruck bei- oder unterordnend zu interpretieren ist.

- Die finale übersetzung hier stützt sich auf die Parallele in v4. So auch P.JoüoN, Grammaire $\$ 116$ b und W.H.SCHMIDT, Exodus 103.

übrigens könnte nach R.MEYER, Hebräische Grammatik III 48, der enklitischen Partikel $\mathrm{kJ}^{-}$(hier übersetzt mit "doch") ein alter Energicus (*'aqtulanna) zugrundeliegen. P.JoüoN dagegen 
(Grammaire $\$ 105 \mathrm{c}$ ) lehnt eine solche Deutung für unsere stelle ab ("n'ajoute guère qu'une nuance d'énergie") und spricht von miBbräuchlicher Verwendung der Partikel. - Abgesehen davon, daB jedes Abweichen meist mit einem Willensentscheid und einem erhöhten Energieaufwand verbunden ist, was die Deutung als Energicus befürwortete, scheinen auch stilistische Gründe die wahl dieser Form mitbestimmt zu haben. Erstens fügt die Partikel in diesem ohnehin schon an a-Lauten reichen vers ein weiteres Qamez hinzu. Und zweitens wird der Rhythmus durch das zusätzliche $\mathrm{kJ-}$ flüssiger und gleichmäßiger; das betonte $k^{-}$kommt nämlich als Hebung zwischen die beiden Senkungen -â und $w^{\mathbf{e}}-\mathbf{z u}$ liegen.

J בער hat eine semantische Breite, die "brennen" und "verbrennen" umgreift (Ges.B.108; KB 139). Damit ist der vorschlag von D.N.FREEDMAN, Bush 246, $k$ emphatisch zu interpretieren und zu übersetzen: "Why indeed the bush continues to burn", überflüssig. Der Erzähler hat so das paradoxe Phänomen des nicht verbrennenden, obwohl doch brennenden Busches in einem Wortspiel eingefangen.

K הנני, wörtlich "Siehe mich!", ist standardantwort auf den Anruf mit Namen (Gen 22,1.11; 31,11; 46,2; usw.). Die Pausaform mit Sere unter dem ersten Nun steht oft in phatischer Funktion am Beginn eines Gesprächs als Ausdruck der Kontaktaufnahme (siehe Jacobsons Sprachfunktionen): über die vorhin erwähnten stellen hinaus noch Gen 27,1; 1 Sam 3,4.16; Jes 58,9. Das impliziert, daß הנני hier nicht sosehr als Ortsangabe ("Hier bin ich!"), sondern als Ausdruck der Gesprächsbereitschaft zu übersetzen ist.

L Der hebräische Infinitivus absolutus dient zur Betonung bestimmter Ausdrucksnuancen (P.JoüoN, Grammaire $\$ 123$ d), wobei nur der Kontext festzustellen erlaubt, um welche Nuance es sich handelt. Für den vorgestellten Infinitivus absolutus unterscheidet Joüon acht Nuancen $(\$ 123 \mathrm{e}-\mathrm{k})$. Unsere Stelle wäre entweder der ersten (Affirmation) oder der siebten ("la perfection ou l'intensité de l'action") zuzuordnen. Unsere Übersetzung als Behauptung stützt sich auf den zusammenhang mit dem Sehen und Kennen Gottes in 2,25 .

M Die Kopula wird im Hebräischen nicht ausgedrückt. 
N Das Pluralsuffix hebt sich von den beiden Singularsuffixen für den Singularbegriff Volk ("seine" Bedrücker und "seine" Schmerzen) ab. Doch ist "Volk" ein Kollektivbegriff, und der Plural somit kein Verstoß gegen die Kongruenz (P.JoüoN, Grammaire \$149 a; R.MEYER, Hebräische Grammatik III 18). Die Wahl des Pluralsuffixes mag die Vielzahl der in diesem Volk enthaltenen Einzelnen, der Gebrauch des Singularsuffixes (bei den Antreibern und den Schmerzen) ihre Gemeinschaft zum Ausdruck bringen.

o כ steht hier eher nicht zur Einleitung einer Begründung, sondern ist Ausdruck einer Folge des Vorangegangenen (so auch w.H.SCHMIDT, Exodus 104, und "The Torah" der Jewish Publication Society, zur stelle). Es kommt damit seiner ursprünglich demonstrativen Bedeutung (Ges.B.341) nahe.

P Wörtlich: "die Söhne Israels". Dieser Ausdruck bezeichnet in Ex 1,7 noch die Nachkommen eines Mannes; ab Ex 1,9 dagegen meint er ein Volk und sollte dann mit "die Israeliten" übersetzt werden.

Q P.JoüON, Grammaire $\$ 116$ f: Sogenannter "impératif indirect" ( + Imperativ nach vorhergehendem Kohortativ oder Imperativ) hat häufig finale Bedeutung. Ebenso: Ges.K. \$110 $i$ und W.H.SCHMIDT, Exodus 105 .

R כ (vgl. auch oben Erläuterung 0) wird hier ebenfalls nicht in kausalem Sinn ("weil") verwendet, es sei denn, man dächte sich hinzu: "Du kannst zum Pharao gehen und die Israeliten aus Ägypten herausführen, weil ..." Nach P.JoüoN, Grammaire $\$ 164$ b könnte man hier ein "כי d'affirmation" sehen. Er zählt unsere stelle aber nicht dafür auf.

S Wie in 3,7 (Erläuterung M) fehlt im Hebräischen die Kopula.

T Das Subjekt ist durch den zusatz des Personalpronomens der 1.P.Sg. zum finiten verb betont.

U Die übersetzung der hebräischen Afformativkonjugation mit deutschem Präsens ist gerechtfertigt durch die Sprechsituation, die es in die Nähe eines performativen Perfekts rückt. Siehe dazu w.SCHNEIDER, Hebräische Grammatik $\$ 48.6 .2$. Die Afformativkonjuga- 
tionen von $\pi$ ib in v13-15 dagegen blicken aus der zukunft auf die vergangenheit zurück und sollten deswegen mit Perfekt übersetzt werden.

$v$ Der Doppelpunkt deutet an, daß das zeichen von $v 12 a$ in $v 12 b$ beschrieben wird; er wird auch von den Ausgaben der RSV, der TOB und der NBE gesetzt. Eine andere Interpretation vertritt B.S. CHILDS, Exodus 56-60, der aber auch einen Doppelpunkt setzt.

W P.JoüoN, Grammaire \$166 f: I zur Einführung einer gleichzeitigen Handlung.

X kann eine Bedingung einleiten, mit Ges.K. \$112 t; gegen P.JoüON, Grammaire $\$ 1671$.

Y Das hebräische אמר (vgl, auch Erläuterung $\mathrm{H}$ zu 3,3) wird hier in diesem Vers bei vier Vorkommen dreimal verschieden übersetzt. Je nach dem Kontext kann sagen, sprechen, denken, fragen oder antworten gemeint sein. Für die Rolle des Erzählers habe ich es vorgezogen, אמר immer mit "sagen" wiederzugeben, um auch im Deutschen den Eindruck der Gleichförmigkeit der Redeeinleitungen zu wahren (auch wo es sich, wie z.B. in 4,2, um eine Frage handelt).

2 Die Kopula "ist" steht nicht im Hebräischen (wie in 3,7.12; vgl. Erläuterungen $M$ und $S$ ). Deswegen wäre auch eine Wiedergabe mit "Was bedeutet sein Name?" (so B.JACOB, Mose 32, und F. ROSENzWEIG, Der Ewige 40) möglich. Siehe dazu unter 3.3 die Analyse von Ex 3,13 .

a Für die Rechtfertigung dieser übersetzung ist auf R.BARTELMUS, HYH 226-235, zu verweisen. Er sieht im Hauptsatz (erstes אהיה) den Sachverhalt der Klassifikation und im Relativsatz eine Existenzaussage. Der paronomastische Relativsatz dient dabei zum Ausdruck des Indefinitums (so auch in einer ausführlichen Untersuchung aller dieser Ausdrücke: B.JACOB, Mose 129-130): "Jahwes Replik auf die betont vorsichtige, umständliche Frage des Mose nach seinem Namen besteht zunächst darin, daß er etwas über seine 'Klassenzugehörigkeit', d.h. doch wohl über sein Wesen aussagt: Er ist von der Art, $\mathrm{daB}$ er keiner bestimmten klasse zugeordnet werden kann." (R.BARTELMUS, HYH 232). - Wir werden in der Analyse 
von 3,14 in c3 und im Exkurs 4 noch ausführlicher auf andere Übersetzungen eingehen.

b "Ich-werde-sein" (hebräisch אהיח) greift die erste Antwort Gottes (v14a) auf und verwendet deren wiederholtes verb nun als Name.

c Wie in $3,7.12 .13$ fehlt auch hier die Kopula.

d Asyndetische Verbindung (gegenüber dem üblichen לרר ורר) ist bei diesem Ausdruck singulär für das AT. Doch finden sich im Kontext weitere solche Verbindungen ohne "und" in Gottes Selbstvorstellungen in $3,6.15 .16 ; 4,5$ bei den Ausdrücken mit Isaak und auBerdem in den völkerlisten in 3,8,17.

Ges.K. $\$ 1331$ deutet die wiederholung der Substantive als Umschreibung des Superlativs und übersetzt: "auf die fernsten Geschlechter".

e Die doppelten (und in $\mathbf{1 7}$ dreifachen) Anführungszeichen sollen anzeigen, daB sich die zitatebene jeweils um eine stufe weiter verschiebt: vom Reden Gottes ("..."; ab v15) über das Ausrichten des Redens Gottes, insofern es die Erscheinung an Mose betrifft ( $>$... ; ab der zweiten Hälfte von v16a), und über die Mitteilung des Redens Gottes in dieser Erscheinung ( $>\ldots<<;$ ab v16b) schlieblich bis zur Enthüllung des diesem letzten Reden Gottes in ihm selbst zugrundeliegenden Denkens ( $)\rangle \ldots\langle<;$ v17).

f Infinitivus absolutus; vgl. Erläuterung $L \mathrm{zu} 3,7$. Hier handelt es sich wohl um die erste Nuance.

$g$ Der Sinn von פקר im AT wird von G.ANDRE, Determining als "to determine the destiny" bestimmt. Sie arbeitet dabei die Verbindung zu schicksal und zukunft heraus.

h Wiederum steht אמ, ähnlich wie in 3,3 (Erläuterung H), für einen Vorgang des Denkens. So ist auch eine übersetzung mit "ich habe beschlossen" (EÜ zur Stelle; W.H.SCHMIDT, Exodus 102) möglich. The Torah der JPS gibt mit "and I have declared" wieder. Der Inhalt (Gottes feststehender Plan) beeinflubt in diesen Fällen jeweils die Nuance beim übersetzen. 
i Subjekt betont; vgl. Erläuterung $T \mathrm{zu} 3,12$.

j P.JoüON, Grammaire $\$ 114$ f sieht im Kohortativ mit deprekativem א- eine Bitte um Erlaubnis: "permets-nous d'aller (toujours: Ex $3,18 ; 5,3 ; 2 R 6,2) "$. Die feine Bedeutungsschattierung mag richtig erspürt sein, doch legt v18 auf die 1.P.Pl. durch viermalige wiederholung das Schwergewicht, sodaß das Wollen dieser "wir" betont wird.

Die übersetzungen der TOB ("il nous faut aller") und der NBE ("tenemos que hacer un viaje") gehen sogar noch weiter, indem sie das Wollen als Müssen interpretieren.

k Es steht dasselbe Wort מדבר, das in 3,1 mit "Steppe" wiedergegeben wurde.

1 Wieder ist das Subjekt betont; siehe Erläuterungen $T$ und $i$ $(3,12,18)$.

m ולא "und nicht" im Sinn von "wenn nicht". Über die Diskussion dazu siehe W.H.SCHMIDT, Exodus 106.

n Ges.B.454 und W.H.SCHMIDT, Exodus 106, letzterer wegen des männlichen Suffixes von מקרבו, sehen in מצרים das Volk: "die Ägypter". Wenn jedoch dieser Vers auf alle (כל) Plagen anspielt, so müßte מצרים als Land und Volk zusammen meinend genommen werden, da in den Plagen sowohl Land wie Leute betroffen werden. מצרים wird so zur Territorium und Bevölkerung zusammenfassenden und vereinenden Bezeichnung einer Israel und Jahwe entgegenstehenden feindlichen Größe. An eine solche "Gegenmacht" könnte auch schon in 3,8 gedacht sein.

Jer 46,8 zeigt, daß מצרים sogar als Land männlich konstruiert werden kann, und damit das männliche Suffix von "in seiner Mitte" nicht notwendig gegen eine übersetzung mit "Ägypten" sprechen muB.

- Nach Ges.B.243 eine typische Redewendung mit $; \pi$; nach P.JoüON, Grammaire $\$ 129$ h (auch Notes 228) wird die Idee des Dativs ziemlich häufig durch den Genitiv ausgedrückt.

p Ges.B.70 zu אשיאה.

q Für לצ in diesem Sinn siehe Y.T.RADDAY, Spoils 142-145. 


\section{Erläuterungen zu Exodus 4}

A Der fehlende Nachsatz veranlabt B.S.CHILDS, Exodus 50, dazu, והן hier nicht konditional aufzufassen. Ex übersetzt (S.48): "Look, they will never ...". Das würde Mose der Aussage Gottes in 3,18 widersprechen machen. Die Gründe, והן hier dennoch mit "wenn" wiederzugeben, sind folgende: 1) 1) והן ist singulär im hebräischen AT. Dazu gibt es noch drei Vorkommen im aramäischen Teil des AT, allesamt in Daniel: 2,$6 ; 3,15.18$. Jedes von ihnen steht als erstes Glied des Vordersatzes eines Konditionalgefüges. Mit Maqef ( $\left(\mathrm{HI}^{-}\right)$gibt es noch ein Vorkommen im AT, und zwar in 2 Chr 7,13. Dort führt es den zweiten von vier Vordersätzen eines Bedingungssatzes ein. 2) 17 alleine (ohne 1) tritt in Ex auch zur Einführung eines Bedingungssatzes auf: 6,12.30. (zumindest ordnet die Konkordanz von A.Even-Shoshan, I 572, diese Stellen so ein.) 3) Die Auslassung des Nachsatzes ist, wenn auch selten, möglich. (P.JoüON, Grammaire \$167 r) 4) Vom Sinn her ergibt sich ein nicht so starker Gegensatz zu 3,18 wie bei der übersetzung von Childs. Statt eines offenen widerspruches handelte es sich nur noch um eine Infragestellung, Bezweiflung der von Gott vorhergesagten Reaktion der Israeliten. Diese "mildere" Interpretation wird durch die stellung innerhalb des Dialogs - wir sind erst etwas über der Hälfte, die stimmung ist noch eher friedlich - und durch die Reaktion Gottes (vgl. dagegen seinen zorn in 4,14) unterstützt.

B 019, normalerweise mit "fliehen" übersetzt, meint hier das erschreckte zurückweichen. Wie der Fortgang in v4 zeigt, ist nicht an eine Flucht gedacht. - Ähnlich "The Torah" der JPS $(103)$ : "and Moses recoiled".

C "(hohle) Hand" im Unterschied zu Th "Hand, Unterarm". Die NBE übersetzt sogar mit "puño" (Faust). Mit dem Wechsel zu ך ist wohl an völlige Kontrolle gedacht (so E.J.HAMLIN, ordeal 37).

D Gegenüber v6 erscheint hier eine andere Präposition ( ב). Doch ist der Grund dafür eher in stilistischer Variation denn in verschiedener Bedeutung zu suchen. 
E Für eine übersetzung von p p "Stimme" als zeugnis siehe: c.J. LABUSCHAGNE, ip 632, übernommen von W.H.SCHMIDT, Exodus 185-186. - Die Wiedergabe mit "Sprache" möchte dem ursprünglichen Wortsinn näher bleiben.

F P.JoüON, Grammaire $\$ 176$ b (Anm.2), sieht in der wiederholung des Verbs ein stilistisches Mittel und weist unter anderem auf ähnliche Vorgehen in Ex hin: 1,15-16; 12,41. Die Wiederaufnahme des Verbs führt zu einem Bruch des Satzgefüges, hier wiedergegeben durch den Gedankenstrich. Dieses Stilmittel unterstreicht so die unerwartete Verwandlung des Wassers in Blut; deswegen auch das Ausrufzeichen am Ende des Satzes.

G כבד wörtlich: "schwer"; von daher übertragen: "schwerfällig, schwierig, ..."

H Durch Personalpronomen betontes Subjekt, vgl. die Erläuterungen $T$, $i$ und 1 zu 3,12.18.19. - Es ist nicht immer leicht möglich, diese Betonung im Deutschen wiederzugeben; in 3,12 liebe sich z.B. übersetzen "daß wirklich ich dich sende". Für die Stellen hier in 4,12.15 habe ich die wiedergabe mit "selbst" gewählt, während alle anderen betonten Personalpronomina nicht in der Übersetzung kenntlich gemacht wurden.

I שלד, wörtlich: "senden durch die Hand (von ...)" bedeutet ein Senden durch die Vermittlung von jemand (Ges.B.832). In allen anderen Fällen wird nach "durch die Hand" eine Person genannt, mit einer Ausnahme (Spr 26,6) immer mit Namen: 1 Sam 16,20; 2 Sam 11,$14 ; 12,25 ; 1$ Kön 2,25 . Es fällt auf, daß alle diese vier stellen mit David oder seinem Sohn Salomo $(1$ Kön 2,25) zu tun haben. Von dieser gebräuchlichen Verwendung ist unsere stelle doppelt abgehoben: 1) Sie nennt nicht den Gesandten, weder mit Namen noch allgemein (der "Tor" von Spr 26,6). Dementsprechend ist die syntaktische Konstruktion hier verschieden. Nach P.JOÜON, Grammaire $\$ 129 \mathrm{q}$, dient ביד hier zur Einführung eines Relativsatzes, wobei das Nomen auf "fast präpositionelle" Weise verwendet wird.

2) Sie versteht sendung nicht mehr als einen eng beschränkten Auftrag, sondern als umfassende, lebensverändernde Aufgabe. Das läBt fragen, ob hier unter Rückgriff auf den aus der Davidsgeschichte bekannten Ausdruck formuliert wird. 
J Yiqtol-Formen können einen Wunsch ausdrücken (P.JoüoN, Grammaire $\$ 113 \mathrm{n})$. Die wiederholung des Verbs des Hauptsatzes im Relativsatz dient nach Joüon zum Ausdruck der Unbestimmtheit (siehe auch Erläuterung a zu 3,14); er übersetzt Ex 4,13 mit "envoie qui tu voudras". Im zuvor zitierten \$129 q jedoch gibt er es wieder mit: "par (qui) tu enverras".

K O.LORETZ, Aharon 454, schlägt eine textgeschichtliche Lösung vor. הלרי stand ursprünglich als Glosse am Rande und wanderte dann an die falsche stelle im Text hinein: Obwohl als Bemerkung zu "Aaron" gedacht, wurde es nach "dein Bruder" eingeschoben. Doch ist eine solche Annahme nicht nötig; die beiden Appositionen stellen Aaron immer mehr als für Mose geeigneten Partner vor Augen. Nach der Namensnennung erwähnt Gott zuerst dessen Beziehung zu Mose und dann seine "Qualifikation" als einer vom stamme der Leviten.

H.VALENTIN, Aaron 125-127.132, verbaut sich diese einfachere Lösung, indem er nur "dein Bruder" als mögliches Prädikatsnomen dieses Satzes sieht.

w.GROSS, Pendenskonstruktion 118.180, zieht הלא und ידפתי zusammen. Er folgt damit der Lösung der Vulgata und der NBE; doch trennen die massoretischen Akzente schon vor ידפתי stärker ab.

L Infinitivus absolutus wie in $3,7.16$.

M J.BLAU, Adverbia 132, sieht in גas psychologische subjekt, das der Präsentativ הנה mit dem Rest des Satzes verbindet. Ob die Rede vom psychologischen subjekt glücklich ist, sei dahingestellt; richtig gesehen ist jedoch die besondere Rolle, die manchen Adverbien am Satzanfang im Hebräischen zukommt. Es wäre lohnend, sie in bezug auf ihre phatische Funktion zu untersuchen (vgl. Erläuterung $\mathrm{K} \mathrm{zu} 3,4)$.

N Siehe H zu 4,12.

- Yiqtol zum Ausdruck des Sollens oder Müssens, oft einem Imperativ gleichkommend, vgl. P.JoüoN, Grammaire $\$ 113 \mathrm{~m}$ (Übersetzung: "ce que vous devez faire").

P Dreimal wird das Subjekt durch Personalpronomen betont. Vgl. 4,15 (N) und $4,12(\mathrm{H})$.

Q Für Yiqtol mit Imperativbedeutung siehe Erläuterung 0 zu 4,15. 


\subsection{ABGRENZUNG}

\subsubsection{Bestimmung der textlichen Einheit}

Die Bibel präsentiert ihre Erzählungen nicht als abgeschlossene, selbständige Einheiten. Die Texte wurden fortlaufend geschrieben, ohne überschriften, Kapitel- oder Versangaben. So stellt sich für jeden, der einen Text untersuchen will, zuerst das Problem seiner Abgrenzung.

Je nach Art der Kriterien werden Texte dann auch unterschiedlich abgeteilt. Für jenen Abschnitt, der normalerweise als "Berufung des Mose" bezeichnet wird, finden sich deshalb verschiedene Anfänge (und Enden). Die meisten Ausleger sehen Ex 3,1 als Beginn an ${ }^{1}$. Für einen Anfang mit 3,1 sprechen folgende drei Gründe :

a) Die unmittelbar vorausgehenden verse 2,23-25 fassen das Vorangegangene zusammen durch den Rückgriff auf Israels stöhnen unter der (Zwangs-) Arbeit $^{2}$. Der besondere Charakter dieser drei verse zeigt sich im fünfmaligen אלהים "Gott". Die überdurchschnittliche Häufigkeit dieses Wortes steht im Kontrast zu den seltenen Erwähnungen Gottes in Ex bis dahin (nur in 1,17.20.21). So erzeugen die Verse 2,23-25 mit dem wort "Gott" ein Crescendo, das auf etwas Neues warten läBt ${ }^{3}$.

- Obwohl durch die Weckung einer Erwartungshaltung eine enge

1 Für 3,1 als Beginn: G.Auzou, G.Beer, R.J.Burns, B.S. Childs (er bringt in seinem Kommentar auf S.51-52 eine Reihe präziser Beobachtungen - die meisten gegen andere Positionen in der Abgrenzung argumentierend -, die die hier folgenden ergänzen), S.R.Driver, M.Fishbane, M.Greenberg, H.Holzinger, F.Hummelauer, J.P.Hyatt, F.Michaeli, R.de Pury, R. Schmid, W.H.Schmidt, G.Te Stroete, J.Weiss, E.zenger und andere.

Dagegen sieht M.Noth den Beginn der Einheit in 2,11, und G.Baentsch, U.Cassuto, R.E.Clements, B.Couroyer, H.Frey, H.GreBmann, P.Heinisch und H.Schneider setzen den Beginn mit 2,23 an.

2 B.S.CHILDS, Exodus 32.

3 M.GREENBERG, Understanding 55, findet diesen Aufbau einer Spannung auch in der Wahl der Verben in v24-25 und besonders im objektlosen letzten Verb. 
Beziehung zwischen 2,23-25 und $c 3$ besteht ${ }^{4}$, legen Inhalt und stil doch eine Trennung nahe. Ex 2,23-25 stellt einen AbschluB dar.

b) 3,1 beginnt mit רמשח "Mose aber". Ein solches betontes Voranstellen des Subjektes ist nach der hebräischen Grammatik Zeichen für einen neuen Anfang . In Gen steht dieselbe Konstruktion relativ häufig am Beginn neuer Abschnitte . Analog kann man auch hier einen Neubeginn sehen.

c) Auch das in der Renaissance für Dramen eingeführte Kriterium der Drei Einheiten von ort, zeit und Handlung läßt zwischen 2,25 und 3,1 einen Bruch annehmen: Mit dem Weiden der schafe setzt eine neue Handlung ein; auch ist der ort (am Rande der Steppe) ein anderer als in 2,23-25, wo Ägypten bzw. Gott im Blickpunkt steht. Schließlich ist auch die erzählte zeit ${ }^{8}$, in unserem Fall die Dauer des Dialogs, von der zeit der vorhergehenden Ereignisse abgehoben. - Dieser Bruch verlangt, bei 3,1 den Beginn einer neuen Szene anzusetzen.

Die genannten drei Gründe für das Ansetzen des Beginns der Einheit mit 3,1 finden auch durch die Gliederung des hebräischen

4 Auf diese Beziehung wird unten (bei 1.2.2) noch genauer einzugehen sein.

5 Ges.K. \$142 d; P.JoüoN, Grammaire \$155 k: "En début absolu on a généralement 1 ordre $S .-V . "$ (S. steht für sujet, $v$. für Verbe). Siehe auch Erläuterung $A$ zur übersetzung in 3,1 .

6 In Gen 3,1 wird so die Schlange, in 4,1 Adam, in 16,1 Sarai, in 21,1 Jahwe, in 24,1 Abraham und in 39,1 Josef als neues Subjekt eingeführt - ergänzen lieBe sich noch in 43,1 "Hunger". Beispiele aus Ex: 1,1 ראל "und diese", 27,20 und 28,1 רואתה "du aber", 29,1.38 רזה "und das" und 33,7 noch einmal "משיה "und Mose"'.

7 S.BARNET (u.a.), Dictionary 148. Angeblich soll dieses Kriterium auf Aristoteles 'Poetik zurückgehen; dieser aber kennt nur die Einheit der Handlung (Poetik 1451 a 30-35). - Der Verweis auf ein aus einer anderen zeit und einem anderen Kulturkreis stammendes Kriterium müßte länger gerechtfertigt werden; doch mag hier genügen, daß es nicht die Hauptlast des Argumentes trägt und mit den beiden zuvor genannten Gründen übereingeht.

8 Dieser Begriff bezeichnet den zeitraum, über den sich die Handlung einer Erzählung erstreckt (Gegenbegriff: Erzählzeit, oder: zeit des Erzählens = zeitspanne, die das vorlesen in Anspruch nimmt) und ist im Deutschen vor allem durch G.Müller und E. Lämmert bekannt geworden. Für einen knappen Überblick siehe $\mathrm{J}$. VOGT, Aspekte 41 , oder O.F.BEST, Handbuch 145 . 
Textes eine Unterstützung. 2,25 schliebt mit einer Setuma ab, d.h. mit jenem zeichen, das das kleinere der beiden gliedernden Spatien im MT anzeigt . Die setuma dient dazu, innerhalb des fortlaufend geschriebenen Textes durch das Freihalten eines kleinen leeren Raumes das Ende des einen ${ }_{10}$ und damit den Beginn eines neuen (Unter-) Abschnittes anzudeuten ${ }^{10}$.

Was das Ende der Berufung des Mose betrifft, setzt die Mehrzahl der Ausleger es auf 4,17 an. Folgende Argumente sprechen dafür:

a) 3,1-4,17 berichten, von wenigen Versen abgesehen, die der zubereitung des Schauplatzes dienen, einen Dialog zwischen Gott und Mose. Dieses zwiegespräch geht in 4,17 zu Ende. Auch sind die Reden der beiden Gesprächspartner so eng miteinander verbunden, $\mathrm{da} B$ es nicht möglich ist, vorher abzutrennen, ohne einen Teil des Dialogs wegzuschneiden.

b) Die letzten drei Verse 4,15-17 enthalten kein einziges Wort, das nicht schon zuvor in 3,1-4,14 vorgekommen wäre. Das Verhältnis von verschiedenen Morphemen/Worten $\mathrm{zu}$ vorkommenden Morphemen/Worten kann als Informationswert ${ }^{12}$ bezeichnet werden.

9 J.OESCH, Petucha 42.

10 Doch ist dieses Argument nicht sehr stark, weil sich nach 2, 22 eine Petucha und damit eine stärkere Abteilung als nach 2,25 findet. Immerhin aber, und das zeigt die Setuma nach nur weiteren drei Versen, wurde auch 3,1 als Neuansatz wahrgenommen.

11 Unter anderen sind zu nennen: G.Auzou, B.Baentsch, G. Beer, R.J.Burns, B.S.Childs, S.R.Driver, M.Fishbane, M.Greenberg, J.P.Hyatt, F.Michaeli, R.de Pury, R.Schmid, G.Te stroete, E. Zenger.

Die Auffassungen bezüglich des Schlusses weichen jedoch noch mehr $a b$ als hinsichtlich des Beginns. Einige sehen das Ende in 3,22: G.H.Davies, H.L.Ellison, H.J.Grimmelsmann und w.H.Schmidt. Andere dagegen gehen über 4,17 hinaus: F.Hummelauer und C.F.Keil legen den SchluB auf 4,18, M.Noth auf 4,23, U.Cassuto, P.Heinisch, H.Schneider und J.Weiss auf 4,31 .

12 Für diesen Ausdruck siehe H.SCHWEIZER, Grammatik 73-74. Doch ist zu beachten, daB ein wiederholtes Wort (in einer zweiten Bedeutung oder in einer anderen syntaktischen Verbindung) auch Träger neuer Information werden kann. D.h., der nach diesem Modell berechnete Informationswert ist eine abstrakte GröBe, weil er semantische Unterschiede in der Verwendung der Morpheme nicht berücksichtigt. Diese überlegung ist für unseren Text besonders wichtig, denn der "Informationswert" von 4,15-17 gegenüber 3,14,14 ist gleich Null (alle 41 wörter sind bereits zuvor vorgekom- 
Während 4,15-16 noch vereinzelt Ausdrücke aufgreift, die innerhalb unserer Einheit nur in c3 vorkamen (פשה , פשה), und damit gegenüber 4,1-14 einen, wenn auch bescheidenen Informationswert aufzuweisen hat, enthält 4,17 nur noch wiederholungen von wörtern aus 4,2.9.15 . Diese wiederholungen lassen 4,17 als SchluB erscheinen. Wo keine neuen wörter mehr verwendet werden, sinkt die Erwartungshaltung des Hörers; das Ende eines Abschnittes ist nahe.

c) Während des ganzen Dialoges wurde die Einheit von Ort, zeit und Handlung gewahrt: Am brennenden Busch sprechen Gott und Mose miteinander, ohne daB ein Bruch festzustellen wäre. In 4,18 dagegen wird das zurückkehren Moses zu seinem Schwiegervater und das Gespräch zwischen ihnen berichtet. Die Verschiedenheit von ort, zeit und Handlung weist so auf einen neuen Anfang hin.

Sprachliche und erzählerische Gründe legen also 4,17 als Ende unserer Einheit nahe. Auch die hebräische Textgliederung entspricht einem solchen Verständnis von 4,17 als AbschluB, indem sie nach diesem Vers eine Petucha setzt, $d . h$. nach dem Ende des Textes die zeile, offen läßt. Das ist ein zeichen für das Ende eines Abschnittes ${ }^{14}$.

Hier stellt sich jedoch eine Frage: Wenn all diese Gründe für ein Abtrennen der Einheit nach 4,17 sprechen, warum finden sich dann so viele Ausleger mit anderen Auffassungen?

Die Antwort darauf ist in den verschiedenen zielrichtungen der Untersuchungen zu finden: Wer nur die Form einer Berufungserzählung sucht, findet all die benötigten Elemente schon in 3,1$12^{15}$. Wer die zeichen in $c 4$ als sekundäre Ergänzung betrachtet, kann auf Grund dieser quellenkritischen Entscheidung in 3,22

men), und dennoch enthalten diese drei Verse neue Information.

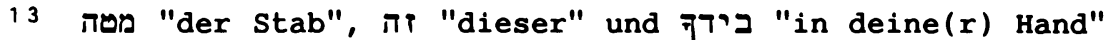
stammen aus 4,2; die übrigen fünf wörter von 4,17 standen bereits

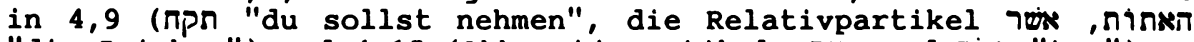
"die Zeichen") und 4,15 (Akkusativpartikel את משת "tun").

\footnotetext{
14 J.OESCH, Petucha 42 und 362. Vgl. auch oben Anm.9.

15 N. HABEL, Call Narratives 301.
} 
abschließen" ${ }^{16}$. Auch die "langen" Positionen $(=$ die über 4,17 hinausgehen) haben einiges für sich, ist doch ihr Material eng mit der Berufung des Mose verwandt. Nach B.Jacob ${ }^{17}$ ist der Dialog eine kunstvolle Komposition, deren Geschlossenheit nicht gestört werden durfte. Das erforderte den Nachtrag ab 4,18. Diesem Phänomen wird gleich (unter 1.2.2) nachzugehen sein.

Die bisher angeführten Argumente zusammenfassend, läßt sich sagen: In der uns überlieferten Letztgestalt des Textes kann 3,14,17 als erzählerische Einheit angesehen werden. Es ist sinnvoll, diese Texteinheit der sprachlichen und erzähltechnischen Untersuchung zugrundezulegen.

\subsubsection{Die Überqänge}

In der vorhergehenden Bestimmung der textlichen Einheit mußten wir zwei Fragen vorläufig offenlassen. Die eine betraf die Beziehung zwischen den letzten Versen von $c 2$ und unserem Text, vor allem 3,1, die andere das Phänomen des Nachtrags ab 4,18.

a) Der übergang $2,25-3,1$

Ex 2,25 hat einen eigentümlichen AbschluB: "Und es sah Gott die Söhne Israels und es (er)kannte Gott." ${ }^{18}$ Die Jerusalemer Bi-

16 Z.B.W.H.SCHMIDT, Exodus 100. Er betitelt 3,1-22 mit "Berufung des Mose", sagt dann aber (106), daB c3 "der ứbersichtlichkeit halber zunächst von der Fortsetzung in Ex 4 isoliert" worden sei, und benennt Ex 4,1-17 schlieblich mit "zweifel des Berufenen" (184).

17 B.JACOB, Mose 136.

18 Die Verbindung von ראה und ידת begegnet auch andernorts. In Gen 18,21 "ich will hinuntersteigen und sehen, ob sie ... getan haben oder nicht; ich will (das) erkennen" drückt sie Gottes Wunsch zur Prüfung der Situation aus. Sie steht vor dem Gericht für Sodom und Gomorra. Weitere Texte sind Jer 2,23 "sieh deinen Weg im Tal, erkenne, was du getan!", 5,1 "seht und erkennt, ob ihr einen findet,..", 12,3 "du, Jahwe, kennst mich und siehst mich".

All diesen (und einer Reihe anderer) Texte ist eine situation des Unrechts gemeinsam, die erkannt und bedacht wird (oder werden soll). Diese Situation des Unrechts führt entweder zu einem Eingreifen Gottes oder zum Aufruf zur Umkehr in Denken und Handeln.

In der studie von P.BOVATI, Giustizia, sind diese beiden

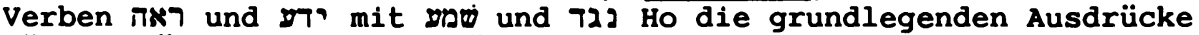
für die "notitia criminis" vor der Erhebung der Anklage (c2, vor 
bel z.B. meint, das Textende sei hier weggebrochen ${ }^{19}$; sie läßt den Satz in ein paar Punkten enden. Das abrupte Ende veranlast also manche zur Annahme eines Textausfalls bzw. zu einer Korrektur. Doch ist beides nicht notwendig, zumal in keiner hebräischen Handschrift Hinweise auf einen Ausfall oder eine andere Lesart zu finden sind.

Von der Erzähltechnik her ist dieser AbschluB dagegen leicht zu deuten: Schon am Ende von Ex 1 ist etwas offengeblieben. Nachdem nämlich die ersten beiden Strategien des Pharao und ihr Fehlschlagen (Ex 1,8-12.14; 1,15-20.21) berichtet worden sind, wird der dritte Plan $(1,22)$ des Pharao genannt, ohne aber dessen Ausgang zu erwähnen, und die Handlung bricht ab. Ex 2,1-10 gibt darauf die ironische Antwort: Gerade aus dem Nil, und ausgerechnet von des Pharao eigener Tochter, wird ein israelitischer Knabe gerettet.

Ähnlich läßt die Erzählung auch hier 20 Ende von c2 den Ausgang offen. Nach scheinbarer Abwesenheit ${ }^{20}$ taucht Gott plötzlich in starker Intensität auf. Gottes Präsenz und die von ihm ausgesagten Verben lassen sein Einschreiten gegen das Unrecht erwarten. Eine Melodie der Hoffnung klingt so an - und bricht in

allem S.58-59).

19 La Bible de Jérusalem, 21974, S.87, Anm.d: "La fin du v. est tronquée." Die erste Ausgabe von 1956 hatte noch zurückhaltender formuliert: "La fin du v. est probablement tronquée et ne donne pas de sens satisfaisant." (S.62, Anm.j)

Auch der kritische Apparat der BHS schlägt mit LxX eine Kor-

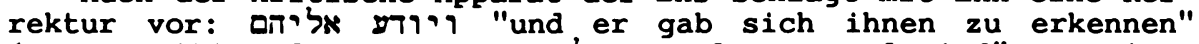
(Transposition des Jod von אלהים vor das He und Einfügung eines Waw beim Verb. So ebenfalls W.H.SCHMIDT, Exodus 79, mit ausführlicher Begrüindung.

Für die Diskussion der vorgeschlagenen Änderungen siehe auch B.S.CHILDS, Exodus 28 (Textanmerkung $\mathrm{zu} 2,25$ ) und P. WEIMAR, Untersuchungen 56-58.

20 Vgl. dazu oben (1.2.1) Argument a) zu Ex 3,1 als Beginn. Die Exoduserzählung führt damit einen charakteristischen zug der Josefsgeschichte weiter. N.SARNA, Understanding 211, schreibt zu Gen 37-50: "Unique, too, is the somewhat secular mould."

C. Westermann (und vor ihm schon G.v.Rad und D.B.Redford) möchte in seinem Genesiskommentar (BK I/3, S.287-288) diesen zug der Josefsgeschichte durch "den übergang von der vorstaatlichen, familiären zur vom Staat bestimmten Gemeinschaftsform" erklären. Ihm entspreche der Wandel von der väterreligion zum örtlich gebundenen Kult. 
3,1 mit dem Wechsel zu Mose und zu einem anderen Schauplatz vorläufig ebenso plötzlich wieder ab.

Der Hörer verlangt nun nach einer Antwort. In ihm sind zwei Erwartungen geweckt worden. Die eine, was Gott seinem Sehen und Kennen an Taten folgen lassen wird; die andere, wie das "Gericht", milder gesagt, die Bereinigung der Unrechtssituation, vor sich gehen wird. Wir dürfen in 3,1-4,17 eine (wenigstens anfängliche) Antwort auf diese beiden Fragen sehen.

Der übergang $z$ wischen 2,25 und 3,1 wird noch deutlicher, wenn aufgrund des vokabulars der charakter von 2,23-25 als Zwischenglied zwischen c1-2 und c3 erkannt wird. Diese drei Verse, die im allgemeinen $P$ zugeschrieben werden ${ }^{21}$, haben eine Reihe von wörtern mit 1,1-2,22 gemeinsam: Jakob $(1,1)$, die Söhne Israels/ die Israeliten $(1,1.7 .9 \ldots)$, "und er $\operatorname{starb"~}(1,6)$, kennen $(1,8)$, der König Ägyptens $(1,8.15 \ldots)$, dienen $(1,13-14)$. Desgleichen enthalten sie aber auch gemeinsame Ausdrücke mit c3: Schreien $(3,7.9$, wobei jedoch statt des verbs klingende Nomen צy verwendet wird), Gottes Wahrnehmen (sehen, hören, wissen 3,7), Abraham, Isaak und Jakob $(3,6.15 \ldots)$, die Israeliten $(3,9.10 \ldots)$, dienen $(3,12)$, der König Ägyptens $(3,18-$ 19 ).

Das Vokabular von 2,23-25 verbindet also in zwei Richtungen. Rückwärts, für c1-2, dient es als zusammenfassung für den Leser, nach vorne, für c3, kündigen diese 3 Verse Themen an, die sie wegen ihrer Kürze nur anschneiden, nicht aber zu Ende führen können. Die Tatsache, daß das Lesen in eine Richtung (vom Anfang zum Ende hin) geschieht, bewirkt, daB Ex 2,23-25 zuerst als AbschluB wahrgenommen wird, bevor die Verbindungen mit dem Folgenden entdeckt werden. Als solchen wollen auch wir es nehmen ${ }^{22}$.

21 B.S.CHILDS, Exodus 28. P.Weimar, Berufung 332-333, ordnet $2,23 a R^{P}$ und $2,23 b-25 P^{G}$ zu. Von letzterem gehört das stöhnen des Volkes (in v23), das Hören Gottes in v24 und das Kennen in v25 zu PgVorl: siehe S. 368 .

Ähnlich im wesentlichen schon J.WELLHAUSEN, Composition 62 , der zum Vierbundesbuch rechnet: "... aus Kap.2 die Verse 23-25 (von וחנואיר". 23 an, ...)

22 Wesentliche der vorhergehenden Gedanken bezüglich der Rolle von Ex 2,23-25 gehen auf eine Vorlesung von J.L.Ska zu Ex 1-14 im Wintersemester 1985/86 am PIB in Rom zurück. 
3,1 knüpft an den Handlungsfaden von 2,16-22 an und spinnt ihn weiter. Mose erscheint als Hirt seines Schwiegervaters Jitro $^{23}$, mit derselben Aufgabe wie früher dessen Töchter. 2, 23-25 dagegen wird überhaupt nicht aufgegriffen. Dieser Kontrast wird durch ein anderes Merkmal noch verstärkt.

3, 1a hat einen ganz strengen Rhythmus, bei dem siebenmal Hebungen und Senkungen einander abwechselnd folgen. Ein solches GleichmaB ist in weitem Umkreis nicht mehr zu finden. Gegenüber den bedrängenden Ereignissen der vorangehenden Verse und ihrem unregelmäBigem Rhythmus ist, auch unterstützt durch das Partizip "war dabei, zu hüten", das Bild einer Ruhe, eines idyllischen, ländlichen Friedens entstanden - der freilich nicht lange währen wird. Auch die dreifache ortsangabe (über die wüste hinaus, zum Gottesberg, Horeb ${ }^{24}$, betont diesen Wechsel. Mose steht nun am Gottesberg, und der Leser mit ihm.

Die oben genannten Argumente bestätigen die vorhin getroffene Abgrenzung. Darüber hinaus lassen sie 2,23-25 als Zwischenglied erkennen. Mit 3,1 ist der übergang vollzogen; dieser Vers beginnt die neue Texteinheit.

Die letzten drei Verse von c2, erzählerisch als Einfügung erkennbar $^{25}$, erfüllen mehrere Aufgaben. Die Mitteilung vom Tod des Königs von Ägypten $(2,23)$ läßt - zunächst für den Leser - den

23 Der Wechsel des Personennamens (von Reguel in 2,18 zu Jitro in 3,1 ) ist nach W.H.SCHMIDT, Exodus, 112, so zu erklären, daB der letztere Name für den zusatz eines Redaktors gehalten werden kann, "der $3,1 \mathrm{a}$ an 4,18 und $18,1 \mathrm{ff}$. anpaBt". Und wegen dieser beiden Vorkommen in c4 und 18 gilt der Name Jitro "in der Regel als Charakteristikum des Elohisten" (S.111), während der Name Reguel in 2,18 als literarisch sekundär zu gelten habe.

Eine offene Frage bleibt dabei aber das Vorkommen zweier verschiedener Namen in 4,18: Jätär und Jitro.

24 C.LEvIN, Dekalog 190-191, schlägt vor, in 3,1 nicht den Eigennamen Horeb, sondern das aus den gleichen Konsonanten gebildete, nur anders zu vokalisierende Nomen horaeb "Dürre, ödland" zu lesen. Der Text hätte dann ursprünglich gelautet: "... und kam - in das ödland." Darin wäre sekundär "zum Gottesberg" eingefügt worden. Der Vorschlag hat weitreichende Folgen: "Von einer altisraelitischen 'Sinai-Tradition' kann keine Rede mehr sein! ... der Exodus ist es, an dem der Dekalog erklärtermaßen seinen heilsgeschichtlichen ort hat". (S.189)

25 Wegen des oben beobachteten besonderen vokabulars und der Anknüpfung von 3,1 an 2,22 . 
Grund für die Flucht des Mose wegfallen und seine Rückkehr in den Bereich des Möglichen rücken. Die oftmalige Erwähnung Gottes und sein Tun wecken wie oben gezeigt die Hoffnung, es könne sich doch etwas an der Situation ändern. In Verbindung mit dem abrupten Schlub steigern sie gleichzeitig die Lesererwartung.

Insgesamt wird deutlich, daB die Einfügung dieses zwischengliedes keinen störenden Fremdkörper ergibt. Im Gegenteil, es erfüllt im zusammenhang von Ex 1-4 ganz wichtige Aufgaben und bereichert diese Erzählung, indem es das Folgende auch als Reaktion Gottes lesen läßt und der sonst überwiegend auf Mose ausgerichteten Handlung ein kleines Gegengewicht entgegensetzt. Die Berufung des Mose ist Gottes Antwort auf die Unterdrückung und das Schreien der Israeliten.

b) Der Nachtrag 4,18-26

${ }_{26}$ Die Deutung von Ex 4,18ff als "Nachtrag" stammt von B. Ja$\mathrm{cob}^{26}$. Nach ihm wurden diese Verse hier eingefügt, weil die kunstvolle Komposition des Dialogs nicht gestört werden durfte. Das scheint vorauszusetzen, daB der Dialog als solcher bestand, als der Nachtrag geschrieben wurde, der nach Jacob dreierlei mitteilen will: daß die Feinde tot sind, daB Mose die Brüder wiedersehen will und wie die Rede Moses an Pharao formell zu lauten habe. Doch ist der Sachverhalt noch komplizierter.

Gehen wir davon aus, daß 4,27 den Beginn eines neuen $A b-$ schnittes (erste Sendung des Mose; bis 6,1) markiert. Dafür sprechen die Petucha davor, der Wechsel in der Handlung zum Gespräch Jahwes mit Aaron in Ägypten, die Tatsache, daß dieses Gespräch das einzige Gottes in Exodus mit einer anderen Person als Mose ist, und der mit diesem Vers einsetzende Beginn von Moses Ausführung seiner Sendung. Damit ergibt sich ein kleiner Textblock, der die neun Verse 4,18-26 umfaBt und der zwischen den Dialog Gottes

26 B.JACOB, Mose 136-137, gibt leider nicht an, bis wieweit er in Ex 4 diesen Nachtrag sieht. Die inhaltliche Bestimmung jedoch läßt vermuten, er sehe den Nachtrag nur bis 4,23.

27 In Ex 20 kann der Dekalog auch als Anrede Gottes an die Israeliten verstanden werden (v19), doch handelt es sich hier um die ganze Gemeinde. 
mit Mose und dessen erste sendung zu liegen kommt. Was ist die Funktion dieser kleinen Einheit?

Diese Frage verschärft sich noch, wenn wir auf den Inhalt dieser Verse achten. Es scheinen drei Gruppen von je drei Versen zu sein. Die erste $(4,18-20)$ bringt eine Wiederholung des Auftrags Jahwes an Mose zu gehen (vgl. 3,10.16; 4,12). Die zweite Gruppe (4,21-23) erneuert, ergänzt und verändert (gegenüber 3,18 ) die Mose anvertraute Aufgabe. 4,24-26 schlieblich, die dritte Gruppe, ist ein rätsselhafter Text, der vielen Auslegern Schwierigkeiten bereitet ${ }^{28}$. Wozu dienen diese Verse 4,18-26?

Zuerst einmal gilt es, ihre innere Einheit zu sehen. Sie sind verbunden durch das Motiv der Reise: v18-20 schildern den Aufbruch, v21-26 Ereignisse während der Reise - v24 sogar ausdrücklich בררך "auf dem Weg". Darüber hinaus gibt es von Vokabular und Themen her enge Verknüpfungen: In 4,18-21 begegnen wir je fünfmal הלב (zurückkehren) und (gehen), dazu steht in jedem Vers מצרים "Ägypten". In 4,22-23 taucht dazu als Gegenbeבן griff das mit Israel identifizierte בני "mein Sohn" auf "Sohn" verbindet mit den Versen 20 und 25, wie auch überhaupt das Wortfeld der Familie alle drei kleinen Textgruppen durchdringt ${ }^{29}$. Die erste und dritte Textgruppe kreisen um die Familie des Mose, die zweite um die Gottes und Pharaos. אמר "sagen" ist ebenfalls allen drei Textgruppen gemeinsam (v18-19 3x; v21-23 4x; v25-26 $2 x)$, und ebenso Jahwe als handelndes oder redendes Subjekt. Thematisch die interessanteste Verbindung ist das allen gemeinsame Element der Lebensbedrohung, das jeweils verschieden formuliert ist: $v 19 b$ "denn es sind all die Menschen gestorben, die nach deinem Leben trachten"; v23 "wenn du dich weigerst, ihn zu entsenden, siehe, ich selbst werde deinen Sohn, deinen Erstgeborenen, erschlagen"; v24 "und er suchte ihn zu töten". So gesehen ist der Text 4,18-26 durch die beiden Motive "Familie" und "Lebensbedrohung" - in ihren Variationen - geeint.

28 Vgl. dazu in letzter zeit vor allem: F.LINDSTRÖM, God 41-55, und C.HOUTMAN, Exodus 4:24-26; weiters die Aufsätze von S.A.Geller, H.Rand und die Ausführungen von M.Fishbane.

29 "sein Schwiegervater", Jitro und Jätär und meine Brüder in v18, seine Frau und seine Söhne in v20, mein Sohn, mein Erstgeborener v22, mein Sohn, dein Sohn, dein Erstgeborener v23, Zippora, ihr Sohn, קת "Bräutigam" in v25, und letzteres Wort noch einmal in $\mathrm{v} 26$. 
Die Betonung der Familie stellt gegenüber dem Dialog, in dem sie, abgesehen von der Erwähnung "Jitros, seines Schwiegervaters" $(3,1)$ und von "Aaron, dein Bruder" $(4,14)$, nicht vorkommt, wenn nicht eine Korrektur, so doch eine wichtige Ergänzung dar. Der Grund für Moses Rückkehr ist von Familiendenken geprägt. Es ist die Sorge um seine Brüder, die ihn nach Ägypten aufbrechen läßt. In der dem Pharao auszurichtenden Botschaft tritt eine ähnliche Motivation bei Jahwe hervor: Israel ist Jahwes Sohn, sein Erstgeborener. Damit erscheint Israel als Mitglied der Familie Jahwes, eine Aussage, welche die des Dialogs ("mein Volk, die Israeliten" 3,10 ) überholt und noch einmal übersteigert. Und schlieblich verdankt Mose seine Rettung seiner Familie. Das kluge Handeln seiner Frau und die Beschneidung seines Sohnes führen zum Ablassen des Angreifers und so zum überleben angesichts der $\mathrm{Be}-$ drohung. Die Bedeutung der Familie ist auch dadurch betont, daB diese Beziehung jeweils in direkter Rede und als Argument gebracht wird (v18.22-23.25-26).

Eine weitere Ergänzung gegenüber dem Dialog stellt das "Gehen" dar. Damit wird der während des Zwiegesprächs dreimal wiederholte Befehl Gottes, dessen Nichtbefolgung durch Mose zum Ausbruch des göttlichen zornes führte, nun endlich ausgeführt. Bereits der erste Vers $(4,18)$, und gleich das erste Wort, löst diese aufgestaute Spannung; die dreifache Erwähnung innerhalb desselben Verses, verteilt auf Erzähler, Mose und Jitro, aber immer auf Mose bezogen, unterstreicht das Gewicht dieses Wortes. In der zahl ergibt sich so auch eine Entsprechung mit den Befehlen Gottes. Die im Dialog offengebliebene und in den Einwänden bis zum ÄuBersten gesteigerte Möglichkeit einer Ablehnung durch Mose bewirkt im Leser den Aufbau einer Spannung: "Wird Mose gehorchen? Wird er gehen?". In 4,18 wird sie mit einem Schlag gelöst. Mose - ganz im Gegensatz zu vorher - ist völlig bereit, ja sogar von sich aus daran interessiert zu gehen.

30 Möglicherweise ist dieses starke Gewicht auf der Familie so $\mathrm{zu}$ verstehen: Im Dialog 3,1-4,17 dreht sich alles um die Sendung, die persönliche Beauftragung des Mose durch Gott, unabhängig von den weiteren Beziehungen. Hier im Nachtrag aber, wo diese Sendung gelebt zu werden beginnt, erweisen sich die familiären Beziehungen als wichtig und tragend. 
Auch das Bild Jahwes ist von dem Bild, das der Dialog von ihm zeichnet, ziemlich verschieden, besonders im letzten Teil (v24-26). Das führt so weit, dab Jahwe seinen eigenen Gesandten töten will, den er erst knapp zuvor mit Mühe dazu bewogen hat, die schwierige sendung anzunehmen. Was ist der sinn dieses scheinbar widersprüchlichen Tuns?

Elemente für eine Antwort könnten sein:

a) die vorhin herausgestellten zusammenhänge mit "Familie" und "Lebensbedrohung". Fishbane zieht eine Parallele von v23, wo Jahwe im Fall der Nichtbefolgung den Tod der Erstgeburt ankündigt, 3 zu v24-26, wo Mose durch die Beschneidung seines Erstgeborenen gerettet wird.

b) Der "Ort" dieser Stelle unmittelbar vor der Rückkehr nach Ägypten läbt in ihr einen übergangsritus erwarten. Die Ähnlichkeiten mit Gen $32,22-33$ sind frappierend ${ }^{33}$ : In beiden Fällen handelt es sich um eine Rückkehr in das Land, aus dem sie (Jakob bzw. Mose) geflohen sind; jeweils wartet ein Bruder; der ort befindet sich zwischen zweiter Heimat und Land der Geburt; es ist eine Auseinandersetzung mit einer göttlichen Macht, die in Verwundung (der Hüfte [?] bzw. durch die Beschneidung) und Benen-

31 Der Singular בנה "ihr Sohn" könnte, verbunden mit 2,22, auf den Erstgeborenen Gerschom hinweisen. Zuvor, in 4,20, stand jedoch בניץ "seine Söhne", sodaß also nicht sicher gesagt werden kann, wer in v25 mit "ihr Sohn" gemeint ist, zumal ja בכר "Erstgeborener" nicht verwendet wird. Doch auch abgesehen davon, ob es nun der Erstgeborene war oder nicht, bleibt das Argument insofern gültig, als auf alle Fälle eine Parallele mit dem ebenfalls in v23 erwähnten בנק besteht.

32 Für die Symbolik von Durchzug und übergang in der Bibel siehe J.L.SKA, Passage 101-103 und 131-134. Dort auch weitere Literatur.

F.LINDSTRÖM, God 50, lehnt die Deutung als rite de passage ab. Doch verbindet er den übergangsritus mit der Hochzeit, während wir ihn hier als Wechsel zwischen zwei Lebensabschnitten des Mose verstehen wollen.

33 F.LINDSTRÖM, God, ordnet beide Texte (Gen 32 und Ex 4) unter sein erstes Kapitel "An Identification of YHWH with Hostile Forces?". S.71-72 nennt als Gemeinsamkeit, daB Jahwe sekundär verantwortlich gemacht zu werden scheint für ein Tun, das ursprünglich einen Dämon charakterisierte. Auf s.72-73 stellt er jedoch die Unterschiede zwischen beiden Texten deutlich heraus. 
nung $\left(\right.$ Jakob $=$ Israel; Mose $=$ Blutbräutigam ${ }^{34}$ ) Spuren hinterläBt; gemeinsamer zeitpunkt ist vermutlich die Nacht (wenn מלו 1 Nachtquartier, Wegstation" so gedeutet werden darf) ${ }^{35}$. Trotz der Unterschiede (was z.B. die Rolle der Familie oder die Länge der Erzählung betrifft) überwiegen all diese Gemeinsamkeiten. Sie führen dazu, unsere stelle nicht (nur) als unerklärbaren, widersprüchlichen Angriff Jahwes $\underset{36}{6}$ Mose $z u$ sehen, sondern daB wir sie vom Typ ihrer Erzählung her ${ }^{36}$ verstehen versuchen. Ex 4,24-26 ist der Bericht eines Übergangsritus, in dem Mose durch die Hilfe seiner Frau besteht, und zugleich ein Vorabbild des Gelingens seiner Sendung.

c) Die Deutung als Übergangsritus erfaBt nicht, warum die Bedrohung gerade von Jahwe ausgeht. Die Täterschaft Jahwes verlangt nach einer Erklärung. Eine solche bietet sich an, wenn man sieht, wie die Aussagen über Jahwe hier in 4,18-26 eine im Dialog zuvor nicht ausgezogene Linie vervollständigen. Dort (bis 3,20)

34 F.LINDSTRÖM, God 46, will in Analogie zu übersetzen: "one would suppose that it meant 'a bridegroom who has shed blood" ". Die Bedeutung des (von Gott verstandenen) Ausdrucks bleibt auch in dieser Auslegung rätselhaft, denn Jahwe kann nicht gut als der gesehen werden, der hier Blut vergiebt. Und auch für Mose läßt sich der so ausgelegte Ausdruck schwer verwenden.

35 F.LINDSTRÖM, God 44, hat allerdings zu Recht darauf hingewiesen, daß die Deutung mit "Nachtquartier" nicht die einzige ist. Die Wegstationen wurden auch untertags, während der Hitze benützt, sodaß selbst ein zeitpunkt während des Tages nicht auszuschlieben ist.

C.HOUTMAN, Exodus 82 , betont, daB man unter מלון nicht ein Gasthaus verstehen muB, sondern daB auch einfach ein Platz gemeint sein kann, der sich aufgrund seiner natürlichen Gegebenheiten zum übernachten eignet.

36 Als weiteres Beispiel für eine solche Erzählung könnte Jos 5,13-15 angesehen werden. Josua begegnet dem himmlischen Heerführer vor der Einnahme Jerichos. Die Bedrohung ist dargestellt durch das gezückte Schwert.

Die Stelle steht genau an der Schwelle zwischen wüstenwanderung, die mit dem Durchzug durch den Jordan abgeschlossen ist, und der ersten Landnahme, die sich in der Einnahme Jerichos konkretisiert.

37 Die Berechtigung, hier von Ritus zu sprechen, kommt aus der Erwähnung der Beschneidung. Ähnlich wird in Gen 32,33 eine EBgewohnheit begründet.

C.HOUTMAN, Exodus 99, weist auf folgende Verbindung hin: Die Beschneidung stellt eine Art "inauguration, dedication" für Moses Aufgabe dar. Durch die Kraft der Beschneidung wird Mose ganz Gott ergeben und von ihm geschützt. Mose ist nun voll und ganz der von Gott Gesandte. 
hatte Gott sich damit "begnügt", die Ägypter zu schlagen, wobei offenblieb, wie; Tod wird mit keinem Wort erwähnt. In 4,18-26 dagegen erscheint Jahwe als Herr auch über den Tod: Er weiB um ihn (v19), er kann ihn wollen (v24) oder bewirken (v23), und er kann von ihm absehen (v26). Diese absolute Souveränität Gottes fügt dem Dialog eine weitere Note hinzu . Sie spiegelt auch Elemente der Plagenerzählung und insbesondere von $\operatorname{Ex}_{39} 12$ voraus, wo Jahwe immer wieder der Herr über Leben und Tod ist ${ }^{39}$.

Erzähltechnisch zeigen sich gegenüber dem Dialog, abgesehen von der auBergewöhnlichen Erhöhung der Spannung durch die letzten drei Verse, vor allem Ergänzungen und Präzisierungen. Neu oder stärker treten hinzu die Bedeutung der Familie, der Gehorsam des Mose und Jahwe als Herr über den Tod. Diese Elemente werden verbunden durch das Motiv der Reise, das ein Bild für den mit Mose geschehenden Wandel darstellt und so äußerlich der im Innern des Mose sich vollziehenden Verwandlung vom Hirten Jitros zum Gesandten Jahwes entspricht.

Parallel mit diesen Rückwendungen verstärken sich auch die Vorausdeutungen $^{40}$. Auf die Beziehung $z u$ den Plagen und besonders zu Ex 12 haben wir oben schon aufmerksam gemacht. während aber v22-23 eine genaue, zukunftsgewisse ${ }^{41}$ vorausdeutung enthalten, künden v24-26 als schwer verständliches Geschehen auf rätselhafte

38 M.FISHBANE, Text and Texture 71, schreibt diesbezüglich: "Moses finds it initially difficult to trust a god who says He would 'be as He would be'. Now, .... Moses is tested in his resolve, in his capacity to acknowledge that He who referred to Himself as 'eheyeh, 'I shall be', is the same One whether He promises life and redemption or causes death and destruction."

39 Jahwes Macht über den Tod wird angesprochen jeweils in den ersten beiden der drei Dreierserien der Plagen $(1,2,4,5,7$, $8)$. Die Stellen sind: 7,$18 ; 8,9.27 ; 9,6.25 ; 10,19$.

In 10,28 , pointiert, maßt sich der pharao Macht über den Tod an; das führt zur Ankündigung des Todes der Erstgeburt 11,4-5 und seiner Ausführung 12,29-30, wobei die Erklärung des Volkes "Wir sind (sonst) alle des Todes!" besonders $\mathrm{zu}$ beachten ist.

zu Jahwes Macht über den Tod siehe auch Ex 12,12.23. Auf die Verbindung mit Ex 12 machen S.A.GELLER, struggle 58; und F.LINDSTRÖM, God, der Ex 12,21-23 zusammen mit Gen 32 und Ex 4 im ersten Kapitel behandelt, aufmerksam.

$40 \mathrm{zu}$ Vorausdeutungen siehe vor allem das zweite Kapitel "Die sphärische Geschlossenheit des Erzählwerks" in E.LÄMMERT, Bauformen 95-194.

41 E.LÄMMERT, Bauformen 142. 
Weise $^{42}$ eine in vielem noch unbestimmte zukunft voraus. Ein Beispiel dafür: ויפגשהו findet in genau derselben Form in 4,27 für das zusammentreffen zwischen Aaron und Mose Verwendung ${ }^{43}$. Dabei wird der negative Kontext von v24 ("suchte ihn zu töten") vollständig verändert; Mose wird herzlich mit einem KuB empfangen. In diesem Miteinander von zukunftsgewissen und zukunftsungewissen Vorausdeutungen bleiben dem Leser Fragen offen: Was wird sich ereignen? Und wie?

Die bisher gemachten Bemerkungen unterstreichen den Eigencharakter von Ex 4,18-26 gegenüber dem Dialog. Es ist aber auch zu beachten, daß besonders 4,18-23 mehrfach eng mit 3,1-4,17 verknüpft sind. 4,18a ähnelt in Konstruktion, Vokabular und Thema (Interesse des Mose) sehr stark 3,3. Darüber hinaus erwähnt es wie 3,1 Jitro als Schwiegervater des Mose. 4,19 wiederholt den Befehl zum Gehen von $3,10.16 ; 4,12$. 4,20b berichtet die wortwörtliche Ausführung von 4,17. 4,21 nimmt wohl, allerdings mit einem anderen Wort (מפתים "Zeichen") auf die Zeichen (אתות) von 4,1-9 Bezug. 4,22-23 erwähnen wie 3,18, was Mose dem Pharao auszurichten hat; durch wiederholtes אמר "sagen" geschieht dabei ein ähnlicher Rückschritt im zitieren wie in 3,16-17. Diese Verbindungen $^{45}$ signalisieren eine zusammengehörigkeit von Ex 4, 18-26 mit dem Dialog. Da aber das Moment des Gegenbildes, der Ergänzung stärker ist, scheint uns die von B.Jacob gefundene Bezeichnung "Nachtrag" passend zu sein. Insofern er die Rückreise nach Ägypten berichtet, kann man ihn gleichzeitig auch als übergang ansehen.

42 In seinem auch auf Ex 4,24-26 eingehenden Artikel (struggle 54) schreibt S.A.GELLER: "The concept of pregnant ambiguity is a cornerstone of modern literary analysis."

43 Es sind überdies die einzigen beiden Vorkommen von פגשי in Exodus und die einzigen in dieser Form im AT.

44 E.LÄMMERT, Bauformen 141: "Je geheimnisvoller die Andeutung, umso sicherer reizt sie auf zu der Frage: Was wird geschehen?"

$45 \mathrm{Zu}$ ergänzen wäre hier noch, daß 4,19b mit der Nachricht vom Tod derer, die Mose nach dem Leben trachten, 2, 23 aufnimmt. 
Die aufgezeigten Beziehungen unseres Textes Ex 3,1-4,17 mit seinen Randtexten bestehen auf mehreren Ebenen. Im Vokabular zeigen sich viele gemeinsame wörter. Von der erzählten Handlung her lassen sich Ex 2,23-25; 3,1-4,17 und 4,18-26 als sinnvolle Abfolge ansehen. Auch die erzählerische spannung verknüpft unseren Text stark mit seinen beiden Randtexten. Die Berufung des Mose $(3,1-4,17)$ ist Gottes Antwort auf die Not der Israeliten (2,23-25), das Gehen des Mose $(4,18-26)$ seine Antwort auf die Sendung durch Gott $(3,1-4,17)$.

Die beiden übergänge erweisen sich so als sehr gut mit unserer Erzählung zusammenpassende und damit abgestimmte Komposition. Die vielen Verbindungen unseres Textes mit seinen übergängen sprechen für starke Bezugnahmen bei der Redaktionsarbeit. 


\section{KAPITEL: FORM UND AUFBAU}

\subsection{FORMALE GESTALTUNG}

Sowohl die inneren Kriterien für die Bestimmung der Einheit wie die Untersuchung der "Randtexte" (die übergänge 2, 23-25 und 4,18-26) führen dazu, daß 3,1-4,17 als selbständige Einheit betrachtet werden darf. Die folgende Untersuchung beschäftigt sich mit der organisation dieser Einheit unter formalen Gesichtspunkten.

Der Form unseres Textes ist in neuerer zeit immer wieder Beachtung geschenkt worden. W.zimmerli hat in seinem Ezechielkommentar zwei verschiedene Typen von "Berufungsberichten", den wortbestimmten und den visionsbestimmten, aufgezeigt und darin in Gouders einen Nachfolger gefunden. Früher schon hatte N.Habel in einem Artikel ${ }^{3}$ Form und Bedeutung dieser Weise der Berufung untersucht und die Verbindung mit der Beauftragung und Legitimierung eines Boten herausgestrichen. Wenige Jahre später hat w.Richter den vorprophetischen Berufungsberichten ein eigenes Buch $^{4}$ gewidmet; dieses gilt seither als Standardwerk, so auch zu Ex 3. Von einem etwas anderen Gesichtspunkt aus hat D.Irvin eine Reihe von Elementen herausgearbeitet, die es erlauben, Ex 3-4 als "traditional episode of the sending of a saviour" $z u$ bezeichnen und mit einigen anderen, ähnlichen Berichten $z_{6} u$ vergleichen. Auch in den Kommentaren - unlängst w.H.Schmidt, mit einem eigenen Exkurs - wird Ex 3-4 kaum mehr behandelt, ohne daB nicht auch auf

1 W.zIMMERLI, Ezechiel (1969) 16-21.

2 K.GOUDERS hat Teile seiner Dissertation zu den prophetischen Berufungsberichten in Form von mehreren Artikeln in der zeitschrift Bibel und Leben, Jahrgänge 1971 und 1972, veröffentlicht.

3 N.HABEL, Call Narratives (1965).

4 W.RICHTER, Berufungsberichte (1970).

5 D.IRVIN, Stories, in: J.H.HAYES, J.MAXWELL MILLER, Israelite and Judaean History (1977), 180-209.

6 W.H.SCHMIDT, Exodus 123-128, bringt "Das sogenannte Berufungsformular" als Exkurs 4. 
die Form, im besonderen auf die Darstellung als Berufungsbericht, eingegangen wird.

Tatsächlich bestehen verblüffende Verbindungen mit anderen Texten, die zum Teil wörtliche übereinstimmungen aufweisen. Ähnlichkeit in Vokabular und Aufbau rechtfertigen und fordern so einen Vergleich mit diesen anderen Texten. Hier aber müssen die den oben angeführten studien vorausgegangenen Arbeiten nicht wiederholt werden; sie sollen nur in ihren wichtigsten Ergebnissen aufgenommen und auf ihre Aussage in unserem Text hin durchleuchtet werden. Dies geschieht vor allem in den Abschnitten 2.1.2 und 2.1.3. Davor steht eine kurze Untersuchung der verteilung der Stimmen von Erzähler und Dialogpartnern in unserem Text (2.1.1). Am Ende wird der unserer Erzählung zugrundeliegende Konflikt und seine Entwicklung behandelt (2.1.4). Je nach diesen unterschiedlichen Gesichtspunkten ergeben sich verschiedene Gliederungen unseres Textes.

\subsubsection{Rede und Gegenrede}

Ein Aspekt der Form eines erzählenden Textes betrifft die Kommunikation. Der (reale) Autor $^{8}$ verteilt die Rollen: Er weist einem (fiktiven) Erzähler seinen Anteil zu, und ebenso den erzählten Figuren (in unserem Fall Gott und Mose). Manchmal vermag

7 Der Gebrauch des Ausdrucks "Erzählung" für unseren weitestgehend aus Dialog bestehenden Text rechtfertigt sich durch die Zugehörigkeit von Ex 3-4 zur epischen Gattung, zur Prosa. D.h., Erzählung wird hier in einem weiten Sinn verwendet. Im Unterschied dazu verwendet das Englische dafür zwei Begriffe, den einen, "narrative", im obigen sinn, den anderen, "narration", meist im engen (und damit dem Dialog gegenüberstehenden) Sinn. Für letzteres siehe z.B. R.ALTER, Art, wo die überschrift von $c 4$ (63-87) lautet: "Between Narration and Dialogue", besonders 6365 .

8 Für die Termini und die im Hintergrund stehende Kommunikationstheorie siehe: C.KAHRMANN u.a., Erzähltextanalyse Bd.1 37 47.

Was den (realen) Autor bei biblischen Texten betrifft, so können damit auch mehrere Redaktionen gemeint sein. Es handelt sich in diesen Fällen dann um einen Plural.

Die Unterscheidung zwischen "real author, implied author and narrator" wird auch von W.C.BOOTH, Rhetoric, vorgenommen. Bei Kahrmann entsprechen dem die Kommunikationsniveaus vier bis zwei, mit dem realen Autor, dem abstrakten Autor und dem Erzähler mit ihren jeweiligen Adressaten. Dazu kommt bei ihr Kommunikationsniveau eins, die Ebene der erzählten Figuren. Zur Diskussion um die Person des Erzählers siehe auch F.K.STANzEL, Theorie 24-38. 
schon deren quantitative Verteilung AufschluB zu geben über die Gewichtung der Personen eines Textes. Dem wollen wir uns hier zuwenden.

Das Schwergewicht unseres Textes liegt eindeutig auf dem Reden. Die Stimme des Erzählers ist in 3,1-2.4a.6b; 4,3.4b.6.7 deutlich vernehmbar, insofern sie vom Reden verschiedene Handlungen berichtet (79 wörter). Darüber hinaus scheint sie in den Redeeinleitungen $z u$ den Reden Gottes und Moses auf ( 56 wörter, 42 für Gott und 14 für Mose) ${ }^{9}$. Der verbleibende Text ist Rede: 509 wörter (425 für Gott und 84 für Mose). Stellt man die Anzahl der wörter einander gegenüber, so ist die Verteilung Rede : Erzähler $=509$ : 135 ; d.h. die Redeteile sind dreimal so lang wie der Anteil des Erzählers. Nimmt man zu den Reden noch die Redeeinleitungen hinzu, erhöht sich das Verhältnis Rede : übriger Erzählerbericht auf 565 : 79. Die Reden und ihre Einleitungen zusammen sind mehr als siebenmal so lang wie die rein erzählenden Teile in unserem Text. Nun aber gelten Texte mit direkter Rede als besonders wichtig ; in ihnen verlangsamt sich das Tempo des Erzählens und gelangt fast zur Deckung mit dem erzählten Ereignis selbst ${ }^{1}$. Der hohe Redeanteil läßt uns bereits jetzt vermuten, der Autor wolle uns Wichtiges möglichst wirklichkeitsgetreu mitteilen.

Auch ist unser Text unbestritten ein Dialog. Es handelt sich um das Reden zweier Gesprächspartner. Tatsächlich decken die ineinander verflochtenen Reden Gottes und Moses, von wenigen Versteilen abgesehen, den ganzen Text von $3,4-4,17 \mathrm{ab}$ :

9 Dabei ist 4,14a (das Erzürnen Gottes) mitgezählt.

10 R.ALTER, Art 65, spricht von "the highly subsidiary role of narration in comparison to direct speech by the characters".

11 Erzählte zeit und Erzählzeit sind gleich. Dadurch kann der Eindruck verstärkt werden, es handle sich um Wirklichkeit.

Für die Verbindung von Wirklichkeitsnähe und direkter Rede siehe auch E.LÄMMERT, Bauformen 87. 
SCHEMA 1: Die Reden Gottes und Moses

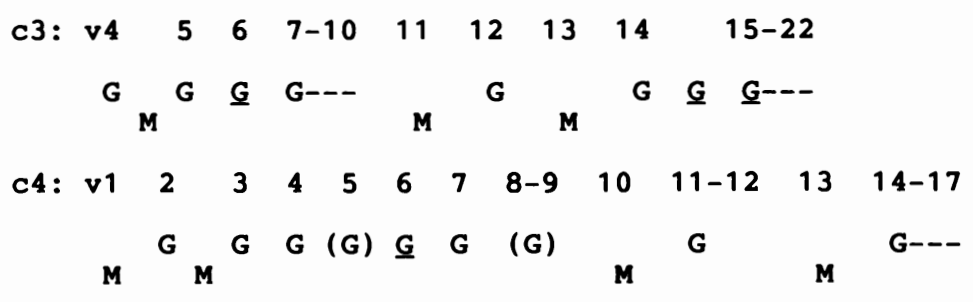

Das bei weitem am meisten wiederholte wort unseres Textes

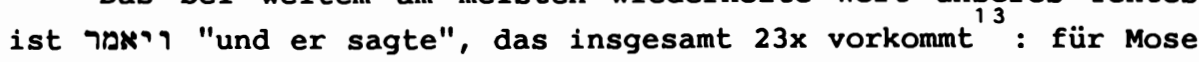
in $3,3.4 .11 .13 ; 4,1.2 .10 .13$ und für Gott in 3,4.5.6.7.12. $14(2 x) .15 ; 4,2 \cdot 3 \cdot 4 \cdot 6 \cdot 7 \cdot 11.14$. Dieses für die Redeeinleitungen. Es kommt in ihnen allen vor, selbst dann, wenn noch ein zweites Verb (wie pר "antworten") verwendet wird. Ein Vergleich zwischen Mose und Gott ergibt, daB Gott mit 15 eingeleiteten Reden anscheinend fast doppelt so oft redet wie Mose $(\mathbf{8 x})$. Doch ist die Sachlage noch komplexer.

während nämlich bei Mose all seine Reden eingeleitet werden - auch das, was er denkt $(3,3)$ - und darauf auch immer ein Reden Gottes folgt, gibt es bei Gott sowohl Reden, die nicht eingeleitet werden, wie solche, auf die keine Reaktion von seiten des Mose erfolgt. Am Ende von 4,4 und 4,7 berichtet der Erzähler jeweils eine Reaktion des Mose auf einen Befehl Gottes. 4,5 und 4,8f setzen darauf ganz unvermittelt und im Bruch $z u$ den sonst in unserem Text üblichen häufigen Einleitungen direkt mit dem Reden Gottes ein. Desgleichen geschieht es mehrfach, daß ein Reden

12 Erläuterungen $\mathrm{zu}$ den verwendeten zeichen:

G entspricht einer (eingeleiteten) Rede Gottes, wobei hier zwischen einem Reden Gottes oder Jahwes nicht unterschieden wird.

M steht für ein Reden Moses (alle Reden sind mit einer Redeeinführung eingeleitet).

$G$ heiBt, daB ein Reden Gottes wiederholt eingeleitet wird, obwohl Gott unmittelbar zuvor redet und keine Unterbrechung durch Mose oder den Erzähler erfolgt ist.

( ) bedeutet, daß die entsprechende Rede nicht eingeleitet ist.

--- entspricht durch mehrere Verse durchgehender Rede.

13 Dazu kommen noch 10 Vorkommen dieses Wortes "sagen" in der direkten Rede, macht zusammen 33 Belege. 
Gottes einem anderen Reden Gottes folgt ${ }^{14}$, ohne daB dazwischen auch nur irgendeine Unterbrechung (durch ein Reden oder Tun des Mose oder sonst eine Bemerkung des Erzählers) erfolgt wäre: 3,6; $3,14 \mathrm{~b}$ und 3,$15 ; 4,6$.

\section{Exkurs 1: Wiederholte Redeeinleitungen}

Das Phänomen mehrfacher Redeeinleitungen begegnet auch auBerhalb der Bibel. Im Gilgamesch-Epos, Tafel $X$, Kolonne III, zeile 8 finden wir eine erste Redeeinleitung für das sprechen Gilgameschs zum Schiffer Urschanabi. In zeile 32 erfolgt eine zweite, identische Redeeinleitung, ohne daB dazwischen eine Reaktion des Schiffers erfolgt wäre .

In unserem Text folgt gleich viermal ein ראיר für Gott auf ein Reden Gottes. Diese - nicht notwendigen - wiederholten Redeeinleitungen sind ein bisher viel zu wenig beachtetes und weithin durch Quellenscheidung (weg)erklärtes Phänomen ${ }^{16}$.

14 Wir waren auf dieses Phänomen bereits in Schema 1 gestoßen. Eine erste allgemeine Beschäftigung damit erfolgt im untenstehenden Exkurs 1; eine genauere Auslegung folgt bei der Analyse der entsprechenden Verse (in c3).

15 R.C.THOMPSON, The Epic of Gilgamish 57, für zeile 32: ilu Gilgamiš a-na ša-šu-ma izakka(ar) a-na m[Ur-šanabi]: "Gilgamesch sprach zu ihm, zu Urschanabi: ..."

zeile 8 ist in dem von Thompson transkribierten Text nicht erhalten; doch lassen die lesbaren Textteile von K.8579 plate 40 und der zusammenhang mit sicherheit in ihr dieselbe Redeeinleitung annehmen.

Die Anmerkung dazu in der deutschen übersetzung von A.SCHOTT u. W.von SODEN, Das Gilgamesch-Epos 79, rechnet mit einem Textausfall. Doch ist - nach einer mündlichen Mitteilung von w.Mayer - eine wiederholte Redeeinleitung ein im Akkadischen gebräuchliches Vorgehen, um ein neues Argument anzudeuten.

Leider geht F.SONNEK, Einführung, zwar auf fehlende (S.231), nicht aber auf wiederholte Redeeinleitungen ein.

16 Z.B. wechselt P.Weimar beim übergang von 3,5 auf 3,6 vom Jehowisten zum Elohisten (Berufung 39 ) und bei $3,14 \mathrm{a}$ zu $3,14 \mathrm{~b}$ vom Jehowisten zur priesterschriftlichen Redaktion (S.47-48). Doch die wiederholten Redeeinleitungen 3,15 auf $3,14 \mathrm{~b}$ und 4,6 auf 4,5 geschehen jeweils innerhalb derselben schicht $(R)$ und finden so keine Erklärung.

Für wiederholte Redeeinleitungen siehe auch C.CONROY, Absalom $130 \mathrm{Anm} .65$; für die Fragwürdigkeit, Wiederholungen innerhalb einer Erzählung verschiedenen Schichten zuzuschreiben: R.N.WHYBRAY, Making 80-84. 
Erneute Redeeinführungen sind im Pentateuch häufig. Die Stellen, bei denen jeweils ein weiteres Reden desselben Sprechers zum selben Gesprächspartner wiederholt eingeleitet wird, ohne daB dazwischen etwas eingefügt wäre, sind folgende ${ }^{17}$ :

Genesis: $9,1.8 .12 .17 / 15,2.3 / 16,9-11 / 17,3.9 .15 / 19,9 /$

$20,9.10 / 24,24.25 / 27,36 / 37,21.22 / 41,39.41 / 42,1.2 /$

$47,3.4$

Exodus: $3,5.6 / 3,14-15 / 4,5.6 / 5,4.5 / 7,14.19 / 7,26 ; 8,1 /$ 25,$1 ; 30,11.17 .22 .34 ; 31,1.12 / 32,7.9 / 33,19-21$

Leviticus: 1,$1 ; 4,1 ; 5,14.20 ; 6,1.12 .17 ; 7,22.28 / 17,1 ; 18,1$; 19,$1 ; 20,1 ; 21,1.16 ; 22,1.17 .26 ; 23,1.9 .23 .26 .33 / 24,1.13$

Numeri: $3,5.11 .14 / 5,5.11 / 15,1.17 / 16,5.8 / 18,1.8 .20$

Deuteronomium: 29,$1 ; 31,1$

In dieser Liste lassen sich sogleich zwei grundlegende Typen unterscheiden, je nach dem Abstand der Redeeinleitungen zueinan$\operatorname{der}^{18}$.

Ist er weit (mehr als drei Verse), so handelt es sich meist um ein Sprechen Gottes. Die einzige Ausnahme im Pentateuch ist Dtn 29,1; 31,1 mit zwei aufeinanderfolgenden Reden des Mose. In allen Fällen führt dabei der Redner ein neues Thema ein. Die erneute Redeeinleitung kennzeichnet also den übergang $z u$ einem neuen Redeinhalt (oft eine Anweisung). Es sind auch meist nicht Gespräche im eigentlichen Sinn, sondern lange Monologe. Für diesen Typ gibt es eine interessante Vorkommensverteilung: Gen $5 x$ (c9 und 17), Ex $8 x^{19}$, Lev $22 x$, Num $6 x$ und Dtn $1 x$.

17 Die erste Angabe betrifft jeweils den ersten Redeeinsatz, die darauf folgende( $n)$ Stellenangabe $(n)$ bis zum Schrägstrich (/) die wiederholten Redeeinleitungen. / trennt ab zur nächsten Stelle und entspricht einem nachfolgenden übergang entweder zum Erzähler, zu einem anderen Redner oder zu einem anderen Angeredeten.

18 Der Abstand der Redeeinleitungen ist ein formales Kriterium. Untersucht man die beiden so entstehenden Gruppen auf ihren Inhalt, zeigt sich auch dort eine deutliche Verschiedenheit: Bei weitem Abstand handelt es sich meist um Anweisungen oder Gesetze, bei geringem Abstand dagegen ist das Sprechen eher persönlich und auf die konkrete Situation bezogen. Das formale Kriterium wird so im Nachhinein (von der inhaltlichen Untersuchung her) als für die Einteilung geeignet bestätigt.

19 Dieser Typ von wiederholter Redeeinleitung kommt in Ex nur in zwei klar definierten Kontexten vor: in den Plagen und in den Anweisungen zur Konstruktion des Heiligtums. (Siehe in der obigen Liste die Vorkommen von Ex 7,14 bis 31,12 .) 
Ist der Abstand jedoch gering (drei Verse oder weniger ${ }^{20}$ ), so ändert sich das Bild. AuBerhalb von Exodus, mit der Ausnahme von Gen 16 (Jahwes Bote ist dort der Redende), begegnen immer nur menschliche Sprecher. In Exodus dagegen ist es mit Ausnahme von Ex 5 (Pharao) ausschlieblich Jahwe, der sein Reden wiederholt einleitet (c3-4; 32-33). Die Verteilung auf die Bücher des Pentateuch ist wie folgt: Gen $11 x$, Ex $8 x$, Num $1 x(16,5.8)$; Lev und Dtn weisen diesen Typ erneuter Redeeinleitung nicht auf.

Inhaltlich gesehen fügt die wiederholte Redeeinführung und das in ihr Berichtete dann meist einen neuen Aspekt oder ein neues Argument zum schon Gesagten hinzu (z.B. Gen 16; 24; 41; 42; 47; Ex 5; 33). Das zweite Reden bringt so oft eine Ergänzung oder Präzisierung. Doch sind dabei zwei weitere Beobachtungen wichtig. Einmal wäre es zwar möglich, die wiederholte Redeeinleitung wegzulassen, doch ergäbe sich dann in den meisten Fällen ein abrupter übergang von einem Gesprächsthema $z u$ einem anderen. Die erneute Redeeinführung trennt so ab und mildert den Bruch. Und zum zweiten, im Gegensatz dazu, finden sich auch stellen, wo die zweite ÄuBerung gegenüber der ersten wenig Neues beinhaltet (z.B. Gen 15; 37). Was ist in diesem Fall die Funktion der wiederholten Redeeinleitung, wenn sie auch scheinbar Gleiches abteilen kann?

Eine Antwort auf diese Frage scheint möglich, wenn der Kontext all dieser stellen berücksichtigt wird. Ohne Ausnahme, wenigstens was die menschlichen Sprecher betrifft, sind es stellen, in denen die so wiederholt Redenden und manchmal auch ihre Gesprächspartner emotional stark betroffen sind. In Gen 15 und 16 stehen Abram und Hagar Gott bzw. seinem Boten gegenüber und erhalten von ihm eine kaum faBbare Botschaft. Bei Lot (Gen 19) und Abimelech (Gen 20) ist ihr Leben in Gefahr. In Gen 24 reagiert Rebekka so einem fremden Mann gegenüber, der sie unmittelbar zuvor reich mit Schmuck beschenkt und um ihre Identität und einen Platz zum übernachten gefragt hat. Und auch für den Knecht Abrahams geht es dabei um das Gelingen seines Auftrags. Esau (Gen 27) ist soeben um den Erstgeburtssegen betrogen worden. Bei Gen 37 steht das Leben Josefs auf dem Spiel, das Ruben seinem Vater ret-

20 Wir rechnen Num 16,5.8 hierher, Lev $23,23.26$ jedoch zur ersten Gruppe, weil letztere stelle inmitten anderer mit weitem Abstand steht. 
ten möchte. In Gen 41 ist es vielleicht nicht so klar, daB auch der mächtige pharao emotional betroffen sein könnte. Doch ist dort die Situation seines Landes kritisch: Eine Hungersnot steht bevor, und das Land braucht einen Mann, der es in diesen Jahren umsichtig planend führt. So mag auch die Einsetzung Josefs zum zweiten Mann nach ihm, die mit einer wiederholten Redeeinleitung geschildert wird, als für den Pharao wichtiger Moment gezeichnet worden sein. Gen 42 steht im Kontext einer drückenden Hungersnot, und Gen 47 läßt sich als Aufregung einfacher Hirten bei der Audienz beim Pharao verstehen, zumal ja ihre Weiterexistenz von derem günstigen Ausgang abhängig ist. In Ex 5 ist der pharao zum ersten Mal mit der Forderung konfrontiert, seine Untertanen zu entlassen. Schlieblich ist auch Num 16 ein höchst spannungsgeladener Augenblick: Mose steht der Auflehnung und Anfeindung durch Korach und seine Anhänger gegenüber.

Aus dem Kontext kann über die tiefgehende emotionale Betroffenheit - meist bei beiden Gesprächspartnern - hinaus noch etwas Weiteres gefolgert werden: Was so mit einer mehrfachen Redeeinführung angesprochen wird, hat immer einen (oder den) kritischen Punkt im Leben des Angesprochenen (z.B. Gen 16) zum Inhalt. Ein solches Reden enthüllt tiefe verletzungen und legt den Finger auf diese wunden Punkte: bei Abram in Gen 15 die bohrende Frage seiner Kinderlosigkeit; in Gen 16 bei Hagar die Beziehung zu ihrer Herrin Sarai; in Gen 37 das Verhältnis der Brüder Josefs zu ihm und ihrem Vater; in Ex 5 der Anspruch des Pharao auf den Dienst der Israeliten. So gesehen stehen immer lebenswichtige Entscheidungen auf dem spiel.

Läßt sich all das, was von den mehrfachen Redeeinleitungen durch Menschen gilt, auch von Jahwe behaupten? Wir stehen hier vor einer grundsätzlichen Schwierigkeit: Der "göttliche Gefühlszustand" bei diesem doppelten Sprechen, nämlich, wie seine Entscheidungen zustandekommen und was für Empfindungen damit verbunden sind, wird vom Erzähler meist sehr zurückhaltend angedeutet. Es läßt sich also nicht so einfach feststellen, ob Gott "emotional betroffen" ist, geschweige denn behaupten, es handle sich um einen "wunden Punkt". Doch finden sich in der Nähe einige Ausdrücke, die auf eine stärkere Beteiligung Jahwes am Reden schlieBen lassen. 
Am schwächsten ist dabei Gen 16, wo nur das Verb מצא "finden", vom Boten ausgesagt, das sorgende göttliche Handeln erwähnt. Alle anderen stellen mit göttlichem sprecher innerhalb des Pentateuch bei mehrfachen Redeeinleitungen mit geringem Abstand fallen ins Buch Exodus, das sind neben unserem Text noch $32,7.9$ und 33,19-21. In Ex 32 reagiert Jahwe auf den Frevel des Volkes, sich ein Kalb aus Gold zu gieBen und es anzubeten, mit zorn (v10) und dem Wunsch, das Volk zu vernichten. In Ex 33 gewährt Jahwe dem Mose dessen Bitte und verspricht, seine Herrlichkeit an ihm vorüberziehen zu lassen. Es ist ein besonderer Moment auch für Gott, denn nie zuvor und nie danach wird im AT von einem Menschen eine solche Nähe und Unmittelbarkeit zu ihm erzählt.

Ein ganz kurzer Blick auf unseren Text Ex 3-4 zeigt zum einen, daß diese Erzählung mit gleich vier Vorkommen die größte Häufigkeit solcher wiederholter Redeeinleitungen (des zweiten Typs, mit geringem Abstand) aufzuweisen hat, weshalb diese hier wohl als bewußt eingesetztes Ausdrucksmittel interpretiert werden dürfen, und zum anderen, daB in ihnen allen entweder gleich anschließend oder zuvor $(4,5)$ Gott über sich selbst spricht: Es sind also Momente der offenbarung, die auch bei Gott selbst eine stärkere Beteiligung vermuten lassen.

(Ende des Exkurses)

Aufgrund der oben (vor dem Exkurs) beschriebenen Eigenheiten kommt es, daB bei 15 eingeleiteten Reden Gottes nur $13 x$ eine Reaktion des Mose (Reden oder Tun) erwähnt wird, Gott aber insgesamt $17 x$ zu sprechen beginnt. Gegenüber den 7 Reden des Mose im Dialog spricht Gott also mehr als zweimal so viel und - bezogen auf die Zahl der wörter - mehr als fünfmal so lang. Das sind zwei Zeichen für ein klares übergewicht Gottes im Dialog. Für sein überwiegen spricht auch, daß Gott den Dialog sowohl beginnt $(3,4)$ wie auch beendet $(4,17)$.

Mose fällt ihm gegenüber ab. Sein Reden ist meist kurz, und auf manche Reden Gottes bleibt er stumm $(3,5.14 a \cdot 14 b ; 4,5)$. AuBerdem stehen jeweils zwei Reden des Mose so nahe beieinander $(3,3.4 ; 3,11.13 ; 4,1.2 ; 4,10.13)$, daB dadurch Blöcke entstehen, in denen Mose über längere zeit hinweg überhaupt nicht hörbar ist. Diese "Blöcke des Schweigens Moses" sind: 3,5-10; 3,14-22; 4,3-9 und 4,14-17 (das sind 26 von insgesamt 39 versen). Sie 
unterstreichen das oben erwähnte übergewicht Gottes im "Dialog", oder, um es genauer zu sagen: Sie stellen heraus, daB der eigentliche Dialog - im strengen Sinn als Wechselrede - sich auf relativ wenige Verse in unserem Text erstreckt.

Im Gegensatz zu den Reaktionen des Mose bestehen jene Gottes, mit einer einzigen Ausnahme $(4,14)$, ausschlieblich im Reden. Auf ein Reden (oder Tun) des Mose antwortet Gott mit Reden, und zwar sofort und immer.

Das Untersuchen unserer Erzählung unter dem formalen Aspekt der Reden führt uns so bereits zu zwei Ergebnissen. Einmal läßt das zurücktreten des Erzählers über weite Teile des Textes und dementsprechend der hohe Anteil an Rede vermuten, daB es sich hier um wichtiges handelt. Das Wechselgespräch zieht sich ununterbrochen über 36 Verse dahin und wird so zum längsten Dialog Gottes mit einem Menschen in der Bibel ${ }^{21}$. Solche Besonderheit im Vergleich mit anderen Texten unterstreicht die Bedeutung der Reden in unserem Text und stellt vor die Frage, was der Grund für diese besondere Ausgestaltung ist.

Durch die Reden legt der Autor das Schwergewicht auf die beiden erzählten Personen Gott und Mose. Sie erscheinen im "Originalton", d.h. mit ihren eigenen Worten, ${ }_{2}$ gleichsam "unverfälscht" durch die Wiedergabe eines Erzählers" . Sie selbst tre-

21 Einzig das "Gespräch" Jahwes mit Ijob (Ijob 38,1-42,6) ist länger. Doch ist dort zu beachten, daB erstens das Reden Gottes aus zwei langen Monologen besteht: c38-39 und 40,6-41,26. Und zweitens macht der Anteil Ijobs am Gespräch nur zwei kurze Bemerkungen aus (dazwischen 40,3-5 und 42,1-6 am SchluB).

Interessant, gerade im zusammenhang mit dem obigen Exkurs, ist die wiederholte Redeeinleitung in 40,1 zur Einführung eines neuen Argumentes. Gott wendet sich direkter Ijob und seinem Fragen $z u$, worauf dieser auch antwortet: 40,3-5. - Die Schlüsselrolle dieser doppelten Redeeinleitung in Ijob 38-42 wird auch in der neuesten Untersuchung dazu (J.van OORSCHOT, Gott) deutlich.

Die längste Rede Gottes - allerdings mit wiederholten Redeeinleitungen - findet sich (meines wissens) übrigens auch in Exodus: In Ex 25,1-30,10 gibt Jahwe die Anweisungen zum Bau des Heiligtums.

22 Es ist aber $z u$ beachten, daß diese vermeintliche Unmittelbarkeit auch, und zwar durch Erzähler und Autor, vermittelt ist. Im Modell von C.KAHRMANN, Erzähltextanalyse 37-47: Die Ebene der erzählten Figuren (Kommunikationsniveau eins) wird umgriffen von den Kommunikationsniveaus zwei bis vier, die den Ebenen des Erzählers, des abstrakten (w.C.Booth "implied") und realen Autors 
ten auf, und dabei wird schon durch die Art ihres Redens deutlich, daß diese beiden Gesprächspartner sehr verschieden sind. Mose ist über zwei Drittel des Dialogs hinweg stumm; Gott ist in seinem Reden konstant und dominierend.

\subsubsection{Das Berufungsschema}

Die Ähnlichkeiten mit anderen Texten (Ri 6; 1 Sam 9-10; Jes 6; Jer 1; Ez 1-3) in bezug auf den Aufbau werden von vielen durch ein gemeinsames "Berufungsschema" erklärt. Dieses Schema enthält eine Reihe von Elementen, die in meist gleicher Abfolge bei diesen Berufungen verwendet werden.

Vergleicht man die diversen Schemata von N.Habel, W.Richter, K.Gouders und anderen, so ist deren größter gemeinsamer Nenner die Folge der vier Elemente: Auftrag - Einwand - Zusicherung des Beistandes - Zeichen. Diese vier Glieder bilden auch den Hauptteil der Berufung. Unsicherheiten bestehen dagegen bezüglich des Anfangs und des Schlusses dieses Berufungsschemas. Habel ${ }^{23}$ erwähnt für den Anfang zwei Elemente (göttliche Begegnung und Einleitungswort); doch scheint das von Richter ${ }^{24}$ an die Spitze gestellte Glied "Andeutung der Not" genauer zu sein: In allen vorprophetischen Berufungsberichten wird es ausdrücklich genannt, und in den Berufungen der Propheten ist es impliziert als Grund für die Beauftragung durch Gott. Was den SchluB betrifft, so ist seine zugehörigkeit zum Schema umstritten; gehört er dazu, so müBte bei unserem Text vieles übersprungen werden (bis hin zu $4,18)$. Damit kommen wir auf ein Schema mit folgenden fünf Elemen$\operatorname{ten}^{25}:$

und ihren jeweiligen Adressaten entsprechen. Siehe auch Anm.60. - In den biblischen Erzählungen kommt dem Dialog eine besondere Rolle zu (vgl. R.ALTER, Art 63-87).

23 N.HABEL, Call Narratives 298-299.

24 W.RICHTER, Berufungsberichte 138.

25 Identisch mit W.RICHTER, Berufungsberichte 138.

Den Elementen 2-5 entsprechen bei N.HABEL, Call Narratives 298300 , die Elemente $3-6$ und bei K.GOUDERS, Berufung 186, die Elemente 2.4.6.7 von den acht Elementen des wortbestimmten Typus der prophetischen Berufungsberichte. 

(1) Andeutung der Not
(2) Auftrag
(3) Einwand
(4) Zusicherung des Beistandes
(5) Zeichen

Nun verkompliziert sich die Anwendung dieses Schemas auf Ex 3-4 dadurch, daB darin nach allgemeiner Annahme wenigstens zwei Quellenschichten enthalten sind und damit das Berufungsschema eine Verdoppelung erfährt.

Del olmo ${ }^{26}$ schlägt dafür folgende Einteilung vor:

I Einleitung (Introducción) 2, 23-25

II Theophanie (Teofanía) 3,1-6

III Sendung (Misión) a) Bote (mensajero) 3,7f.16-20

b) Retter (salvador) 3,9-12

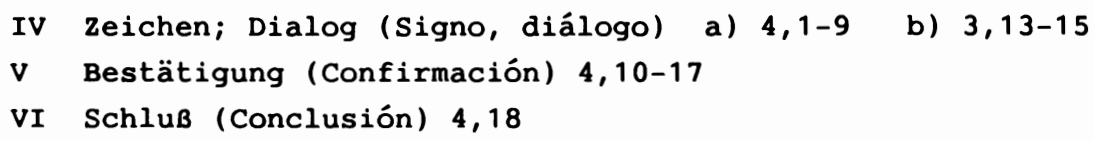

Nur die beiden Elemente Sendung und zeichen erscheinen verdoppelt. Doch wird bereits deutlich, daB innerhalb unseres Textes eine verschiebung entsteht: während auf der Ebene b) (sie entspräche dem Elohisten) mit 3,15 Auftrag und zeichen bereits abgeschlossen sind, beginnt auf der Ebene a) (= Jahwist) erst die eigentliche Sendung . Diese wiederholung bekräftigt für den Leser die wichtigkeit des Geschilderten; zugleich befähigt sie ihn zu einer intensiveren Aufnahme und verlangt von ihm, auf zwei Ebenen, d.h. von zwei Gesichtspunkten aus wahrzunehmen.

Die Gliederung del olmos erfaBt den Text jedoch nicht genau genug. Das zeichen von 3,12 scheint nicht auf; unter "Bestätigung" fallen zwei Einwände, ein erneuerter Auftrag und die Bestellung Aarons; die "Zusicherung" von 3,12 wird nicht als solche erfabt. In all dem macht sich auch bemerkbar, daß er das Element "Einwand" zu wenig berücksichtigt.
26 G.del OLMO LETE, Vocación 71 und 88-90.
2) In 3,16 kommt dort das erste Mal לק "geh!" vor. 
Das zwei Quellenschichten berücksichtigende Schema von Rich$\operatorname{ter}^{28}$ sieht für Ex 3-4 (vereinfacht) so aus:

J: (1) Ich habe die Not gesehen und ihr Schreien gehört. 3,7

(2) Geh und versammle und sage 3,16

(3) Sie werden mir nicht glauben 4,1

(5) Zeichen 4,8-9

E: (1) Das Schreien der Söhne Israels ist zu mir gekommen und ich habe die Bedrückung gesehen 3,9

(2) Geh, ich sende dich, und führ heraus 3,10

(3) Wer bin ich, daB .. 3,11

(4) Ich bin mit dir 3,12

(5) zeichen $3,12(4,17)$

Hier sind die einzelnen Elemente präzise erfaßt. Beim Elohisten ergibt sich ein vollständiges Schema auf knappem Raum $(3,9-$ 12); beim Jahwisten ist das Schema in die Länge gezogen und es fehlt die zusicherung des Beistandes. Gerade dieses Fehlen, verbunden mit der unsicheren zugehörigkeit von 4,1-9 zu $J$ (davon sind die Elemente "Einwand" und "Zeichen" betroffen), lassen Schmidt ablehnen, daß auch $J$ ein Berufungsformular verwendet habe.

Was nach dieser Kritik bleibt, ist mindestens die einfache Verwendung des Berufungsschemas (bei $E$ ) und seine Abfolge . Tatsächlich zeigt sich gerade in Ex 3,9-12 ein hoher Grad an übereinstimmung von Text und Schema, der jene bei den anderen Texten übertrifft ${ }^{31}$. In Ex 3 ist also die Abfolge relativ treu eingehalten, während sie in anderen Texten freier verwendet wird. Die Abfolge als geprägt $z u$ verstehen hilft überdies, die einzelnen

28 W.RICHTER, Berufungsberichte 138.

29 w.H.SCHMIDT, Exodus 129.

30 Doch wenn P.WEIMAR, Berufung 43-46, recht hat, so bleibt nicht einmal dies. Dann wäre nämlich der Textbestand von 3,9-12 auf vier schichten ( $J, E$, Je, und $R^{P}$ ) aufzuteilen, und aus $E$ fiele heraus: zur Hälfte der Auftrag in 3,10 ("geh, ich sende dich": Je), und ebenso das zeichen in $3,12\left(R^{P}\right)$.

31 So kommt $z . B$. in $R i \quad 6$ schon vor dem Auftrag in v14 ein Einwand in v13; ähnlich auch in 1 Sam 9, wo überdies $\pi$ ש "senden" in v26 nicht in diesem technischen Sinn, sondern in der Bedeutung von "entlassen" verwendet wird. Noch weiter entfernt vom Schema ist 1 Sam 3 . 
Elemente nicht allein als biographische Angaben zu deuten ${ }^{32}$.

Das Festmachen der einzelnen Glieder des Berufungsschemas an genau bestimmten Formulierungen hat dazu geführt, daB nur ein kleiner Teil von Ex 3-4 von diesem Schema erfaBt wird, dieses also (in den verschiedenen vorgeschlagenen versionen) nicht in der Lage ist, die Form unseres ganzen Textes zu bestimmen ${ }^{33}$. Wohl aber tauchen einzelne Elemente wiederholt über den Text verstreut auf: Auftrag in $3,10.16 ; 4,12 ;$ Einwand in $3,11.13 ; 4,1$. 10.13; Zusicherung des Beistands in 3,12; 4,12.15. Besonders der fünffache Einwand ${ }_{34}^{e r f o r d e r t}$ eine entsprechende Berücksichtigung im formalen Aufbau .

Das Berufungsschema rechnet mit der geordneten Abfolge der Elemente: Auftrag - Einwand - zusicherung - Zeichen. Es lohnt sich, diese Abfolge über unseren ganzen Text hinweg zu untersuchen.

SCHEMA 2: Abfolge der Elemente des Berufungsschemas

(Einleitung) 3,1-9

\begin{tabular}{|c|c|c|c|c|c|c|c|c|}
\hline Auftrag & 10 & & 16 & & & & $12 a$ & \\
\hline Einwand & 11 & 13 & 4,1 & & & 10 & & 13 \\
\hline zusicherung & $12 a$ & $14 \mathrm{f}$ & 5 & & $\mathbf{f}$ & $(11)$ & $12 b$ & 15 \\
\hline $\begin{array}{l}\text { Zeichen } \\
\text { (SchluB) }\end{array}$ & 12 & & $3 f$ & $6 f$ & $9 b$ & & & $\begin{array}{c}(17) \\
18\end{array}$ \\
\hline
\end{tabular}

In Schema 2 werden vor allem zwei Sachverhalte deutlich: Gegenüber dem einfachen, einmal ausgeführten Schema der Berufung gibt es sowohl mehrfache Erweiterungen (alles, was nach 3,12

32 Wenn ein Autor eine "Form" gebraucht, um seinen "Stoff" (für diesen Ausdruck siehe J.VOGT, Aspekte 58-59) darzustellen, so darf das nicht von vornherein als unhistorisch abgetan werden, genauso, wie es falsch wäre, jede einzelne Angabe nun als wirklich historisch geschehen aufzufassen. Der Text schafft eine eigene Realität, deren Beziehung zur faktischen Geschichte sehr komplex sein kann.

33 Gegen del OLMO, Vocación 88-90. - Natürlich kann von einem Text keine starre Anwendung eines Schemas erwartet werden; siehe dazu Anm.35 und C.HARDMEIER, Texttheorie, 35-51.

müssen.

34 Wir werden darauf unter 2.1 .3 und 2.1 .4 zurückkommen 
kommt) als auch einige Umstellungen (wo die Reihenfolge durcheinander gerät) ${ }^{35}$.

a) Eine auffallende Erweiterung besteht in der dreimaligen Sendung $(3,10.16 ; 4,12 a)^{36}$. In keinem anderen Berufungsbericht muB die Sendung, ausgedrückt im Auftrag zu gehen, wiederholt werden. Wenn es hier jedoch gleich dreimal geschieht, so muB gefragt werden, was das bedeutet.

b) Eine andere Erweiterung betrifft die Verdoppelung des Einwandes in 3,11.13 (auf den Auftrag in 3,10) und parallel dazu in 4,1.10 (auf 3,16 hin). Somit begegnen die ersten beiden sendungsaufträge jeweils einem doppelten Widerstand ${ }^{37}$, was insgesamt (mit 4,13) zu fünf Einwänden führt.

c) Normalerweise folgen die Einwände direkt auf die Sendung $(3,10-11 ; 4,12-13 ;$ und in anderen Berufungsberichten). Hier aber steht der mittlere Auftrag zu gehen $(3,16)$ am Anfang eines langen Redens Gottes; der Sprecherwechsel mit dem Einwand kommt erst nach sieben Versen in 4,1. Die Sendung wird in dieser Position am Beginn zum Fundament für das nachfolgende Geschehen (3,17-22). Sie wird Ausgangspunkt der Bewegung zur Befreiung.

d) Schlußendlich ist die Mitbestellung einer weiteren Person für Berufungsberichte im AT ebenfalls ungewöhnlich. Dieses Hineinnehmen Aarons in die Sendung des Mose verlangt auch nach der Rollenverteilung 4,15-16.

35 Ein Schema ist natürlich immer eine Abstraktion, ein durch Vergleich mehrerer Texte gefundenes gemeinsames Muster, und deshalb nie fest, sondern immer flexibel. Dennoch liegt, wo das Schema geändert wird, meist ein Grund vor, den es zu finden gilt und nach dessen Sinn zu fragen ist.

36 Dazu kommt dann noch der Auftrag zu gehen in 4,19, unmittelbar vor seiner Ausführung.

37 Entfernt $\mathrm{zu}$ vergleichen ist damit $\mathrm{Ri} 6,13.15$, wo Gideon vor Jahwes Boten auch zwei Einwände formuliert. Doch unterscheidet sich Ri 6 von Ex 3 darin, daB dort der erste Einwand bereits auf die Anrede erfolgt und somit der sendungsauftrag in v14 (ebenfalls mit לך "geh!") nur noch auf einen Einwand trifft. 
Erwähnenswert sind ebenso die Umstellungen:

a) Die Abfolge: Auftrag (Sendung) - Einwand - Zusicherung wird einmal durchbrochen. Normalerweise trifft die Sendung immer zuerst auf einen Einwand, der dann seinerseits mit einer Beistandszusage beantwortet wird. Doch in 4,12 folgt auf den Auftrag zu gehen (v12a) direkt die zusicherung (v12b). Gott scheint den Einwand $^{38}$ umgehen zu wollen, was ihm jedoch nicht gelingt.

b) Meist folgt das zeichen auf die zusicherung. In 4,3-9 haben wir aber zweimal die umgekehrte Reihenfolge. 4,3-4 und 6-7 bringen jeweils zuvor das zeichen, bevor in 4,5 und 8-9 die bekräftigende Antwort ${ }^{39}$ ergeht. Die Macht der zeichen soll Mose überzeugen, bevor noch die deutende Rede erfolgt. Das Gewicht liegt auf den materiellen zeichen ${ }^{40}$.

Schema 2 zeigt überdies noch etwas: Die dreimalige Sendung trifft nicht nur auf eine fünffache Ablehnung, sondern wird auch in mehrfachen Antworten (je nach zählung sind es 5-11) ${ }^{41}$ bekräftigt. Fünf Antworten ergeben sich, wenn die (auch wiederholtes Reden umfassen könnenden) Reaktionen Gottes gezählt werden: 3,12. 14-15; 4,3-9. 11-12. 14-15. Es werden elf "Antworten", wenn alle Redeeinleitungen gezählt werden: $3,12.14 \mathrm{a} .14 \mathrm{~b} .15 ; 4,2(?) .3 .4 .6 .7$. 11.14. Wenn man nur die direkt auf die Einwände eingehenden, bekräftigenden Reden Gottes nimmt, kommt man auf acht Antworten (diese können am ehesten als zusicherungen genommen werden): 3,12. 14a. 14b. 15; 4,5, 8-9. 11-12, 14-15. In den variablen zählungsmöglichkeiten manifestiert sich ein sehr unterschiedlicher Antwortcharakter.

38 Ähnlich Ri 6,14, doch ist dort die zusage (v14b) mit הלא "Nicht ...?" oder: "GewiB ...!" eingeleitet.

39 4,9 mit einem zusätzlichen dritten zeichen.

40 Das geht zusammen mit dem Verstummen des Mose in 4,3-9, mit seinem zurückschrecken in 4,3 und mit dem unvermittelten Redeeinsatz in 4,5 durch למען "damit ...".

41 Für die zählung der Antworten siehe auch gegen Ende von 2.1.3 im besonderen Anm.52. Die dort angegebene Zahl von 13 Antworten ist darauf zurückzuführen, $\mathrm{daB} z \mathrm{z}$ den 11 eingeleiteten Reden von hier auch noch die beiden nicht eingeführten in 4,5 und 4,8-9 mitgezählt werden. 
Habel hat die Frage nach der Funktion des Berufungsschemas gestellt. Er sieht in Gen 24 einen logischen Präzedenzfall und schliebt daraus auf eine Praxis, in der Gesandte oder Boten in einem speziellen Auftrag ihre Glaubwürdigkeit in einer besonderen Art und Weise präsentierten. Auch abgesehen von der Richtigkeit der Verbindung mit Gen 24 bleibt die Legitimierung des Boten die Hauptfunktion eines solchen Berufungsberichtes. Wer so als von Gott beauftragt geschildert wird, sich selbst noch im Einwand gegen die Sendung gesträubt hat und dann mit Beistandsformel und zeichenvollmacht ausgerüstet worden ist, dessen Auftreten erscheint nicht als eigene Erfindung oder Einbildung ${ }^{43}$, sondern wirklich als Exfüllung eines göttlichen Auftrags. In dem Berufenen begegnet der Bevollmächtigte Gottes.

Das Berufungsschema hat auch eine erzählerische Funktion. Für den Leser bietet es einen Deuteschlüssel, der ihn alles folgende Tun des Mose unter dem Gesichtspunkt des göttlichen Auftrags, dem Mose sich nicht widersetzen konnte, lesen läßt. Zusätzlich erhält er durch die inhaltliche Bestimmung der Sendung schon einen überblick über das Kommende. Diese Vorausdeutung bietet orientierung in dem folgenden berichteten Geschehen und gibt dem Leser ein Wissen, das teils nicht einmal die Personen der Handlung von Exodus (z.B. der Pharao) haben.

\subsubsection{Der Bericht von der Sendung des Retters}

D.Irvin ${ }^{44}$ hat aus dem Vergleich mit anderen Texten des Alten Nahen Orients einen Erzählungstyp herausgearbeitet, den sie "tra-

42 N.HABEL, Call Narratives 320-323. Er schreibt: "... we are justified in asking whether there is any plausible precedent from the life and heritage of Israel for the specific Gattung which we have isolated." (320).

43 Gegen die von $\mathrm{N}$.Habel und anderen angenommene Funktion der Legitimation hat sich vor kurzem F.D.HUBMANN, Bote 331 , gestellt, der in den Berufungen "theologisch durchreflektierte Zusammenfassungen" sieht. Doch schließen die beiden Aspekte einander nicht aus: Was von der Entstehung des Textes her als zusammenfassung zu sehen ist, kann auf der Ebene des Gesamttextes durch seinen Inhalt und besonders durch die stellung zu Beginn legitimierende Funktion haben. Vgl. im NT bei Paulus Gal 1,1.

44 D.IRVIN, Stories 180-209. 
ditional episode of sending the saviour" ${ }^{45}$ nennt. Er hat mit dem Berufungsschema die feste Reihenfolge gemeinsam, weist aber weit mehr Elemente auf. Die von ihr aufgezählten 17 Elemente kommen nie alle zusammen in einer Erzählung vor, sondern sind vielmehr jene Bausteine, aus denen der Erzähler nach seiner Wahl seine Geschichte zusammenstellt. Im folgenden ihre Präsentation von Ex 3-4:
(3) The problem presented 3,7-9a
(4) The solution proposed 3,8
(6) The hero is called 3,10
(7) The hero demurs 3,11
(8) The hero is reassured 3,12

(12) Wonders as reassurance to the hesitant hero 4,1-9
(7) The hero demurs
4,10
(8) The hero is reassured
$4,11-12$
(14) (Final) instructions (and weapons) are given 4,15-17
(15) The hero departs
$4,18-20$

(16-17) The conflict. The outcome 4,29-31

$\begin{array}{ll}\text { (7) The hero demurs } & 4,13 \\ \text { (9) Another hero is called } & 4,14-15 \\ \text { (14) Instructions are given } & 4,21 \\ \text { (16-17) Conflict, outcome } & 5 \mathrm{ff}\end{array}$

Es wird sofort deutlich, daß die Einwände (Element 7) die Erzählung zweimal verzögern. Zweimal wird durch sie die Reihenfolge unterbrochen und die Erzählung springt zurück auf eine Stufe, die - handlungsmäßig, nicht vom Inhalt her - bereits überwunden ist. Unser Text stellt sich so in drei Durchgängen dar, eine Besonderheit, die sonst keinem der von Irvin untersuchten vergleichstexte eignet ${ }^{48}$.

45 D. IRVIN, Stories 200.

46 Sie heiBen bei ihr "plot-motif": Ein "plot-motif" ist ein Handlungselement, das die Geschichte einen Schritt vorwärtsbewegt.

47 Die Liste für Ex 3-4 findet sich auf S.209.

48 Abgesehen von "Telepinu", wo aber nur die letzten drei Glieder 15-17 dreimal wiederholt werden. D.IRVIN, Stories 206. 
Ein weiterer Vorteil dieser Gliederung ist, daB sie größere Teile des Textes genauer ergreift als dies mit dem Berufungsschema möglich war. Doch scheint mit der von Irvin herausgearbeiteten Liste der 17 Handlungselemente eine noch schärfere Erfassung denkbar:

(1) The problem is described Ex 1-2

(2) The meeting of the divine assembly 2,24-25 (?)

$$
(+3,2-6 ? ?)
$$
A
(3) The problem presented
3,7 . (9)
(4) The solution proposed
$3,(8) .10$
(6) The hero is called
3,10
(7) The hero demurs
3,11
(8) The hero is reassured
3,12

evtl.(14) Instructions are given $3,12 \mathrm{~b}$

B
(7) The hero demurs
3,13
(8) The hero is reassured
$3,14-15$
(14) Instructions are given
$3,16-22$

C
(7) The hero demurs
4,1

(12) Wonders as reassurance to the hesitant hero 4,2-5.6-8

(13) Wonders as part of his instructions 4,9
D (7) The hero demurs 4,10
(8) The hero is reassured 4,11-12

evtl.(14) Instructions are given 4,12b (?)

$\mathbf{E}$
(7) The hero demurs
4,13
(9) Another hero is called
4,14
(14) Instructions are given
$4,15-17$

in 4,15 auch Element (8)
(15) The hero departs
$4,18-20$
(17) The outcome
$4,29-31 \quad(+5$ ff $)$

Hier führen die fünf Einwände zu ebensovielen Gesprächsteilen. Auch wird deutlich, wie die gesamte Exoduserzählung, speziell aber die nahestehenden c1-2, der Rest von c4 und evtl. c5ff, die Funktion einzelner Elemente des "Berichts von der Sendung des 
Retters" übernehmen ${ }^{49}$. Dies gilt besonders für den Anfang und den SchluB, das sind gerade die Teile, die schon beim Berufungsschema Schwierigkeiten bei der Einordnung machten. Mit den von Irvin vorgeschlagenen Elementen läßt sich dieser zusammenhang mit den angrenzenden Kapiteln und auch die innere Abfolge über unseren gesamten Text hinweg weit genauer verfolgen.

Bevor wir anschlieBend zur Auswertung des Schemas gehen, das wir oben vorgeschlagen haben, sollen zuerst dessen Grenzen erwähnt werden.

a) Die Definition der einzelnen Elemente, wie Irvin sie vorschlägt, ist sehr breit. Das ist zum einen notwendig, um damit eine Reihe von Berichten erfassen zu können, bietet aber auch Nachteile. Element (6) "The hero is called" z.B. wird im Text (S.201) umschrieben mit "name an individual for the task", und Irvin ordnet dem $3,10 \mathrm{zu}$. Es wäre vielleicht besser, dieses Element "the hero is commissioned" zu nennen, denn ein Ruf mit Namensnennung ergeht bereits in 3,4, ohne daB dort die Aufgabe erwähnt würde.

b) Wir haben den Beginn unserer Erzählung, 3,1-6, dem Element (2) zugeordnet. Doch handelt es sich hier nicht um eine göttliche Ratsversammlung. Der Glaube an den einen Gott Jahwe und die für die Bibel geltenden Konventionen präsentieren uns statt einer Götterversammlung eine Form einer Epiphanie.

c) Für die Elemente (3) und (4) muBten wir zwei Verse angeben und dabei die sonst streng beachtete Reihenfolge aufbrechen. So wird in 3,8 bereits eine Lösung besprochen, bevor 3,9 noch einmal auf das Problem zurückkommt.

d) DaB der Text feiner ist als eine formale Gliederung, wird unter anderem daran deutlich, daß die Imperative von "gehen" in verschiedenen Elementen aufscheinen: bei 3,10 (4) und (6); für 3,16 (14); und in 4,12 (8). Darauf ließ sich nicht Rücksicht

49 Diese Zusammenhänge sind immer wieder gespürt worden und sind u.a. für die langen (über 4,17 hinausgehenden) Positionen in der Abgrenzung (siehe Anm.11 zu c1) verantwortlich. Auch P.WEIMAR, Berufung, führt seine Analyse bis $c 5$ weiter. 
nehmen; der Aufbau hätte sonst noch mehr verfeinert werden müssen.

e) Schlieblich gehen in der Präsentation von D.Irvin der zweite und dritte Durchgang ineinander 50 . Das läßt den Eindruck entstehen, dem Erzähler sei die sonst geprägte Abfolge der Elemente durcheinander geraten. Doch zeigt die genauere Erfassung in fünf Durchgängen, daß die Reihenfolge auch dort eingehalten ist.

Die vorgebrachte Kritik betrifft nur einzelne (und meist kleinere) Punkte an einem im wesentlichen korrekten Erzählschema. Sein Erkennen bietet neue Aspekte für das Verstehen unseres Textes: Die oben vorgeschlagene Darstellung macht auf einen Blick deutlich, wie die Einwände des Mose das Gespräch viermal auf eine bereits überschrittene stufe zurückholen und damit das Ende des Gesprächs immer wieder hinauszögern. Dies resultiert in den vier zusätzlichen Gesprächsgängen B-E. Bereits in B-D werden dabei schon jedesmal stufen erreicht, die unmittelbar vor dem (erwarteten) Weggang des Helden stehen ${ }^{51}$; der Einwand des Mose vermag immer einen Aufschub $\mathrm{zu}$ bewirken. Das erhöht die Spannung im Leser, der sich mehr und mehr fragt, ob es Mose vielleicht gelingt, sich der Sendung zu entziehen, oder, wie lange Mose dieses Spiel noch spielen kann. Andererseits aber vermag dieses viermalige Zurückspringen auf bereits überwundene Gesprächsstufen auch den zornesausbruch Jahwes in 4,14 zu erklären. Gott hat allen Grund, diese Hinhaltetaktik nicht weiter mitzumachen und dem Mose durch seinen zorn $z u$ verstehen zu geben, daB des Redens ein Ende gekommen ist.

Ebenso zeigt die obige Präsentation, wie nicht nur die Einwände, sondern auch die Bestätigung und zusicherung für den Helden - das sind die Elemente (8) und (12) - fünfmal wiederholt werden. Das führt zu einem Paradox: Die Einwände zeigen Schwierigkeiten und Schwachstellen der Sendung auf und lassen so den Gesandten als nicht ganz geeignet bzw. seinen Auftrag als unsi-

50 D. IRVIN, Stories 209.

51 Dem entsprechen Elemente mit den Nummern (13) oder (14). 
cher erscheinen. Doch indirekt vervielfachen sie die zusagen Gottes $^{52}$ und bewirken so gerade das Gegenteil, nämlich eine verstärkung von ${ }_{5}$ Gesandtem und sendung durch wiederholte göttliche Legitimierung ${ }_{54}^{53}$. Mose wird damit der am intensivsten bekräftigte Beauftragte Gottes ${ }^{54}$.

Auch wenn mit diesem Bericht von der Sendung des Retters schon eine ziemlich genaue Erfassung des Ablaufs des Textes möglich war, so kann diese durch eine Untersuchung des zugrundeliegenden Konfliktes noch weiter vertieft werden.

\subsubsection{Der Konflikt Begehren - Erfüllung}

Die treibende Kraft in der Entwicklung der Erzählung und besonders des Dialogs ist das Begehren Gottes: Er will von Mose etwas. Dieses Begehren ist auf Erfüllung, auf Verwirklichung gerichtet. Wir erwarten, daB Mose dem Begehren Gottes nachkommt. Tatsächlich jedoch geschieht diese Erfüllung erst außerhalb unseres Textes - und damit nicht mehr im Gespräch selbst -, als nämlich Mose in 4,18 von Gott weggeht und seinem Schwiegervater

52 Schema 2 (oben unter 2.1.2) zeigte uns bereits, wie die dreifache Sendung Gottes einer fünffachen Ablehnung begegnet. Diese fünffache Ablehnung wird durch mehrfache Antworten Gottes aufgefangen. 3,12 geht auf 3,11 ein. 3,13 erhält gleich drei Antworten: $3,14 \mathrm{a}, 14 \mathrm{~b} .15$. Berücksichtigt man bei 4,1 neben den beiden direkt auf Moses Befürchtung eingehenden Antworten 4,5 und 4,8-9 auch die Befehle bzw. die Frage $(4,2)$ als Antworten, so werden es sieben. Die Einwände von 4,10 und 4,13 finden (wie 3,11) jeweils eine Antwort. Je nach zählung erhält Mose also auf seine fünf Einwände bis zu 13 Antworten, von denen wenigstens 8 als echte Antworten angesehen werden können. Statt die Sendung abzuschwächen, führen die Einwände also zu ihrer noch größeren Bestärkung.

53 Auch sonst ist im AT zu finden, daB Gott Schwaches oder kleines erwählt. Gideon kommt aus einem unbedeutenden Geschlecht und ist selbst der Geringste zuhause ( $R i \quad 6,15)$. David ist der Jüngste (1 Sam 16,11); niemand denkt anfangs daran, daB Gott ihn bestimmt hat. Jeremias bezeichnet sich selbst als jung, unerfahren $($ Jer 1,6$)$. - Auch bei Paulus begegnen wir öfter dem Paradox der Erwählung des Schwachen: 1 Kor $1,27-28 ; 2$ Kor 1,$9 ; 4,7 ; 12,9$.

54 In diesem Zusammenhang ist bemerkenswert, daB D.Irvin von dieser Form schreibt (stories 202): "The form of the episode demands final success. Stories which are not about ultimate success are not cast in this form."

Einer, der mit der Form des Sendungsberichtes vertraut ist, sieht in Mose nicht nur den stärkstens von Gott legitimierten Beauftragten, sondern zugleich den, dem durch die Form seines Auftrages schon Erfolg versprochen ist. 
mitteilt, er wolle nach Ägypten gehen. Der Konflikt Begehren Erfüllung spannt sich so über unseren ganzen Text. Er ist der Motor, der das Gespräch in Bewegung hält, und ist für dessen Spannung verantwortlich.

Gott will von Mose mehreres. Grundsätzlich lassen sich dabei zwei Ebenen unterscheiden, die eine der kurzfristigen wünsche ${ }^{55}$, die andere der Begehren auf Dauer. Beide werden in Imperativen oder volitiven ausgedrückt; sie unterscheiden sich nur durch die Möglichkeit ihrer Realisierung: Im einen Fall (erste Ebene) ist es eine Sache weniger Augenblicke, im anderen ist eine innere Bereitschaft dafür notwendig, die eine grundsätzliche Änderung der Einstellung erfordert und sich über eine längere zeitspanne, wenn nicht sogar das ganze weitere Leben erstreckt. Was Gott auf dieser zweiten Ebene von Mose möchte, ist eine völlige Neuorientierung Moses, seine Verwandlung. Die Ebene des Begehrens auf Dauer betrifft ausschlieblich die Sendung des Mose und ist immer mit dem Schlüsselwort הלך" "gehen" $(3,10.16 ; 4,12)$ verbunden. Sie trifft prinzipiell auf den Widerstand des Mose, zweimal sofort $(3,11$, wobei Mose sogar dieses "Gehen" in seiner Antwort aufnimmt, und 4,13), einmal verzögert $(4,1)$. Dem Begehren Gottes stellt sich dabei ein Begehren des Mose gegenüber, der vor der übernahme der Sendung einige Fragen geklärt wissen möchte. Mose will auch etwas von Gott. So wandelt sich der Konflikt Begehren Erfüllung in einen, bei dem Begehren gegen Begehren steht.

Nicht so auf der Ebene der kurzfristigen wünsche Gottes (vor allem in 3,$5 ; 4,3-7 ; 4,17)$. Sie werden allesamt erfüllt, und zwar sogleich. Während also auf einer Ebene Gottes Begehren seine Erfüllung findet, trifft auf der zweiten Ebene Gottes Begehren auf ein Begehren des Mose. Dieser Gegensatz betrifft nicht nur die "theoretischen" Konfliktmodelle, er prägt sogar das Handeln des Mose, in dem auch diese Spannung von Gehorsam und versuchtem Entgegensetzen des eigenen Begehrens aufscheint. - Zu ergänzen ist hierbei noch, daß alle Einwände des Mose, mit Ausnahme des

$55 \mathrm{Zu}$ diesen sind auch $3,14.16 .18$ und $4,9 \mathrm{zu}$ zählen. "So sollst du sagen", "... und versammle", ... sind zwar nicht gleich zu verwirklichen, weil sie sich auf die zukunft beziehen. Doch in der Zukunft können sie in kurzer zeit realisiert werden; sie verlangen keine bleibende Umstellung im Gerufenen. 
letzten $^{56}$, beantwortet werden. Gott reagiert ebenso prompt auf das Begehren des Mose wie letzterer auf der ersten Ebene auf dessen wünsche.

In Schema 3 (folgende Seite) wird ein sich wiederholendes Aufbaumuster ersichtlich. Auf Gottes Aufforderung an Mose zu gehen folgen zweimal je zwei Einwände und Antworten, die sich durch die Wiederaufnahme von stichworten ineinander verketten. Der zweite Einwand des Mose $(3,13$ und besonders 4,10) erscheint dabei jeweils ein wenig lockerer mit Gottes vorhergehender Antwort verbunden - mit nur einem bzw. keinem stichwort, das aufgegriffen würde -, worin auch zum Ausdruck kommt, daB diese zweiten Einwände inhaltlich Neues beginnen: in 3,13 das Thema des Namens Gottes, in 4,10 das des eigenen Nicht-reden-Könnens. Gott dagegen geht immer auf Mose ein, in 4,14 inhaltlich und in allen anderen Fällen durch das Aufgreifen (und Weiterführen) von stichworten.

Auf das dritte Begehren Gottes hin wird das in den ersten beiden Fällen gleich gebliebene Aufbaumuster geändert. Einwand und Antwort wechseln nur noch einmal hin und her. Moses Einwand greift Gottes Reden überhaupt nicht mehr auf; er besteht in der Ablehnung des Auftrags. Auch Gottes Antwort enthält neue Elemente. Dazu gehört vor allem die erste von Gott im Dialog berichtete Reaktion, sein zornigwerden. Und in 4,17 beendet Gott zum ersten Mal sein Reden mit einem Begehren, das gleich erfüllt werden kann (im Gegensatz zum "gehen", dessen Erfüllung ja eine Lebensaufgabe darstellt). Das "nimm den Stab" ist der erste kleine Schritt, auf der (ersten) Ebene der unmittelbar erfüllbaren wünsche, auf der Mose bisher immer gehorcht hat. Er tut es auch diesmal.

Die unterstrichenen Ausdrücke in den Schemata 3 und 4 (übernächste Seite) beziehen sich auf die zweite Ebene, die der Begehren auf Dauer. Gott hat ein einziges, nämlich, daß Mose geht. Dreimal finden wir es im Imperativ, und immer schliebt es sich an ein vorhergehendes Reden Gottes an $(3,7-9 ; 3,14-15 ; 4,11)$. Es kommt also nicht unvorbereitet, sondern jedesmal in einem zusammenhang mit dem Reden Gottes von sich selbst (seine Teilnahme am

56 Sogar 4,13 kann durch die Mitbestellung Aarons als teilerfüllt gelten. 


\section{Begehren (1.Mal)}

Gott sendet 3,10 :

geh!, senden, herausführen

Moses Einwand 3,11: Frage "Wer bin ich?" gehen, herausführen

Gottes Antwort 3,12:

senden, herausführen

Moses Einwand 3,13: Fragen "Was ist sein Name?" - Was soll ich ihnen antworten?"

senden

Gottes Antworten 3,14-15:

$2 x$ senden, $2 x$ sagen, Name

Begehren (2.Mal)

Gott sendet 3,16 :

geh!, erscheinen, hören $(3,18)$

Moses Einwand 4,1: Frage "Wenn sie nicht glauben ..?" - hören, erscheinen

Gottes Antworten 4, 5.8-9:

4x glauben, erscheinen, 2x hören

Moses Einwand 4,10: " kein Mann von Worten bin ich ..." - Mund, Zunge

Gottes Antwort (Frage) 4,11:

Mund, stumm

\section{Begehren (3.Mal)}

Gott sendet 4,12 :

geh!, Mund

Moses Einwand 4,13: "Sende, wen du senden willst!" - $2 x$ senden

Gottes Antwort 4,14a: Zorn

4,14-17: Aaron mit Mose;

nimm (den Stab)!

Erfüllung

Mose geht 4,18: $3 x$ gehen (in 4,20: Stab, 2x nehmen) 


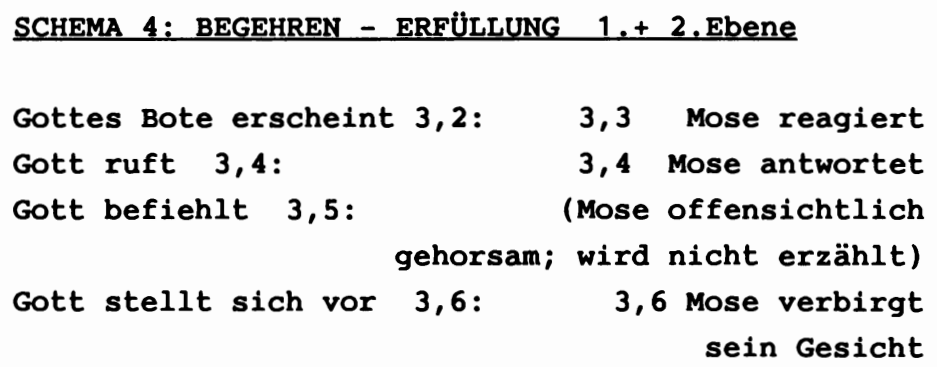

Gott fragt 4,2:

Gott befiehlt 4,3:

Gott befiehlt 4,4:

Gott antwortet 4,5

Gott befiehlt 4,6:

Gott befiehlt 4,7:

Gott antwortet 4,8-9

+ "du sollst nehmen ..."

Gott fragt $4,11+$

Gott sendet 4,12: Geh!

Gott reagiert: zorn 4,14

Gott antwortet 4,14-17

+ "du sollst nehmen ..."
4,1 Mose fragt

4,2 Mose antwortet

4,3 Mose gehorcht

4, 4 Mose gehorcht

4,6 Mose gehorcht

4,7 Mose gehorcht

\section{4,13 Mose bittet}

+ Imperativ

4,18 Mose geht 4,20 Mose nimmt 
Leiden der Israeliten; sein Name; seine Schöpfermacht). Doch erst in 4,18 findet dieses Begehren Gottes Erfüllung. Sie wird dreifach berichtet, vom Erzähler (Und Mose ging), von Mose (Ich will gehen) und von Jitro (Geh!). Damit schliebt sich der Konflikt, er ist zu Ende.

Im Schema 4, das beide Ebenen vollständig zusammennimmt, wird auch deutlich, wie oft Mose auf Gottes wünsche eingeht oder ihm sonst in einer Form gehorsam ist: 3,2-6; 4,2-4.6-7. Nicht weniger als neunmal kommt Mose Gottes Begehren nach.

- Auf der Ebene des Auftrages zu gehen erscheinen die Arten der Einwände des Mose klarer. Die ersten drei Male sind es Fragen - ehe Gott deren letzte $(4,1)$ mit einer Gegenfrage $(4,2)$ beantwortet und Mose damit die Führung des Gespräches aus der Hand nimmt. Die letzten beiden Male sind es Bitten, von denen die zweite mit einem Imperativ an Gott verbunden ist, der direkt das Entbrennen von Gottes zorn bewirkt. Am Ende hat Mose keine andere Wahl mehr: Er muß gehen, und er will gehen $(4,18)$.

Die oben beobachtete Verschiedenheit der beiden Ebenen des Begehrens aufgreifend läßt sich nun einiges weiter präzisieren. Der Konflikt Begehren - Erfüllung muß deswegen so lange auf seine Auflösung warten, weil Mose Gottes Begehren auf der zweiten Ebene dauernd ein Begehren seinerseits auf der ersten Ebene gegenüberstellt. Durch drei Fragen und zwei Bitten konfrontiert Mose Gott mit seinen wünschen und erreicht damit nicht nur eine Verzögerung seiner Sendung, sondern auch deren Modifizierung (Bestellung Aarons) und weitere klärung. Um es in den Ausdrücken von Verhandlungsgesprächen zu sagen: Gott hat zwar sein Verhandlungsziel durchsetzen können, aber es ist Mose gelungen, einige Bedingungen für sich herauszuschlagen.

Die beiden Ebenen des Begehrens überlagern einander also, wobei die zweite, die entscheidende und das Gespräch weitertreibende, über weite strecken durch die erste verdeckt wird. Dieses zudecken wird noch verstärkt durch die gegensätzlichen Muster: Auf Ebene 1 werden alle Begehren erfüllt , sowohl von Gott wie auch von Mose. Auf der zweiten Ebene dagegen bleibt Gottes Begehren bis zum Ende des Dialoges unerfüllt, wofür Mose der Verant- 
wortliche ist. Sein Widerstreben (in Worten) gegenüber der sendung wird überdeckt durch perfekten Gehorsam bei Gottes Befehlen (vor allem in seinem Tun; siehe 3,3-6 und 4,2-7). Hinter einem wortwörtlichen Erfüllen des zunächst Geforderten verbirgt sich in

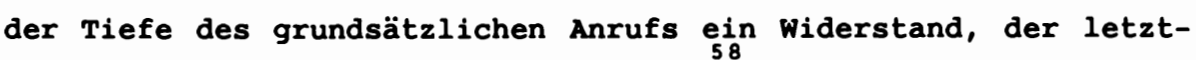
lich erst angesichts des zornes Gottes ${ }^{58}$ überwunden wird. Widerstand und Gehorsam sind in der Person des Mose verbunden. Diese Verbindung erlaubt, den Widerstand nicht als Auflehnung gegen Gott, sondern eher als vorläufige menschliche Unfähigkeit zur Übernahme der Sendung zu deuten. AuBerdem setzen die Einwände, in denen sich der Widerstand artikuliert, voraus, daB Mose sich in Gottes Plan hineindenkt und teilweise mit ihm identifiziert. Mose ist in seinem Verhalten also nicht irrational, widersprüchlich. Die scheinbaren Gegensätze auf den zwei Ebenen des Begehrens erklären sich aus den Folgen, die sich für das weitere Leben des Mose daraus ergeben.

Die beiden Ebenen des Begehrens sorgen auch für den Aufbau der Spannung innerhalb unserer Erzählung. Beim Drama wird dabei die Handlung in Exposition, erregendes Moment, steigende Handlung, Höhepunkt, Wendepunkt, fallende Handlung, Moment der letzten Spannung und Schluß (oder Katastrophe) eingeteilt . Es wäre

58 Zum zorn Gottes schreibt G.SAUER, ๆK, er sei hervorgerufen durch eine "das Wesen Gottes verletzende Tat des Menschen" (S.223) und mache deutlich, dab "nicht gleichberechtigte partner einander gegenüberstehen" (S.224).

59 Hilfreich zur Analyse sind dazu die stichworte "Drama", "Freytag-Pyramide" und "Peripetie" in O.F.BEST, Handbuch. Darüberhinaus auf Englisch: M.K.DANZIGER, W.STACY JOHNSON, Introduction 22, M.H.ABRAMS, Glossary 109, und jüngst, mit Blick auf das AT, G.W.COATS, Tale 63-70. 
möglich, unter diesen Aspekten auch unsere Erzählung ${ }^{60} \mathrm{zu}$ untersuchen.

\subsubsection{Ergebnis}

Das Durchgehen unseres Textes nach verschiedenen formalen Gesichtspunkten hat folgende Beobachtungen ergeben:

Der erste Eindruck am Ende ist, vor einem recht komplexen Text zu stehen. Ex 3,1-4,17 ist in seiner formalen Gestaltung nicht einfach, durchsichtig. Mehrere Ebenen sind ineinander vermischt; zugrundeliegende literarische schemen werden erweitert und variiert; insgesamt entsteht eine für Berufungsberichte unübliche Länge . Das mag u.a. ein Anzeichen für die von den meisten Autoren angenommene Verwendung mehrerer Quellenschichten sein.

Doch läßt sich - scheinbar im Gegensatz dazu - auch eine recht große Einheitlichkeit feststellen. Der Wechsel von Rede und Gegenrede, die Verwendung des traditionellen Berichts von der

60 Je mehr - wie gerade in unserem Text - in einer Erzählung die Personen reden und so zu selbständigen Figuren werden, desto näher rückt die Erzählung an das Drama heran. Diese Nähe führt immer wieder zu Vergleichen zwischen beiden, so z.B. durch E.LÄMMERT, Bauformen 62, bei der konsekutiven Verknüpfung, und durch J.VOGT, Aspekte 68, bei der Personenrede in der Erzählung. Doch bleibt trotz dieser Ähnlichkeit der grundlegende Unterschied festzuhalten, daß die im Drama autonomen Figuren in der Erzählung als erzählte auftreten. Diese Eigenart der Erzählung wird von F.K. STANzEL, Theorie des Erzählens, mit "Mittelbarkeit" bezeichnet (siehe besonders c1 "Mittelbarkeit als Gattungsmerkmal der Erzählung"). Personenrede in der Erzählung möchte dabei in dieser grundsätzlichen Mittelbarkeit den Eindruck der Unmittelbarkeit und damit der größeren Wirklichkeitsnähe erwecken.

Kurz sei ein möglicher Spannungsaufbau für Ex 3-4 vorgestellt:

Exposition 3,1-9

Erregendes Moment 3,10

Steigende Handlung $3,11-4,12$
Höhepunkt
Wendepunkt

Fallende Handlung 4,15-23

Moment der letzten Spannung 4, 24-26

SchluB 4, 27-31

(Auch dabei wird die Verbindung von $\mathrm{Ex} 3,1-4,17 \mathrm{mit}$ den folgenden Texten spürbar, wie sie bereits in 1.2 .2 angesprochen wurde.)

$61 \mathrm{Zu}$ vergleichen wäre damit nur Ez 1-3. Dort ist aber ein weitaus gröBerer Teil der Theophanieschilderung gewidmet.

Ebenso ist 1 Sam 9-10 lang. Jedoch sind in diesen Text auch Erzählungen eingefügt, die direkt wenig mit "Berufung" zu tun haben. 
Sendung des Retters, dem unsere Erzählung weitgehend folgt und die fast alle verse zu decken vermag, das Fortschreiten eines Grundkonfliktes, der vor allem auf der zweiten Ebene des Begehrens erkennbar war - alle diese Gründe lassen nicht zu, Ex 3,14,17 einfach nur als grob zusammengefügte Komposition anzusehen.

Auch inhaltlich lassen sich bereits einige Schlüsse ziehen. Der oft genannte Titel für unseren Text, "Berufung des Mose" ist bei all seiner Berechtigung mindestens einseitig. Tatsächlich ist Gott, wie wir bei der Untersuchung der Reden (2.1.1) gesehen haben, in unserer Erzählung dominant. Gott spricht öfter und länger als Mose. Der hohe Redeanteil innerhalb der Erzählung miBt den erzählten Personen höhere Bedeutung zu und läBt weiter darauf schlieben, daB es sich hier um sehr wichtiges handelt, das möglichst original, wirklichkeitsgetreu wiedergegeben wird. Dabei zeigt das Phänomen der wiederholten Redeeinleitungen zusätzlich starke persönliche Beteiligung an.

Die Verwendung des Berufungsschemas (2.1.2) ist gekennzeichnet durch Erweiterungen und Umstellungen. Die Sendung wird dreimal ausgesprochen, begegnet fünfmal dem Widerstand des Mose und erfährt eine Modifikation durch die Mitbestellung einer weiteren Person. Parallel zum widerstand des Berufenen vervielfachen sich die göttlichen zusicherungen, sodaß am Ende ganz klar ist: Mose geht, nicht, weil er will, sondern weil Gott ihn drängt und befähigt. Er ist gänzlich Gottes Gesandter.

Beim Vergleich mit dem traditionellen Bericht von der Sendung des Retters (2.1.3) wurde sichtbar, wie die Einwände des Mose das Gespräch viermal auf eine bereits überschrittene stufe zurückholen und damit das Ende hinauszögern. Dieser wiederholte Aufschub macht einerseits den zorn Jahwes $(4,14)$ verständlich, andererseits erhöht er im Hörer/Leser die Spannung, wie die Erzählung nun ausgehen wird.

62 "Moses Berufung" für 3,1-22: W.H.SCHMIDT, Exodus 100; "The call of Moses" für 3,1-4,17: B.S.CHILDS, Exodus 47; "Die Berufung des Mose" für 2, 23-5,5: P.WEIMAR, Berufung (Titel).

63 Die Verwendung der in 2.1 .2 und 2.1.3 besprochenen Formen rechtfertigt teils eine solche Bezeichnung. 
Die Ursachen für diese Spannung liegen in dem Konflikt Begehren - Erfüllung (2.1.4), der auf zwei Ebenen ausgetragen wird. Auf der Ebene der kurzfristig erfüllbaren wünsche gehorcht Mose sofort und immer. Sein Tun und seine Antworten bezeugen völlige Ergebenheit gegenüber Gott. Auf der Ebene des Begehrens auf Dauer - sie betrifft die Sendung - trifft Gottes Ansinnen jedesmal auf den in Einwänden zum Ausdruck kommenden Widerstand des Mose, der erst zuletzt überwunden wird. Beachtenswert ist auch, daB Gott in allem auf Moses Begehren eingeht.

Das Gegenüber von anrufendem Gott und dem ihm ausgesetzten Mose prägt unsere Erzählung. Die stärke dieses mit worten Gott gegenüberstehenden Mose fordert Gottes ganzen Einsatz und schenkt uns so nicht nur den (für die Bibel) umfassendsten Einblick in Berufung, sondern auch eine Enthüllung dessen, wer und wie Gott selbst ist.

\subsection{VIER SEMANTISCHE FELDER}

In 2.1.5 ist zunehmend klarer geworden, daB wir mit einer starken literarischen Durchformung unseres Textes $z u$ rechnen haben. Vor allem die präzise Anwendung des Berufungsschemas und seine Veränderung in wiederholung und Variation der Abfolge, die Ausformung nach dem Bericht von der Sendung des Retters und der dramatische Spannungsaufbau sind in unserer Erzählung in einer Weise ausgestaltet, $d a B$ sie den Text zu einer Einheit machen. Diese Prägung unseres Textes zu einem Ganzen, zu einer Einheit besteht auf der Ebene der Form, einer Ebene, auf der Ex 3,1-4,17 mit anderen Texten vergleichbar ist.

Die in 2.1 herausgearbeiteten Formen des Textes erlaubten zwar seine Organisation, doch geschah dies noch nicht nach inhaltlichen Gesichtspunkten ${ }^{64}$. Anders ausgedrückt: Weil die Unter-

64 Die Unterscheidung formal - inhaltlich stellt in der exegetischen Untersuchung kein Gegensatzpaar dar: Jede Form ist inhaltlich gefüllt, und jeder Inhalt ist geformt. $2 . B$. konnte das Element "Einwand" für die Form des Berufungsberichtes nur aufgrund der semantischen Valenz der in $1 \mathrm{hm}$ enthaltenen wörter als solches bestimmt werden, d.h. aber, dab inhaltliche Kriterien die Wahrnehmung formaler Elemente beeinflussen. Dennoch hat die un- 
suchung der Form am "Typ", an dem, was mit anderen Texten verbindet, interessiert war, konnte die Eigenart von Ex 3-4 nicht voll berücksichtigt werden. Eine Gliederung unserer Erzählung muB also noch stärker inhaltlich auf den Text eingehen. Diese Forderung wird unterstützt durch die schwierigkeit, die sich ergäbe, wollte man mit diesen Formen von 2.1 eine Gliederung erstellen.

Die Versuche, den Text zu gliedern, sind unzählbar. Meistens aber sind diese Einteilungen intuitiv vorgenommen worden, was sich darin zeigt, daB praktisch nie die Kriterien genannt werden, nach denen der jeweilige Aufbau erstellt worden ist. oft ist weder begründet noch ersichtlich, warum mit einem bestimmten vers ein neuer Abschnitt beginnen soll. Daraus ergibt sich die Forderung nach der Nennung von Kriterien. Zudem müssen diese am Text selbst gewonnen worden sein.

Eine erste weiterführende Beobachtung ergibt sich in der Wiederholung von bestimmten Verben, die in Teilen unserer Erzählung gehäuft auftreten . Es sind dies die Verben ראה "sehen", "שלף "senden, gehen", אמן "slauben", דבר "sprechen". Dazu kommt, daB diese Verben jeweils von anderen Ausdrücken begleitet sind, die zum selben Wortfeld gehören und die sich über dieselben Teile der Erzählung erstrecken. Zusammen bilden sie "semantische Felder" ${ }^{66}$. Mit ihnen ist es möglich, Ex 3-4 in vier Abschnitte zu untergliedern.

terscheidung zwischen Form und Inhalt ihre Berechtigung, insofern sie zwei verschiedene Aspekte beim Erfassen eines Textes bezeichnet.

65 B.S.CHILDS, Exodus 70 .

66 Ein "semantisches Feld" (oder Wortfeld) bezeichnet zunächst Ausdrücke mit ähnlicher Bedeutung. In einem erweiterten Sinn sollen mit diesem Begriff hier auch jene Textabschnitte benannt sein, die durch die Verwendung von Ausdrücken gekennzeichnet sind, die zu einem Wortfeld gehören. 


\subsubsection{Das semantische Feld des Sehens: Ex 3,1-9}

Das gehäufte Vorkommen von 67 ר am Beginn unserer Erzählung ist immer wieder aufgefallen ${ }^{67}$ Von $3,2-9$ begegnen wir neunmal der Wurzel $i x$, davon $7 x$ im $Q^{68}$. Subjekt des Sehens ist immer entweder Gott oder Mose. Mit diesem Verb verbindet sich נבט "blicken" in 3,6 .

An Verben der Wahrnehmung, zu denen ja "sehen" gehört, treffen wir in 3,7 zusammen mit שמע "wissen/kennen". Damit stehen in 3,7 dieselben drei Verben, die bereits in Ex 2,24-25 zur Beschreibung für Gottes Bemerken der Not verwendet wurden. - Wir finden zusätzlich zwei ganz ähnlich wie ראה רוngende wörter: In 3,1 רעה "hüten" und in 3,6 das oft in Wortspielen mit ראה verwendete "fürchten"

Nicht nur die Verben, auch einige Nomina zeugen von der Bedeutung des Sehens in den ersten Versen der Erzählung. המראה "die Erscheinung" bezieht sich auf das Phänomen des sonderbaren, weil brennenden und doch nicht verbrennenden Busches, der in 3,2-4 insgesamt $5 x$ erwähnt wird und der zusammen mit anderen ortsangaben die Szenerie bildet. Orte und Busch sind die von den Personen der Erzählung gesehenen wie auch für die Hörer/Leser zu sehenden objekte.

Mit 3,5 nimmt der Anteil des Sprechens deutlich zu, ab 3,7 wird es für lange zeit nicht mehr unterbrochen ${ }^{70}$. Die vorläufig letzte Bemerkung des Erzählers 3,6b scheint auch insofern eine zäsur in unserem semantischen Feld vorauszusetzen, als dort das Ende des Sehens des Mose berichtet wird. Daß in 3,7-9 nur noch

67 Z.B. N.LOHFINK, Abwertung 5: "In Ex 3,2ff wird mit der Wurzel $r^{\prime} h$ geradezu gespielt."

68 Die restlichen zwei Vorkommen sind: in 3,2 im $\mathrm{Ni}$, in 3,3 einmal als Nomen.

Sonst kommt ראר in unserer Erzählung kein weiteres Mal im $Q$ vor; nur noch dreimal im $\mathrm{Ni}: 3,16 ; 4,1.5$.

69 Wortspiele mit dem Wechsel Gen 22,11-14; 42,35; 50,15.19 (zusätzlich noch ה军); Ex 2,11-14 (zusätzlich auch $\pi$ 7) ; 14,31. Vgl. J.BECKER, Gottesfurcht 6 .

70 Das Sprechen geht mit Ausnahme der Redeeinleitungen ununterbrochen bis 4,3 weiter. 
vom Sehen Gottes die Rede ist, bestätigt eine solche Untergliederung von 3,1-9 in die beiden Teile 3,1-6 und 3,7-9.

Am Sehen läßt sich auch eine Entwicklung in unserer Erzählung aufzeigen. Es beginnt damit, daB Jahwes Bote sich zu sehen gibt $(3,2 a)$. Mose bemerkt ("und er sah" 3,2b) dieses Erscheinen, das seltsame Phänomen erregt seine Aufmerksamkeit ${ }^{71}$ und weckt in ihm den wunsch, es genauer anzusehen ${ }^{72}$. In 3,4 wird berichtet, daB der zum Anschauen hingehende Mose seinerseits von Jahwe gesehen wird ${ }^{73}$.

In diesen Versen 3,2-4 ist auffällig, daB die wurzel ראה jeweils doppelt verwendet wird. Immer tritt eine andere Nuance hervor. In 3,2 ist es der Gegensatz der beiden stammformen $\mathrm{Ni}$ und Q, der erlaubt, das Geschehen aus zwei Blickwinkeln darzustellen. Das Wortspiel in 3,3 faBt in dem Nomen "Erscheinung" etwas, was für den Hörer bereits als Jahwes Bote eingeführt worden ist; Mose weiB noch nicht und scheint zu unterschätzen, was in dieser Erscheinung steckt. 3,4 spricht, vereinfacht ausgedrückt, von Jahwes Sehen des Sehens Moses. Wer das Wahrnehmen eines anderen sieht, ohne selbst gesehen $z u$ werden, ist dem anderen voraus. Nicht nur, daB die Bewegung zum Sehen von Jahwe ausgeht dadurch, daB er sich in seinem Boten zu sehen gibt ${ }^{74}$ er umfaBt auch noch einmal die dadurch ausgelöste Bewegung, indem er das Wahrnehmen

71 Einige Studien zu הנה "siehe" als Aufmerksamkeitssignal: L.ALONSO SCHÖKEL, Nota estilística sobre la partícula hinneh, Bib

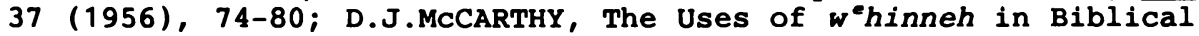
Hebrew, Bib $61(1980), 330-342 ;$ und bei A.BERLIN, Poetics and Interpretation of Biblical Narrative besonders die seiten 62-67 und 91-95.

72 ראה 3,3 ist nicht mehr nur als Wahrnehmen wie in 3,2, sondern als genaueres Ansehen, fast Inspizieren zu verstehen.

73 Im Pentateuch findet sich viermal "und es sah Jahwe": Gen 6,$5 ; 29,31 ;$ Ex 3,4 und Dtn 32,19 .

Gemeinsam ist diesen stellen, das jeweils ein sehr dezidiertes Eingreifen Jahwes knapp darauf folgt, in Gen 6,6-7 im Beschlub zu vernichten, in Gen 29,31 im öffnen des Schoßes Leas und in Dtn 32,19 in der Verwerfung Israels. Hier ist das Einschreiten Jahwes Im Rufen zu sehen.

74 Auf der Ebene der Gesamterzählung von Ex geht dem noch 2,25 voraus: Gottes Sehen der Israeliten löst die Erscheinung an Mose aus. 
des Mose wahrnimmt und darin deutlich macht, daß sein Sehen von dem des Menschen verschieden ist.

Die Bewegung des Sehens ist in 3,4 nicht zu Ende. Sie wird zweifach in 3,6-9 weitergeführt. Auf die Selbstvorstellung Gottes in 3,6a verbirgt Mose aus Furcht, Gott anzusehen, sein Gesicht. Der zuvor sehr aktive, mutig auf Neues zugehende und am sehen interessierte Mose hat Angst bekommen: Um Gott nicht zu sehen, macht er sich unfähig zu sehen ${ }^{75}$. An diesem Punkt, wo der Mensch nichts mehr sieht, geht Jahwes Sehen weiter. Unmittelbar darauf lauten die ersten Worte der ersten längeren Rede Jahwes in diesem Dialog "Sicherlich habe ich gesehen ...". Schon die grammatische Konstruktion hebt diese zwei Worte heraus. Es ist ein absoluter Infinitiv ${ }^{76}$.

Das Objekt des Sehens hat sich gegenüber 3,1-6 entscheidend gewandelt. Es betrifft nicht mehr die beiden Gesprächspartner bzw. die Erscheinung, sondern ע "Not/Elend". Zusammen mit anderen Ausdrücken ergibt sich so vor allem in 3,7.9 ein Wortfeld "Not", das das Leiden einer mit "mein Volk" bzw. "Israeliten" bezeichneten Gruppe in Ägypten beschreibt. Diese Not wird von Jahwe intensiv wahrgenommen. Dreimal ראר und die bereits vorhin erwähnten anderen verben der Wahrnehmung

75 Literatur zum Verbergen des Gesichtes: S.BALENTINE, God und H.SIMIAN-YOFRE, פנים. - Balentine führt den Ausdruck auf eine akkadische Parallele zurück (S.44) und unterscheidet im AT zwei Kontexte, nämlich bei den Propheten im zusammenhang mit sünde, und in den Psalmen verbunden mit der Klage (S.77).

סת $\mathrm{Hi}+$ פנים wird im AT 30x verwendet, überwiegend für Gott. Nur an drei stellen meint es den Menschen: Ex 3,6; Jes 50,6; 53,3 . An diesen Stellen steht das "Gesicht" für die Kommunikation mit anderen. In Jes 50,6 verbirgt der Knecht sein Gesicht nicht vor Schande und Spott, d.h. er setzt sich ihnen aus. Die anderen beiden stellen beschreiben, das jemand nicht sehen will; die visuelle Kommunikation wird jeweils durch verstärktes Hören ersetzt (Jes 52,$14 ; 53,1 ;$ in Ex 3,7 beginnt der eigentliche Dia$\log )$.

Statt o kann auch לוט Q (David trauert um Absalom 2 Sam 19,5 ) oder Hi (Elia bereitet sich vor, Gott zu begegnen 1 Kön 19,13 ) oder aber כס $\mathrm{Pi}$ (u.a. Gen 38,15; Jes 6,2) stehen.

76 Zuvor nur einmal in Ex: 2,18. In unserer Erzählung begegnen wir dieser Konstruktion noch zweimal: 3,16 und 4,14.

ker.

77 Schreien, Peiniger, Schmerzen, Hand, Bedrückung, Bedrük- 
unterstreichen diese Intensität. Mit 3,9 geht das Sehen zu Ende. In unserer Erzählung wird ראה im $Q$ nicht mehr vorkommen.

\subsubsection{Das semantische Feld der Sendung 3,10-22}

Zwei Schlüsselverben bestimmen diesen Abschnitt: של "senden" und "הלך "gehen". Beide kommen je siebenmal in 3,10-21 vor. Weitere zum selben Wortfeld gehörige Verben sind $\mathrm{kY}$ Hi "herausführen" (3x in 3,10-12), ברא "kommen" $(3,13.18)$ und "hinaufführen" $(3,17$; auch schon in 3,8$)$. Zum weiteren Umfeld der Sendung gehören auch deren Empfänger: der Pharao, auch als König Ägyptens bezeichnet, und die Ältesten Israels. Diese drei Ausdrücke kommen jeweils zweimal vor.

Wie bei 3,1-9 scheint auch hier eine Unterteilung möglich, wobei jedes Mal der Imperativ zu gehen ${ }^{78}$ den Beginn bildet. So ergeben sich die beiden Unterabschnitte 3,10-15 und 3,16-22. Im ersten geht es um die Personen der Handlung: Nach der Aufforderung zu gehen kommt in der Frage des Mose $(3,11)$ zuerst die Person des Gesandten in den Blick, dann $(a b 3,13)$ der, der sendet. Der zweite Unterabschnitt betrifft die Sendung selbst: Die zukunft wird in mehreren stufen vorgestellt.

Der Beginn mit 3,10 bereitet eine schwierigkeit, insofern der Wechsel zwischen dem semantischen Feld des Sehens und dem der Sendung mitten in Jahwes Reden zu stehen kommt. Doppeltes, scheinbar zusammengehörendes רפת "und nun" in 3,9-10 vergrößert diese Bedenken. Ist es möglich, daB 3,10 trotzdem den Beginn eines neuen Abschnittes darstellt?

Zuerst einmal muB ganz allgemein gesagt werden, daB der Beginn eines neuen semantischen Feldes nicht unbedingt mit einem Bruch innerhalb der Erzählung gleichzusetzen ist. Auch wenn ein neuer Abschnitt beginnt, so bedeutet dies nicht, daB er keine Verbindungen zum vorhergehenden aufweisen darf - im Gegenteil: Soll die Erzählung eine Einheit sein oder eine durchlaufende

78 In $3,10.16$. Siehe dazu oben in 2.1.4 die zweite Ebene des Begehrens. 
Entwicklung enthalten, sind solche Verbindungen geradezu gefordert. In diesem Fall besteht eine Verbindung durch das fortdauernde Sprechen Jahwes. Diese Verbindung ist jedoch nicht so stark wie die für die Trennung vorgebrachten Argumente: Ende des alten Schlüsselwortes und Beginn neuer Schlüsselwörter, verändertes Thema, Wechsel von Narrativ zu Imperativ.

Bleibt noch das Argument des doppelten ועחה, dessen Vorkommen an unserer stelle in letzter zeit einige Aufmerksamkeit gefunden hat ${ }^{79}$. Eine Untersuchung der in der Fußnote angeführten Stellen führt $z$ folgendem Ergebnis: Doppeltes רפתה steht meist am Ende eines Redens, das etwas von einem anderen will. Das erste ועת faBt dabei zusammen, was bereits vorher gesagt wur$\mathrm{de}^{81}$. In unserem Fall betont es nochmals den Beweggrund für Gottes Tun. Das zweite רעת steht in innerem zusammenhang mit dem ersten, indem es dieses weiterführt oder dessen Konsequenzen aufzeigt. Fast ausschlieblich leitet es einen Wunsch oder eine Bitte ein . Dies trifft auch auf Ex $3 \mathrm{zu}$. Dort beginnt mit der Aufforderung an Mose, zu gehen, ein neues Thema ${ }^{84}$.

In unserem Fall Ex 3 lassen sich noch weitere Unterschiede zwischem dem doppelten רעתה feststellen, die erlauben, dazwischen abzutrennen. Ex 3,(7.)9 bezieht sich auf die vergangenheit, 3,10

79 M.GREENBERG, Understanding 73-74; J.MAGONET, Bush 309.

Die mir bekannten stellen für doppeltes רת sind: Gen $44,30.33 ; 45,5.8$; Ex $3,9-10 ; 1$ Sam $24,21-22 ; 25,26-27$; 26,19-20; 2 Sam 2,6-7; 7,28-29; 19,10-11; 1 Kön 8,25-26; Ru 3,11-12; 2 Chr $6,16-17$.

80 Ausnahmen sind die Stellen in Gen 45, 1 Sam 25, 1 Kön 8 und 2 Chr 6; doch setzt es auch dort Abschnitte. In allen anderen Fällen ist im nächsten oder übernächsten Vers der übergang zum Erzähler oder zum anderen Gesprächspartner.

81 J.MAGONET, Bush 309.

82 M.GREENBERG, Understanding 74.

83 Einzige Ausnahme: Ruth 3,12. Aber dort fordert Boas im unmittelbar folgenden v13 Ruth auf, bis zum Morgen bei ihm auf der Tenne zu bleiben. - In Gen 45 wird der Wunsch in v9 als Aufforderung genannt.

84 Einfaches 4,12. Auch an diesen beiden Stellen ist es mit 7 "gehen" verbunden, drückt - fast in Form einer Zusammenfassung am Ende Bitte oder Aufforderung aus und führt im jeweils nächsten vers zum Sprecherwechsel. 
dagegen auf die zukunft. Auch haben v7-9 stärker die Person Gottes und sein Tun im Blick als v10, in dem das Handeln Moses neu dazukommt.

Die beiden Verben הלק und sind, wenn sie sich auf Mose beziehen, als die zwei Seiten einer Münze anzusehen. Die eine Sache, un die es geht, ist jeweils die Sendung. rל beschreibt dabei die Seite dessen, der den Auftrag gibt, also den Blickwinkel Gottes, הלק dagegen die Seite dessen, der diesen Auftrag ausführen soll, hier den Gesichtspunkt Moses. Wir wollen der verwendung dieser beiden Schlüsselverben kurz nachgehen.

7ל "Geh!": In diesem Imperativ drückt sich Gottes Anliegen aus. Dieser Wunsch stellt, wie wir gesehen haben (2.1.4), die entscheidende Bitte Gottes dar; seine Erfüllung, zwar erwartet, aber in der Erzählung nicht eintretend, bildet auf einer zweiten Ebene des Begehrens den Hintergrund und ist ein Hauptgrund für das Fortbestehen der spannung. Dem entspricht, daB in all den acht Vorkommen von $77^{85}$ keine Narrativform ${ }^{86}$ enthalten ist. Die vier Formen der Präformativkonjugation sind futurisch bzw. als Kohortativ $(3,18)$ zu verstehen; es bleibt neben dem Imperativ von 4,12 noch ein Infinitiv $(3,19)$ und der weitere, bereits als Einleitung des zweiten Teils erkannte Imperativ in 3,16 .

Die Entwicklung geht dabei folgendermaßen vonstatten: Die Aufforderung Jahwes in 3,10 wird von Mose mit einer Frage beantwortet $(3,11)$ : "Wer bin ich, daß ich gehen soll ...?" Damit verschwindet das Gehen vorläufig. Erst vier Verse später, wieder im Imperativ, erfolgt eine erneute Aufforderung an Mose. Wenn dann in 3,18-21 weiter vom "Gehen" gesprochen wird, ist nicht mehr Mose allein gemeint, sondern mit ihm die Israeliten. Das Gehen betrifft auch nicht mehr die eigentliche Sendung des Mose, sondern bereits deren Folge: הלק in 3,18-21 zielt auf den Auszug der Israeliten. Der Bogen reicht von "wir wollen gehen" (v18) über

$85 \quad 3,10.11 .16 .18 .19 .21(2 x) ; 4,12$.

86 Der erste Narrativ mit הל אל kommt erst unmittelbar nach unserer Erzählung in 4,18.

87 Für die in 3,18 die Ältesten in vertretung sprechen. 
"er läBt euch nicht gehen" (v19) schlieblich doch zum Gehen in v21. Wie bereits in 3,2-4 zu 3 רeobachtet, finden wir auch hier bei הלק eine doppelte Verwendung des Verbs, diesmal allerdings im Vers, in dem es zum letzten Mal vorkommt $(3,21)$ : "Wenn ihr geht, werdet ihr nicht leer gehen".

In 3,10 folgt unmittelbar auf ל "Geh!" " רח " dich senden". Die oben beschriebene enge Verbindung der beiden Schlüsselverben kommt hier auch in der Nebeneinanderstellung und der lautlichen Nähe zum Ausdruck. Das Senden bildet eine Art Echo zum vorhergehenden Imperativ ${ }^{88}$. Das Gehen des Mose erhält seine Kraft und Unterstützung durch den, der dazu den Auftrag gibt; auch deswegen wird in 3,12, in Gottes Antwort auf den Einwand des Mose, das "ich habe dich gesandt" nochmals wiederholt und dabei betont vorangestellt. Die folgenden drei verse 3,13-15 enthalten je einmal של שלחני של "er hat mich gesandt" mit vorausgehendem, wachsendem Namen Gottes. Das Gewicht kommt so auf den Sendenden zu liegen; die vielen Vorkommen von Gott und die Frage nach seinem aw "Namen" mit den Antworten darauf unterstreichen dies. Die letzten beiden verwendungen von direkt die Sendung des Mose, sondern stellen ein Wortspiel dar, das sich auf die Ereignisse vor dem Auszug bezieht. "Ich werde meine Hand senden (=ausstrecken)" führt zu "danach wird er (der Pharao) euch entsenden (entlassen)". Ähnlich wie in 3,2-4.21 wird also mit doppelter Verwendung derselben Wurzel gearbeitet, wobei hier die Stammformen variieren ( $Q \mathrm{zu} P i)$.

Die Verbindung von 3,10-22 zum Abschnitt zuvor ist bereits einmal beim doppelten וצתה angesprochen worden. Das übergreifende Sprechen Jahwes ist nicht das einzige Band, das die Sendung mit dem Sehen zuvor verknüpft. In 3,16 bezieht sich $\mathrm{N}$ ( $\mathrm{Ni}$ explizit auf die Erscheinung zurück. Im selben Vers wird - zwar mit anderen Worten, doch mit ähnlicher Bedeutung - durch den absoluten

88 Das tritt umso mehr hervor, als in 3,16 und 4,12 die

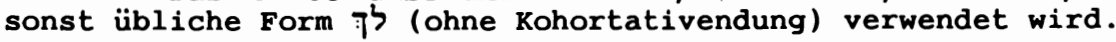

89 Gottes "Überprüfen" (פקד) führt die intensive Wahrnehmung der Not von 3,7 weiter; es ist umfassender, setzt sie voraus und ist deren logische Folge. $\mathrm{Zu}$ פ siehe neben G.ANDRE, Deter- 
Infinitiv auf 3,7 Bezug genommen. Und 3,17 wiederholt in vielem wörtlich 3,8. Dieser Bezug der Sendung vor allem zu 3,7-8 besagt, daB die an Mose ergehende Sendung eine direkte Folge von Jahwes Wahrnehmen der Not ist. Im doppelten als Grund $(3,9)$ und Konsequenz $(3,10)$ präzisiert werden.

\subsubsection{Das sem. Feld der Glaubwürdiqkeit 4,1-9}

Nach längerem Reden Gottes wechselt in 4,1 der Sprecher. Mose geht dabei nicht auf das von Gott unmittelbar zuvor (in 3,19-22) Gesagte ein, sondern bringt einen weiteren Einwand und leitet damit das neue Thema der Glaubwürdigkeit ein.

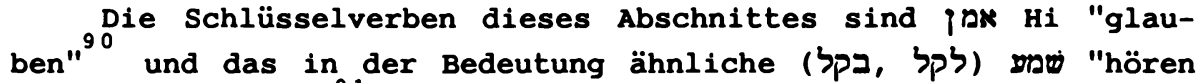
(auf die stimme)" . Zum selben semantischen Feld gehört dreimaliges $\mathrm{x}$ "zeichen" in 4,8-9. Auffallenderweise beziehen sich alle diese vorkommen nur auf die Rahmenverse und den Mittelvers 4,1.5.8-9. Die beiden so gerahmten Teile 4,2-4.6-7 heben sich durch eigenes vokabular davon $a b$. In ihnen finden wir $8 \times 7$ "Hand", 12x das Suffix 1- "sein" und 5x 7 "Gewandbausch".

DaB Rahmen und Gerahmtes nicht beziehungslos nebeneinanderstehen, wird mehrfach deutlich. Einmal gibt es jeweils einen harten Übergang vom Erzähler zum Sprechen Jahwes . Dann stellt das erste Wort sowohl von 4,5 wie auch von 4,8 eine Verbindung mit dem unmittelbar vorausgehenden dar: למען "damit ..." gibt den Zweck des zuvor Getanen an; וחיה "und es wird sein" beschreibt eine zu erwartende Wirkung dessen, was Mose ausgeführt hat. überdies nimmt auch nix auf das Gerahmte Bezug.

mining, auch w.SCHOTTROFF, פקד.

90 Mit fünf Vorkommen in $4,1.5 .8(2 x) .9$ zugleich das am meisten verwendete Verb in diesem Teil unserer Erzählung.

91 In $4,1,8.9$.

92 In 4,5.8 fehlen die Redeeinleitungen zu Jahwes Sprechen. 
Die beiden Schlüsselverben werden dreimal, in 4,1.8a.9 parallel verwendet, ohne daB sich ein grober Bedeutungsunterschied feststellen lieBe $\mathbf{9}^{3}$. Die in ihnen gezeichnete Entwicklung beginnt bereits vor unserem Abschnitt, nämlich in 3,18, wo Jahwe behauptet "und sie werden auf deine stimme hören". In seiner Erwiderung stellt Mose dies in Frage $(4,1)$ : "Wenn sie aber nicht ..." . Die Formulierung als Bedingungssatz, dem der Nachsatz fehlt, wahrt eine Balance: Es ist kein offener Widerspruch zu 3,18, läвt aber verstehen, daB Mose auch mit einer anderen Reaktion (dem Unglauben der Israeliten) rechnet.

Die Antwort Jahwes ergeht zweifach auf zwei Ebenen. Auf der ersten Ebene, der der Handlung, leitet die Gegenfrage: "Was ist in deiner Hand?" eine Reihe von an Mose ergehenden Befehlen und ihre prompte Ausführung ein. Auf der zweiten Ebene, der des Sprechens, erfolgt mit 4,5 die erste Antwort "damit sie dir glauben ...". Nur die Verbindung mit den Handlungen zuvor läBt 4,5 als Antwort auf Moses Problem in 4,1 verstehen.

Jahwes Eingehen auf Mose wiederholt sich in 4,6-9 nochmals auf den beiden Ebenen, mit einem Unterschied: Das Tempo der Bewegungen ist schneller geworden, und die Auswertung (v8-9) länger. War in v3-4 die Hand jeweils nur in einer Richtung in Bewegung (werfen und ergreifen), so verdoppelt sich diese Bewegung in 4,67. Die Hand, die in den Gewandbausch hinein- und wieder herausgeführt wird, kommt bei sechs Verben ${ }^{96}$ nicht zur Ruhe ${ }^{97}$. Erst abschliessendes drittes שוב in 4,7b stellt die Hand wieder her und

93 Für die feinen Nuancen siehe weiter unten bei 3.5. Doch scheint das Gemeinsame selbst bei den unterschiedlichen Formulie-

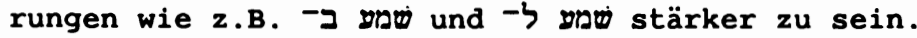

94 Zur Frage der übersetzung von ורז Bedingungssatzes siehe die Erläuterung zur übersetzung.

95 Natürlich hat Gott recht bei dieser Meinungsverschiedenheit: 4,31 berichtet vom Glauben der Israeliten. Doch ist zu beachten, daB dieser Glaube auf die vorangegangenen zeichen erfolgt. Und wie die weitere Entwicklung bis zum Auszug und bei der Wanderung durch die wüste zeigt, ist Mose mit seiner Einschätzung der Israeliten auch realistisch.

96 Je zweimal בשוא.

97 Der Effekt der Ruhelosigkeit wird durch viele einsilbige wörter noch verstärkt. 
signalisiert den Endpunkt der Bewegungen ${ }^{98}$.

Die Auswertung 4,8-9 ist wie schon die beiden Verse zuvor repetitiv. Sie gibt die definitive Antwort Jahwes auf Moses Erwiderung. Drei Stufen lassen sich in Jahwes Voraussicht der Reaktion der Israeliten unterscheiden:

a) (v8a) Im Bedingungssatz räumt Jahwe die Möglichkeit ein, daß das erste zeichen noch keinen Glauben findet.

b) Der Nachsatz des Bedingungssatzes (v8b) zeigt, daB Jahwe dann damit rechnet, $\mathrm{daB}$ das zweite zeichen Glauben findet. Sollte diese Einschätzung sich als falsch herausstellen (Vordersatz des Bedingungssatzes in v9a), so gibt es

c) als letzte Stufe die Verwandlung von Nilwasser zu Bluí auf dem Trockenen. Bei diesem letzten Tun werden keine zweifel mehr erwartet; wenn Mose das ausführt, kann nach Gottes Meinung dessen Glaubwürdigkeit nicht mehr in Frage gestellt werden ${ }^{100}$.

Die Verbindungen mit den ersten beiden Abschnitten unserer Erzählung besteht über das schon erwähnte שמע לקל "hören auf die Stimme" und dann vor allem über ראה Ni in 4,1.5. Das den Israeliten in den Mund gelegte "Nicht ist dir Jahwe erschienen!" stellt eine Verdrehung von 3,16 ("Jahwe, der Gott eurer Väter, ist mir erschienen") dar, das sich wiederum auf die Erscheinung des ersten Abschnittes bezieht. Diese Umkehrung seines Redens kann von Gott nicht stehengelassen werden; in 4,5 stellt er wieder richtig "... das dir Jahwe erschienen ist".

Die Beziehung von 4,1-9 zu den beiden vorangehenden Abschnitten mit ihren semantischen Feldern ist demnach so zu sehen, daB daraus jeweils ein Aspekt in Frage gestellt wird. Nicht Gottes Sehen, sondern sein Sich-Mose-zu-sehen-Geben wird (von den Israeliten) verneint. Ebenso wird auch nicht die Sendung des

98 Die nächste vom Erzähler berichtete Bewegung wird erst 4,18 sein: "Und Mose ging ...".

99 Wohl zu beziehen auf 4,3-4.

100 Damit geht überein, das tatsächlich nie berichtet wird, die Israeliten hätten angezweifelt, daB Jahwe dem Mose erschienen sei. 
Mose, sondern nur ihr Resultat, nämlich das Hören der Israeliten, (von Mose) verneint. Allein Gott scheint an seinen Plan zu glauben. Doch offenbar gelingt es ihm, Mose von dessen eigener Glaubwürdigkeit zu überzeugen; jedenfalls geht dieses Thema zu Ende. Dafür taucht ein neues auf.

\subsubsection{Das sem. Feld des Sprechens 4, 10-17}

Wieder stimmt mit dem Wechsel des Sprechers (Jahwe zu Mose) der Beginn eines neuen semantischen Feldes überein. Von 4,10 bis 4,16 erstreckt sich die achtmalige Verwendung der Wurzel דבר "sprechen/Wort", davon sechsmal als Verb. Dazu gehört siebenmaלישון "פiges "Mund", weiters "lehren" (2x in v12.15), "Zunge" (4,10), אלם "stumm" und "taub" (beide in 4,11). Mit dem semantischen Feld des Sprechens wird ein Thema aufgenommen, das bereits in der sendung öfters aufgetreten ist ${ }^{101}$ : Eine Bedingung für die Ausführung der Sendung ist das Reden-Können. Mose bezweifelt, dafür die nötigen Fähigkeiten zu besitzen.

Das Schlüsselverb דבר ist auf drei Personen bezogen: Jahwe $(4,10)$, Mose $(4,12.15)$ und Aaron $(4,14[2 x], 16)$. Die anfängliche Feststellung des Mose, er sei kein Mann von Worten $(4,10)$, steht im Gegensatz zu Jahwes Sprechenkönnen (ebenfalls in 4,10: "seit du zu deinem Knecht sprichst") und wird von Jahwe in 4,12 aufgefangen mit einer erneuten Aufforderung $z u$ gehen ${ }^{102}$ und mit der Zusage "Ich werde dich lehren, was du sprechen sollst". Der weitere Einwand Moses in v13 löst Jahwes zorn aus, nicht aber ein neues Thema: In v14 sagt Jahwe betont (absoluter Infinitiv) von Aaron, daB er sprechen kann. Mose bleibt weiter verpflichtet zu sprechen (v15), mit einer Einschränkung: Er muB nur zu seinem Bruder Aaron reden. Das Nomen mit Artikel "die Worte in seinen Mund legen" läßt bei seinem Sprechen feste, genau bestimmte worte vermuten. Die zusage des Lehrens wird im selben vers 15 noch ausgeweitet; sie betrifft nicht nur Mose und sein Sprechen, son-

101 In 3,13-18 wird häufig "sagen" verwendet. Doch kommt dieses Wort mit Ausnahme der Redeeinleitungen hier nicht vor.

102 Der dritte Imperativ zu gehen; vgl. 3,10.16. 
dern auch Aaron und das Tun der beiden Brüder. Das letzte דבר in 4,16 schildert das Ankommen des Sprechens beim Empfänger. Aaron ist für diese Vermittlung gegenüber dem Volk zuständig.

Die mit dem Wort פה geschehende Entwicklung unterstützt im Wesentlichen diese bei 7 gesehene Linie. Darüberhinaus gibt es einige Ergänzungen. Im einzelnen: Nach der Erklärung seiner Unfähigkeit "ungeschickt mit dem Mund bin ich" $(4,10)^{10}$ bekommt Mose rhetorische Fragen zu hören: "Wer hat dem Menschen einen Mund gemacht? Oder wer macht stumm? ..." Wo Sendender und Schöpfer in einer Person vereint sind, ist der Rekurs auf Unfähigkeit nicht möglich. Man kann nicht gut die mangelnde Befähigung $2 u$ etwas bei dem einklagen, der einen so geschaffen hat und als solchen senden will.

Nach den Fragen gibt Jahwe in 12 die zweite, positive Antwort. Die allgemeine Aussage von 3,12 wird spezialisiert auf "Ich werde mit deinem Mund sein". Diese zusage wird in v15 aufgegriffen und, ähnlich wie wir es mit ירה Hi beobachten konnten, nun auch auf Aaron erweitert. Dabei meint פ $2 x$ den Mund Aarons. Dieser Wechsel findet in v16 seinen letzten Ausdruck darin, daB Aaron als פה פür Mose bezeichnet wird. Er ist zu Moses Sprecher geworden. - Beide Schlüsselwörter zusammen zeichnen so dieselbe Entwicklung von der behaupteten Unfähigkeit des Mose zur zusätzlichen Bestellung seines Bruders Aaron zum Sprechen.

Wir haben bereits drei Verbindungen mit den vorangehenden semantischen Feldern festgestellt: der erneute Imperativ 4,12; im selben Vers die Zusage "ich werde sein mit ..."; die Nähe des Schlüsselverbs דבר zu dem in 3,13-18 im Dialog verwendeten אמר. Zum semantischen Feld der sendung besteht noch eine weitere verbindung. Sie geht über das dort als Schlüsselverb erkannte $\pi$, das in 4,13 zum letzten Mal und doppelt verwendet wird "Sende, wen du senden willst!" 104 . Mit diesen Verbindungen

103 Siehe dazu den Exkurs 5 bei der Analyse von Ex 4,10 unter 3.6 .

104 Wie schon in 3,20 mit demselben verb und in 3,21 mit הל finden wir zum AbschluB eine doppelte Verwendung. 
bestätigt sich die enge Beziehung von Sendung und Redenkönnen weiter.

(Schema 5 siehe nächste Seite)

\subsubsection{Rückblick}

In allen semantischen Feldern sind wir wenigstens einem Verb begegnet, das über eine Reihe von Versen dominiert. Teils sind sie, wie אמן in Ex 4, sogar nur dort zu finden und tauchen sonst in der Erzählung nicht auf. Diesen Schlüsselverben gesellen sich weitere Ausdrücke zu, die ähnliche Bedeutung tragen. Entscheidend ist dabei, daB diese Eigenheiten die gesamte Erzählung prägen, und überdies, dab sie alle inhaltlich an einem Thema orientiert sind: der Sendung des Mose. Diese Sendung wird unter vier Aspekten geschildert, nämlich wie sie entsteht (Sehen), wie sie ergeht (Sendung), wie sie aufgenommen (Glaubwürdigkeit) und wie sie vermittelt wird (Sprechen).

Diese Aspekte entfalten das eine Thema der Sendung nach deren Hauptgesichtspunkten ${ }^{106}$. Versucht man, sich den zeitlichen Ablauf vorzustellen, so entdeckt man, daB der letzte Aspekt, die Vermittlung der Sendung, vor ihre Annahme zu stellen wäre. Die ersten beiden Aspekte dagegen stehen in der korrekten zeitlichen Abfolge. Die gegenüber dem erwarteten Ablauf veränderte Reihenfolge der Aspekte muB später noch begründet werden (in der Analyse von Ex 4,10 unter 3.6).

Es gibt auch kleinere Schwächen an diesem Aufbau mittels der semantischen Felder. Wir sahen, daß der übergang von 3,9 nach

105 Die Beziehungen zu den anderen semantischen Feldern sind weit schwächer: Zum "Sehen" läßt sich keine wichtige Verbindung herausfinden, und zur Glaubwürdigkeit läßt sich nur ni "zeichen", evtl. ergänzt durch מט und "stab", "nehmen" als Gemeinsamkeit ansehen; doch stehen alle diese Ausdrücke nur am Ende (oder bereits auBerhalb?) des semantischen Feldes des Sprechens in 4,17 .

106 Ein Vergleich mit anderen Berufungsberichten zeigt dabei, das diese Aspekte sich auch sonst finden, fedoch nicht in dieser Ausführlichkeit und Systematik wie hier. 


\section{Schema 5: Semantische Felder und ihre Schlüsselwörter}

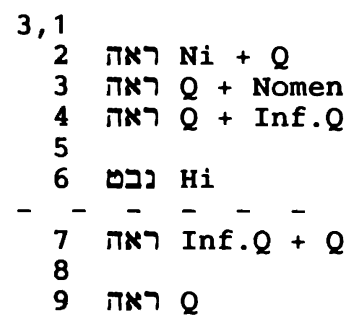

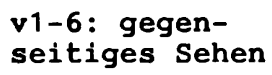

v7-9: Sehen Gottes

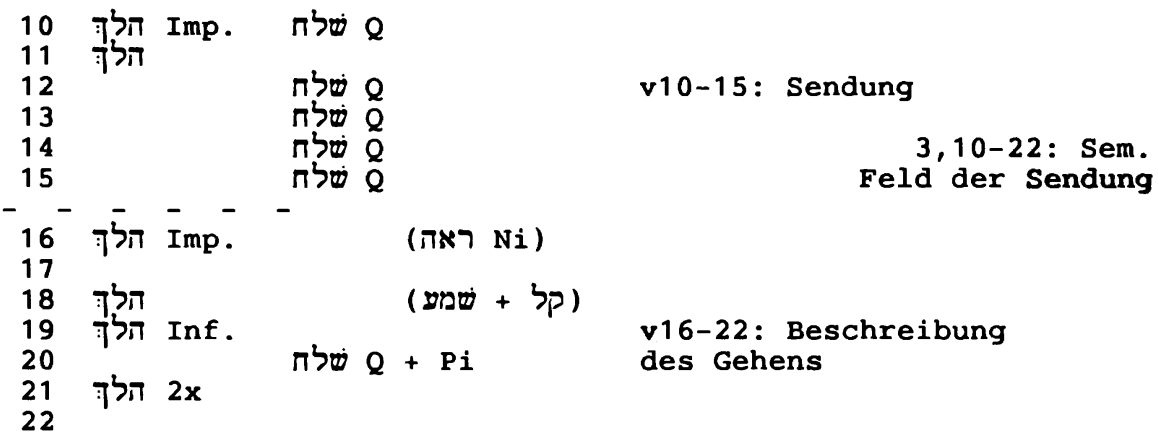

4,1-9: Sem. Feld der Glaubwürdigkeit

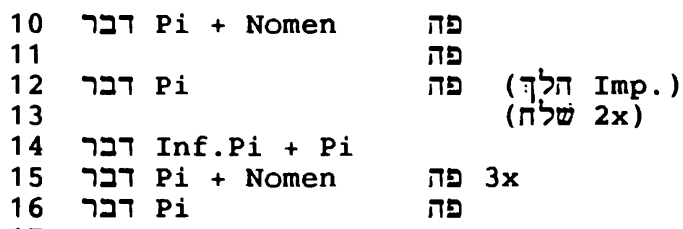


3,10 mitten in der Rede Gottes geschieht. Dafür konnten wir zwar Gründe nennen, aber im Vergleich mit den anderen übergängen, die zusätzlich durch Sprecherwechsel gekennzeichnet sind, ist diese Abtrennung des letzten Verses der Jahwerede von 3,7-10 ein "Schönheitsfehler"107. Weiters stützen wir uns auf ein einziges Kriterium. Gerade bei einer stark durchformulierten Erzählung sollten besser mehrere Kriterien herangezogen werden ${ }^{108}$. Dazu kommt, daB wir die ersten beiden semantischen Felder jeweils unterteilen konnten. Damit ging eine Reihe weiterer Texteigenheiten überein, die einen zweiten Textaufbau in sechs Bildern vorschlagen lassen. Dabei decken sich die semantischen Felder der Glaubwürdigkeit und des Sprechens mit den Bildern 5 und 6 ; die Unterschiede bezüglich der Gliederung betreffen also nur Ex 3 .

\subsection{DIE SECHS BILDER ${ }^{109}$}

Den entscheidenden Ansto $B$ zum Versuch, Ex 3-4 in der hier beschriebenen Weise zu gliedern, bot folgende Entdeckung: Von 3,7 bis 3,12 und von 3,16 bis 3,22 kommt in jedem Vers מצרים ten" vor, sonst dagegen nie innerhalb unserer Erzählung. Mit dieser Beobachtung verbanden sich andere, in den nächsten drei Absätzen beschriebene Auffälligkeiten. Sie formen Blöcke, die in sich jeweils einen engen Zusammenhalt aufweisen. Diese Blöcke erwarten.

107 Doch sind in einer Erzählung UnregelmäBigkeiten zu

108 Für Begründung und Ausführung dieses Postulats bei exegetischen Untersuchungen hat sich vor allem A.Vanhoye (siehe Anm.112) eingesetzt.

109 Die wahl des Wortes "Bild" für die kleinen Abschnitte in Ex 3,1-4,17 drängte sich mir von folgenden Ähnlichkeiten her auf. Das besondere Vokabular eines Abschnittes kann den Farben eines Gemäldes verglichen werden; Serien und Reihen stellen die Linien und Konturen dar; Wiederholungen an Anfang und Ende in Verbindung mit SchluBsignalen entsprechen dem Rahmen des Bildes.

Eine nachträgliche Bestätigung für die Wahl dieses Wortes fand ich bei S.Ph.de VRIES, Jüdische Riten und Symbole 104, der von der Bibel schreibt: "Beschreibt sie Ereignisse und Personen, schildert sie sie wie ein Gemälde. Die Bibel läBt sich also nicht nur lesen, sie läßt sich sehen."

$\mathrm{Zu}$ ergänzen wäre, daß eine solche Einteilung in Bilder nicht allein für unseren Text charakteristisch ist; besonderes Vokabular und/oder andere sprachliche Eigenheiten lassen auch bei anderen Texten eine Einteilung in Bilder zu. Siehe dazu die Beispiele in Anm. 111. 
sind abgehoben vom Vorhergehenden und vom Folgenden. Sie stellen also nicht so sehr den Ablauf unserer Erzählung als vielmehr ihren (eher statischen) Aufbau dar. So ergibt sich für Ex $3^{110}$ folgende Untergliederung: 3,1-6, 7-12, 13-15, 16-22.

Die Verwendung bestimmter wörter hebt jeden dieser Textteile von den anderen ab und prägt ${ }^{11}$ ihn so. Für das Wahrnehmen solcher Prägungen sind zwei Gesichtspunkte hilfreich, die ich "exklusives" und "typisches vokabular" (abgekürzt exkl./typ. Vok.) nennen möchte. Wo ein wort oder mehrere wörter nur innerhalb eines bestimmten Abschnittes einer Einheit vorkommen, also nicht noch einmal an anderer stelle innerhalb der Einheit angetroffen werden können, darf man diese wörter zum exkl. Vok. eines Abschnittes zählen. Unter typ. Vok. dagegen fallen jene wörter, die in einem Abschnitt gehäuft und möglichst wenig innerhalb anderer Abschnitte der Einheit aufreten. Exkl. und typ. Vok. zusammen geben einem Abschnitt sein Gepräge.

Da ein Kriterium alleine zur Erhebung des Aufbaus eines Textes nicht genügt ${ }^{112}$, müssen wir weitere Gesichtspunkte für die Komposition heranziehen. Gerade unsere Erzählung zeigt eine Eigenheit, die bisher nicht genug beachtet worden ist: Es gibt

110 Für Ex 4 ist sie identisch mit den durch die beiden semantischen Felder gefundenen Teilen 4,1-9 und 10-17.

111 Die besondere Auswahl der je in einem Bild verwendeten wörter ist nicht nur für unsere Einheit typisch, sondern ganz allgemein ein Ausdruck stärkerer literarischer Durcharbeitung eines Textes durch Autor/Redaktor(en) und so auch anderswo zu finden.

Beispiele: Innerhalb des P-Schöpfungsberichtes z.B. werden בדל "trennen, scheiden" und "rufen, nennen" nur an den ersten vier Tagen (Gen 1,1-19) verwendet, ברך "segnen" dagegen nur an den letzten drei (Gen 1,20-2,4). - In Gen 18,1-15 zeichnen im

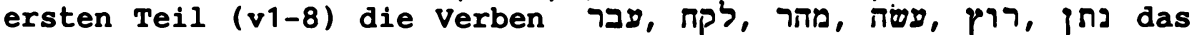
Bild eines rastlos das Mahl für die Fremden zubereitenden Abraham, während in v9-15 שוב, זכן , זמן Saras ungläubiges Lachen über die Geburt eines Sohnes in ihrem Alter in den Mittelpunkt stellen. - Bei Ex 1-2 sind die לאים-Israeliten" nur in 1,1-13 und 2,23-25 anzutreffen, während Formen von i , בת "Sohn/Tochter" den Mittelteil dazwischen (Ex 1,15-2,22) ausfüllen.

112 Ein gutes Beispiel dafür bietet die Untersuchung von A.VANHOYE, La structure littéraire de l'Epître aux Hébreux, besonders $S .37$.

Auf deutsch auch tellweise zugänglich in der übersetzung von K.Plötz: A.VANHOYE, Homilie für haltbedürftige Christen. Struktur und Botschaft des Hebräerbriefs (Regensburg 1981) 35, wo sechs Kriterien zur Erfassung der struktur genannt werden. 
einzelne wörter, die durch mehrere Verse hindurch jeweils (wenigstens) einmal vorkommen. Sind diese vorkommen ununterbrochen, so wollen wir von "Serie" sprechen". Ist jedoch mindestens ein Vers dazwischen, in dem das entsprechende wort nicht enthalten ist, so zählen die über mehrere Verse verteilten Vorkommen desselben Wortes als "Reihe" 114 .

Manchmal begegnen wir auch Wiederholungen derselben Ausdrücke am Anfang und am Ende eines Bildes, die so eine Art "Rahmen" darstellen". Darüberhinaus findet sich noch am Ende jedes Abschnittes eine Art "SchluBsignal", bestehend in der mehrfachen Wiederholung eines oder mehrerer Ausdrücke.

Wir wollen versuchen, die durch diese Merkmale gekennzeichneten Bilder im folgenden zu beschreiben.

\subsubsection{Erstes Bild: Inszenierung Ex 3,1-6}

Am Anfang einer Erzählung geht es meist darum, uns mit dem ort und den Personen vertraut zu machen. Die ersten Verse von Ex 3 erfüllen diese Aufgabe. Sie stellen Mose in seiner gewohnten Tätigkeit vor Augen und ebenso Gottes erfolgreiches Bemühen, mit ihm in Kontakt $z u$ treten. $3,6 b$ berichtet für längere zeit ${ }^{116}$ die

113 Z.B. formt מצרים "Ägypten" eine solche Serie von 3,712.

114 Z.B. kommt Vers von 3,10-15 vor und bildet so eine Reihe.

Die verseinteilung ist eine künstliche, spät vorgenommene Gliederung des Textes. Deswegen ist die Feststellung von Vorkommen pro vers sehr formal und damit auch die Unterscheidung zwischen "Serie" und "Reihe" mit umso gröBerer Vorsicht zu gebrauchen, je ungleichmäBiger die Verslängen werden. Dennoch bleibt festzuhalten, daß die Verseinteilungen nicht gänzlich willkürlich vorgenommen wurden, sondern Sinneinheiten enthalten (meist in der Länge von 3 bis 4 sätzen), und daB deshalb sowohl die prinzipielle Feststellung von durch mehrere Verse wiederholten wörtern wie auch die Unterscheidung Serie - Reihe bedeutsam sein können. Sie gewinnen umso mehr an Wert, je gleichmäßiger die Verslängen sind.

115 Dieses stilmittel findet sich in Poesie häufiger. Ps 8,2-10 verwendet dazu einen ganzen Satz: "Jahwe, unser Herr, wie wunderbar ist auf der ganzen Erde dein Name!" Ein Beispiel für unseren Text wäre das vorkommen von $\square$ " "Name" in 3,13 und 3,15 , also im ersten und letzten vers des dritten Bildes.

$$
116 \text { Bis } 4,3 \text {. }
$$


letzte Handlung; wir dürfen annehmen, daB damit der erste vorbereitende Teil abgeschlossen ist.

Mit dieser erwarteten Einführung in ort und Personen korrespondiert das Vokabular: Mose wird 5x genannt, darunter die einzigen beiden Male, in denen sein Name in der Rede vorkommt. "Gott" wird 7x erwähnt; dazu kommen noch $2 x$ Jahwe und $1 x$ sein Bote. Was die Orte betrifft, so findet sich eine Fülle von Ausdrücken. Die Verse 1b.2a.3a.4.5 enthalten alle entweder Verben der Bewegung oder Ortsangaben (oder beides). Viele der dabei verwendeten wörter gehören zum exkl. Vok. und kommen nur einmal $\operatorname{vor}^{118}$. Zum exkl. Vok. zählen aber auch einige wörter, die wiederholt werden: הסנה "der Dornbusch" (5x), מתוך "mitten aus" und סו "abweichen" (je 2x), weiters, ohne jedoch Bewegung oder Ort auszudrücken, je $2 x$ "xeuer" und "(ver-)brennen". In Verbindung mit dem typ. Vok., zu dem neben dem schon erwähnten Mose vor allem fünfmaliges ראה "sehen" "19 gehört, finden wir so drei Schwerpunkte in diesen ersten sechs Versen: die beiden Personen, die Orte und Bewegungen, und das Sehen, wobei dieses Sehen sich vor allem auf einen sonderbar brennenden und doch nicht verbrennenden Dornbusch bezieht.

Die Schilderung dieser doppelten Erscheinung, der des Boten Jahwes und der des Feuers, legt bereits den Akzent auf das Sehen. Die mehrfache wiederholung dieses wortes in unserem Abschnitt verstärkt noch diese Akzentuierung. Es entsteht ein Bild vor den Augen des Hörers, vergleichbar der Inszenierung eines Dramas, wo auch der optische Eindruck, die Gestaltung der Bühne eine Vorahnung dessen geben, was im stück zu erwarten ist. Mit dieser Deu-

117 In 3,4. Sonst wird der Name Mose in unserer Erzählung immer vom Erzähler verwendet.

118 z.B. חרב "Horeb", הרב "führen", הלם "hierher", פמרמה "Boden".

119 Die erste Verwendung in 3,2 steht im $\mathrm{Ni}$, wo dieses Verb "erscheinen" bedeutet. Die fünf Vorkommen werden ergänzt durch zwei weitere Worte: מראה "Erscheinung" in 3,3 und "blicken" in 3,6 .

Dieses אר? "und es erschien" in 3,2 könnte, obwohl von ראה "sehen" stammend, auf Grund seines Sinnes (erscheinen) auch dem Paradigma der Bewegung zugeordnet werden.

נבט in 3,6 .

120 Mit Ausnahme von אר?? "und es sah (Jahwe)" in 3,4 und 
tung als Inszenierung harmonieren auch das wiederholte Ansprechen des Ortes und der geringe Anteil an direkter Rede.

Der durch die drei Schwerpunkte gebildeten inneren Einheit der Verse 1-6 entsprechen auch zwei kleinere Anzeichen für ein

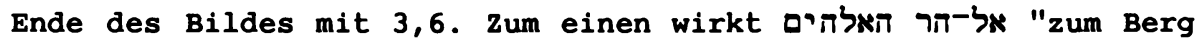
Gottes" in 3,1 und "zu Gott" in 3,6 wie eine Rahmung $_{122}^{121}$. Zum zweiten kommt in v6 das Wort אלהים "Gott" fünfmal $\operatorname{vor}^{122}$. Mehrfache Wiederholung kann ein Anzeichen für ein nahes

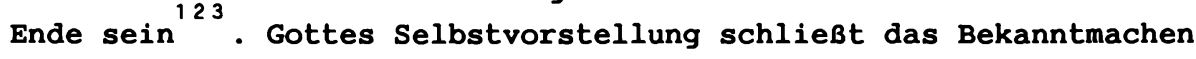
des Lesers mit den Personen und der Personen untereinander ab.

\subsubsection{Zweites Bild: Gottes Anliegen Ex 3,7-12}

Nach der Vorstellung der Personen können wir erwarten, den Grund zu erfahren, der Gott zu seinem Sprechen bewegt. Tatsächlich stellt uns das exkl. Vok. vor zwei Wortfelder, eines, das Not und Bedrückung" , ein anderes mit den Ausdrücken ירד "heruntersteigen" und נצ' "herausreissen", die beide Gottes rettendes Eingreifen bezeichnen, und denen sich das zum typ. Vok. gehörende, eine Dreierserie von 3,10-12 bildende אצי Hi "herausführen" anfügt.

Diese polaren wortfelder von Not und Befreiung ruhen auf einem durch typ. Vok. gebildeten Gegensatzpaar: מצרים "Ägypten, Ägypter" und עם, עמי "Israeliten". Die Erwähnung von weiteren sechs völkern und eines als gut und weit beschriebenen Landes in $v 8$ verstärken diesen Kontrast in bezug auf die Personengruppen und die ihnen zugeordneten Länder. Den unveränderten Grundton bildet dabei das in jedem Vers wieder-

121 Es sind zugleich die einzigen beiden Vorkommen von האלהים in diesem Bild.

122 Nachher nicht mehr bis 3,11.

$123 \mathrm{Vgl}$. dazu das zu "Informationswert" in c1 Anm.12 Gesagte. - Wiederholungen für sich alleine machen keine Aussage. Es hängt von weiteren Gründen $a b$, ob sie als Betonung oder als zeichen für ein Ende oder als etwas anderes interpretiert werden dürfen.

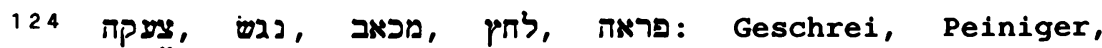
Schmerz, bedrücken, Pharao. 
מצרים מצוte und so eine von 3,7-12 durchlaufende Serie formende "Ägypten".

3,7 greift mit viermaliger verwendung der 1.P.Sg. ${ }^{125}$ auf die am Ende des letzten Bildes geschehene Selbstvorstellung Gottes zurück. Gottes Tun steht in den weiteren Versen im Mittelpunkt und läuft auf die Sendung des Mose in 3,10 zu. Ab dort wird das Tun des Mose stärker betont ${ }^{126}$. So ließen sich innerhalb dieses Bildes noch einmal zwei Teilbilder annehmen, eines von v7-9 mit Gottes Wahrnehmen der Not, das andere in v10-12 mit der sendung Moses $^{127}$. In $v 12$ wird $7^{-}$"du/dein" viermal verwendet; es ist dessen letzte Erwähnung bis v18, wo dieses Suffix das nächste Mal auftaucht. Wiederholtes $\eta^{-}$stellt so, ähnlich wie fünfmaliges "Gott" in 3,6, eine Art SchluBsignal dar. Die verse 7 und 12 sind gerahmt durch das Wort פם "Volk". V12 greift dazu noch "Berg" aus 3,1 wieder auf; innerhalb unserer Einheit sind dies die einzigen Vorkommen.

\subsubsection{Drittes Bild: Der Name des Sendenden Ex 3,13-15}

Jede sendung ist untrennbar mit ihrem Auftraggeber verbunden. Dieser wird in der Frage nach dem Namen angesprochen, wobei ם "Name" als Schlüsselwort sowohl die Inklusion bildet als auch zusammen mit כה "Goschlecht" (je 2x), דר "Gedenken" und פלם "ewig" zum exkl. Vok. gehört. Dem Sendenden wird so ein Name zuteil, der auf immer bleibt.

Das typ. Vok. unterstreicht dies. Die Serie von שלח "senden"

125 Als Subjekt bei allen drei finiten verben und einmal als Suffix beim Nomen פמט "mein Volk".

ben.

126 Durch vier Verben in 3,10-12, die ihn als Subjekt ha-

127 Die Grenze der beiden Teilbilder stimmt genau überein mit dem übergang zwischen den beiden semantischen Feldern des Sehens und der sendung. Vgl. 2.2.1 und 2.2.2.

Die beiden Teilbilder sind auch gerahmt: $v 7$ und 9 sind verbunden durch ראוק und das Suffix der 3.P.P1., v10 und 12

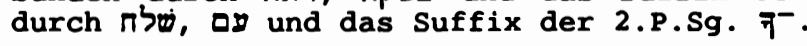


(v12-15) betont die Beziehung Moses zu diesem Sendenden ${ }^{128}$. Dieses Senden bezieht sich auf eine Gruppe oder es betrifft sie. Es sind die Israeliten, die auch mit ${ }^{-129}$ angesprochen werden; beide Ausdrücke gehören zu längeren Reihen ${ }^{130}$ und stehen dem im vorigen Bild erwähnten "Ägypten" gegenüber, das hier - signifikant - beim Sprechen Gottes von sich selbst, fehlt. Zum typ. Vok. gehört auch "Mose", der Name des Gesandten", ebenso wie אהיה ( $3 x$ in v14) und "sagen", das hier eine doppelte Serie bildet: von 3,11-15 in der stimme des Erzählers $_{133}^{132}$, und von 3,13-18 in den Reden der Gesprächspartner ${ }^{133}$, teils sogar mehrfach. Weiters ist auffallend, daB sich neunmal das Personen untereinander verbindende אצ "zu", nie aber das für objekte gebrauchte findet.

Das Insistieren auf den Personen und ihren Beziehungen kommt auch in den Wiederholungen zum Ausdruck: In v13 beziehen sich fünf Ausdrücke auf Mose und sechs auf die Israeliten. Das SchluBsignal in $v 15$ besteht wie schon in v6 aus fünffachem "Gott". Das entspricht dem Inhalt dieses Bildes und bekräftigt noch einmal den Namen.

\subsubsection{Viertes Bild: Jahwes Plan Ex 3,16-22}

Gottes Reden von sich selbst mündet ein $^{134}$ in einen erneuten

128 של "senden" im Sinn von "eine Person beauftragen" wird nur noch in 4,13 verwendet. Die vier vorkommen in 3,20 und 4,4 benützen ${ }^{\circ}$ im Sinn von "die Hand ausstrecken" (3x) oder "entlassen".

129 Suffix der 2.P.Pl.mask. "euch/euer", das hier zum ersten Mal in unserer Erzählung erscheint.

130 "Israeliten" von 3,9-15; כם von 3,13-22.

131 "Mose" bildet eine Serie von v13-15 und wird nachher bis 4,1 nicht mehr erwähnt. Es gibt in unserem Text sonst nirgends drei aufeinanderfolgende Verse mit seinem Namen.

132 Dem entsprechen die Redeeinleitungen; deren nächste folgt erst in 4,1 .

133 3,13-15 sind so genau jene verse, in denen sich der Gebrauch von אמר überschneidet: Die Gesprächspartner reden selbst, und sie reden vom Reden.

134 Obwohl damit ein neues Thema angesprochen wird, erfolgt keine wiederholte Redeeinleitung. Wenn unsere im obigen Exkurs gemachten Beobachtungen zutreffend sind, so würde erneutes "und er sprach" dem Inhalt des folgenden Sprechens grobes Gewicht 
Auftrag zu gehen (v16), der einen ausführlichen Blick in die zukunft einleitet. Bestimmend ist dabei der Gegensatz zwischen dem wiederum auftauchenden מצרים "Ägypten" mit einer ununterbrochenen Serie von v16-22 (also durch das ganze Bild hindurch) und dem zwar in v18.21 fehlenden, dafür aber insgesamt $8 x$ vorkommenden - "euch/euer", das die meist gebrauchte unter einer Reihe anderer Bezeichnungen für die Israeliten darstellt. Mit 3,22 gehen diese beiden Ausdrücke für unsere Erzählung zu Ende ; der Konflikt zwischen diesen beiden Gruppen scheint damit gelöst.

Eine weitere Untersuchung von Vok. und Inhalt legt eine Aufteilung in zwei Teilbilder nahe: v16-18 und v19-22.

Das exkl. Vok. von v16.18 besteht vor allem in den Ausdrükken für die dreitägige Opferreise, in "versammeln", פקד "vot "heimsuchen, überprüfen", קרה "begegnen" (diese letzten beiden Verben haben die Beziehung Jahwe - Israel im Blick) und in drei Ausdrücken, die auf verschiedene Weise Israel meinen: ip

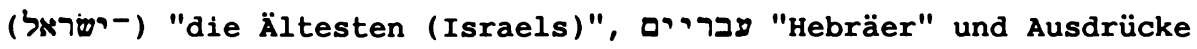
der 1.P.Pl. "wir/uns(er)". V16 und 18 sind stark gerahmt durch die "Ältesten", הלק "gehen", die Kombination "Jahwe, Gott ... + Name im Genetiv)" und die 2.P.Sg.mask. "du" ". In die Mitte kommt v17 zu stehen, der in vielem eine Wiederholung von 3,8 ist.

Zum typ. Vok. gehört die Fortsetzung der Serie von "sa-

zumessen. So aber, nur leicht abgehoben durch die verschiedene Ausdrucksweise, wobei Parallelismus und Reim in v15b als poetische Mittel trennend wirken, liegt die Betonung auf Jahwe in v15. zudem erscheint Moses Sendung (in 3,16 ) noch enger mit Gottes Sein verknüpft.

135 Eine Ausnahme bildet der Gebrauch von ${ }^{-}$in 4,15, doch wird es dort für Aaron und Mose (und nicht für die Israeliten) verwendet.

136 Die Verwendung einer bestimmten Person, zumal, wenn sie noch verschieden ausgedrückt wird (persönliches Fürwort, subjekt beim Verb oder Suffix), ist sicher kein starkes Argument. Das gilt auch für andere verse (z.B. die 1.P.Sg. in 3,13$)$. Doch gewinnen diese Beobachtungen an Gewicht, wenn sie sich mit anderen verbinden: Treten sie gehäuft auf, oder gehören sie gar zum exkl. Vok. (wie die 1.P.Pl. in 3,18 ), oder bezeichnen sie für längere zeit das letzte Auftreten einer Person ("du" z.B. kommt bis 4,1 nicht mehr vor), dann darf zu Recht nach ihrer Bedeutung gefragt werden. 
gen" in der direkten Rede ${ }^{137}$. Den AbschluB in v18 bildet viermalige 1.P.P1. Dieser Vers nimmt überdies מרבר "Steppe/ wüste" aus 3,1 wieder auf. Es sind die einzigen beiden Vorkommen dieses Wortes in unserem Text.

Für v19-22 findet sich das exkl. Vok. vor allem in der Bestrafung Ägyptens (נכה "schlagen", בכל-נפלאתי "mit all meinen wundertaten"), in dex Begnadung der Israeliten (z.B. i "Gnade" und 7 "leer" in v21; dazu elf der 18 wörter von v22). Die Beziehung zwischen den beiden völkern scheint am Ende zu einer friedlichen Lösung zu gelangen. Eine solche Deutung als Ende, Auflösung könnte unterstrichen sein dadurch, daß einige bisher häufige Worte in diesen vier Versen völlig fehlen: אמר "sagen", Jahwe, Gott, אֶל "zu", 2.P.Sg., ...

Trotz der Besonderheit von v22, nämlich so viel exkl. Vok. zu enthalten, finden wir in ihm auch wieder ein SchluBsignal, ausgedrückt durch die viermalige wiederholung der 2.P.Pl. "ihr/ euer".

In diesem Bilde bestimmt vor allem das exkl. Vok. das auf dem Hintergrund der Gegenüberstellung "Ägypten - Ihr" gezeichnete Geschehen. Im ersten Teilbild geht es dabei um die Intensivierung der Beziehung mit dem Sendenden, im zweiten wird der zugrundeliegende Konflikt zwischen den beiden Gruppen gelöst. Die szene wird damit frei für ein neues Bild.

\subsubsection{Fünftes Bild: Jahwes Machterweis Ex 4,1-9}

Unter den ca. 25 Ausdrücken, die zum exkl. Vok. des fünften Bildes 138 gehören, nimmt "glauben" wegen fünf Vorkommen und Verteilung über das ganze Bild eine sonderstellung ein. Die

137 In der ganzen folgenden Erzählung begegnen wir אמר in der direkten Rede nur noch einmal in 4,1 .

138 Wie schon gesagt, deckt sich die Gliederung in Ex $4 \mathrm{mit}$ der durch die semantischen Felder gefundenen. Neben dieser übereinstimmung können wir eine Veränderung in der Gestaltung der letzten beiden Bilder feststellen: zum einen gibt es keine langen Serien mehr (wohl aber noch Reihen), und zum anderen bestehen die SchluBsignale nicht mehr in der gehäuften wiederholung derselben Person, sondern in der Wiederholung mehrerer wörter. 
weiteren Ausdrücke sind vor allem $z u$ den verschiedenen (ausgeführten oder erwähnten) zeichen zu rechnen: נוס "Schlange", נוס "fliehen", אחז "ergreifen", usw... Auffällig sind die vielen "materiellen" Ausdrücke" . Dabei ragen חיק "Gewandbausch" und שוב "wiedertun" mit fünf bzw. drei Verwendungen heraus. Die dadurch angedeutete Thematik von zeichen und Glauben bzw. Unglauben spiegelt sich ebenfalls im typ. Vok.: T "Hand" (8x), אל "nicht" $(7 x)_{f}$ nix "zeichen" $(3 x)$, u.a. Typisch ist ebenso fünfmal Jahwe , das erneute Auftreten der 2.P.Sg. (in Verben und Suffixen insgesamt 10x) und noch mehr das Suffix $t^{-}$der 3.P.Sg.mask., je viermal in 4,4.6.7, davon $10 x$ auf Mose bezogen. Dieses Sprechen von Mose in der 3.P. weist auf den Erzähler hin, der hier zum ersten Mal seit 3,6 wieder deutlicher wahrnehmbar wird.

Die Suche nach einem ähnlich markanten Schlubsignal, wie wir es bisher immer beobachten konnten, führt uns aber zu einer erstaunlichen Beobachtung: Mit 4x אלהים "Gott" befindet es sich bereits in 4,5. V1-5 formen so das erste Teilbild, wobei eine Inklusion zwischen $v 1$ und 5 mit אמן "glauben" und scheinen" 141 besteht; 4,5 gibt die Antwort auf die Frage von 4,1. Überdies zeigen sich Verbindungen zwischen 4,2 und 4,4 mit מט "stab", ᄀי "Hand" und "und Jahwe sprach". In die Mitte der so entstehenden palindromischen struktur kommt 4,3 zu stehen. Flucht und Verstummen sind Moses Reaktion auf Jahwes erstes zeichen.

Die im Vokabular aufgezeigten Gemeinsamkeiten erlauben nicht, v6-9 von 4,1-5 abzuheben; doch formen 4,6-9 das zweite Teilbild. Das weitere zeichen Jahwes ist vor allem mit dem bereits oben erwähnten חיק "Gewandbausch" verknüpft. Somit wird Mose persönlich betroffen, was auch in fünfmaligem יד "Hand" in 4,6-7 sichtbar wird. Das auch oben vorgestellte שוב (im Hi) wiedertun, wiederholen" bietet einen Schlüssel für die sprachliche und formale Gestaltung dieser Verse 6-9. Nicht nur, daB die Satzkonstruktionen sich wiederholen ${ }^{142}$, auch viele wörter werden

139 Schlange, Schwanz, (hohle) Hand, Schnee, Fleisch, Wasser, Trockenes, Blut, ...

140 In keinem anderen Bild ist dieser Name so häufig.

1414,5 ist eine wörtliche wiederholung des letzten Satzes von 4,1, wenn auch in anderer Reihenfolge und ohne verneinung.

142 Siehe unten unter 3.5 . 
wiederholt. V6 und 7 haben fünf wörter gemeinsam, v8 und 9 gar sieben. Und auBerdem werden innerhalb von 4,9 sieben wörter wiederholt. Diese Repetition wirkt als SchluB. Eine vierfache Wiederholung von Ausdrücken ${ }^{143}$ aus 4,1 sowohl in 4,8 als auch in 4,9 rahmt das 5. Bild und bestätigt v8-9 als dessen Ende.

\subsubsection{Bild: Mitbestellung Aarons Ex 4,10-17}

2wölf neue wörter in 4,10 lassen gegenüber dem sehr repetitiven v9 verstärkt aufhorchen. Die Wiederholung der Wurzel רבר "reden, sprechen, Wort", verbunden mit dem zum selben Wortfeld gehörenden פה "Mund", wobei beide zusätzlich auch noch exkl. Vok. sind, macht gleich mit dem zentralen Thema vertraut: reden kön-

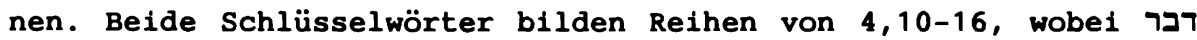
in v11 und 13 und פ in v13-14 nicht vorkommt. Die anderen verse weisen teils mehrfache Vorkommen auf. zum exkl. Vok, zählen auch ירה (Hi) "lehren", "schwerzüngig", "stumm", "taub"144, viermaliges "Nicht?", und schlieBlich, im Kontrast, das Erzürnen (חרה) Jahwes und, als die letzten beiden neu vorkommenden wörter, שמח "sich freuen" und לכ "Herz, Gemüt, Verstand" für Aaron.

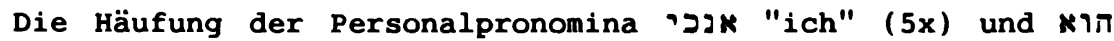
"er" (4x) im typ. Vok. und elfmaliges vorkommen der 2.P.Sg. mask. deuten darauf hin, daB die Rollen und Beziehungen der einzelnen Personen zueinander geklärt werden; dreimaliges פִם "mit" (v12.15) drückt dabei Jahwes Unterstützung für die von ihm beauftragten Personen aus. Das Verhältnis von Jahwe und Mose wird in 4,10 in den Termini "mein Herr" und "dein Knecht" erfaßt, während 4,14.16 die Beziehung zwischen Aaron und Mose mit "dein Bruder" 146 und mit "Mund/Sprecher" bzw. "Gott" angibt.

zuzuordnen.

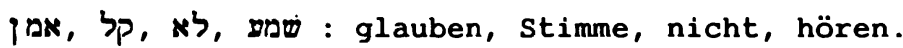

144 Auch diese Ausdrücke sind dem Wortfeld des Sprechens

145 Zum ersten Mal nun auch für Gott verwendet.

146 א kann auch den Verwandten bezeichnen: Ges.B.22. Erst die Genealogie in Ex 6 rechtfertigt die übersetzung als Bruder. 
Auch in diesem Bild läßt sich eine Unterteilung in zwei Teilbilder vornehmen. Der besondere Charakter von 4,13 zeigt sich in vielem: Es weist kein einziges neues Wort mehr auf. Die beiden Schlüsselwörter פל שלח fehlen. Statt dessen wird "senden" zweimal in einem Sinn verwendet, der mit dem zweiten und dritten Bild verbindet. Zugleich nimmt 4,13 dieselbe Anrede von 4,10 "Bitte, mein Herrl" auf. Das Teilbild 4,10-13 lebt von der Gegenüberstellung des allmächtigen Jahwe mit dem ihn zwar anerkennenden, aber trotzdem seine sendung höflich ablehnenden Mose.

4,14-16 stellen die Person Aarons neu in den Blick. Je 2x הוא viermaliges פה legen noch stärker als im ersten Teilbild das Gewicht auf das Sprechen.

4,17 hebt sich von v14-16 dadurch ab, daß die beiden Schlüsselwörter פר fehlen und alle seine wörter bereits in den Versen 4,2.9.15 vorkommen. Im besonderen scheint die Verbindung mit $4,2.9^{147}$ für eine starke verklammerung der Bilder 5 und $6 \mathrm{zu}$ sprechen.

Wohl auch deswegen besteht die Rahmung des 6.Bildes zwischen 4,10 und 4,16: neben den Schlüsselwörtern פר and פה Ausdrükke für die Beziehungen (Herr, Knecht in 4,10; Mund/Sprecher, Gott in 4,16$)$ und die persönlichen Fürwörter (ich $2 x$ in $v 10 ; 2 x$ er und $1 x$ du in v16). 4,16 gibt die endgültige Antwort auf den Einwand von 4,10. Der repetitive Charakter von v15-17 $7^{148}$ zeigt nicht nur den SchluB des sechsten Bildes, sondern unserer ganzen Erzählung an.

(Schema 6 siehe nächste Seite)

\subsubsection{Auswertung}

Was sich nach diesem Durchgang durch die sechs Bilder unserer Erzählung zeigt, ist eine überraschende Einheitlichkeit in der Art ihrer Komposition. Jedes von ihnen weist in bezug auf

147 Siehe oben unter 1.2.1, vor allem Anm.13.

$148 \mathrm{Vgl}$. die in der Abgrenzung unter 1.2.1 zum Ende vorgebrachten Argumente. 
Schema 6: Hauptmerkmale der sechs Bilder

exkl. + typ.Vok., Serien und Reihen

Schlußsignale

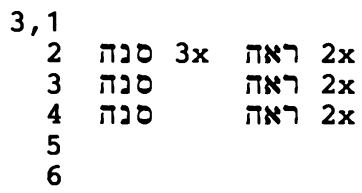

3,1

2 2x ראה $2 x$

3 ראה $2 x$

4 2x ראה $2 x$$$
5
$$$$
6
$$

\begin{tabular}{|c|c|c|c|c|}
\hline $\begin{array}{r}7 \\
8 \\
9 \\
-\quad- \\
10 \\
11 \\
12\end{array}$ & צ'צרים & & 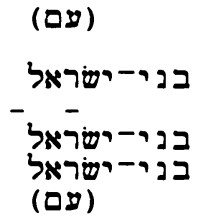 & (עם +) \\
\hline $\begin{array}{l}13 \\
14 \\
15\end{array}$ & & & 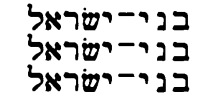 & $\begin{array}{l}\text { 2x } \\
\text {-כם } 2 x \\
-כ ם\end{array}$ \\
\hline $\begin{array}{r}16 \\
17 \\
18 \\
-\quad 19 \\
19 \\
20 \\
21 \\
22\end{array}$ & 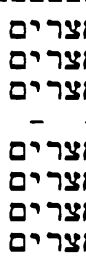 & & 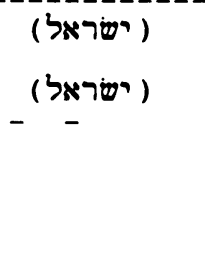 & $\begin{array}{l}\text {-כx } \\
\text {-כםם -כם -כם } 2 \text {-כם } \\
\text {-כם }\end{array}$ \\
\hline $\begin{array}{r}4,1 \\
2 \\
3 \\
4 \\
5 \\
-\quad 6 \\
6 \\
7 \\
8 \\
9\end{array}$ & אמן & $\begin{array}{l}\mathrm{Hi} \\
-\end{array}$ & $\begin{array}{l}\text { יד } 2 x \\
\text { יד } 2 x \\
-\quad \text { יד } 2 x \\
2 x\end{array}$ & 3x \\
\hline $\begin{array}{l}10 \\
11 \\
12 \\
13 \\
-\quad 14 \\
15 \\
15 \\
16 \\
17\end{array}$ & דבר דבר דבר דבר & $\begin{array}{l}\overline{2 x} \\
2 \mathrm{x}\end{array}$ & $\begin{array}{l}\text { פ פה פה } \\
\text { פה } 3 x \\
-\quad- \\
\text { פה } 3 \text { פה }\end{array}$ & \\
\hline
\end{tabular}

INSZENIERUNG

אלהים

GOTTES ANLIEGEN

$\mathrm{Hi}$

אצי $\mathrm{Hi}$

אצי $\mathrm{Hi}$

$4 \times$ ๆ $^{-}$

DER SENDENDE

אלהים 5x

JAHWES PLAN

4x 1.P.Pl.

4x 2.P.Pl.

JAHWES MACHTERWEIS

אלהים

vielfache Wiederholungen innerhalb von v8-9 und v9 MITBESTELLUNG AARONS

von v15 bis 17 kein neues Wort mehr; v17 besteht gänzlich aus 4,2.9.15. 
seine Konstruktion sehr ähnliche, wenn nicht sogar dieselben Merkmale auf. In allen Bildern konnten wir exkl. und typ. Vok. feststellen, das eng mit den Themen der Bilder verbundene wortfelder ergibt. Jedes Bild wird mit einer Art SchluBsignal beendet und ist überdies durch das vorkommen von Serien oder Reihen geprägt. Die einzelnen Bilder erscheinen so jeweils als eigene kleine Einheiten, die in ihrer Eigenart ernstgenommen werden müssen. Auffällig ist dabei auch noch, daB die Bilder 2, 4, 5 und 6 in Teilbilder unterteilt werden können.

Neben dieser Unterteilung in kleine, meist 3-4 Verse umfassende Teilbilder fällt auf, dab einige ${ }_{50}$ Serien/Reihen die Grenzen zwischen den Bildern 2-4 überschreiten ${ }^{150}$. Das deutet darauf hin, dab hier eine gemeinsame Aussage, ein fortlaufender Faden besteht. Die Auslegung muB darauf Rücksicht nehmen, daB sich die Gewebetechnik in 3,7-22 über die Bildgrenzen hinweg fortzieht und daB deswegen die Bilder 2, 3 und 4 enger zusammengehören ${ }^{151}$. Auch sonst ist selbstverständlich, daB die einzelnen Bilder nicht isoliert für sich stehen, sondern einen engen zusammenhang untereinander aufweisen.

Der Rückblick auf die in den sechs Bildern zutage tretende Komposition unserer Erzählung bestätigt so die unter 2.1 .5 besprochene Polarität von Einheitlichkeit und Komplexität. Die im vorletzten Absatz genannten Gemeinsamkeiten sprechen für eine Einheitlichkeit von $3,1-4,17$.

Doch hat uns die Komposition neben ihrer Einheitlichkeit auch einige Unterschiede enthüllt, die vor allem $c 3$ und $c 4$ voneinander abheben. Am auffälligsten ist die andere Form der Schluß-

149 Auf die vollständige Darstellung aller dieser wörter habe ich zugunsten einer deutlicheren Herausarbeitung der wichtigeren Ausdrücke bei den einzelnen Bildern ebenso verzichtet wie ich es hier tue.

150 Die Serie der ne Israels" $(3,9-15)$ und $(3,10-15)$ durchbrechen die Grenze $3,12 / 13$.

Ähnlich gehen in den Reden (Serie in 3,13-18), אמרהים (Reihe in 3,13-18; zusätzlich האלה in 3,12) und das Suffix (Reihe 3,13-22) über die Grenze 3,15/16 hinweg.

151 Diese zusammengehörigkeit wird auch durch die unter 2.2 vorgestellten semantischen Felder bestätigt. Das 2. Feld der Sendung erstreckt sich nämlich von 3,10 bis 3,22 . 
signale durch Wiederholungen ${ }^{152}$. Dann sind die in $c 3$ häufigen und ineinander verflochtenen Serien in $c 4$ fast verschwunden; meist stehen Reihen ohne Verflechtung untereinander an ihrer stelle. Auch bestehen zwischen den Bildern in $c 4$ nicht so viele Verbindungen wie in $c 3$. Schlieblich ist der den Bildern 2-4 zugrundeliegende Konflikt zwischen Jahwe, den Israeliten und Ägypten in den Bildern 5 und 6 nicht mehr präsent. Statt der Gruppen und ihrer Beziehungen zu Jahwe treten Beglaubigung und Befähigung des Gesandten in den Vordergrund.

Diese leichten Veränderungen von c4 gegenüber c3 lassen mehrere Deutungsmöglichkeiten zu. Die meisten Ausleger erklären mit verschiedenen Quellen $^{153}$. Andere sehen in $c 4$ eine (gegenüber dem vorigen Kapitel) niedrigere Ebene mit gleichsam technischer Atmosphäre . Doch können die veränderungen auch inhalts- und stellungsbedingt sein: Die neuen Themen und das Ende des Dialogs erfordern eine andere Sprache. Auf der Ebene der Komposition allein ist also keine Entscheidung in der Frage einer Einheitlichkeit zu treffen.

In ähnlicher Weise, wie wir bei den vier semantischen Feldern von kleineren Schwächen gesprochen haben (unter 2.2.5), müssen auch die Grenzen dieses Aufbaus mit Hilfe der sechs Bilder erwähnt werden. Die vorhin genannten Unterschiede und Veränderungen wie auch die grenzüberschreitenden Reihen/Serien zeigen deutlich, daB zum einen die Gemeinsamkeiten der sechs Bilder (wie z.B. SchluBsignale) in verschiedener Weise ausgeführt sind, zum anderen die einzelnen Kriterien je nach Bild unterschiedlich stark zu gewichten sind. Dennoch können die so abgrenzbaren Text-

152 Diese Besonderheit erscheint noch verstärkt dadurch, daB in 4,5 vierfaches

153 Zuletzt w.H.SCHMIDT, Exodus 192, zu Ex 4: "So bilden 116(17) eine sinnvolle Folge und sind wahrscheinlich literarisch einheitlich", und 193-197, wo er hinter 4,1-17 eine jehowistische Redaktion auf dem Weg zur deuteronomistischen vermutet. Es ist somit von $c 3$ mit den beiden Quellenschichten $J$ und $E$ und einigen späteren zusätzen abzugrenzen.

Vor Schmidt hat noch P.WEIMAR, Berufung (für die zuteilung siehe die Synopse 371 und $379-380$ ) selbst in $c 4$ Quellen unterschieden: $4,2-4 \mathrm{zu}$ Je Vorl $, 4,1.5 \mathrm{zu}$ Je, 4,6-18 $\mathrm{zu} \mathbf{R}^{\mathrm{P}}$.

154 Siehe dazu das Buber-zitat (Werke II, 56) bei พ.H. SCHMIDT, Exodus 187-188. 
teile als Blöcke mit relativ groBem innerem zusammenhalt angesehen werden, die von uns - ihrer Eigenart wegen - Bilder genannt wurden.

Wir haben in 2.2 und 2.3 zwei unterschiedliche Gliederungen für denselben Text vorgeschlagen. Diese Unterschiede betreffen die Einteilung von Ex 3. Wir stehen damit vor einem ähnlichen Phänomen wie es uns bereits bei den verschiedenen Formen in 2.1 begegnete: Ex 3,1-4,17 scheint so komplex zu sein, daB mehrere Gliederungen möglich sind ${ }^{155}$.

Diese zwei aufgezeigten Gliederungen sind nicht willkürlich, sondern zeichnen sprachliche Eigenheiten unseres Textes nach. Die erste, erstellt über Schlüsselverben und semantische Felder, betont stärker den Ablauf des Geschehens: vom Sehen über Senden und Glauben zum Sprechen. Dabei tritt die Person des Mose mit seiner Rolle besonders hervor. Die zweite Gliederung ist eher statisch, insofern sie hauptsächlich auf den einzelne Verse zusammenbindenden Serien/Reihen aufruht. Dabei kommen die Nomina mehr in den Blick. Die so entstehenden sechs Bilder betonen stärker Jahwes Absicht und machtvolles Eingreifen. Beide Aspekte, die semantischen Felder und die Bilder, sind komplementär.

155 Damit steht unser Text nicht allein. Im P-Schöpfungsbericht Gen 1,1-2,4a finden wir in $6+1$ Tagen 8 Werke und 10 worte Gottes. Auch wenn die Einteilung in 7 Tage dort die Hauptgliederung darstellt (die meisten wiederholungen sprechen dafür), so sind auch die beiden anderen Untergliederungen deutlich sichtbar und aussagekräftig: Der dritte und sechste Tag enthalten je zwei Werke, der siebte keines; Gottes Sprechen gilt in besonderer Weise dem Menschen (dreimal: Gen 1,26.28.29-30). Wichtig ist dabei auch, daB die verschiedenen Gliederungen nicht auf mehrere Quellen zurückzuführen sind. Vgl. P.BEAUCHAMP, Création 66-74.

Den hier vorgestellten Gliederungen ging ein Versuch voraus, den Text mit Hilfe der acht zu unterteilen. Er enthüllte zwar einiges Auffällige, was die Länge der Reden des Mose und die Abstände zwischen ihnen betrifft, erwies sich aber insgesamt als nicht weiterführend. Ein Teil dieser RegelmäBigkeiten ist von B.RENAUD, Figure 514, gesehen worden. Die von ihm gezeichnete konzentrische struktur überzeugt jedoch vor allem deswegen nicht ganz, weil die Einwände des Mose eine immer mehr sich steigernde Linie bilden (während die konzentrische struktur das schwergewicht auf die Mitte legen würde) und weil 4,13-17, wo es zur schärfsten Auseinandersetzung kommt, darin keinen Platz hat. 


\section{KAPITEL: ANALYSE DER ENTWICKLUNG}

Zwischen den Feldern/Bildern und zwischen den einzelnen versen gibt es Kontinuität. Sie herauszuarbeiten ist jetzt unsere Aufgabe. Aus praktischen Gründen benutzen wir die Einteilung in die sechs Bilder, wobei jeweils zuerst eine Vers-für-Vers-Analyse und dann ein Rückblick erfolgt.

Bei dieser Analyse gilt das Interesse vor allem der Bewegung der Erzählung. Es soll untersucht werden, wie die Erzählung Vers für vers fortschreitet und welche besonderen Aussagen in der sprachlichen und stilistischen Gestaltung sichtbar werden. Dabei werden Weisen der Darstellung zutage treten, die einen gezielten Umgang des Erzählers mit seiner Information verraten und die uns Einblick in seine Erzähltechnik geben. Zum Herausarbeiten der feinen Bedeutungsunterschiede wird der vergleich mit anderen Texten (hauptsächlich in Gen und Ex 1-15) immer wieder notwendig und hilfreich sein.

\subsection{Ex 3,1-6: Inszenierung}

Ex 3,1: Mose aber war dabei, die Schafe Jitros, seines Schwiegervaters, des Priesters von Midian, zu hüten./ Und er führte die Schafe an den Rand der steppe und kam zum Gottesberg, zum Horeb.

Unsere Erzählung setzt mit einer ungewöhnlichen syntaktischen Konstruktion 'ein, die aber in ihrem gleichmäßigen Rhythmus (siehe 1.2.2) Spiegelbild ihres Inhalts ist: Die gewöhnliche Tätigkeit ${ }^{2}$ des Mose wird beschrieben. Mit "Jitro" wird ein zweiter Eigenname genannt. Die beiden Appositionen ("sein Schwiegervater" und "Priester Midians") charakterisieren indirekt auch Mose. Er ist bei einem fremden Volk (Midianiter) in Diensten.

1 G.W.COATS, Tale 65. Vgl. unter 1.2.1 Anm.6.

2 So interpretiert N.HABEL, Call Narratives 303, das Hüten. Die hebräische Konstruktion verwendet das Partizip तø zur Bildung eines Durativs, der eine längerdauernde Handlung bezeichnet (R.MEYER, Hebräische Grammatik III 57). 
In v1b führen zwei Narrative (= wayyiqtol-Formen) das Partizip von v1a fort. Die beiden Narrative von v1b enden jeweils mit einer Ortsbestimmung. Während das Partizip gleichsam das im Hintergrund stehenbleibende Bild - Mose als Hirte - andeutet, geben die Narrative einzelne Phasen des sich vor diesem Hintergrund abspielenden Geschehens wieder.

Beide Ortsangaben enthalten Besonderheiten. אחר המרבר "hinter die wüste", "am Rand der steppe" findet sich hier das einzige Mal in der Bibel; sein genauer sinn ist umstritten . Die zweite Ortsbestimmung ist doppelt: "zum Gottesberg (, dem) Horeb". Die Bezeichnung "Gottesberg" ist antizipiert"; erst die folgenden Ereignisse rechtfertigen diese Benennung. Die Identifizierung dieses Gottesberges mit dem Horeb und nicht mit dem sinai bereitet auch Schwierigkeiten. Ähnlich wie bei Jitro wird auch hier durch Nebeneinanderstellen eine Identifizierung vorgenommen, nur das der Eigenname nun am Ende kommt.

Der erste Vers unserer Erzählung zeigt, wie die Ruhe der gewohnten Tätigkeit des Mose langsam gestört wird. Zwei Bewegungen (führen und kommen) erwecken in Verbindung mit neuen, ungewöhnlichen ortsangaben Spannung.

3 RASCHI, Kommentar zur Stelle: "am Rand"; B.S.CHILDS, Exodus 47.49: "behind the wilderness"; "westlich" als von abgeleitete Bedeutung; M.GREENBERG, Understanding 68, sieht darin (aufgrund von Ex 34,3) eine fruchtbare Hochebene. E.FOX, Names 23, zieht eine Parallele zu dem in manchen Märchen zu findenden Ausdruck "tief in den Wald". In ähnlicher Weise würde "hinter" hier das Abgelegene, Geheimnisvolle des ortes unterstreichen. In diesem Sinn lautete eine gute übersetzung "am Ende der wüste".

4 So bereits RASCHI, Kommentar zur Stelle, und M.GREENBERG, Understanding 68 (auch Anm.2).

Die Konkordanz von Even-Shoshan gibt 7 Vorkommen für diesen Ausdruck an, davon vier in Ex. Hier ist es das erste Vorkommen in der Bibel.

5 H.SCHMID, Mose 29, sieht darin E am Werk, w.H.SCHMIDT, Exodus 136-137, dagegen eine dtr Hand. Siehe auch Anm.24 in $\mathrm{c1}$.

Die Konkordanz nennt für den Horeb 17 Vorkommen, von denen die stelle hier die erste ist. Es kommt $3 x$ in Ex und $9 x$ in (meist späten) Texten des Dtn vor. Die nächste Parallele ist 1 Kön 19,8 (dort auch der Gottesberg). 
Ex 3,2: Da erschien ihm Jahwes Bote als Feuersflamme mitten aus einem Dornbusch heraus./ Und er sah, und da: Der Dornbusch brannte lodernd, aber der Dornbusch wurde nicht aufgezehrt.

Die Erscheinung von Jahwes Boten wird durch zwei Elemente näher bestimmt, nämlich durch "als Feuersflamme" und durch "mitten aus dem Dornbusch". Beide Angaben sind sowohl in ihrer Typik als auch in ihrer Eigenart $\mathrm{zu}_{6}$ sehen. Das Erscheinen Gottes oder seines Boten ist oft mit Feuer, und mit der Erwähnung eines Baumes, vor allem eines strauches verbunden. Doch ist die Ausgestaltung dieser beiden Elemente besonders. kontrahierte Form von להבה "Flamme" angesehen" מתוך הסנה "mitten aus dem Dornbusch" gibt in der Linie der Ortsbestimmungen aus 3,1 den präzisen Endpunkt: Rand der Steppe - am Gottesberg Horeb - mitten aus dem Dornbusch. Die Bewegung der Erzählung führt auf diesen einen kleinen Punkt hin.

Der nächste Narrativ אר:? setzt Subjektwechsel (zu Mose) voraus. Von der Erzählerperspektive schwenkt die Betrachtung über zum standpunkt des Mose, und wir sehen gleichsam mit seinen $\mathrm{Au}-$ gen" . רהנה "und da:" deutet dabei auf das zu Sehende hin, es

6 Nach M.LURKER, Wörterbuch 95, ist Feuer im AT ein Sinnbild für Gottes Sein und Wirken.

7 Allgemein zum Baum: K.JAROS, Elohist 255. Zum Strauch als Erscheinungsort Jahwes: M.A.BEEK, Dornbusch 160 .

8 Diese Kontraktion ist singulär, ebenso wie die Kombination von להבה mit nachfolgendem

Einer der wenigen, die לכת nicht als Kontraktion verstehen, ist RASCHI (Kommentar zur Stelle). Er sieht darin eine Form von ל "Herz".

9 o kommt auBer in Dtn 33,16 nur hier, und zwar $5 x$, vor. Deswegen gestaltet sich die Identifizierung dieses strauches schwierig. J.FELIKS, Bush 1528-1530, listet fünf mögliche Planzen auf: wild jujube (zizyphus spina - Christi), acacia (Loranthus acaciae), Cassia obovata, shrub (Colutea istria) und bramble (Rubus sanguineus (sanctus)).

Die Erwähnung des $\pi$ o könnte aufgrund der lautlichen Nähe zu ' 19 die Gotteserscheinung an Mose in Erinnerung zu rufen, die sich an einem ähnlich klingenden ort ereignete.

10 Daß Mose nicht als Subjekt erwähnt wird, erleichtert diese Identifizierung mit seinem Sehen. 
steigert die Aufmerksamkeit ${ }^{1}$ für das Kommende. Tatsächlich sieht Mose nicht, wie zu erwarten wäre, eine Feuersflamme mitten aus einem Busch, sondern ein seltsames Phänomen. Der Busch brennt ohne zu verbrennen. Die stilistische Präsentation dieses Phänomens zeigt mehrere züge: a) Die beiden Sätze, die seine Wahrnehmung beschreiben, stehen im Parallelismus, jeweils mit "der Dornbusch" beginnend. Dieses GleichmaB steht jedoch im Kontrast zu den inhaltlich entgegengesetzten Aussagen. b) Doppelte Alliteration $^{12}$ unterstreicht zusätzlich zum Parallelismus dieses GleichmaB. c) Die beiden Partizipien בצִ בצִ "brennend" und "verzehrt werdend" unterbrechen die Erzählfolge. Wie "hütend" in 3,1 wollen sie einen bleibenden Eindruck hinterlassen.

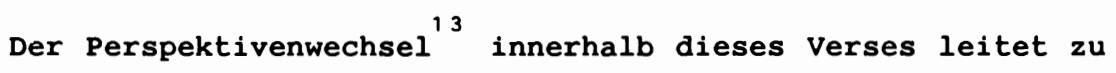
Vorsicht in unserer Erzählung an. Die Erscheinung von Jahwes Boten wird auf zwei Ebenen, von zwei Gesichtspunkten her (Erzähler und Mose) geschildert. Es entsteht so ein Kontrast zwischen dem, was der Erzähler sagt und dem, was Mose sieht: Ab 3,2 weiB der Leser mehr als Mose.

Ex 3,3: Da sagte sich Mose: "Ich will doch abbiegen, um diese großartige Erscheinung $z u$ sehen!/ Warum verbrennt der Dornbusch nicht?"

Erneuter Narrativ (רמר) führt die Erzählung weiter. Doch setzt hier, zum ersten Mal in unserem Text, die Wiedergabe von Worten ein. Was Mose hier denkt/sagt, kennzeichnet ihn. Seine eigenen Worte zeigen ihn als entschlubkräftig (zwei Kohortative) und interessiert oder neugierig (die Frage v3b). Beides scheint

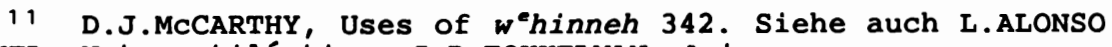
SCHÖKEL, Nota estilística, J.P.FOKKELMAN, Art, u.a.

והנח wird in unserem Text dreimal vom Erzähler verwendet $(3,2 ; 4,6.7)$. Jedesmal weist er damit den Leser/Hörer auf etwas hin, was er sehen bzw. bemerken soll.
$12 ב-2$ und $x-x$.
13 J.MAGONET, Bush 305, und A.BERLIN, Poetics 66-67. 
für Mose typisch zu sein" ${ }^{14}$. Sein besonderes Augenmerk gilt "dieser großen Erscheinung", wobei das Nomen" durch Adjektiv und Demonstrativpronomen herausgehoben ist. Überdies entsteht durch die Verwendung von בפר im Sinn von "verbrennen" ein spiel mit dem in v2 verwendeten Partizip derselben Wurzel im Sinn von "brennen".

Ex 3,4: Und Jahwe sah, daB er abgebogen war, um zu sehen./ Da rief ihn Gott mitten aus dem Dornbusch heraus und sagte: "Mose! Mose!" Und er sagte: "Siehe mich!"

Die Erzählung geht weiter mit יהוה ירא יה "und Jahwe sah". Dieser seltene Ausdruck (siehe 2.2.1) nimmt das gleiche wort in gleicher Form wieder auf, das in $v 2 b$ einen Perspektivenwechsel eingeleitet hatte. Auch hier ändert der Erzähler seinen standpunkt. Er berichtet nun aus der sicht Gottes ${ }^{16}$. Die in der Infinitivkonstruktion (סראות) ausgedrückte Absicht ist nicht als Kontrast zu v3 aufzufassen ${ }^{17}$.

Die auf das Sehen zu erwartende Reaktion Jahwes (siehe in c2 Anm.73) erfolgt im Rufen. Dieses Rufen hat einige Eigenheiten.

a) קרא wird im Pentateuch, wenn Gott der Sprecher ist, mit Ausnahme von Gen 3,9 und Num 12,5 nur für den Anruf an Mose verwendet.

b) Wir erfahren nicht gleich, was Gott ruft. Fünf wörter schieben sich zwischen Verb und Anruf. Dieser Aufschub (vgl. auch Gen 3,9) läßt den Hörer/Leser warten; die Spannung wird so erhöht.

14 Vgl. dazu seine Motivation in Ex 2,11 und die Formulierung in Ex 4,18 .

15 מראה kommt in Ex nur noch in 24,17 (das Aussehen der Herrlichkeit Jahwes) vor. Dort steht es zusammen mit und wie hier im Vers zuvor. - Das wort מראה trägt u.a. auch zur lautlichen Färbung dieses Verses bei: a- (12 Patach oder Qames) und ä-Laute ( $6 x$ Segol) dominieren gegenüber nur fünf anderen Vokalen.

16 So auch A.BERLIN, Poetics 67.

17 W.H.SCHMIDT, Exodus 103, deutet die Unterordnung von v4 als Näherbestimmung. 
c) Ein Vergleich mit den anderen Stellen, wo Gott Mose ruft, zeigt, daß die Ortsangabe üblich ist (hier das aus v2 wiederholte "mitten aus dem Dornbusch", das erlaubt, die Erscheinung des Botens Jahwes mit ihm selbst und seinem Rufen in direkte Beziehung zu setzen).

d) Schon seit frühester zeit hat אלהים "Gott", das im Kontrast zu Jahwe zuvor in $\mathbf{v a}$ steht, AnstoB erregt. In den letzten 100 Jahren wurde dieser "Subjektwechsel" meist mit zwei verschiedenen Quellen erklärt" . Selbst bei der Annahme, der Redaktor habe zwei Quellen verarbeitet und zusammengefügt, bleibt immer noch die Frage bestehen, was dieser Wechsel von Jahwe zu אלהים bedeutet. Auf diese Frage soll später (in c4) eingegangen werden. $\mathrm{zu}$ beachten ist, daß sich diese beiden Benennungen auf eine Person beziehen - die Erzählung erlaubt nicht, sehen und rufen zwei Göttern zuzuschreiben - und daß diese Identifizierung von Jahwe und Gott nicht für Mose, wohl aber für den Leser/Hörer besteht ${ }^{19}$.

e) Schließlich kommt $x$ bei Berufungen äußerst selten vor. Die einzige andere mir bekannte stelle (außer bei DtJes) ist 1 Sam 3. Dort ist das Rufen so häufig, daß die Erzählung fast zu einem Ruf-Spiel wird.

Der Inhalt des unmittelbar folgenden Redens Gottes ist gegenüber der Einleitung (sechs wörter) erstaunlich kurz: "Mose! Mose!" Der Name des Mose ist das erste Wort, das Gott in $20_{0}$ spricht. Eine solche Anrede mit Namen trifft man auch sonst ${ }^{20}$,

18 J.WELLHAUSEN, Composition $(41963$, S. $70 ; 21889$; doch wurden die Untersuchungen zu Ex bereits im Winter $1874 / 75$ fertiggestellt) teilt $v \mathbf{4 b}$ mit dem "charakteristischen Anruf im Vokativ" und dem " $E$ l $\circ \mathrm{h} i \mathrm{~m}$ nach dem kurz vorhergehenden $J$ a $h$ $w$ " dem Elohisten zu. B.BAENTSCH, Exodus-Levitikus-Numeri 19, übernimmt diese Einschätzung, schreibt jedoch die Ortsbestimmung "mitten aus dem Dornbusch" dem Jahwisten zu.

Vgl. dazu W.H.SCHMIDT, Exodus 108, der in der Differenz der Gottesnamen immer noch ein Hauptkriterium zur Unterscheidung der Quellen sieht, das allerdings "im zusammenhang mit anderen sprachlichen wie sachlichen - Argumenten anzuwenden" sei.

Die Schwierigkeit der wechselnden Gottesbezeichnungen ist sehr früh gespürt worden und zeigt auch textkritische Reflexe: Der Codex Samaritanus ändert Jahwe von v4a in אלהים "Gott" um. Die Septuaginta gibt אלהים von v4b mit xúpı os wieder. Die Vulgata schlieblich läBt "Gott" in v4b aus. Alle diese varianten wollten die Differenz der beiden Gottesnamen harmonisieren und so diesen Ansto $B$ beseitigen.

19 A.G.van DAALEN, Plaats 33, spricht von einem Wissensvorsprung des Lesers.

20 Gen 21,$17 ; 22,1 ; 31,11 ; \ldots$ 
sie macht den Anruf persönlich" Hier begegnet uns der Name gleich doppelt. Dieses Phänomen ist komplex; wir wollen ihm in einem Exkurs nachgehen.

\section{Exkurs 2: Doppelter Namensanruf}

Es gibt viele Deutungen für die Verdoppelung des Namens. Meist wird sie als Eigentümlichkeit des Elohisten angesehen ${ }^{22}$, doch ist diese Entscheidung von der zuordnung von $v 4 b$ aufgrund des אלהים mitbeeinfluBt. Inhaltlich sieht $\operatorname{man}_{23}$ darin, daB Gott Mose ermutigen und ihm Zuneigung zeigen wolle $e^{23}$, oder aber, daB der Anruf dringlich sei ${ }^{24}$. Um eine Entscheidung treffen zu können, wollen wir die Vorkommen von doppelten Anreden im AT untersuchen.

Die Massora gibt dafür vier Stellen an: Gen 22,11; 46,2; Ex 3,4 und 1 Sam 3,10. Das ist insofern korrekt, als andere verwandte stellen nicht die beiden Eigenschaften dieser vier Texte teilen, nämlich Verwendung des doppelten Eigennamens und Erwartung einer Reaktion. Wir finden doppelte Eigennamen, jedoch nicht als Anrede, noch in Ex 34,6 (dort spricht Jahwe seinen eigenen Namen zweimal vor Mose aus), 2 Sam 19,5 (David schreit, weinend über seinen verlorenen Sohn Absalom), Ps 122,2-3 (das Wallfahrtslied nennt zweimal hintereinander Jerusalem; siehe auch Lk 13,34).

21 B.JACOB, Mose 18, streicht heraus, daB Gott den Menschen beim Namen kennt (vgl. Ex 33,12.17), noch bevor dieser ihn erkennt.

Im Alten Orient bedeutete das Aussprechen des Namens die Präsentation der dahinter stehenden Macht (siehe B.GLADIGOW, Gottesnamen 1219). Die vielen Verwendungen von $ם$ " "Name" für Gott selbst im AT machen dies ebenso deutlich wie die enge Verbindung von "Name" und Person im NT, siehe z.B. den Gebrauch von bvopa in Apg 2-5, besonders in $2,21.38 ; 3,6.16 ; 4,7.10 .12$. 17.18.30; $5,28 \cdot 40.41$. Jedes Mal ist mit bropa Jesus gemeint, und oft handelt es sich um die Macht, die mit dem Aussprechen dieses Namens gegenwärtig wird.

22 So auch W.H.SCHMIDT, Exodus 107, 121-122. Zuletzt F.KOHATA, Jahwist 17 .

23 E.J.YOUNG, Call 12.

24 So B.JACOB, Mose 18; und M.GREENBERG, Understanding 71 , wobei letzterer präzisiert: Gott wolle Mose aufhalten, noch bevor er heiligen Boden betrete. 
Einen doppelten Aus- bzw. Anruf, jedoch nicht mit Eigennamen, finden wir in 1 Kön 13,2 (2x Altarl), 2 kön 2,12 (Elischa ruft Elia zu bei seiner Entrückung: "Mein Vater, mein Vater!") 2 kön 11,14 ( $2 x$ Verrat!), Ps 22,2 (Das Gebet beginnt mit: "Mein Gott, mein Gott!").

Von diesen stellen heben sich unsere vier nicht nur durch die Verbindung von Anruf und doppeltem Eigennamen ab, sondern auch durch eine Reihe anderer Eigenheiten. 1 Sam 3 hat aber aufgrund besonderer Ausgestaltung des Rufens eine Sonderstellung.

a) Immer ist der Angeredete über den Anredenden im Unklaren. Es handelt sich (mit Ausnahme von 1 Sam 3 ) um den Beginn einer Gesprächssituation, in der der Angesprochene (auch Samuel anfangs) nicht weiB, mit wem er redet. Zusatzinformationen machen für den Leser deutlich, daB der Angeredete es anfangs nicht mit einer faBbaren, identifizierbaren Gestalt zu tun hat. Es bleibt vorerst offen, wer redet. In 1 sam 3 ist das noch unterstrichen durch die verwechslung mit Eli.

b) In keinem Fall wird diese Anrede erwartet. Sie kommt immer als überraschung. Abraham wird unterbrochen beim opfern seines Sohnes Isaak; Jakob wird in seinem Schlaf gestört. Mose wird bei seinem Zugehen auf den Busch durch das Rufen überrascht, und auch Samuel kann, weil ein Wort Jahwes damals selten war (v1), nicht mit dieser Anrede rechnen.

c) Die überraschung ist umso gröBer, als es jeweils besondere zeitpunkte im Leben der betroffenen Personen sind. Allesamt sind es Höhe- oder Wendepunkte bei den Angerufenen ${ }^{26}$. Für Mose und Samuel beginnt damit ein neuer Lebensabschnitt. Auch für die zwei Patriarchen sind es entscheidende Ereignisse ihres Lebens: Abraham ist dabei, seinen Sohn zu opfern, an dem die VerheiBung hängt, und damit deren Erfüllung aufs Spiel zu setzen. Jakob ist auf dem Weg nach Ägypten und riskiert dadurch, daß seine Nachkommen nie mehr ins Land Israel zurückkehren.

d) Die in a) angedeutete unklare Gesprächssituation wird jeweils bald geklärt. In allen Fällen ist es Gott, der redet. In Gen 46,3 und Ex 3,6 erfolgt jeweils eine selbstvorstellung, in

25 Gen 22,11 "der Bote Jahwes vom Himmel"; Gen 46,2 "in einem Nachtgesicht"; Ex 3,4 "mitten aus dem Dornbusch"; 1 Sam 3,2 "schlafend im Tempel".

26 In dieser Weise interpretiert auch C.M.MARTINI, Vita di Mosè 39-41 (auf deutsch: Dein stab hat mich geführt 42-44). 
Gen 22,14 macht Abraham durch seine Namensgebung "Jahwe sieht" klar, als wen er seinen Gesprächspartner erfahren hat, und in 1 Sam 3,8-9 (also nach der dritten Anrede, aber noch vor dem doppelten Anruf) erkennt Eli, daß Jahwe der Rufende ist. Alle Fälle eines doppelten Anrufs mit Eigennamen sind somit Gottesoffenbarungen.

e) Mit dieser Gottesoffenbarung verbinden sich zusagen: Gen 22,17-18 "ich will dich reichlich segnen"; Gen 46,4 "ich ziehe mit dir"; Ex 3,12 "ich werde mit dir sein". In 1 Sam 3 erscheint dieses Element doppelt gewendet: In v11-14 ergeht ein Urteilswort, und die zusage wird nicht mehr im Dialog, sondern in der Erzählung berichtet (v19: "Gott war mit ihm").

f) Die standardantwort auf den Anruf ist in allen Fällen (in 1 Sam 3 nur bei der ersten Anrede in v4) " הנג "Siehe mich!"

g) Als Letztes mag noch ein gemeinsames Kontextelement genannt sein: Immer ist eine Art von Feuer erwähnt. In Gen 22 handelt es sich um ein Brandopfer; dieses wort komnt mehrmals vor, dazu auch "Feuer" (v7). Gen 46,1 berichtet von einem Schlachtopfer, das (nach Lev 3,3-5) ebenfalls mit elnem Feuer ${ }^{27}$ verbunden $^{2}$ ist. Ex 3 nennt den brennenden Dornbusch, und $1 \operatorname{sam} 3,3$ die Lampe Gottes, die noch nicht verlöscht war.

Ein kurzer Blick auf das NT möge den Exkurs abschlieBen. Mir sind drei doppelte Namensanrufe bekannt: Lk 10,41 "Martha, Martha!"; Lk 22,31 "Simon, Simon!" und Apg 9,4 "Saulus, Saulus!". sie sind insofern vom Sprachgebrauch des AT abgehoben, als der doppelte Eigenname nicht nur dem Anruf dient, sondern sofort mit einer Rede weitergeführt wird. Lukas verwendet also den doppelten Eigennamen als intensive Anrede in entscheidenden Lebenssituationen - was bei der ersten stelle vielleicht auch durch das "eine Notwendige" (Lk 10,42) angedeutet ist ${ }^{28}$.

(Ende des Exkurses)

27 R.de vaux, Institutions II 295: "La part de Jahvé est brûlée sur l'autel".

28 Von diesen stellen heben sich vier andere ab, die die Anrede "Herr, Herrl" verwenden: Mt 7,21.22; 25,11 und die Parallele zur ersten Stelle, Lk 6,46. Auch dabei geht es um lebensentscheidende Situationen. 
Die Antwort des Mose ist typisch. הנני "Siehe michl" bringt das zu erwartende Eingehen Moses auf Gottes Anrede. In der Pausaform wird es sechsmal zu Gott gesprochen: Gen 22,1.11; 31,$11 ; 46,2 ;$ Ex 3,4 und 1 Sam $3,4^{30}$. Meist (mit Ausnahme von 1 Sam 3) erfolgt unmittelbar darauf ein weiteres Sprechen Gottes. So auch hier in $\mathbf{5}$.

Ex 3,5: Und er sagte: "Nähere dich nicht hierher!/ zieh deine Sandalen von deinen Füßen, denn das Gebiet, auf dem du stehst, ist heiliger Boden."

Dem Anruf mit Namen entsprechend redet Gott Mose mit "du" an. Und Gott fordert gleich zwei Dinge von ihm: sich nicht zu nähern und die Sandalen auszuziehen. Diese zwei Aufforderungen stellen nach der Anrede mit Namen den Beginn des Gesprächs mit Mose dar.

a) Gott verlangt durch das Verbot des Nahens von Mose eine Distanz. קרב "sich nähern" findet sich mehrmals verneint " Von diesen Vorkommen sind besonders die kultischen Vorschriften (Gruppe 2 und 3 der vorigen Anm.) für unsere stelle bedeutsam: Der Umgang mit dem Heiligen ist nur für bestimmte Leute unter bestimmten Bedingungen gestattet. Menschen mit körperlichem Feh-

29 Die Pausaform (mit Sere unter dem Nun mit Dagesch) stellt 14 von 180 vorkommen von הנה mit Suffix der 1.P.Sg.

30 Es fällt auf, daß es mit Ausnahme von Gen 22, $; 31,11$ nur die oben beim doppelten Namensanruf erwähnten stellen sind. Die restlichen acht Vorkommen der Pausaform richten sich an Menschen: Gen 27,$1 ; 37,13 ; 1$ Sam 3,$16 ; 2$ Sam 1,7 ; Jes 52,$6 ; 58,9$; $65,1(2 x)$.

31 Verneintes pרב findet sich in vier Kontexten:

1) Es verbietet Geschlechtsverkehr unter bestimmten Umständen: Lev 18,6.14.19; Ez 18,6 (evtl. auch Spr 5,8).

2) Es gehört zu den Vorschriften des priesterlichen Dienstes: Lev 21,17 (ein Mensch mit körperlichem Fehler darf nicht opfern); Num 17,$5 ; 18,4$ (kein Unbefugter = Nicht-Levit darf sich zum Räuchern oder dem Altar nahen).

3) Auf der Linie von 2) die Warnung an das volk, der Lade nicht nahezukommen: Jos 3,4. (Die Warnung, sich dem Sinai nicht zu nähern, wird in Ex 19,12-13 aber mit g' "berühren" ausgedrückt.)

4) In beschreibenden Texten ("es naht nicht") im Sinn von: "Du brauchst keine Angst zu haben!" (Jes 54,14; Ps 91,10 und öfter). 
ler, Nicht-Leviten und Volk müssen sich davor hüten, Heiligem zu nahe zu kommen ${ }^{32}$.

b) Das Gebot, die Sandalen auszuziehen, findet sich sonst nur noch in Jos $5,15^{33}$. Beide Male wird die Aufforderung mit der Heiligkeit des Ortes begründet. Warum das Ausziehen der Sandalen die Heiligkeit des Bodens respektiert, kann nur aus dem Vergleich mit anderen Stellen, die auch von solchem Ausziehen sprechen, erschlossen werden. In Ex 12,11 sind die Sandalen $\underset{34}{\text { an }}$ den FüBen beim Paschamahl vorwegnehmendes zeichen der Freiheit ${ }^{34}$. Auch kann mit

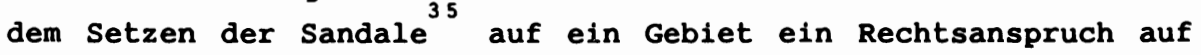
dieses bekräftigt werden. Umgekehrt ist mit ihrem Ausziehen die Aufgabe eines Rechtsanspruches, der Verzicht auf ein einem zustehendes Recht verbunden.

Unter diesen zwei Aspekten wird die Sandale zum Sinnbild der Selbstbestimmung und des Besitzes . Wenn Mose seine Sandalen auszieht, erkennt er den zu ihm Sprechenden als seinen Herrn an (wobei er noch nicht einmal weib, wer es istl) und ebenso, dab er hier auf fremdem Boden steht.

32 קרב "nahen" drückt dabei eine noch größere Distanz aus als נגו "berühren".

33 Dort sind "Sandale" und "FuB" im Singular.

34 Es ist in Ex die einzige stelle auBer unserer, die noch von נמל "Sandale" spricht. Die Sandalen werden sonst auch mit den Reisevorbereitungen erklärt (so H.RINGGREN, לو 498). - Nach M.LURKER, wörterbuch 277, ist der Schuh ein zeichen der Erdverbundenheit, das Tragen von Sandalen ein vorrecht der Freien. weitere stellen für BarfuBgehen sind Jes 20,2 und Ez 24,17.23 (dort als zeichen der Trauer).

35 Die Sandale auf etwas setzen als zeichen der Macht oder des Rechtsanspruchs findet sich in Jes 11,15 (7ר $\mathrm{Hi}+2$ ) und Ps $60,10=108,10(\pi 36 \mathrm{Hi}+ל$ (ע). Vgl. auch Lk 15,22.

Der Kontext der Leviratsehe scheint demgegenüber eher sekundär zu sein (anders aber P.PROULX, L.ALONSO SCHÖKEL, Sandalias 21; sie gehen besonders auf die jüdische Tradition und neutestamentliche zusammenhänge ein). Das AT kennt zwei Weisen: - Dem Betreffenden wird die Sandale ausgezogen (Dtn 25,9-10). - Der Betreffende zieht selbst die Sandale aus und übergibt sie (Ru $4,7-8)$.

36 Andere, jedoch abgeleitete Deutungen unserer Stelle: A.OHLMEYER, Erlösergott 110, sieht im Lösen der Sandalen ein zeichen der Ehrfurcht. M.GREENBERG, Understanding 72, glaubt, Sandalen, die zum Schutz vor Dreck und Verletzung getragen werden, stellten bei heiligem Boden eine Beleidigung dar. 
c) Die Erwähnung des "heiligen Bodens" hat manche verleitet, in unserer Erzählung, wenigstens zu Beginn, eine Entdeckersage zu sehen $^{37}$. Doch verläuft im jetzigen Text die Entwicklung gerade umgekehrt. Nicht Mose entdeckt die Heiligkeit des ortes, sondern er wird darauf aufmerksam gemacht. AuBerdem fehlen sowohl nähere Bestimmung des Ortes wie Erwähnung eines Kultes ${ }^{38}$.

אדמת-קרש, wörtlich "Boden (der) Heiligkeit", ist eine singuläre Verbindung. In der schon erwähnten Parallelstelle Jos 5,15 ist "Boden" ausgelassen; damit wird der Ort (מקמם) als heilig erklärt. Die einzige andere verwandte stelle in Sach 2,16 spricht von ארמת הקרש, wörtlich "Boden des Heiligtums", womit das Gebiet Juda gemeint ist und wovon der Ausdruck "Heiliges Land" herstammt $^{39}$. Unsere stelle läßt sich wegen des Relativsatzes jedoch nicht in diesem Sinn auslegen. Sie ist vielmehr davon her zu verstehen, daß "heilig" eine Beziehung zu Gott besagt. Der Boden, auf dem Mose steht, steht in Beziehung zu Gott. Durch dieses Wort שרק kann Mose zum ersten Mal erahnen, wer sein Gegenüber ist.

(Ende c)

Nach der Untersuchung der drei Elemente bleibt noch anzumerken, das diese Form eines Gesprächsbeginns von Gott mit einem Menschen äußerst ungewöhnlich ist. Untersucht man andere Theophanien und Berufungen auf die in ihnen ergehenden Gebote oder Verbote, so kann man nirgends (auBer Jos 5; dort aber am Endel) ein solches Distanzverlangen von seiten Gottes feststellen wie hier. Im Gegenteil, es erfolgt eher die Aufforderung, sich nicht zu fürchten $^{40}$. Warum der unwissende Mose hier von Anfang an so

37 H. GRESSMANN, Mose 30 und 33.

38 Vgl. dazu Gen 12,$7 ; 16,17 ; 22,14 ; 26,25 ; 28,16 ; 35,14$; Ri 6,24: In allen diesen Texten wird die stelle ausdrücklich genannt, an der Gott erschienen ist, und sie wird durch Benennung oder Errichtung eines Altars/Denksteins ausgezeichnet. Erwähnenswert ist auch, das diese Verse immer am Ende von Epi- oder Theophanie stehen und die menschliche Reaktion darstellen. Hier in Ex 3,5 steht aber die Erwähnung des heiligen Bodens am Anfang der Begegnung mit Gott.

39 Für die Schwierigkeit einer genauen übersetzung dieser Ausdrücke siehe Ges.B., das Ex 3,5 unter ש্p (S.704) mit "heiliger Ort" und unter (S.11) mit "geweihte Erde" wiedergibt.

40 Gen 15,$1 ; 26,24 ; 46,3 ; \ldots$ 
scharf aufgefordert wird, ist aus dem Bisherigen allerdings noch nicht ersichtlich.

Nicht die Übersetzung, wohl aber das Verständnis des Relativsatzes ist umstritten. Partizipien unterbrechen die in den Narrativen erstellte Erzählfolge. Bereits zweimal sind wir diesem

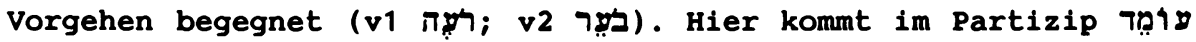
"stehend" die Bewegung des Abweichens (v3-4) zum Stillstand.

Die nicht berichtete Ausführung der Befehle Gottes stellt die Frage, ob Mose auf diese Aufforderungen eingegangen ist oder nicht. Eine Antwort kann nur indirekt erfolgen: Normalerweise wird in der Bibel (und auch sonst in Erzählungen) das Selbstverständliche (wie z.B. daB ein Mensch dem Befehl Gottes gehorcht) nicht berichtet, es sei denn, es liegt darin eine besondere Bedeutung. Für unseren Fall heiBt das, daB stillschweigend vorausgesetzt wird, Mose habe gehorcht.

Ex 3,6: Und er sagte: "Ich bin der Gott deines Vaters, der Gott Abrahams, der Gott Isaaks und der Gott Jakobs."/ Da verbarg Mose sein Gesicht, denn er fürchtete sich, den Gott anzublicken.

Die wiederholte Redeeinleitung (siehe Exkurs 1 in c2) bedeutet eine stärkere persönliche Beteiligung des sprechers. Hier stellt Gott sich selbst vor. Damit erfährt Mose endlich, wer ihn bisher angesprochen hat. Brennender Busch, Anruf mit Namen und die beiden Befehle werden für Mose nun als zeichen Gottes verständlich. Dem entspricht auch seine doppelte Reaktion: Furcht läßt ihn sein Gesicht verbergen. Der Erzähler dreht jedoch deren Reihenfolge um. Was zeitlich später kommt, das Verbergen des Gesichtes, wird (im Narrativ) zuerst berichtet. Die auslösende Furcht dagegen kommt in der Erzählung erst an zweiter stelle. Die Erzählbewegung wird so unterbrochen; das ermöglicht, den stativ N?? zu verwenden, der in seiner Aussage dem Partizip sehr nahe

41 Nach W.FuSS, Redaktion 29, wäre "der umständlich erläuternde Relativsatz ... zu entfernen". $\mathrm{R}^{\mathrm{Je}}$ zeige eine Vorliebe für solche Relativsätze mit Partizip. - P.WEIMAR, Berufung 233-234, möchte im zweiten Befehl und dessen Begründung die jehowistische Redaktion sehen (während die Aufforderung, sich nicht zu nahen, der Dornstrauchgeschichte zuzuordnen sei). 
kommt. Diese Furcht Moses davor, Gott anzublicken, ist nicht nur Sache eines Augenblicks, sondern hält an ${ }^{42}$.

Die Selbstvorstellung Gottes ist unter zwei Gesichtspunkten unüblich:

a) Sie besteht aus einer Kombination von Gottesbezeichnungen. Gott selbst verbindet die Benennung "Gott deines Vaters" mit der Formel "Gott Abrahams, Gott Isaaks und Gott Jakobs" Letztere Formel bringt die gegen Ende der Genesis und in Ex ${ }_{4}$ spürbar werdende Tendenz zur zusammenfassung der Patriarchen ${ }^{45}$ zum AbschluB.

42 Umso mehr, als es bis 4,3 die letzte vom Erzähler berichtete Handlung auBerhalb des Redens ist.

43 Die seltene Formel wird zuvor in Gen 46,3; $(49,25 ;)$ 50,17 gebraucht. - Die Vorschläge von H.G.MAY, God 103, und N. WYATT, Development 439, wollen lesen "I am El your father", müssen jedoch mit Textänderungen rechnen.

44 Diese Formel begegnet so innerhalb der Bibel nur in unserer Erzählung. Siehe P.WEIMAR, Berufung 341-342 (mit Anm.20). - Weitere Vorkommen, in denen jedoch Jakob durch Israel ersetzt

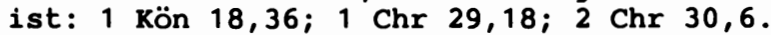

Die Formel kommt jedoch nicht unvorbereitet. Im Lauf der Genesis wird immer wieder auf den Gott der Patriarchen verwiesen. Folgende Stellen zeichnen die Entwicklung: Gen 24,12 "Jahwe, Gott meines Herrn Abraham"; 26,24 "Ich bin der Gott Abrahams, deines Vaters"; 28,13 "Ich bin Jahwe, der Gott Abrahams, deines (GroB-) Vaters und der Gott Isaaks"; 31,42 "der Gott meines Vaters, der Gott Abrahams und der Schrecken Isaaks"; $(31,53$ "der Gott Abrahams und der Gott Nachors", mit verb im Plural!); 32,10 "Gott meines (GrOB-) Vaters Abraham und Gott meines Vaters Isaak, Jahwe, der ..."; 43,23 "euer Gott und der Gott eurer väter"; 46,1 "dem Gott seines Vaters Isaak"; 46,3 "Ich bin der El, der Gott deines Vaters"; 48,15 "der Gott, vor dem meine väter gewandelt sind, Abraham und Isaak, der Gott, der mich (=Jakob) hütete"; 49,25 "vom El deines Vaters"; 50,17 "Knechte des Gottes deines Vaters".

Auch die drei Namen Abraham, Isaak und Jakob finden sich zuvor schon in Gen 50,24 und Ex 2,24.

45 Um dazu nur die drei wichtigsten Stellen aus der vorigen Anmerkung zu erwähnen: - In Gen 48,15 spricht Jakob vom Gott, vor dem sein Vater Abraham und Isaak gewandelt sind, und der ihn gehütet hat. - Gen 50,24 nennt zum ersten Mal alle drei Patriarchen in einer Konstruktion im zusammenhang mit dem Land, das Gott ihnen versprochen hat. - Ex 2,24 führt diese Linie weiter, indem es die drei Patriarchen im zusammenhang mit Gottes Bund mit ihnen nennt. Gerade die letzten beiden stellen setzen voraus, das es derselbe Gott ist, der allen dreien im Schwur der Landgabe und im Bund begegnet ist, und bereiten so (zusammen mit anderen stellen wie z.B. Gen 28,13 ) die zusammenfassung in Ex 3,6 vor, das es derselbe Gott ist, der sich in der Geschichte immer wieder gezeigt hat und der jetzt dem Mose erscheint. 
Gottes Selbstvorstellung enthält einige weitere Aspekte: - Einmal wird damit die Gesprächssituation für Mose geklärt. Die Identität der beiden Gesprächspartner ist nun festgelegt.

- zum zweiten besteht die "Selbstdefinition" Gottes im Aufzeigen seiner Beziehungen. Als "Gott deines Vaters" steht er in Beziehung zu Moses Vater und dadurch auch zu Mose selbst. Diese direkte Beziehung zu Mose wird jener zu den Patriarchen vorangestellt, obwohl sie zeitlich später einzureihen wäre. Die Beziehung zu Abraham, Isaak und Jakob zeigt seine konstante Treue durch die Generationen $^{46}$.

- Auch die sprachliche Ausgestaltung zeigt Konstanz im Wandel: Die ersten sechs wörter der Selbstvorstellung beginnen alle mit Alef ${ }^{47}$. Diesem gleichbleibenden Anlaut folgt jeweils ein Vokal, der bei diesen ersten sechs wörtern immer zwischen a und ä wechselt.

- Die Wiederholung von אלהים vor allen Patriarchen, die sich im Blick auf 3,16 als nicht notwendig erweist, führt zur Häufung dieses Wortes: Gottes Präsenz ist hier auch sprachlich sehr stark.

b) Der Selbstvorstellung Gottes folgt normalerweise weiteres Reden Gottes. Hier aber wird zuerst die Reaktion des Mose berichtet, die so herausgehoben erscheint. Das Verbergen des Gesichtes

46 M.GREENBERG, Understanding 73.

47 Zwei Gründe lassen die Alliteration als beabsichtigt erscheinen. 1) Im Vergleich mit 3,16 wird deutlich, das "Gott" vor den Eigennamen Isaak und Jakob nicht wiederholt zu werden brauchte. Durch die Wiederholung verlängert sich die zahl der gleich anlautenden Worte. 2) Normalerweise werden Aufzählungen im Hebräischen syndetisch miteinander verbunden (P.JOÜON, Grammaire $\$ 177$ o: "Généralement on met le waw devant chaque nom". Als Beispiel für syndetische verbindung in unserem Text siehe die völkerliste $3,8.17$ ). Deswegen würde vor pry" "Gott Isaaks" ein Waw erwartet, das denn auch von einigen Manuskripten, dem Samaritanus und der Septuaginta geboten wird (vgl. die textkritische Anm.b der BHS zu Ex 3,6, und ähnlich bei 3,15 und 4,5). Der asyndetische AnschluB erhöht die zahl der Alliterationen von vier auf fünf, bzw. von fünf auf sechs (bei 3,6$)$.

Alef ist zwar der schwächste Konsonant des hebräischen Alphabets. Doch ist auffällig, das die meisten Alliterationen in unserem Text mit diesem ersten Buchstaben des Alphabets beginnen (gleich 6x: 3,2.6.14.15.16; 4,5). Die Schwäche des Konsonanten führt zum Hervortreten der Anlautvokale. In 3,6 ergibt sich die Folge: $a-\ddot{a}-a-\ddot{a}-a-\ddot{a} ;$ in 3,14: $\ddot{a}-a-a ̈$. Auf Alliteration mit Alef macht auch C.CONROY, Absalom 116, aufmerksam. Er schreibt davon: "... seemingly a favourite usage by the narrator". 
kommt nur noch eimal bei einer Gotteserscheinung vor ${ }^{48}$. Wie es Mose getan hat, bleibt offen. Dafür wird uns die Begründung gegeben: "weil er sich fürchtete". Furcht wird hier am Anfang einer Gotteserscheinung oder Berufung erwähnt, während sie sonst meist am Ende komnt, dann, wenn die Menschen Gott als Gott erkennen". Mose nimmt bereits anfangs die Haltung ein, die sonst erst als Ergebnis der Gottesbegegnung entsteht.

"Gott anzublicken" ist singulär im AT. Sonst findet sich eine ähnliche stelle mit נבט Hi noch einmal in Num 12,8, wo Jahwe von Mose sagt: "und das Aussehen, und nicht in Rätseln, und die Gestalt Jahwes erblickte er" ${ }^{50}$. Sollte tatsächlich Num 12 mit unserer stelle zu verbinden sein, würde das voraussetzen, daB Mose Gott bereits angeblickt hat - was insofern möglich ist, als v6b auch als Furcht vor weiterem Anblicken interpretiert werden $\operatorname{kann}^{51}$.

Das Wortspiel ראי - "sehen - fürchten" ist in der Bibel beliebt $^{52}$. Hier unterstreicht es eine Entwicklung, die von einem Mose, der eigens abweicht um zu sehen (v3), zu einem Mose führt, der sein Gesicht verbirgt, um nicht zu sehen. Ein wandel hat begonnen.

\section{Rückblick auf die Inszenierung}

Die Erzählung verwendet mehrere raffinierte sprachliche Ausdrucksmöglichkeiten. Hier sollen nur die allerwichtigsten

48 Nur einmal wird gesagt, wie jemand sein Gesicht verbirgt: In 1 Kön 19,13 verhüllt (לו') Elia es mit dem Mantel.

G.del OLMO LETE, Vocación 69, versteht unsere stelle (wie LXX) als "abwenden", indem er die Wurzel

49 Gen 28,$17 ; \mathrm{Ri} 6,23 ; 13,22$.

50 Die Verwendung von מראה $(2 x)$ in von verbinden überdies mit unserer stelle. Ex 33-34 verwendet dagegen

51 B.JACOB, Mose 20, meint jedoch, Mose habe Gott nicht gesehen, sondern sofort die Augen niedergeschlagen, als er ihn hörte.

52 Siehe c2 Anm.69 und die These von B.COSTACURTA, La paura nell'AT (AnBib), deren Veröffentlichung demnächst zu erwarten ist. 
hervorgehoben werden, die auch für die weiteren Bilder nachweisbar sind.

- In v2a.2b.4a begegnen wir verschiedenen Blickpunkten. Aus der Sicht des Erzählers, Moses und Gottes können wir nacheinander dasselbe Geschehen erfassen ${ }^{53}$.

- Dieser Unterschied im Wissen wird in der doppelten Benennung Gottes in v4 (Jahwe und Gott) weiter ausgebaut und in v6 mit der Selbstvorstellung Gottes vor Mose etwas abgebaut ${ }^{54}$.

- In unserem Text sind mehrfache Doppelungen auffällig: je zweimal ראה "sehen" in v2-4; vפר in verschiedenem Sinn in v2-3; Mose in v4; Redeeinleitungen in v5-6; zwei Benennungen Gottes in v6; evtl. auch die Angaben $z u$ Jitro und zum ort in $v 1$.

- Schlieblich ist das schlüsselwort des semantischen Feldes (ראוד ( $^{55}$ eng mit dem verbunden, was der Text beim Hörer/Leser erreichen will: Er soll sehen. Ortsangaben, Feuer, Busch, Bewegungen, Sandalen ... malen die Szene reichhaltig aus; dabei weisen והנה, die ${ }_{56}$ artizipien und der stativ auf besonders beachtenswerte Punkte hin 56 .

Exkurs 3: Epiphanie- und Berufungselemente in Ex 3,1-6

Wir haben unter 2.1.2 und in der Besprechung der einzelnen Verse von Ex 3,1-6 schon gesehen, daB manche Elemente unserer Erzählung auch in anderen Berufungs- oder Epiphanieberichten

53 J.MAGONET, Bush 305-306, und A.BERLIN, poetics 66-67.

54 J.MAGONET, Bush 306-307, spricht von "device of the ignorance of Mose".

55 K.GOUDERS, Berufung 172-173, arbeitet "sehen" als das charakteristische Verb beim visionsbestimmten Typus der prophetischen Berufungsberichte heraus.

56 Die Ausmalung der Szene hat einen inneren zusammenhang mit ihrem Inhalt. Vgl. dazu E.LÄMMERT, Bauformen 91: "Überaus häufig ist die Korrelation von Landschaftsbildern, von Sonnenschein oder Gewitterausmalung usw. zur Deutung oder Kontrastierung der Vorgangsstimmung wie auch zur Förderung des Vorgangs". In der dazugehörigen Anm.41a spricht er sogar ausdrücklich von "feurigen Zeichen" (allerdings im Zusammenhang mit Schauerromanen; er stützt sich dabei auf H.Garte). 
(hinfort $B E B)^{57}$ verwendet werden. Diesen Beziehungen $z u$ anderen Texten soll hier mehr nachgegangen werden.

I) "Und Mose hütete" beschreibt die gewöhnliche Tätigkeit des Mose, seinen Alltag. Selten beginnen BEB im AT mit solchen Elementen (am nächsten kommen Ri 6,11; 1 Kön 19,19), im NT jedoch oft (z.B. die Berufung der beiden Apostelpaare Mk 1,16-20 oder die des 2öllners Levi Mk 2,13-17). Inhaltlich steht (neben den Patriarchenerzählungen, dort aber nicht in BEB) die Berufung Davids in 1 Sam 16 am nächsten, von dem auch gesagt wird (v11), er hüte Schafe.

II) "und er führte an den Rand ..." Inmitten der gewohnten Tätigkeit geschieht etwas Besonderes. AuBergewöhnliches Tun findet sich am Beginn von BEB häufig (Gen 16,6 "fliehen", Gen 21,14 "irren", Gen 22,9 "den Sohn binden"; Gen 26,1; 28,11 "die Heimat verlassen"); das Ungewohnte erweist sich so als jene situation, in der Gott sich bevorzugt zeigt.

III) "an den Rand der Steppe, ... zum Gottesberg (, dem) Horeb". Ortsangaben finden sich in den allermeisten BEB, und zwar sogar mehrfach wie hier: Gen 12,$6 ; 16,7 ; 21,14-16 ; 28,11$. Die einzige andere stelle, die Gottesberg und Horeb miteinander nennt, ist 1 kön 19,8. Sie gibt den Endpunkt der Flucht des Elia an.

IV) "Und es erschien Jahwes Bote". ראה Ni wird für Gott ca. $45 \times$ verwendet $^{58}$. Dabei ist festzuhalten, daB es in keinem anderen

57 Hier werden zum Vergleich folgende anderen Texte herangezogen:

a) Berichte von Berufungen im AT, wobei Berufung in einem weiten Sinn gefast wird und $z$.B. auch Gen 12 und 1 Sam 16 dazugezählt werden.

b) Schilderungen von Erscheinungen Gottes oder seines Boten. Dabei wird die prinzipielle Unterscheidung von C.WESTERMANN, Lob und Klage 73 (Theophanie = Gott erscheint, um sich zu offenbaren; Epiphanie = Gott erscheint, um seinem Volk zu helfen), zwar aufgenommen, doch in einem weiten sinn verwendet, insofern statt Gottes auch sein Bote erscheinen kann, statt des Volkes auch einzelne betroffen sein können und die "Hilfe" z.B. auch in der bestärkenden Wirkung einer solchen offenbarung bestehen kann.

Das Schwergewicht liegt auf den Texten aus der Gen, bei denen auch die Bindung Isaaks (Gen 22) berücksichtigt ist, weil sie nachträglich ( $14 \mathrm{~b}$ ) als Erscheinen (האר Ni) Jahwes bezeichnet wird. Zu den Stellen aus der Gen treten Jos 5 und 1 Kön 19 wegen ihrer engen sprachlichen Beziehungen mit Ex 3.

Jörg JEREMIAS, Theophanie, versteht in seiner grundlegenden studie unter Theophanie das mit dem Aufruhr der Natur verbundene Kommen Jahwes. Berichte von solchen Erscheinungen Gottes sind in poetischen Texten zu finden. Die einzige mit unserer Untersuchung gemeinsame stelle ist 1 Kön 19. 
Text so oft auftritt wie hier ${ }_{60}^{59}$. Wichtig ist, daB damit nie die Theophanie im Kult gemeint ist.

Auch der Bote (Jahwes) ist ein häufig vertretenes Element in BEB. Er kommt mehrfach vor in Gen 16; 22; Num 22; Ri 6; 13. Mit den letzteren beiden stellen besteht insofern eine besonders enge Verbindung, als nur sie dieselbe Kombination von האר Ni und Jahwes Boten (wie in Ex 3,2) aufweisen: Ri 6,12; 13,3. Die Berufung Gideons, die Ankündigung der Geburt Samsons und die Berufung des Mose stehen so einander nahe ${ }^{61}$.

v) "in einer Feuersflamme": Nicht das Feuer, wohl aber die Flamme ist in BEB selten. Während die weibliche Form להבה hauptsächlich prophetischem Sprachgebrauch zuzuschreiben ist ${ }^{62}$ und sonst in BEB nicht vorkommt, findet sich die männliche Form להב zweimal in $\mathrm{Ri}$ 13,20, steht dort allerdings am Ende der Erscheinung des Boten vor Manoach und seiner Frau.

vI) "mitten aus einem Dornbusch": Siehe dazu den Aufsatz von M.A.Beek, der Ex 3 aufgrund der Erwähnung des Dornbusches mit Gen 21 und 1 Kön 19 verbindet.

VII) "und er sah": Das zur Einführung der Doppelperspektive wichtige Wahrnehmen des Menschen findet sich noch zweimal am Beginn einer Erscheinung: Gen 18,2 und Jos 5,13. Beide Male geht "und er erhob die Augen" voraus. Die beiden Richterstellen 6, 22 und 13,22 sowie Gen 22,13 sprechen vom Sehen des Menschen am Ende.

VIII) Das paradoxe Phänomen des brennenden und doch nicht verbrennenden Dornbusches: Es scheint in bewuBter Absetzung von dem sonst oft gebrauchten Ausdruck אכלו "verzehrendes Feuer", der häufig von Gott ausgesagt wird, zu stehen. Der Ausdruck hier verneint den verzehrenden Aspekt des Feuers und bleibt dennoch

59 Von Ex 3,2 bis 4,5 zählen wir vier Vorkommen; dann folgt Ri 13,3-21 mit drei Vorkommen.

60 R.RENDTORFF, Offenbarung 24.

61 Die großen Ähnlichkeiten zwischen Ex 3-4, Ri 6 und 13 wurden von A.BESTERS, Fils 328, gesehen. Er arbeitet an Gemeinsamkeiten heraus: Bote Jahwes, der von einem geheimnisvollen Feuer begleitet ist; der zweck ist, einen Menschen aus der Mitte des Volkes herauszugreifen, der es aus der fremden Bedrückung (durch Ägypter, Midianiter, Philister) erretten soll; die Einwände enthalten "bitte mein Herr"; auch spielt der göttliche Name bzw. seine Identität eine große Rolle.

6212 von 17 Vorkommen. 
auf seinem Brennen bestehen, etwas, was auf natürliche Weise nicht möglich ist. Das Paradox dieses Busches ist einzigartig in der Bibel. Das ihm am nächsten kommende Phänomen, das einen ähnlichen widerspruch enthält, scheint mir die Erzählung von der Wolle auf der Tenne in Ri 6,36-40 zu sein. Doch sind die Unterschiede groB: Gideon erbittet dieses zeichen; es kommt nachher und ist überdies von der eigentlichen Berufung getrennt. Das zeichen dient der göttlichen Bestätigung dessen, daB Gideon retten wird.

IX) "ich will abweichen": Ein zugehen auf Gott findet sonst nur in Gen 18,2 statt, wo Abraham sogar auf die Männer zuläuft. Gerade der umgekehrte zug findet sich in Num 22,23; dort biegt die Eselin, die Jahwes Boten mit dem Schwert stehen sieht, vom Weg $a b$ und vermeidet damit die Begegnung.

X) "um zu sehen" scheint sonst nie in BEB vorzukommen. Das Gegenteil findet sich in Gen 21,16, wo Hagar nicht den Tod ihres Sohnes mitansehen will.

XI) "großartige Erscheinung": Diese Verbindung des 103x vorkommenden מראה mit גרל (sonst nur noch in Jos 22,10: (2). Eine Verbindung zu Ez 1, wo מרול למראה $14 x(1,5$. 13.14.16.26-28, meist mehrfach) vorkommt, ist verlockend, zumal sich auch andere in Ex 3 verwendete Ausdrücke finden (מחר "mitten aus" Ez 1,4-5; איט "Feuer" Ez 1,4.13.27; בער "brennen" Ez $1,13 ; . .$.$) . Doch ist מראה ohne Ausnahme entweder mit Suffix oder$ mit nachfolgendem Nomen rectum verbunden, oft ist auch כ" כie" vorangestellt. Während von Mose die Erscheinung zunächst als solche (in ihrem Eigenwert) aufgefaBt wird, ist מראה in der vision Ezechiels nur das Aussehen von etwas und verweist damit über die erscheinende Gestalt hinaus auf das Eigentliche.

XII) "Warum ...?" Fragen zu Beginn von BEB sind selten. Als Antwort auf eine Anrede hin finden sie sich in Gen 15,2; $R i$, 13.15 (und auf eine bereits ergangene Erscheinung hin in $\mathrm{Ri}$ 13,11-12). Hier aber ist die Frage nicht Anrede an jemand, sondern Selbstgespräch. Ein solches ist in BEB nur noch einmal gegen Ende zu finden: Gen 17,17.

XIII) "Und Jahwe sah". Von einem Wahrnehmen Gottes zu Beginn von BEB wird sonst nur in Gen 21,17 gesprochen, doch heiBt es dort "und Gott hörte". Von Gottes Sehen wird zweimal am Ende von Epiphanien gesprochen: Gen 16,13 und 22,14. Hagar und Abraham benennen auf diese Weise die erscheinende Person bzw. den Berg der Erscheinung. 
XIV) Wechsel in der Gottesbezeichnung, in unserem Fall hier gleich doppelt: von Jahwes Boten zu Jahwe, und von Jahwe zu Gott. Entgegen dem, was meist vermutet wird, ist ein solcher Wechsel geradezu ein typischer zug in BEB. Meist beginnt Jahwes Bote die Erscheinung; im Lauf der Erzählung wechselt die Benennung zu Jahwe (so in Gen 16,9.13; 22,11.14; Ex 3,2.4; Num 22,22.28; Ri $6,11.14$ und vielleicht auch $\mathrm{Ri} 13,3.8)$.

Auch das Vorkommen von Gottes Boten zeigt Wechsel in der Benennung: Er kann Gott (Gen 21,17; 48,15.16[nur 7לאל]), Jahwe (Gen 28,12-13; Ex 13,21 mit 14,19), El (Gen 31,11.13) und Jahwes Boten ( $\operatorname{Ri} 6,20.21 ; 13,3.9)$ repräsentieren.

Erzählungen wie Gen 21, Num 22, Ri 13 und 1 Kön 19 lassen dabei eher an eine echte Botenfunktion denken und damit eine stärkere Trennung zwischen Boten und Gott als möglich erscheinen. Doch ist die Gestalt des Boten nicht eigenständig; er ist die Weise, wie Gott begegnet ${ }^{63}$, und identifiziert sich mit seinem Auftraggeber. Das wird deutlich in Texten wie Gen 31,13, wo Gottes Bote sagt: "Ich bin der El von Bethel". Auch Ex 23,21 spricht für diese enge Beziehung von Bote und Gott, wenn Jahwe von ihm sagt: "Mein Name ist in ihm."

Auch Gott und Jahwe sind neben Ex 3,4 an zwei stellen eng miteinander verbunden. Gen 28,20-21 heiBt es: "Wenn Gott mit mir sein wird ..., so wird Jahwe mir Gott sein". Und in Ri 13,23 antwortet die Frau des Manoach auf dessen bestürzte Feststellung im Vers zuvor ("Sicherlich müssen wir sterben, denn wir haben Gott gesehen"): "Wenn es Jahwe gefallen hätte, uns zu töten ..."

Das Auftreten des Boten und der Wechsel in der Gottesbezeichnung bringt eine schillernde Färbung in die BEB. Der in ihnen sich zeigende Gott ist mit menschlichen Mitteln (und auch mit der Sprache) nicht eindeutig erfabbar. Die Fülle der oben genannten Beispiele weist den Wechsel in der Gottesbezeichnung als einen charakteristischen zug von BEB aus.

XV) "und er rief": Als Bezeichnung einer Handlung, durch die Jahwe Kontakt herstellt, hat $x$ im Pentateuch mit ${ }_{6}$ Ausnahme von Gen 3,9 und Num 12,5 ausschlieblich Mose zum objekt ${ }^{64}$. Wegen

63 D.N.FREEDMAN, B.E.WILLOUGHBY, מלאך 900.

64 C.J.LABUSCHAGNE, אר 673-674. Derselbe (in: Wege 154) glaubt, in ארp? "und er rief" als Einleitungsformel zu Gottesreden ein Gliederungselement für den Pentateuch gefunden zu haben, das Ex 1-18; 19-40; Lev 1 - Num 10; Num 11-36 in je sieben Gruppen zu je sieben solchen Formeln teilt. 
dieser Besonderheit des Pentateuch finden wir $x$ selten, nämlich nur noch dreimal. Dort aber ruft Gottes bzw. Jahwes Bote (Gen $21,17 ; 22,11,15)$. Sonst findet sich $\mathrm{k}$ im Sinn des Anrufens nur noch in 1 Sam $3,6.8^{65}$.

XVI) Eine Ortsbestimmung, wie hier "mitten aus dem Dornbusch", ist für das Rufen üblich. Gen 21-22 nennen dreimal "vom Himmel her"; auch die vier anderen auf Mose zu beziehenden Stellen (auBer Ex 3,4 noch Ex 19,3.20; 24,16 und Lev 1,1) geben jeweils einen ort an.

XVII) "Mose, Mosel": Einfacher Namensanruf findet sich noch z.B. in Gen 21,$17 ; 22,1 ; 31,11$. Die offenbar sehr geprägte Verwendung des doppelten Namensanrufs (siehe Exkurs 2 ) verbindet mit Gen 22; 46 und 1 sam 3.

XVIII) הנני "siehe mich", Gott gegenüber als Antwort gebraucht, verbindet ebenfalls mit den zuletzt genannten drei stellen.

XIX) "Nähere dich nicht!": Das verbot nahezukommen ist am ehesten mit der Sinaitheophanie (Ex 19,12-13; dort aber נגו zu verbinden.

xx) "Zieh deine Sandalen aus!" hat eine Parallele in Jos 5,15 (siehe dazu die Analyse von Ex 3,5).

XXI) "das Gebiet, auf dem du stehst": Das darin verwendete מקו findet sich in vielen Epiphanieschilderungen.

XXII) "heiliger Boden" ist singulär in BEB. Siehe dazu die Analyse von Ex 3,5.

XXIII) Die wiederholte Redeeinleitung in v5-6 ist für Gotteserscheinungen recht häufig: Gen $15,2-3 ; 16,9-11 ; 17,3.9 .15$; mit kurzem Einschreiten des Erzählers dazwischen Gen 17,1.3 und 35,10-11. Siehe auch den Exkurs 1 .

XXIV) Gottes Selbstvorstellung steht am Beginn vieler Epiphanien: Gen 17,$1 ; 26,24 ; 46,3 \ldots$

XXV) Das Verbergen des Gesichtes findet sich sonst nur noch in der Gottesbegegnung des Elia in 1 Kön 19,13.

XXVI) "er fürchtete sich": Furcht ist in einigen BEB am Ende erkennbar: Gen 28,17; Ri 6,22; 13,22; dagegen in Jes 6,5 und Jer 1,6 schon am Anfang (die letztgenannten vier stellen verwenden aber nicht ). Doch wird ירא Meist in der Aufforderung "Fürchte dich nicht!" verwendet, z.B. Gen 21,17 ; Ri 6,23.

65 Die Gestalten von Mose und Samuel werden so aneinander angeglichen. Vgl. dagegen die Verwendung von $k$ p in der Berufung des Jesaja, wo die Serafim das dreifache "Heilig" ertönen lassen. 
XXVII) "Gott anzublicken": wie bereits in der Analyse von Ex 3,6 gesehen, ist diese Verbindung mit נבט singulär. Evtl. besteht eine Beziehung zu 1 Sam 16,7, wo Samuel nicht auf das Aussehen des Erstgeborenen Isais blicken soll.

Die Fülle der hier aufgelisteten Elemente mag auf den ersten Blick unübersichtlich erscheinen. Sicher wäre auch jedes einzelne Element einer wesentlich ausführlicheren Untersuchung und Darstellung würdig gewesen, die aber im Rahmen dieser Arbeit nicht geleistet werden kann.

Dieser Exkurs hatte mehrere ziele: a) zum einen, bei den einzelnen Elementen hervortreten zu lassen, wie weit sie "normale" (also auch sonst einigermaßen häufig anzutreffende) Elemente in BEB sind. Ex 3,1-6 erscheint vielfach mit solchen typischen Elementen ausgestattet $\left(z_{. b_{6}} I I\right.$, III, XIV, XVI, XXI, XXIII, XXIV und Teile anderer Elemente ${ }^{66}$ ). Dabei ist auffällig, das unser Text den Gotteserscheinungen der Genesis sehr nahe steht, während die Beziehungen dieser Einleitung zu den großen Prophetenberufungen (Jes, Jer, Ez) minimal sind: XI, XXVI. Ex 3,1-6 enthält viele enge inhaltliche und vokabularische zusammenhänge mit Epiphanieschilderungen der Genesis.

b) zum anderen heben sich durch die Herausarbeitung der typischen züge singuläre Ausdrücke ab: $V$, VIII, IX, X, XI, XII, XIX, XXII, XXVII. Sie betreffen besonders das Phänomen des Feuers und die Reaktion des Mose darauf. Daneben erscheinen einige der oben erwähnten typischen Elemente hier in besonderer Ausgestaltung (2.B. II, XXIV). Ex 3,1-6 erscheint so als eine sehr eigenständige und eigenwillig gestaltete Einleitung eines Berufungsberichts.

c) Schlieblich ist wohl das wichtigste Ergebnis dieser Untersuchung, daB einige Elemente mit ganz wenigen anderen Texten

66 Diese wie die folgenden Listen sind mit den unter den jeweiligen Paragraphen gemachten Präzisierungen zu nehmen. oft ist ein Element nicht wörtlich, aber dem Sinn nach anderswo zu finden. 
verbinden $^{67}$ : Gen 18,1-2 (VII, IX); Gen 21 (VI, XVI); Gen 22 (XIII, XV, XVII, XVIII); Gen 46 (XVII, XVIII); Jos 5,13-15 (VII, $X X, X X I I) ; \operatorname{Ri} 6$ (IV, VIII); Ri 13 (IV, V); 1 Sam 3 (XV, XVII, XVIII); 1 Sam 16 (I, XXVII) und 1 Kön 19 (III, VI, XXV). Die Gotteserscheinungen an Abraham, Hagar, Jakob, Josua, die Eltern Samsons, Elia und die "Berufungen" Gideons, Samuels und Davids enthalten eine Reihe von ganz charakteristischen zügen, die allesamt in dieser Eingangsszene der Berufung des Mose zusammenflieBen. Wie ist das zu deuten?

Aufgrund der literarischen Art der Untersuchung ist bezüglich historischer Schlüsse Vorsicht geboten. Die teils exklusiven und sprachlich engen Beziehungen $z u$ so vielen anderen Texten scheinen mir zeichen literarischer Abhängigkeit zu sein - wobei offenbleibt, in welche Richtung. Auch die zusätzliche Beobachtung, daB manche der gemeinsamen Elemente hier in Ex 3 sehr knapp ausgeführt sind, während sie in den anderen Texten breiter dargestellt werden und damit dort leichter zu verstehen sind, kann nicht viel weiter helfen. Denn es könnte sowohl die breitere Ausgestaltung wie die knappere zusammenfassung später sein. Doch erlauben die engen Beziehungen zu den übrigen BEB einen anderen SchluB: Die Berufung des Mose kann bereits in ihrer Eingangsszene als Konzentration der an groBe Gestalten der Frühzeit Israels ergangenen Gottesoffenbarungen verstanden werden; in Mose verdichtet sich diese Linie der offenbarung Gottes. Das gegenseitige zugehen von Jahwe und Mose zeichnet in der Fülle der Elemente und in der Art ihres Ablaufs so etwas wie ein Ideal oder Modell für Gottesbegegnung.

(Ende des Exkurses)

\subsection{Ex 3,7-12: Gottes Anliegen}

Der zusammenhang von erstem und zweitem Bild ist vor allem durch das weiterlaufende Schlüsselwort ראה (siehe 2.2.1) gegeben.

67 Zum Teil in exklusiver Weise, sodaB die Verbindung nur mit diesem einen Text besteht.

68 Konzentration wurde hier an Stelle von "Zusammenfassung" genommen (um deren gewöhnliche konnotation "geschichtlich später" zu vermeiden). Konzentration soll den besonderen Charakter von Ex 3,1-6 zum Ausdruck bringen, das auf knappem Raum viele sonst breiter ausgeführte Elemente enthält. 
Nach der Inszenierung, die mit Ort, Personen und Umständen des Geschehens vertraut macht, ist der Leser nun frei für das eigentliche Gespräch. Das dem Auftreten Gottes zugrundeliegende Anliegen wird nach zwei Seiten entfaltet. Die eine Seite schildert die innere Motivation Gottes, sein Wahrnehmen der Not seines Volkes (v7-9). Die Weise, wie dieser Not abzuhelfen ist, macht die andere Seite aus; sie besteht in der Sendung des Mose (v10-12). Beide Teile hängen durch Vokabular und durch das doppelte רפתה (in v910) eng zusammen.

Ex 3,7: Und Jahwe sagte: "Sicherlich habe ich das Elend meines Volkes gesehen, das in Ägypten ist, / und ihr Schreien habe ich gehört, vor seinen Antreibern; ja, ich kenne seine Schmerzen."

Die Redeeinleitung zu Beginn markiert den nächsten Erzählschritt. Die Verwendung von יהוה bestärkt den Leser nochmals (nach $v 4$ ) in seinem wissen, daB dieser Gott Jahwe ist.

Gottes Wahrnehmen ist mehrfach betont. Der absolute Infinitiv von ראה dient der Hervorhebung und verlangt die besondere Aufmerksamkeit des Hörers . Auch ist das Sehen Gottes dadurch hervorgehoben, daB es am Anfang steht. Weiters scheint die ver-

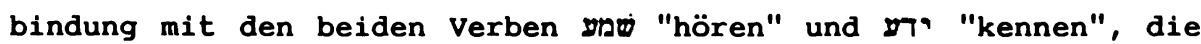
an Ex 2,24-25 anknüpfen, für Vollständigkeit und Abgeschlossenheit dieser Wahrnehmung Gottes zu sprechen ${ }^{70}$.

Das zuerst genannte Objekt der Wahrnehmung Gottes ist "die Not meines Volkes" ${ }^{71}$. Diese Not wird im selben Vers weiter ausge-

69 T.MURAOKA, Emphatic 92 und 166.

70 Eine solche Deutung stützt sich auch auf stilistische Elemente: 1) chiastischer Satzbau:

v7a Verb - objekt

v7ba Objekt - Verb

vib $\beta$ Verb - objekt

Die beiden entgegengesetzten Richtungen des Untersuchens ergeben zusammen vollständigkeit.

2) Einleitendes emphatisches 'כ beim dritten Glied kann als abschlieBende Zusammenfassung der Wahrnehmung verstanden werden. - Ein weiteres Argument dafür bringt das erste Wort von v8, das bereits Gottes Einschreiten zeigt und so diese Deutung bestätigt.

71 Beachte die Alliterationen: $-9-(x)-7-7$. 
führt durch ein Crescendo: "Ihr Schreien" und "seine Bedrücker" führen auf "seine Schmerzen" hin"

Die drei anderen genannten GröBen sind "mein Volk", Ägypten und die Bedrücker. Ersterer Ausdruck verdient besondere Aufmerksamkeit: Es ist das erste Mal in der Bibel, daB Gott "mein Volk" ausspricht . Dabei ist erstaunlich, daB wir nicht erfahren, wer Gottes volk ist. Der Relativsatz ${ }^{4}$ gibt $\underset{75}{75}$ eine weitere Präzisierung, läßt aber ebenso wie die Suffixe ${ }^{75}$ die Identität dieses Volkes offen. Zwei Erklärungsmöglichkeiten bieten sich an. Die eine sieht in der Wahl des Ausdrucks "mein Volk" durch Jahwe eine Betonung der persönlichen Beziehung zwischen Gott und Volk. Die andere versteht "mein Volk" als weiten Begriff, der nicht durch eine einzelne Identifikation gefüllt werden $\operatorname{kann}_{76}$ und deswegen immer offen bleibt für ein breiteres Verständnis ${ }^{76}$. Für beide Erklärungen gilt aber, daß der Ausdruck "mein Volk" vorbereitet ist durch die Erzählungen von Ex 1-2, dabei vor allem durch die Erwähnung von "das Volk der Söhne Israels" in 1,9 durch den Pharao, und $\mathrm{daB}$ an unserer stelle eine weitere klärung zu erwarten ist, wer für Gott "mein Volk" ist. Der weitere zusammenhang der folgenden Verse wird klären, wer als "mein Volk" zu verstehen ist.

Ähnlich offen wie "mein Volk" bleibt vorerst auch die Identifizierung der Bedrücker und ihre Beziehung zu Ägypten, das hier nur als Land genannt ist. Durch das auf das Volk zu beziehende

72 R.MOSIS, כאב 11: "Das mit bezeichnete Leiden ist schlechthin bedrohlich".

73 N.LOHFINK, Beobachtungen 276. - "Mein Volk" im Mund Gottes kommt im Pentateuch nur in Exodus, und zwar $16 x$ vor. Das "erste Mal" ist hier nicht zeitlich zu verstehen, in dem Sinn, daB Ex 3,7 die früheste Stelle für "mein volk" wäre, sondern meint die Wahrnehmung des Lesers, der vom Anfang der Bibel (von Gen 1 her) alles der Reihe nach liest und hier zum ersten Mal auf diesen Ausdruck stößt.

74 w.FUSS, Redaktion 38, sieht in "das in Ägypten ist" einen für den $\mathrm{R}^{\mathrm{Je}}$-stil typischen überflüssigen Relativsatz (wie in 3,5$)$.

75 Die Suffixe wechseln in der zahl. Steht das Nomen im Sg., ist das Suffix im Pl., und umgekehrt.

76 Siehe dazu die Bemerkung in Ex 12,38, daß sich viel Mischvolk den Israeliten beim Auszug anschloB. 
Suffix "seine (Bedrücker)" wird allerdings klar, daB es einen Konflikt zwischen diesen beiden Größen gibt.

- In Ex 3,7 berichtet Gott, daB er die Not einer Gruppe in Ägypten wahrgenommen hat. Diese Wahrnehmung ist abgeschlossen .

Ex 3,8 "So bin ich heruntergestiegen, um es aus der Hand der Ägypter herauszureiBen und es hinaufzuführen von diesem Land in ein gutes und weites Land, in ein Land flieBend von Milch und Honig, / in das Gebiet des Kanaaniters, Hetiters, Amoriters, Perisiters, Hiwiters und Jebusiters."

Die von Jahwe eingegangene Beziehung zu seinem Volk hat über das Wahrnehmen der Not bereits zu einer Tat geführt: "Ich bin herabgestiegen" $"$, und sie hat zwei ziele: Befreiung und Hinaufführung ins Land. ירד muB hier auf die Erscheinung vor Mose bezogen werden ; es bringt die erste Reaktion Gottes nach der wahrnehmung der Not und leitet so den Beginn des Einschreitens Got$\operatorname{tes}^{80}$ ein.

Die Präsentation Ägyptens ist gegenüber dem vorigen Vers nicht mehr so neutral. "Aus der Hand der Ägypter" setzt bereits voraus, daB Druck ausgeübt wird. Die parallel dazu stehende Bezeichnung "von diesem Land" wirkt farblos, besonders, wenn sie mit dem Bestimmungsland für das Volk verglichen wird (zweimal מן "von, aus" gegen dreimal אל "hin, zu"). Der einfachen Landes-

77 J.HALBE, Privilegrecht 78-79, spricht von "Voruntersuchung", rechnet jedoch auch noch 88 dazu.

78 F.конатA, Jahwist 25-26, sieht in der perfektischen Formulierung, daB die Befreiung bereits angefangen hat.

ירד "herabsteigen", $20 x$ in $\mathrm{Ex}$, davon $7 x$ in 19,11-25 und $8 x$ in Ex 32-34, meint meist Mose. Für Jahwe dagegen wird es in Ex $19,11.18 .20 ; 34,5$ verwendet.

\section{G.MAYER, 900-901. \\ $80 \mathrm{Vgl}$. יר in Gen 11,$5 ; 18,21$.}

Mehrere Autoren sehen in 3,7-8 den Beginn eines "Gerichts": J. PLASTARAS, Dio 58-59, stellt die beiden Schritte überprüfung (verifica) und Urteil (sentenza) fest. J.HALBE, Privilegrecht 7779, arbeitet den forensischen Aspekt von 3,7-8 heraus, setzt ihn jedoch hinter den soteriologischen. Auch nach P.BOVATI, Giustizia 298, bestehen bei עמ in Verbindung mit py die beiden Aspekte des Heils- und Gerichtshandelns. 
/Volksbezeichnung מצרים ${ }_{81}$ entspricht (durch die AuBenglieder) die Liste der sechs völker" . Und die Benennung mit "dieses Land" verschwindet geradezu vor den Attributen des ziellandes (Entsprechungen durch $(\mathrm{p})$ ): "gut und weit" 82 "flieBend von Milch und Honig" ${ }^{83}$.

Die hier zum ersten Mal das Volk selbst betreffende VerheiBung des Landes ${ }^{84}$ zeigt sich so als besonders attraktiv gestaltet, was umso deutlicher wird, wenn man die realen Größen- und Fruchtbarkeitsverhältnisse der beiden Länder vergleicht. Die Vorstellung des verheißenen Landes beginnt dabei mit einer sehr offenen Bezeichnung , nennt dann konkreter eine Eigenschaft und endet bei der Aufzählung der völker, die es bewohnen. Letzteres erlaubt eine Identifizierung, ohne den Namen des Landes zu nennen.

Ex 3,8 ist ausgespannt zwischen die Vergangenheit "ich bin heruntergestiegen" und die Absicht Gottes hinaufzuführen, die

81 Für die Listen siehe: S.FRENSDORFF, Ochlah Liste 274. Nach J.HALBE, Privilegrecht 143-146, sind die völkerlisten von 3,8.17 der Hauptgruppe IIa zuzuordnen und nicht von dtr Hand eingefügt. - N.LOHFINK, LandverheiBung 67, arbeitet heraus (allerdings zu Gen 15,19-21, wo die Liste mit 10 völkern die umfangreichste ist), daB damit der gesamte Bereich Palästinas abzudekken versucht wird. - Zur Diskussion um die historische Entwicklung der Listen siehe T.ISHIDA, Structure, besonders 463-478.

82 Die Kombination dieser beiden Adjektive zur Bezeichnung des Landes ist einmalig.

83 In Ex findet sich diese Formel noch in 3,$17 ; 13,5 ; 33,3$. "Fließend" bezeichnet dabei den überfluB, Milch und Honig sind ungefährliche, leicht verdauliche GenuBmittel selbst für unmündige Kinder (B.JACOB, Mose 23).

Die Milch kam damals von Schafen und ziegen (T.S.FRYMER, Milk 1578; O.KEEL, Orte I 113), während die Herkunft des Honigs umstritten ist. Nach den Lexika (T.S.FRYMER und L.I.RABINOWITZ, Honey 963; E.EBELING, Dattelpalme, Dattelschnaps 169) wird der Honig überwiegend aus Dattel- (evtl. auch Honig-) Sirup gewonnen. E.NEUFELD, Apiculture, dagegen hält es für undenkbar, daB es im alten Palästina keine Bienenzucht gegeben habe. Siehe dazu auch O.KEEL, Orte I 169.

\section{D.CLINES, Theme 36.}

85 J.MAGONET, Bush 307-308, interpretiert die Verschiedenheit und Umstellung der Bezeichnungen des Landes gegenüber 3,17 damit, das Gott dem Mose das Land zuerst "schmackhaft" machen muB, indem er es für ihn attraktiv beschreibt, noch bevor er seine geographische situierung nennt. 
erst in der zukunft zu realisieren ist - wie das geschehen soll, läßt der Vers offen.

Ex 3,9: "Und nun, siehe: Das Geschrei der Israeliten ist zu mir gekommen, / und ich habe auch die Bedrückung gesehen, wie die Ägypter sie unterdrücken."

Gleich durch zwei Worte weckt Gott erhöhte Aufmerksamkeit in Mose: ופתה הנה "und nun, siehe: ..." Das erste Wort läBt vermuten, daß wir in der Nähe des Endes des Redens Gottes stehen. Man erwartet eine Konsequenz, etwas Neues als abschließende Folge des bisher Gesagten (vgl. 3,18; 4,12) - die aber hier in v9 gerade nicht kommt . Das zweite Wort הנה ist uns zur Einführung der Wahrnehmung einer Person bereits in $v 2 b$ begegnet (jedoch als ורנהות); wird es in einem Dialog verwendet, so möchte der Redende den Angesprochenen in seine Wahrnehmung hineinnehmen, das dieser sie auch zu seiner macht ${ }^{87}$.

Im Kontrast $z u$ der durch die beiden Einleitungswörter geweckten Spannung steht der Inhalt dieses Verses. Er nimmt Gedanken aus 3,7 wieder auf, was durch die wiederholung von ipys und bestätigt wird. Doch sind die Unterschiede zu 3,7 bedeutungsvoll.

a) Zum ersten Mal taucht in unserer Erzählung der Ausdruck "Israeliten" bereits in der Schilderung der Not in Ex 3,7 annehmen, daB es sich um die Israeliten handeln muB, gesagt wird das aber erst

86 Sie kommt deswegen nicht, weil רתו nicht allein, sondern im zusammenhang mit seiner Wiederholung am Beginn von v10 zu sehen ist. Dabei wiederholt beim doppelten ופת (siehe oben unter 2.2.1) das erste zusammenfassend noch einmal das Gesagte, hier den Beweggrund für Gottes Handeln, nämlich seine Wahrnehmung der Not. Sie wird dadurch als auslösendes Moment betont.

87 Vgl. D.J.MCCARTHY, Uses of $w^{e} h$ inneh 342: "It is used primarily when there is something dramatic or emotionally telling". Dramatisierung und Emotionen möchten den Angesprochenen meist zur Identifizierung mit dem standpunkt des Sprechenden bewegen.

88 A.BESTERS, Fils 326-327.332, möchte diesen Ausdruck wie überhaupt die Redaktion von Ex 3,9-15 der $P$ zuschreiben. 
jetzt. ' בניטים stellt gegenüber dem Ausdruck "mein Volk" die objektive Note heraus.

b) Die Formel "das Schreien ist zu mir gekommen" 199 ist einer neuen Stufe bzw. dem AbschluB der Untersuchungsphase in Konfliktfällen zuzuordnen. Dabei ist immer Jahwe der Richter, und sein Einschreiten folgt unmittelbar.

c) Eine ganz ähnliche Konstruktion wie v9b fand sich in Ex 1,14b: "mit all ihren Arbeiten, die sie mit ihnen in Mishandlung arbeiteten". Die Doppelung der Wurzel des Nomens im Verb des Relativsatzes verstärkt und stellt auBer 2weifel: Es handelt sich hier wirklich um Bedrückung.

d) zudem führt die Formulierung des Relativsatzes etwas weiteres gegenüber $\mathbf{v 7}$ Neues ein. Zum ersten $\underset{90}{\mathrm{Mal}}$ werden ganz klar die Schuldigen genannt. Es sind die Ägypter 90 , die hier mit den Bedrückern identifiziert werden.

Die aufgezeigten Unterschiede machen deutlich, daB Ex 3,9 nicht einfach wiederholung von Früherem ist. Es bringt Präzisierungen, die teils zum Verständnis nützliche Identifizierungen enthalten, teils den rechtlichen Aspekt ${ }^{9}$ herausstreichen. Vor allem dieser rechtliche Ton ist neu; er rechtfertigt die durch die beiden Einleitungswörter erzielte erhöhte Aufmerksamkeit.

Ex 3,10 "Und nun geh! Ich will dich zum Pharao senden,/ damit du mein Volk, die Israeliten, aus Ägypten herausführst!"

89 Gen 18,21 und 1 Sam 9,16 (im Hi noch Ijob 34,28). Im ersten Fall will Gott zur Untersuchung des Falles hinuntersteigen; die Folge ist das Gericht über Sodom und Gomorra. Im zweiten Fall begründet Jahwe damit dem Samuel, daB er morgen Saul zu ihm schicken wird, und dieser (Samuel) ihn zum Nagid und Retter vor den Philistern salben soll.

P.BOVATI, Giustizia 289 (vor allem Anm.135) und 299, ordnet הע בוא ist es wohl (analog zu Ps 18,7) als Er- oder Anhörung (ascolto) $\mathrm{zu}$ interpetieren.

90 Die negative Besetzung von מצרים war bereits in v8 leicht angedeutet. Dort wäre aber auch eine übersetzung "aus der Hand Ägyptens" möglich gewesen. Zu beachten ist, daB v9 innerhalb des zweiten Bildes die einzige stelle ist, an der מצרים eindeutig die Leute, und dazu als Schuldige nennt.

91 J.HALBE, Privilegrecht 97, zu Ex 3,9-10: "In mehreren Begriffen klingt Rechtssprache an". 
Das zweite ופחה bringt endlich, was nach dem ersten erwartet worden war: die Konsequenz aus dem Wahrnehmen und Heruntersteigen Gottes. In schöner Formulierung werden dabei Imperativ und Kohortativ zusammengebunden durch eine Art Echo', wobei die beiden neu einsetzenden wörter den Beginn des nächsten semantischen Feldes markieren. Gleichzeitig präsentieren sie auch das zentrale Anliegen Gottes. Mit dem Aussprechen dieses Wunsches steht die entscheidende Frage im Raum.

Die Entsendung eines Boten durch Gott war noch nie da, sie

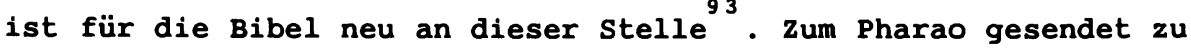
werden bedeutet für Mose, zu dem zu gehen, der ihm nach dem Leben trachtet (Ex 2,15), da er die zusatzinformation Ex 2,23 noch nicht hat - sie wird ihm erst Ex 4,19 gegeben. Auch hier entdekken wir also ein Spiel mit der (vorläufigen) Unwissenheit des Mose. Gegenüber $v 8$ wird ein anderes Verb für die Befreiungsaufgabe gebraucht: אצ $\mathrm{Hi}$ "herausführen" ${ }^{94}$. Gottes Hinaufführen geschieht durch das Herausführen des Mose. Für Mose ergeben sich durch seinen Auftrag gegensätzliche Bewegungen. In v10a soll er zum Pharao (nach Ägypten) gehen; in v10b soll er das Volk aus Ägypten herausführen. Möglicherweise ist dieser Gegensatz ein Ausdruck der Schwierigkeit seiner Sendung.

Auch bei den anderen Ausdrücken zeigen sich Veränderungen. מצרים hat nach v9 wieder neutrale Bedeutung angenommen. Es meint

92 Fליקל senden nimmt lautlich (Wiederholung von $\left.{ }^{\prime}\right)$ jenes für gehen wieder auf.

93 B.JACOB, Mose 24. של zur Sendung eines Menschen wird im Pentateuch nur für Mose verwendet ( $W . R I C H T E R$, Berufungsberichte 157). - Doch interpretiert Josef in Gen 45, 7-8 mit diesem Wort sein Verkauftwerden durch seine Brüder.

94 Für die komplexe Geschichte der Verwendung von אצי Hi für die Herausführung aus Ägypten ist H.D.PREUSS, $\mathrm{kY}$ ? 807-821, zu konsultieren. D.DAUBE, Pattern 32-33, betont die Verbindung dieses Ausdrucks mit sozialen Rechten und pflichten.

Kצ' $\mathrm{Hi}$ ist in unserer Erzählung immer mit Mose verbunden (vgl. z.B. 1 Sam 12,8, wo dagegen Mose und Aaron zugeschrieben wird, Israel aus Ägypten herausgeführt zu haben). Siehe auch L.ALONSO SCHÖKEL, Salvación 19-24.

In Anm.5 zu Ex 3,10 findet sich in der französischsprachigen Ausgabe des Raschikommentars (die Anmerkungen stammen von M.Rosenbaum und A.M.Silbermann) die Bemerkung, das die finite verbform (statt der auch möglichen Nennform) die zusicherung ausdrükke, Mose sei fähig zu dieser Aufgabe. 
nicht mehr so sehr die Schuldigen an der Bedrückung, sondern eher

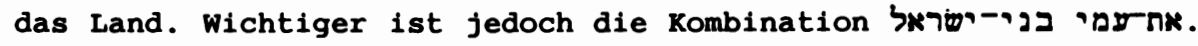
Wie schon mehrfach in unserer Erzählung finden wix auch hier eine Identifikation $^{95}$. Das Nebeneinanderstellen der beiden zuvor nur einzeln genannten Ausdrücke klärt die offene Frage nach ihrer gegenseitigen Beziehung ${ }^{96}$.

In Ex 3,10 faBt Jahwe sein Anliegen in der Sendung des Mose zusammen. Die Schwierigkeit der Sendung des Mose liegt nicht nur darin, ein Volk aus Ägypten herauszuführen, sondern daß er (nach seinem Kenntnisstand) zu jemand gehen muB, der ihn töten wollte.

Ex 3,11: Und Mose sagte zu dem Gott: "Wer bin ich, daB ich zum Pharao gehe/ und daß ich die Israeliten aus Ägypten herausführe?"

Die Redeeinleitung ist in ihrer verwendung von mit 3,1.6 kohärent. Wenn etwas von Mose auf Gott hin geschieht, wird Gott mit Artikel gebraucht.

Nach der Antwort auf den Anruf (v4) redet Mose hier wieder, zum ersten Mal länger. Die Formulierungen der beiden parallelen כ - Sätze nehmen wörtlich die Rede Gottes von v10 auf, wobei Mose sie auf sich bezieht und in die 1.P.Sg. setzt. In der genauen Übernahme durch Mose fehlen aber zwei entscheidende Ausdrücke aus dem Sprechen Gottes: פמי שלח und

Nun kann aus dem Fehlen allein nicht viel geschlossen werden, doch zeigt der weitere Erzählverlauf, das dieses Fehlen unter drei Rücksichten bezeichnend ist:

95 J.MAGONET, Bush 308.

96 A.G.van DAALEN, Plaats 34, zeigt, daB "Volk" und "Israeliten" in Ex 3,7-12 eine konzentrische Struktur ergeben:

v7 mein Volk

v9 Israeliten

v10 mein Volk, die Israeliten

v11 Israeliten

v12 Volk 
a) Beide Ausdrücke hätten den Gebrauch der 2.P.Sg. erfordert, etwa "daB du mich gesendet hast" und "dein Volk". Eine Anrede Gottes mit "du" wäre hier schon möglich gewesen. Wir werden darauf bei der Besprechung von Ex 4,10 zurückkommen. - Das Auslassen dieser beiden wörter führt dazu, daß Mose nur noch von seinem "Ich" spricht $(3 x)$.

b) של ist ein Schlüsselwort, das Moses Einstellung offenlegt. In 3,13 verwendet er es in einem Bedingungssatz, in 4,13 lehnt er so seine Entsendung ab.

c) Die Auslassung von wäre genausogut denkbar, daß Mose - wie Gott - die Israeliten als פמי "mein Volk" bezeichnete. In Ex 2,11 bewegt ihn die Sorge um "seine Brüder" (zweimal erwähnt). Offenbar identifizierte sich der junge Mose mit ihnen. Wir werden auch auf diesen Aspekt, nämlich die Beziehung zwischen Mose und den Israeliten in Ägypten, weiter achten müssen.

Die sonst genaue Aufnahme des Sprechens Gottes ist noch in einem Punkt verändert. Es geht ihr die Frage voraus: אנכי מי "Wer

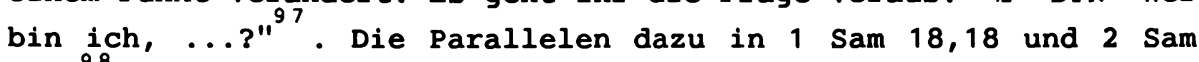
$7,18^{98}$ lassen die Antwort des Mose in dem Sinn lesen, das er sagt: "Ich bin es nicht wert, daB ..."

In Ex 3,11 begegnet Mose der Aufforderung zur Sendung mit der Erklärung seiner eigenen Unwürdigkeit. Ihre Formulierung deckt aber auch zwei kritische Punkte in der Einstellung des Mose auf.

Ex 3,12: Und er sagte: "Ich werde mit dir sein, und dies wird dir das zeichen sein, daß ich dich sende:/ Wenn du das Volk

97 Es könnte eine Verbindung zur anderen מי - Frage von Ex 2,14 bestehen. Wenn ja, würde die Infragestellung der Autorität des Mose durch den Unrecht tuenden Israeliten von Mose selbst aufgegriffen und fände in 3,12 eine Antwort durch Gott.

98 Beide Male spricht David zu einem Höhergestellten. Im ersten Fall ist es Saul, der ihm seine älteste Tochter Merab zur Frau anbietet, im zweiten Fall Jahwe, der ihm verspricht, ein Haus/eine Dynastie zu bauen. Der weitere Kontext macht klar, daB David sich dieser großzügigen Angebote nicht für würdig hält. wird so als ein Ausdruck der Demut verständlich. 
aus Ägypten herausführst, werdet ihr den Gott auf diesem Berg verehren."

Einfaches ר ואיאמר ohne weitere Angabe des Subjekts genügt für den Sprecherwechsel. Gott geht mehrfach auf den Einwand des Mose, im besonderen auf die Frage nach seinem "Ich" und die Überzeugung von seiner Unwürdigkeit, ein.

a) Die Beistandszusage Gottes "ich werde mit dir sein" 9 setzt dem Mose, der sein eigenes Ich als der Sendung unwert empfindet, Gottes Mit-ihm-Sein entgegen. Moses Sendung basiert somit nicht auf dem, was er ist, sondern darauf, daB Gott mit ihm ist $^{100}$.

b) Zusätzlich zur Beistandszusage erhält Mose ein zeichen, das diese Sendung von Gott bestätigt. Dabei ist das "Ich" Gottes (in der Linie des vorigen Punktes) durch Personalpronomen betont.

c) Mit פִ greift Gott die beiden von Mose ausgelassenen Ausdrücke auf. Nach Gottes Verständnis des an Mose ergangenen Auftrages dürfen diese Ausdrücke nicht fehlen.

d) Während Mose sich nicht getraut, Gott anzureden, gebraucht Gott viermal das Suffix der 2.P.Sg. für Mose. Beim letzten Mal ist das Suffix sogar Subjekt des Verbs.

e) Die in v11 nur angedeutete Frage einer möglichen Identifizierung Moses mit seinen Brüdern in Ägypten wird von Gott durch eine Verbform der 2.P.Pl. explizit aufgenommen. "Ihr werdet verehren" faBt Mose mit der Auszugsgruppe zusammen zu einer Einheit.

Das Verständnis dieses schwierigen Verses erfordert noch weitere klärungen. - Da ist zunächst die Frage, was mit dem zeichen gemeint ist. Unter den verschiedenen Antworten ${ }^{101}$ scheint $^{1}$

99 Zur Beistandsformel (היה עם "sein mit") siehe N.LOHFINK, Darstellung 38-40, W.RICHTER, Berufungsberichte 148-151, und A.M.BESNARD, Mystère 39. Letzterer rechnet Ex 3,12 als erstes Vorkommen der Beistandsformel, was zwar für $\pi$ הא, nicht aber für die Formel gültig ist, die sich bereits in Gen 25,3 (und ohne in Gen 28,20 ) findet.

100 J.G.JANZEN, Name 234: "who Moses is can henceforth be measured adequately only by including a reference to this God henceforth present with him".

101 Als zeichen werden gesehen:

1) der brennende Dornbusch (B.S.CHILDS, Exodus 56-60; er muB allerdings mit einer nachträglichen Vorstellung des Dornbusches in der Erzählung rechnen).

2) die zukünftige Verehrung (viele vertreter, u.a. M.GREENBERG, 
trotz aller Schwierigkeiten doch wegen des Kontextes zu bevorzugen zu sein, daB das zeichen die Verehrung Gottes auf dem Berg meint. Im Gesamt der Exoduserzählung (siehe Ex 1,17-18) wirft es die Frage auf: "Wem dienen, dem Pharao oder Gott?"103 - "Auf diesem Berg" stellt einen Rückbezug zu v1 dar. Indem diese Formulierung den Eigennamen Horeb vermeidet, erleichtert sie den Bezug zur Sinaitheophanie (Ex 19,16).

Aus den vorhin genannten Schwierigkeiten lassen sich zweierlei Folgerungen ziehen. zum einen, in der Art des zeichens, daB Gott von Mose Vertrauen verlangt: Letzten Endes kann seine Sendung nur durch ihren glücklichen Ausgang, in diesem Fall durch die gemeinsame Verehrung der Befreiten auBerhalb des Landes der Knechtschaft $^{104}$ Erfüllung finden - und damit im höchsten sinn bestätigendes zeichen sein. Zum andern läBt Gottes Sprechen in der Benennung seiner selbst etwas offen. Auch das kann in Verbindung mit diesem von Mose verlangten vertrauen gesehen werden.

Die Antwort Gottes in Ex 3,12 geht nicht nur auf den Einwand des Mose ein, sondern wirft auch noch einen weiten Blick voraus in die zukunft. Das Schauen auf Gottes Verbindung mit ihm und auf das glückliche Ende seines Auftrages sollen Mose zur Annahme seiner sendung bewegen.

\section{Rückblick auf Gottes Anliegen}

In diesem Bild konnten wir verschiedene Erzähltechniken beobachten.

Understanding 76-78; die Schwierigkeit dieser Interpretation liegt darin, daB sich das zeichen erst in der zukunft ereignen wird und deswegen von den sonst in der Bibel verwendeten zeichen sehr verschieden ist).

3) der Name von v14-15 (G.w.COATS, Moses 39 und 140 Anm. 29; es ist aber schwer zu rechtfertigen, daB sich ir über den Einwand in v13 hinweg auf den Namen beziehen soll).

4) Jahwes Taten in ̈̈gypten: v20 (N.WYATT, Development 439; er muB als ursprüngliche Textfolge v12a.20.12b annehmen).

102 A.BESTERS, Fils 332, sieht in diesem kultischen zeichen (parallel zu Gen 9 und 15) die Theologie der $P$.

103 Siehe dazu G.Auzou, Service (besonders 79-82), und M.GREENBERG, Understanding 127-128.

104 Ziel und Ausgangspunkt der Sendung entsprechen einander in bezug auf ort und auftraggebenden Gott. 
a) Immer wieder begegneten wir Ausdrücken, die für den vom Anfang der Bibel beginnenden Leser hier zum ersten Mal auftauchen. Solche Ausdrücke sind neu. Wir dürfen annehmen, daß beim ersten Auftreten eines wichtigen Wortes dieses durch den zusammenhang und seinen Gebrauch geklärt wird. Von daher ist z.B. für "mein Volk" und "senden" an unserer stelle eine Klärung zu erwarten.

b) Wir stellten sogenannte Identifizierungsprozesse fest: "Mein Volk" aus v7 wird in v10 mit den Israeliten identifiziert . Ebenso werden die in $v 7$ unbestimmt gebliebenen Antreiber in $v 9$ mit den Ägyptern gleichgestellt. - Solche Identifizierungen setzen eine doppelte Bezeichnung derselben Größe voraus und führen somit das Phänomen der Doppelung aus dem ersten Bild weiter. Dazu passen auch: absoluter Infinitiv und Satzkonstruktion in v7; Doppelung der Infinitive und der Länder in v8; zweimal לחץ in v9; doppeltes v9-10 und parallele Satzkonstruktion in v11.

c) Der Erzähler arbeitet in der Ausgestaltung des Redens Gottes offensichtlich mit einem vorläufig unwissend gelassenen Mose. Seine Entsendung zum pharao in v10 und das Sprechen von "den Gott anbeten" in v12 enthalten ihm noch Informationen vor, die der Leser bereits weiB: daß der Pharao gestorben ist und "der Gott" Jahwe ist.

d) Ein anderer interessanter zug an Mose wird enthüllt in seiner Antwort. Die Formulierung von v11 läBt gegenüber dem Auftrag v10 die zwei Schlüsselwörter של und aus. - Dem steht Gottes Vision gegenüber, der im "ihr werdet verehren" Mose und die Israeliten zusammenschlieBt.

e) Viermaliges "aus Ägypten" (dabei das erste Mal in v8 "aus der Hand/Gewalt Ägyptens") setzt eine Art Kontrapunkt: Die Israeliten und Ägypten stehen im Kontrast zueinander.

\subsection{Ex 3,13-15: Der Name des Sendenden}

Ex 3,13: Und Mose sagte zu dem Gott: "Wenn ich zu den Israeliten komme und ihnen sage: >Der Gott eurer väter hat mich zu

105 Diese Identifizierung ist mehrfach herausgehoben. Einmal, weil die Israeliten bereits im vers zuvor erwähnt wurden, zum zweiten, weil es die einzige Doppelbezeichnung (mein Volk, die Israeliten) für diese Gruppe in unserer Erzählung ist, und zum dritten, weil sie in den Mittelpunkt der oben (Anm.96) beschriebenen konzentrischen struktur zu stehen kommt. 
euch gesandt. // und sie mich fragen: >Was ist sein Name?<, was soll ich ihnen antworten?"

Der Erzähler leitet den Sprecherwechsel genauso wie in v11 ein. Neben der Redeeinleitungsformel erwähnt er sowohl das neue Subjekt des Sprechens als auch den Angesprochenen. האלחים Gott" liegt auf der Linie von v1.6.11-12: אים mit Artikel für ein Tun des Menschen auf Gott hin.

Der Inhalt des Sprechens greift nur noch in einem Wort das Vorhergehende auf. "er "er hat mich gesandt" verbindet mit v12, alle anderen wörter sind neu, ebenso wie die Thematik. Hatte in v11 Mose die Frage gestellt: "Wer bin ich ...?", so könnte man parallel dazu das Thema von v13-15 mit: "Wer bist du?" angeben. Nur daß Mose, bezeichnenderweise, die Frage nicht so stellt.

"siehe" unterstreicht den Sprecherwechsel durch den neuen Blickpunkt - wir schauen nun mit den Augen des Mose - und kann hier als der Einführung eines Relativsatzes entsprechend verstanden werden, der drei Vordersätze enthält und dessen Nachsatz eine Frage ist. In dessen drittem Vordersatz steht die Frage der Israeliten: "Was ist/bedeutet sein Name?"106. Indem Mose die Frage den Israeliten in den Mund legt, gibt er ihnen verstärkte Bedeutung. Im wörtlichen zitieren kommen sie selber und ihr Anliegen zur Sprache. Zugleich verhindert es die Anrede Gottes mit

106 ist Streitobjekt in der Auslegung. Von jüdischer Seite, siehe dazu vor allem den jüngsten ausführlichen Artikel von Y.T.RADDAY, Name 88-93, wird die מה - Frage durchgehend als Frage nach den Eigenschaften (und damit der Bedeutung) verstanden, deren Sinn wiedergegeben werden könnte mit "Von welcher Art ist dein Wesen?". (So auch M.BUBER, U.CASSUTO, M.GREENBERG, B.JACOB, I.KINYONGO, J.A.MOTYER, F.ROSENZWEIG). - Dagegen steht die Auffassung von B.S.CHILDS, Exodus 50, und anderen, in v13 eine Frage nach dem Namen zu sehen.

In der Diskussion benützen beide Seiten Gen 32,28 (Und er sprach zu ihm: "Was ist dein Name?" - Und ex sagte: "Jakob"; oder aber: ... "Was bedeutet dein Name?" ... "er täuscht") als Argument für sich.

Meines Erachtens lassen sich sowohl Gen 32,28 wie Ex 3,13 nur dann voll verstehen, wenn man mit Doppeldeutigkeit rechnet: In beiden Fällen wird faktisch eine Antwort auf die Frage nach dem Namen gegeben und zugleich mit der Bedeutung des Namens gespielt. ( $\mathrm{zu}$ Gen 32,28 bemerkt J.P.FOKKELMAN, Art 215: "The man asks the patriarch's name and as he replies "Jacob" we realize that the name indicates his nature".) 
"du" (wie in v11), die im Falle indirekter Rede (z.B. "sie werden mich nach deinem Namen fragen") notwendig geworden wäre.

Die Antwort des Mose zeichnet sich durch weitere Auffälligkeiten aus. - Mose richtet den Israeliten aus: "Der Gott eurer väter hat mich zu euch gesandt." Es ist anzunehmen, daB Mose sich mit "Gott eurer väter" auf v6 zurückbezieht. Wenn das der Fall ist, so heiBt das, daB Mose Abraham, Isaak und Jakob als Väter der Söhne Israels kennt" ${ }^{107}$. Indem Mose aber "Gott eurer väter" sagt, obwohl es in $v 6$ auch der Gott seines Vaters war, verändert er die Aussage Gottes und setzt sich somit von den Israeliten ab. Korrekt hätte er "Gott unserer väter" sagen können. - Neben dem אמר der Redeeinleitung verwendet Mose selbst אמר noch dreimal in verschiedenem Sinn. Das erste Mal heibt es "sagen", das zweite Mal "fragen", das dritte Mal "antworten". Die Verwendung von erlaubt das wörtliche Anführen der Reden als zitate und führt eine zweite Gesprächsebene ein, das Reden innerhalb des Redens. Das Spielen mit אמר in unserem Vers setzt den Auftakt zu einer Serie von im Reden ergehenden Reden (bis v18). - Schlieblich kommt, obwohl das von Mose Gesagte in Ägypten handelt, dieses Wort hier nicht vor, wohl aber geht die Reihe der söhne Israels ( $a b$ v9) weiter.

Der Frage nach dem Gesendeten (v11-12) folgt in Ex 3,13 die nach dem Sendenden. Mose bekennt sich als unwissend. Doch zunehmend tritt ein anderer zug an ihm hervor: Obwohl er brilliant formulieren kann , redet er Gott noch nicht direkt an und nimmt auch die Gelegenheit nicht wahr, seine Gemeinschaft mit den Israeliten auszudrücken.

107 A.G.van DAALEN, Plaats 35, stellt zurecht heraus, daB Moses Aussage vor den Israeliten diese Kenntnis voraussetzt.

108 H.G.MAY, God 102, setzt die Formel "Gott der väter" frühestens exilisch an (11 vorkommen sind dtr, 29 in den ChrBüchern und 1 in Dan; dazu die vier stellen innerhalb unserer Erzählung $3,13.15 .16 ; 4,5$ als die einzigen im Pentateuch). W.H. SCHMIDT, Exodus 134-135, sieht darin einen Hinweis auf E.

109 Siehe neben dem zitieren und dem Spielen mit אמר auch den Wechsel אלדם - אליכם - איכם 
Ex 3,14: Und Gott sagte zu Mose: "Ich werde sein, wer immer ich sein werde."/ Und er sagte: "So sollst du den Israeliten sagen: >"Ich-werde-sein" hat mich zu euch gesandt.<"

So unauffällig, wie die anscheinend zu 3,13 parallele Redeeinleitung "Und Gott sagte zu Mose" ausschauen mag, so wenig ist sie es wirklich. Sie kommt nur dieses einzige Mal so in der Bibel vor. Am nächsten kommt die Einleitung von v15, die um עוד "wieder, noch" ergänzt ist, dann Ex 6,2, wo aber zuerst "sprechen" und erst im zweiten Satz אמר verwendet wird. Sonst gibt es keine Stelle im Pentateuch, die vom Reden Gottes zu Mose spricht.

Nicht nur die Redeeinleitung, auch das Reden Gottes selbst ist ohne Parallele 11 . Das AT bietet zwar eine ganze Reihe ähnlicher Konstruktionen , aber keine genau mit unserer zu vergleichende stelle. Entweder ist das Verb transitiv, oder das Relativpronomen ist mit einer Präposition kombiniert. Der Sinn der Antwort Gottes ist objekt vielfältiger Forschung geworden, wir wollen darauf eigens im Exkurs 4 (am Ende dieses Bildes) eingehen. Dieser Sinn wird aber auch mitbestimmt durch den Kontext ${ }^{113}$, den wir innerhalb der Entwicklung hier herauszuarbeiten versuchen. Dabei ergeben sich folgende Beobachtungen: - Es ist nur die erste von drei ${ }^{114}$ Antworten Gottes auf die Frage der Israeliten: "Was ist sein Name?" Die erneuten Redeeinleitungen in v14b.15 erhöhen die Feierlichkeit und lassen auf intensive Sprecherbetei-

110 "Und es sprach Gott zu Mose und er sagte zu ihm: ..."

111 B.N.WAMBACQ, 'eh'yeh 324, u.a.

112 Siehe Exkurs 4, vor allem die unter a) im dritten Absatz genannten Stellen.

113 Namhafte Autoren haben immer wieder diese Beziehung betont: B.JACOB, Mose 15; W.H.SCHMIDT, Jahwename 126. - F.ROSENZWEIG, Ewige 43, legt diese Beziehung zum Kontext in der Weise aus, daB der Name hier an den namenoffenbarenden Moment gebunden wird. Ähnlich J.A.MOTYER, Revelation 23.

114 Die dreistufige Antwort ist von vielen gesehen worden. Um nur einige zu nennen: N.Wyatt, J.G.Janzen, A.Besters, H.Sadakata u.a. Da v16 von den vorherigen Antworten abgehoben ist und eine eigene Rede beginnt, wäre sogar zu rechtfertigen, von vier Antworten Gottes zu sprechen, deren letzte (mit der erneuten Aufforderung an Mose zu gehen) aufgrund ihres Anschlusses an die vorletzte den engen zusammenhang zwischen sendendem Gott und gesandtem Mose unterstreicht. 
ligung schließen (siehe Exkurs 1). Gleichzeitig setzen sie Einschnitte im Reden, die als Pausen gedeutet werden können und das Sprechen verlangsamen. - Nach den sonst im AT verwendeten Namen zu urteilen, kann die Antwort Gottes in v14a nicht als die Bekanntgabe eines Namens ${ }^{115}$ verstanden werden. Das scheint dadurch bestätigt, daß Gott hier, im Gegensatz zu v15, das Wort ם " "Name" nicht gebraucht. - Die erste Anwort אהיה אישר אהיה fügt sich mehrfach genau in das bisherige Sprechen Gottes ein, das bestimmt war durch die Betonung seines eigenen Ich (v6-7.9.12), durch die Verwendung von Relativsätzen (v5.7.9), durch Alliteration (v6; hier dreifach, wieder mit Alef) und durch die verwendung von היה "sein" (v12). Als letztes stellt das Phänomen der Doppelung (hier die wiederholung der verbform bisher häufig beobachtetes stilmittel dar, wobei diese Doppelungen zwei Momente auszudrücken schienen: 1) verstärkung (Mose in v4; sehen in v7; bedrücken in v9). 2) Wandel, Variation, Ergänzung (האר in $v 2-4)$.

Die eigene Redeeinleitung macht $v 14 b$ als zweite Antwort kenntlich. Die Formel כה תמר תo sollst du sagen" "116 leitet das Folgende explizit als etwas wörtlich Auszurichtendes ein. Die Israeliten sind dessen Adressaten. Damit wird eine Antwort an jene Gruppe vorgestellt, die in v13 nach dem Namen gefragt hat. Dabei kommt Gott in der verwendung von אמר innerhalb des Redens und im Gebrauch eines "zitates" dem Reden des Mose in v13 nahe $^{117}$.

Die den Israeliten zu gebende Antwort greift ein Element aus v14a und zwei wörter aus dem Reden Moses in v13 auf. אהיה ersetzt dabei, wie aus der Parallele zu v13a ersichtlich, die an der Subjektstelle stehende Gottesbezeichnung. Es wird wie ein Name verwendet. Jedoch mahnt allein schon die Tatsache zur vor-

\section{B.JACOB, Mose 130 .}

116 Die Formel kommt hier zum ersten Mal so in der Letztgestalt des Pentateuch vor. Vorbereitet ist sie in der Josefsgeschichte durch Vorkommen in der 3.P.Sg. bzw. 2.P.Pl.: Gen 45,4; 50,17. . כה חאוrd nur noch dreimal in Ex verwendet: 3,$15 ; 19,3$;

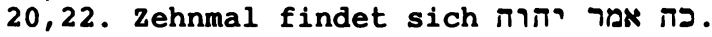

117 Es gibt auch eine lautliche Affinität der Reden der beiden Gesprächspartner: In v14a.b überwiegen, ähnlich wie beim Sprechen Moses in v3, die ä- und a-Laute. 
sicht, daB dieses "Ich-werde-sein" ein wort ist, das normalerweise keine Person bezeichnet. Diese Benennung kann kein Name im gewöhnlichen Sinn sein. אהיה antwortet so eher auf die Frage nach der Bedeutung des Namens, in der Weise, daß es die zukünftige Existenz von dessen Träger aussagt.

Ex 3,14 gibt auf den Einwand des Mose zwei Antworten, die einen engen Zusammenhang untereinander, aber auch mit der gesamten Erzählung aufweisen . Das Sprechen Gottes von seinem Namen erfolgt stufenweise, sowohl was die Angesprochenen (zuerst Mose, dann auch die Israeliten im Auftrag an Mose) als auch den Inhalt (das zitat in v14b führt ein Element aus $v 14 a$ in der Art eines Namens weiter) betrifft.

Ex 3,15: Und weiter sagte Gott zu Mose: "So sollst du $2 u$ den Israeliten sagen: >Jahwe, der Gott eurer Väter, der Gott Abrahams, der Gott Isaaks und der Gott Jakobs, hat mich zu euch gesandt. / Das wird mein Name auf ewig, und das meine Anrufung von Geschlecht zu Geschlecht sein.<"

Erneute feierliche Redeeinleitung (vgl. v14a) bringt die dritte Antwort Gottes. In ähnlicher weise wie vorher v14b auf v14a zurückgriff, nimmt diese Antwort v14b auf und führt es wei$\operatorname{ter}^{119}$. Dabei wiederholt Gott "So sollst du zu den Israeliten sagen" $120^{\circ}$ und "hat mich zu euch gesandt". Der Unterschied zwischen v14b und 15 liegt im Ersetzen von אהיה durch eine Formelkombination von Gottesbezeichnungen und im hymnischen Nachsatz v15b.

Die Formelkombination beginnt mit einem Paukenschlag: "Jahwe". Dieser Name scheint lautlich eng mit dem אהיד von v14 verbunden zu sein, wobei das verschiedene Präformativ (Jod statt

$118 \mathrm{Z.B}$. führt $\mathrm{v} 14 \mathrm{~b}$ auch die Reihen der "Israeliten" und von "senden" weiter.

11.9 J.G.JANZEN, Name 235, bezeichnet v14-15 als sorgfältige dreistufige semantische Gleichung. Das Wort "Gleichung" ist allerdings in diesem zusammenhang mit vorsicht zu gebrauchen, denn die drei Antworten sind gerade nicht gleichwertig.

120 Die leichte Veränderung ( tungslos und eher stilistisch bedingt zu sein, damit die exakte Wiederholung dieses längeren Ausdruckes vermieden wird. Vgl. im fünten Bild das "Hören auf die stimme". 
Alef) das Verhältnis zwischen beiden als Sprechen Gottes selbst (1.P.Sg. in v14b) zu Sprechen über sich (3.P.Sg. in v15) insinuiert. Über die Verschiedenheit des dritten Konsonanten (Waw statt Jod) muB man dabei hinwegsehen ${ }^{121}$. Aus diesem zusammenhang mit v14 erscheint "Jahwe" als die Umsetzung einer Selbstaussage ("ich werde sein") in einen "Namen" (mit der möglichen Bedeutung: "Er wird sein") ${ }^{122}$.

Gott läBt es nicht beim bloßen Namen bewenden. Er fügt ihm "der Gott eurer Väter, der Gott Abrahams, der Gott Isaaks und der Gott Jakobs" hinzu. Diesem Vorgehen der identifizierenden Nebeneinanderstellung sind wir bereis in v1 (Jitro, der Schwiegervater des Mose, der Priester Midians; zum Gottesberg, dem Horeb), in v6 bei der Selbstvorstellung Gottes und in v10 (mein Volk, die Israeliten) begegnet. Die erste Apposition "Gott eurer väter" greift wörtlich auf Moses Sprechen in v13 zurückk. Gott übernimmt (wieder einmal) eine Formulierung des Mose ${ }^{123}$. Ihre Ergänzung durch die zweite, lange, bereits in v6 verwendete Formel des Patriarchengottes erhöht die Feierlichkeit und Gewichtigkeit der Aussage. Dabei bewirkt die Identifizierung der beiden Appositionen mit Jahwe, die auch ausgedrückt werden könnte in der dreigliedrigen Gleichung "Jahwe = der Gott eurer väter = der Gott Abrahams, der Gott Isaaks und der Gott Jakobs", eine weitere Dimension an dem "Jahwe" genannten Gott. Er ist nicht nur, wie

121 Was allerdings nicht so schwerwiegend ist, denn diese beiden Konsonanten stehen einander sehr nahe. Das zeigt sich $z$.B. bei den Verben mit langem mittlerem Vokal (hohle Wurzeln), weiters beim Vergleich von hebräischem valent הרוא/א.

122 Siehe dazu die Bibelübersetzung von M.BUBER, F.ROSENZWEIG, Die fünf Bücher der Weisung 158. Sie geben in v14b wieder mit: "ICH BIN DA schickt mich zu euch." Für יהוה setzen sie: "ER". Für eine Begründung dieser Wahl: F.ROSENZWEIG, Ewige 41-43. W.H.SCHMIDT, Exodus, Sinai und Mose 42, dreht die Gedankenrichtung um: "Die Deutung 3,14 faBt JHWH als Verbform (3.P.Sg.) und setzt sie in eine Selbstaussage um." so versteht auch M.SAE$B \phi$, Offenbarung 54 , das Verhältnis von 3,15 zu 3,14 als eines von offenbarung $z u$ offenbarungsgetragener Neuinterpretation.

Für eine ausführliche Diskussion (mit Literaturangaben) zum Problem des Jahwenamens, seiner Bedeutung und insbesondere der möglichen hypothetischen vorstufen auf der Suche nach einer Etymologie siehe B.S.CHILDS, Exodus 60-64; M.ROSE, Jahwe; W.H. SCHMIDT, Exodus 169-174, und D.N.FREEDMAN, P.O'CONNOR, יהות 533554 .

123 Der vergleich mit 3,18 zeigt, daB Jahwe sich als "unser Gott" angeredet sehen möchte. 
aus dem Zusammenhang und der lautlichen Nähe mit v14 zu entnehmen, der Gott, der in zukunft sein wird, er ist auch der, der in der vergangenheit ${ }^{124}$ als Gott den vorfahren der Israeliten nahe war. Jahwe erweist sich so als derselbe Gott, der sowohl in der vergangenheit war als auch in der zukunft sein wird und jetzt

Mose sendet.

Der hymnische, an Psaltersprache erinnernde ${ }^{126}$ AbschluB v15b unterstreicht nach der starken Betonung der vergangenheit durch "väter" und Patriarchen in v15a noch einmal den zukunftsaspekt. Parallelismus und Reim schaffen poetische Sprache, der auch der Inhalt angemessen ist. Die Parallele von $ם$ und 7 D $^{127}$ macht deutlich, daB es sich um eine bleibende Erinnerung handeln soll. Der Name Gottes dient also nicht nur zur Anrede, sondern auch zum Andenken in künftigen Generationen. In diesem Blick auf die Zukunft überschreitet Gott den gegenwärtigen Augenblick ${ }^{128}$.

124 Diese Beziehung Jahwes zur Vergangenheit wurde bereits in 3,6 angesprochen. Dabei sind zwei stufen zu unterscheiden:

1) "Gott eurer väter", das ist die Generation zuvor, die zeit der Eltern und GroBeltern ( verstanden werden) und meint so die unmittelbare, direkter betreffende vergangenheit.

2) der Gott der Patriarchen: eine entferntere Geschichte, die bei Menschen auch in Vergessenheit geraten kann (vgl. Ex $1,8)$.

125 Die Präsenz Gottes wird auch sprachlich herausgestellt durch 5x אלהים.

126 F.KOHATA, Jahwist 8-9. Sie sieht darin eine liturgische Formel, die aus Jerusalem stammt.

127 Y.T.RADDAY, Name 100-102, faBt ש und zusammen als Hendiadyoin auf; beide würden "Sein, Wesen" bezeichnen. Nach ihm steht רi hier "zum Zwecke, zu entkleiden". Radday sieht dabei richtig die schillernde, über den blossen "Namen" hinausgehende Bedeutung von $\square \dot{w}$, wird aber dem vollen Wert von 7 i nicht gerecht (siehe dazu den nächsten Absatz).

128 RASCHI, Kommentar zur stelle, legt die defektive Schreibung von ofy in der Weise aus, daB er sie, im Kontrast zu unserer stelle, die das ewige Andenken dieses Namens Jahwe stiftet, als Aufforderung zum Verbergen des Gottesnamens versteht. Damit findet die geschichtliche Entwicklung, ארני und andere wörter bzw. Abkürzungen als Ersatz für den Gottesnamen zu verwenden (G.H.PARKE-TAYLOR, Yahweh 85-86) eine nachträgliche Rechtfertigung.

Daraus resultiert u.a. die Schwierigkeit, die korrekte Aussprache des Gottesnamens anzugeben. Einen guten Anhaltspunkt bietet wohl THEODORET, Quaestiones in Exodum (XV), der die Aussprache der Samaritaner zu seiner zeit mit 'Iaßk wiedergibt. 
Eine Parallele von "Name" und "Andenken, Anrufung" in bezug auf Gott findet sich noch zweimal im AT: Ps 135,13, der die fast wörtliche Entsprechung (nur gewendet in die Anrede) zu Ex $3,15 \mathrm{~b}$ ist, und Jes 26,8. Gegenüber dem häufig gebrauchten $(864 x)$ ist das seltene זכר aussagekräftiger. Bei den 23 Vorkommen ist achtmal das Andenken an Gott gemeint . Als ein Schlüsselwort für die literarische Konvention des Einsetzungsberichtes (siehe unter 4.1.1) verbindet es den namensoffenbarenden Moment (durch Gott) mit der in zukunft geschehenden Erinnerung (durch die Israeliten).

"Das ist mein Name" sagt Gott. Aber worauf ist das "das" zu beziehen? Die oben bei 3,14 genannten Gründe lassen es nicht wahrscheinlich erscheinen, daB auch eine der beiden Antworten von v14 als eigentlicher Name zu verstehen ist; auBerdem ist es wohl geraten, innerhalb des durch die Redeeinleitung v15a eingeleiteten Sprechens Gottes zu bleiben. Doch selbst dann bleibt noch die Frage, ob Jahwe allein oder Jahwe zusammen mit den beiden Appositionen als "Name" zu verstehen ist. In einem modernen Veständnis des Namens und im gewöhnlichen Gebrauch der Bibel legte sich die erste Möglichkeit näher. Der Name für Gott wäre dann alleine Jahwe.

Doch ist auch die andere Lösung nicht auszuschließen. DaB mit dem "Namen" auch die lange Form "Jahwe, der Gott eurer väter, der Gott Abrahams, der Gott Isaaks und der Gott Jakobs" gemeint sein könnte, legen folgende Gründe nahe:

a) Wie wir gesehen haben, spielt der Text mehrfach auf zwei Ebenen. Die Frage der Israeliten in v13 ist doppeldeutig, und ebenso erzeugen die verschiedenen Antworten Gottes in v14-15 eine

129 Die Stellen sind: Ex 3,15 ; Ps 6,$6 ; 30,5 ; 97,12$; 102,13; 135,13 ; Jes 26,8 ; Hos 12,6. Dazu kommen zwei stellen, wo das Andenken mit Gottes wundertaten oder seiner Güte $z u$ verbinden ist: Ps 111,$4 ; 145,7$. - ?? kommt sonst noch einmal in Ex vor $(17,14)$.

Unsere Stelle ist das einzige Vorkommen für זרר "mein Andenken" in der Bibel. Meist hängen am Nomen Suffixe (14x). Diese persönliche, engere Verbindung mit dem, dessen gedacht wird, durch die Suffixe zeigt sich noch deutlicher beim Vergleich mit dem bedeutungsverwandten, von derselben wurzel stammenden wort ז כרון "Andenken, Gedächtnis" ( $8 x$ in Ex), das bei 24 Vorkommen nur zwei Suffixformen aufzuweisen hat.

Das Verb ז זר "gedenken" kommt übrigens siebenmal in Ex (von $222 x$ im AT) vor. Dabei sprechen Ex 2,24; 6,5 jeweils davon, daB Gott seines Bundes gedenkt. 
Atmosphäre, die die Bedeutung eines Wortes nicht in sich alleine, sondern im zusammenhang des Ganzen betont.

b) Die mehrfachen Antworten Gottes auf die Frage nach seinem Namen stehen gleichfalls gegen eine zu enge inhaltliche Bestimmung dieses Namens in nur einem Wort und legen nahe, in einem zweiten Verständnis diese Identität Jahwes mit dem Vätergott als zum Namen gehörig aufzufassen.

bung $^{130}$ zeigt, daB der Name eines königs (bzw. des Messias) nicht nur aus dem Eigennamen besteht, sondern durch Titel angereichert ist, sodaß sich im Idealfall fünf Namen/Titel ergeben. Zählt man hier in Ex 3,15 nach, so kommt man auf Jahwe + vier Gottesbezeichnungen, also auch insgesamt fünf Benennungen.

Die letzte Frage wird gestellt durch die praktisch identischen Einleitungsformeln für das Sprechen $z u$ den Israeliten in v14b und 15, die aber verschiedene Antworten enthalten. MuB Mose an die Israeliten zwei verschiedene Botschaften ausrichten? Darauf läßt sich folgende Antwort geben. Erstens ist aus dem engen Zusammenhang der beiden Aufträge klar, daß es nicht verschiedene, sondern einander ergänzende Botschaften sind (vgl. die Deutung der Träume des Pharao durch Josef). Zweitens können wir aufgrund der Doppeldeutigkeit der Frage der Israeliten in v13 (nach Name und Bedeutung) auch mit einer doppelten Antwort an sie rechnen. Dabei durchleuchtet die erste Antwort (v14b) die Bedeutung des in der zweiten Antwort (v15) gegebenen Namens Jahwe von Gottes freier, zukünftiger Existenz her.

Gottes Selbstoffenbarung in seinem Namen "Jahwe" stellt stilistisch und inhaltlich den Höhepunkt ${ }^{131}$ unserer Erzählung dar. Die lange Redeeinleitung, der Gebrauch von "Jahwe" durch Gott selbst, der gleichmäBige Rhythmus der Gottesbenennungen und

130 O.KEEL, Welt 243 (und Bild 351): Bei einer Thronbesteigung in Ägypten ist der Hauptinhalt des Protokolls der "große Name", die fünfteilige Königstitulatur, die der Pharao aus diesem Anlas erhält. - Ähnliche fünfteilige Namen finden sich in 2 Sam 23,1 für David und in Jes 9,5 für den Messias; für die Diskussion siehe u.a. A.ALT, Befreiungsnacht; H.CAZELLES, Titulature; $H$. WILDBERGER, Jesaja I 365 und 381-384.

131 J.MAGONET, Bush 310. - Es ist zu beachten, daB sprachlicher und spannungsmäBiger Höhepunkt verschieden sein können (vgl. Anm. 60 in c2). 
die poetische Sprache am Ende erzeugen hohe Feierlichkeit. Mose steht nun in seinem Wissen auf derselben Ebene wie der Leser.

\section{Rückblick auf den Namen Gottes}

Auf den Einwand des Mose in v13 gibt Gott drei Antworten, deren letzte beide auf die in doppeltem Sinn zu verstehende Frage der Israeliten nach seinem Namen eingehen. Der für immer bleibende Name heiBt "Jahwe (, der Gott eurer Väter, der Gott Abrahams, der Gott Isaaks und der Gott Jakobs)"; seine Bedeutung liegt neben seiner Beziehung $z u$ den vätern (und damit zur Vergangenheit der Israeliten) in dem durch die ersten beiden Antworten betonten Aspekt des zukünftigen, freien, unangefochtenen Seins.

Die Weise, wie v13-15 formuliert sind, erzielt mehrere Effekte.

a) Die Antworten Gottes werden immer länger, wobei anknüpfend jeweils etwas aus der vorigen Antwort aufgenommen wird. So entstehen drei zusammenhängende stufen, die eine steigerung bilden und in der offenbarung des Gottesnamens ihren Höhepunkt finden. Gleichzeitig ist in dieser feierlichen Gestaltung angedeutet, daB es sich mit dem Namen Gottes nicht so einfach wie mit anderen Benennungen verhält; er ist mit Vorsicht zu gebrauchen, umso mehr, als sich für das Reden von Gott eine Gleichung ergibt: der Gott der väter = "Ich-werde-sein" = Jahwe.

b) In seinem Reden geht Gott genau auf Mose ein, in einem Grad, der sogar seinen Formulierungen entspricht (אמר im Reden; "hat mich zu euch gesandt"; "Gott eurer väter"). Dieses genaue Eingehen wird vor allem erreicht durch die einleitende Formel "So sollst du zu den Israeliten sagen". Dadurch geht die Reihe der Söhne Israels und damit ihre Präsenz während der offenbarung Gottes ununterbrochen weiter ${ }^{133}$. Die Antworten Gottes sind zwar durch Mose vermittelt, aber direkt an die Israeliten gerichtet. Das kann mehrfach ausgelegt werden, sei es als Ehre für die Is-

132 Die letzte stufe, v15, bildet mit Nennung des Namens und fünffachem אלהים den Abschluß.

133 Die Reihe der "Israeliten" geht mit diesem dritten Bild zu Ende; sie wird ersetzt durch die Verwendung der 2.P.Pl. (vor allem die Reihe ${ }^{-}$"euer/euch"), die hier im dritten Bild beginnt. Parallel dazu bringen die Redeeinleitungen in jedem Vers den Namen des Mose. Ägypten dagegen ist in diesen Versen nie zu finden; es hat in der offenbarung Gottes keinen Platz. 
raeliten, sei es als göttliche Hilfe für Mose ${ }^{134}$, sei es als Autorisierung der an die Israeliten ergehenden Botschaft, insofern sie wörtlich Gottes Sprechen wiedergibt.

c) v15b gleicht einem Testament ${ }^{135}$, indem es etwas für immer festlegt. Diese Festsetzung wird innerhalb unserer Erzählung strikt befolgt. Bis 3,15 verwendete nur der Erzähler Jahwe und Gott, während sowohl Gott wie auch Mose von Mit 3,15 wechselt der Gebrauch der Gottesbezeichnung: Alle (Gott, Mose und der Erzähler) verwenden immer Jahwe, wenn sie von Gott sprechen. Meist wird Jahwe noch durch eine angefügte Gottesbezeichnung ergänzt. allein ist dadurch zu einem Ausdruck geworden, der nun sogar auch Mose bezeichnen kann $(4,16)$. Dieser Sprachgebrauch wird dann festgehalten über unsere Erzählung hinaus ${ }^{36}$

Gott offenbart hier seinen Namen. Für wen? Der Erzähler hat den Hörer/Leser längstens $a b 3,4$ (wenn nicht $a b 3,2$ ) damit vertraut gemacht, daB der hier erscheinende und redende Gott Jahwe ist. Also bedeutet 3,15 für den Hörer/Leser nicht die offenbarung eines neuen Namens. Wenn den Israeliten der Name unbekannt gewesen wäre, hätte dies zur Folge gehabt, daß Mose seine Sendung mit einem fremden Namen, dem eines nicht bekannten Gottes, legitimieren hätte müssen. Legitimation ist aber normalerweise Rückgriff auf Bekanntes. Es ist also anzunehmen, daß die Israeliten "Jahwe" als Gottesnamen kannten"

134 M.GREENBERG, Understanding 97. - Sie wird ermöglicht dadurch, daB Gott im Reden ein "doppeltes Ich" verwendet. Er gebraucht in v14-16 "Ich" für sich selbst und für Mose. Beide sind sauber geschieden durch verschiedene grammatische Konstruktionen: für sich selbst in den Subjekten der Verben und Suffixen an den Nomina; für Mose in den Suffixen an Verben und Präpositionen.

135 Siehe dazu unten in 4.1.1 die literarische Bestimmung von $v 15 b$ als Einsetzungsbericht.

136 Abweichungen von diesem Sprachgebrauch, wenigstens bis zum Auszug, sind mit besonderen Aussagen zu erklären: Ex 5, 3 kann auf die Frage nach Jahwe durch den Pharao in 5,2 nicht wieder diesen Namen verwenden. - Die Besonderheit der Redeeinleitung von 6,2 haben wir schon oben (siehe Analyse zu 3,14 ) gesehen. - 7,1 ist eine Variation von 4,16, die unsere Auffassung nur bestätigt.

- Erst in 13,17-18 steht אלהים wieder allein für Gott.

137 In den Patriarchenerzählungen verwendet die Bibel oft den Namen Jahwe. J.A.MOTYER, Revelation 25, zählt 116x Jahwe von Gen 12 bis Ex 3,12. Auch der Name von Moses Mutter Jokebed ent- 
Auch ist im zusammenhang mit dem für Ägypten vorauszusetzenden Polytheismus anzunehmen, das die Israeliten nach dem Namen des sendenden Gottes zwecks seiner Identifizierung fragen. In diesem Fall handelte es sich für sie um keinen neuen Namen, sondern um die in einem polytheistischen Kontext notwendige Benennung Gottes in Abhebung von anderen Göttergestalten ${ }^{138}$. Auch wenn also vermutlich der Name "Jahwe" für die Israeliten nicht neu war, teilt die Nennung dieses Namens ihnen mit der Identität des sie ansprechenden Gottes doch Neues mit.

Für Mose ${ }^{139}$ ist zumindest eines neu: daß der ihm erscheinende Gott mit Jahwe zu identifizieren ist. Damit hat Mose in seinem wissen mit den Hörern/Lesern gleichgezogen, die Verwendung der doppelten Perspektive durch den Erzähler zur Erzeugung eines Unterschieds im wissen findet hier ihr Ende.

Das Besondere an der offenbarung Gottes liegt also nicht so sehr an der Neuheit seines Namens Jahwe, sondern in seinem Inhalt, darin, daB Jahwe der für die Israeliten sich einsetzen

hält ein auf Jahwe hinweisendes theophores Element.

138 Eine solche Auslegung träfe auf der vom Erzähler präsentierten Ebene der Erzählung und der in ihr vorgesteliten "Geschichte" (als Projektion in die Vergangenheit) zu. Auf diese Ebene gehört die Situierung der Erzählung in der ferneren Vergangenheit, vor der Volkswerdung, in Ägypten. Das Reden von den "Göttern Ägyptens" (Ex 12,12) ist dazuzurechnen.

- Davon wäre zu unterscheiden eine zweite Ebene des Textverständnisses, bei dem die Frage nach dem Namen Gottes zur Legitimation des Beauftragten diente (B.S.CHILDS, Exodus 65-70). Zeitlich ist diese Ebene der Vorgeschichte unserer Erzählung zuzuordnen. Sie läßt nicht die Entstehung des ganzen Textes, sondern nur die Herkunft der Frage nach dem Gottesnamen auf dem Hintergrund der Auseinandersetzung zwischen wahrer und falscher Prophetie verstehen.

- Schlieblich ist eine dritte Ebene (in der zeit des Autors/ der Redaktion) abzuheben, in der die Frage nach dem Namen und dessen Bedeutung für die Identität einer Gruppe verstärktes Gewicht gewonnen hat.

139 J.P.HYATT, Jahweh 130 und 136 , betont die Beziehung zu Midian und vermutet, Mose habe bei seinem Aufenthalt dort diesen Namen "gelernt". Auch andere Ausleger nehmen einen nichtisraelitischen Ursprung des Jahwenamens an (A.MURTONEN, Treatise 43-49; E.A.KNAUF, Yahwe 468-470, leitet mit J.Wellhausen Jahwe von der nordwestarabischen Wurzel hwy (begehren, fallen, wehen) ab.

Da unser Text den Charakter einer literarischen Projektion in die Vergangenheit hat, läBt sich in dieser Frage kaum über Hypothesen hinauskommen. 
wollende und dem Mose erscheinende Gott ist. Das ist für alle neu, für Hörer/Leser, für die Israeliten und für Mose.

Nach 3,15 folgt weiter Rede Gottes: Er legt seinen Plan bis zum Auszug vor. Gottes Selbstoffenbarung erscheint so zwischen zwei längeren Ausführungen seines Plans plaziert ${ }^{140}$, sein Name ist nur in diesem engen zusammenhang mit seinem Befreiungshandeln zu verstehen.

\section{Exkurs 4: Zum Verständnis von Ex 3,14a}

Unsere Erzählung hat sich bisher als eine literarische Komposition erwiesen, die im Ablauf der Verse offenbar eine minutiös fortschreitende Entwicklung zeichnet. Diese Entwicklung läuft auf die offenbarung des Jahwenamens durch Jahwe selbst in v15 zu. $3,14 a$ bedeutet einen Schritt daraufhin und ist in diesem zusammenhang zu sehen.

Weiters ist anzunehmen, daB wir es mit literarischer Formung zu tun haben, deren Beziehung zur "realen Folie der Geschichte" in unserem Fail wegen des zeitlichen Abstandes und fehlender anderer zeugnisse für eine Untersuchung unzugänglich bleibt. Was wir mit hoher Wahrscheinlichkeit annehmen dürfen, ist ein zeitlicher Abstand von einigen Jahrhunderten, der die erste Anrufung und Verehrung Gottes unter dem Namen Jahwe durch die Israeliten von der Formulierung unseres Textes trennt. Wenn auch an der Treue der überlieferung in der damaligen zeit kein zweifel besteht, so spricht doch die Feinheit des uns vorliegenden Textes für seine literarische verfabtheit. Daraus folgt dann aber, daB es unmöglich ist, den sprachlichen Ursprung des Jahwenamens aus unserer Erzählung mit Sicherheit zu erheben. Jeder Versuch, aus Ex 3,14-15 die Herkunft des Jahwenamens ableiten zu wollen, steht von vornherein auf fragwürdiger Basis.

Statt dessen scheint unser Text eher mit dem auch sonst in der Bibel zu beobachtenden Mittel der Etymologie zu spielen. Das lautlich den in Jahwe enthaltenen Konsonanten nahekommende Verb היה dient dazu, diesen Namen Gottes zu "erklären". Dabei ist die 
lautliche Ähnlichkeit wichtiger als die (nicht auszuschlieBende) geschichtliche Herkunft des Namens von dieser Wurzel ${ }^{141}$. Wir wollen im folgenden versuchen, die grammatische Konstruktion zu untersuchen (a), daraus eine übersetzung zu erstellen (b) und schlieblich die Bedeutung dieser wendung $z u$ verstehen (c).

\begin{abstract}
a) Die Wendung אהיה איה איד verwendet zweimal das Verb in der Präformativkonjugation und verbindet sie durch die Relativpartikel. Dazu gibt es ähnliche, aber keine genau parallelen Konstruktionen im AT, sodaB der Vergleich mit ihnen immer ein Moment der Unsicherheit enthält. Deshalb werden wir uns zuerst dem Verb selbst zuwenden.
\end{abstract}

היה "sein, werden, geschehen" hat im biblischen Hebräisch vor allem ${ }^{143}$ die Funktion, den Aspekt der "zeit" zu bezeichnen. Die Präformativkonjugation dient dabei überwiegend für die Kennzeichnung eines zukünftigen Seins. אהיח kommt 42x (ohne 3,14b) im AT vor; bis auf ${ }_{144}$ wei Ausnahmen sind alle diese Stellen futurisch zu verstehen . Da die Kennzeichnung des Präsens beim Verb

141 E.A.SPEISER, Genesis 37-38, spricht von "sound symbolism" an Stelle von technischer Etymologie. Damit kommt Ex 3,14 den anderen sogenannten volksetymologien in der Bibel nahe, deren letztes Beispiel vor unserem Text knapp zuvor in Ex 2,22 der Name von Moses Sohn Gerschom ist.

A.M.DUBARLE, Révélation 15, möchte eine Parallele zu jenem bei Geburten zu beobachtenden vorgehen sehen, bei dem eine der anwesenden Personen einen kurzen Satz ausspricht, nach dem das Kind dann benannt wird (z.B. Gen 35,18$)$.

142 Die grundlegende Untersuchung zu diesem verb hat R.BARTELMUS, HYH. Bedeutung und Funktion eines hebräischen "Allerweltswortes" vorgelegt, in dessen letztem Kapitel er auch Ex 3,14 behandelt. Im folgenden stütze ich mich neben A.NICCACCI, Esodo 3,14a: "Io sarò quello che ero" e un parallelo egiziano, hauptsächlich auf ihn.

\title{
143 Siehe R.BARTELMUS, HYH 110 und 228.
}

144 Die Ausnahmen sind Ru 2,13 und 2 Sam 15,34. In beiden Fällen scheint ein doppelter Sinn intendiert: In Ru 2,13 bedankt sich Ruth bei Boaz für sein Erbarmen, das umso gröBer ist, weil sie hinzufügt: "und daß du zum Herz deiner Magd gesprochen hast, obwohl ich doch nicht wie eine deiner Mägde war". Es ist aber auch möglich - auf der Ebene der Gesamterzählung - zu verstehen "wo ich doch nicht wie eine deiner Mägde sein werde" (weil sie seine Frau wird).

Ähnlich in 2 Sam 15,34, wo David dem Huschai den Auftrag gibt, in die stadt zu Absalom zurückzukehren und zu ihm zu sprechen: "Dein Knecht! Ich, o Kön1g, war der Knecht deines Vaters, 1ch, seit langem. Und nun: Ich bin dein Knecht." Die Szene vor 
"sein" fast ausschlieBlich durch Nominalsatz" ${ }^{145}$ erfolgt, kann diese bei anderen Verben zutreffende dritte Möglichkeit für die Übersetzung der Präformativkonjugation, wollte man nicht mit einer aussergewöhnlichen, einzigen Ausnahme rechnen, mit ziemlicher sicherheit ausgeschlossen werden. Von den beiden anderen Möglichkeiten (Übersetzung mit Futur oder Imperfekt) sprechen sowohl die Wahrscheinlichkeit (die überwiegende Mehrzahl der stellen hat futurische Bedeutung) als auch der an den beiden Ausnahmen sichtbar gewordene notwendige zusammenhang mit weiteren Selbstbezeichnungen dafür, auch die אהיח von 3,14a futurisch, im sinn von "ich werde sein" zu verstehen.

Selbstverständlich muß dieses Verständnis an der Gesamtkonstruktion geprüft werden. Die Deutung als paronomastischer Relativsatz wird allgemein $\underset{146}{ }$ ehalten, ist aber in letzter zeit wieder in Frage gestellt worden ${ }^{146}$. Unabhängig von dieser Benennung sind die anderen, syntaktisch ähnlichen Konstruktionen zu vergleichen. Die Ex 3,14a am nächsten kommenden Texte sind Ex 33,19 רחנתי אתאשר אחן "und ich werde mich erbarmen, wessen ich mich erbarme", 2

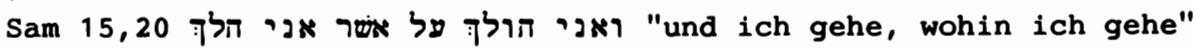

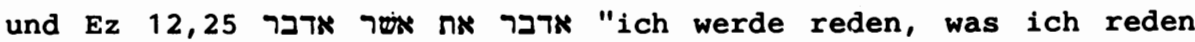
werde". Sie alle verwenden in Hauptsatz und Relativsatz dasselbe Verb in derselben Person, in allen Fällen sind die beiden Sätze durch die Partikel nächsten durch zweifache Präformativkonjugation. Jedes Mal wird die im Verb enthaltene Bedeutung (sich erbarmen, gehen, reden)

Absalom verlangt die übersetzung von mit Imperfekt, der weitere Verlauf der Erzählung wird aber eine zusätzliche Note im Reden Huschais enthüllen. Faktisch bleibt er weiter Knecht Davids, sodaß also auch ein Lesen im Sinn von "Ich, o König, werde der Knecht deines Vaters sein" berechtigt ist.

DaB אהיה in diesen Fällen die Bedeutung "ich war" übernehmen kann, ist beide Male aus dem Kontext zu verstehen und auch der unterwürfigen Selbstbezeichnung Knecht/Magd zuzuschreiben.

145 Nur einmal wird in der Bibel das Partizip von היה verwendet: $\operatorname{Ex} 9,3$.

146 NICCACCI, Esodo 3,14a S.9, möchte Ex 3,14 von den paronomastischen Relativsätzen ausschließen, weil er hier (im Unterschied zu allen anderen) direkt abhängig ist. Doch liegt die Deutung als Paronomasie nicht an der Form der Abhängigkeit, sondern an der lautlichen Ähnlichkeit. 
bestätigt, ihre Ausführung aber offengelassen ${ }^{147}$. Es ist anzunehmen, daB dies auch auf Ex 3,14a zutrifft, obwohl dort das in den anderen Fällen bei der Relativpartikel stehende fehlt $^{148}$. Ex 3,14a will also verstärkt das zukünftige Sein Gottes aussagen, dabei aber offenlassen, wie dieses sein wird.

Das Relativpronomen verbindet die beiden Verben $z u$ einer Konstruktion, die von manchen als "idem per idem" bezeichnet wird. Dabei ist jedoch zu beachten, das die beiden gleichlautenden Verben nicht für den gleichen Sachverhalt stehen. Das Verb des Hauptsatzes trifft eine Klassifikation", während das Verb des Nebensatzes eine Existenzaussage macht. Das nicht weiter bestimmte Relativpronomen ר läBt die Aussage des Relativsatzes als das Subjekt des Hauptsatzes betreffend erscheinen; es müBte somit im Deutschen mit einem Relativpronomen im ersten Fall wiedergegeben werden.

b) Wenn wir die bisherigen überlegungen festhalten und für eine übersetzung fruchtbar machen wollen, so ergibt sich wörtlich: "Ich werde sein, der ich sein werde." Soll auch noch die Nuance des offenbleibens, die in der paronomastischen Konstruktion liegt, Ausdruck finden, lautet die übersetzung von Ex 3,14a: "Ich werde sein, wer immer ich sein werde."

147 Die von B.JACOB, Mose 129-130, zusammengestellte Liste enthält noch einige weitere, jedoch nicht so nahestehende Ausdrücke, die aber auch dieselbe Aussage erreichen: "Es ist ein Satz, welcher über die Tatsache vergewissern, aber des Details entheben will."

Dabei ist zu beachten, daB in unserer Erzählung die doppelte verwendung desselben verbs äuBerst häufig ist. Neben den absoluten Infinitiven in $3,7.16 ; 4,14$ finden wir folgende Vorkommen:

3, 2-3 Der Dornbusch brannte lodernd ... Warum verbrennt er nicht?

3,14 Ich werde sein, wer immer ich sein werde.

3,20 Ich sende meine Hand .... und er wird entsenden.

3,21 Wenn ihr geht, werdet ihr nicht leer gehen.

4,8 Wenn sie nicht glauben ... werden sie glauben

4,9 Und es wird sein ... und es wird ... - es wird ...

4,11 Wer hat ... den Mund gemacht, und wer macht stumm ...?

4,13 Sende doch, durch wessen Hand du senden willst!

4,16 Und es wird sein ... er wird sein ... du wirst sein.

148 Doch kann eine Akkusativpartikel oder eine Präposition bei היה kaum erwartet werden, wenn es "sein" aussagen soll.

149 R.BARTELMUS, HYH 231: Weil der Nebensatz unbestimmt ist, kann das אהיח des Hauptsatzes keine Identifikation vornehmen. 
Die meisten übersetzungen geben unsere Wendung ähnlich wieder. Doch gibt es auch viele andere Vorschläge, die sich im wesentlichen in drei Gruppen teilen lassen:

- Eine Gruppe rechnet damit, daB bereits in v14a אהיח nicht als Verbform, sondern als Benennung wie in $v 14 b$ verwendet wird. Beispiele sind: "[My name is] 'ehye for/in that I will be/am (present).".$^{151}$ und "je suis celui qui est: je suis"". In beiden Fällen wird elliptischer Sprachgebrauch vorausgesetzt. Der Text wird dabei ergänzt durch etwas, was nicht ausdrücklich in ihm geschrieben steht.

- Die zweite Gruppe stützt sich auf eine Eigenart der hebräischen Sprache. Sie besteht darin, im Relativsatz dieselbe grammatische Person wie im Vordersatz zu verwenden ${ }^{153}$. Selbst wo in der deutschen übersetzung im Relativsatz die 3.P. steht, kann im Hebräischen in übereinstimmung mit dem Hauptsatz die 1. oder 2.P. gefordert sein. Als übersetzung für Ex 3,14a ergäbe sich: "I am he who is." 154 . Doch können die für diese übersetzung herangezogenen Vergleichsstellen nicht überzeugen. Sie verwenden allesamt ein Personalpronomen und einen Namen oder ein Nomen im Vordersatz. AuBerdem handelt es sich nie in Hauptsatz und Relativsatz um dasselbe Verb, und auch nie um היח. Die syntaktische verschiedenheit ist zu groB, als daß man darin eine Parallele sehen könnte.

- Eine dritte Übersetzungsmöglichkeit lautet: "Io sarò quello che

150 Abgesehen von den umschreibenden übersetzungen, wie z.B. "Ich werde mächtig sein" oder "Ich werde mich erweisen" ...

151 M.GREENBERG, Understanding 81-82; zwei übersetzungen könnten lauten: "[Mein Name ist] 'ehye, denn ich werde (gegenwärtig) sein." und "[Mein Name ist] 'ehye, in ihm bin ich (gegenwärtig)."

152 F.MICHAELI, Exode 44, "Ich bin, der ist: Ich bin." In Anm.9 fügt er eine übersetzung an, die seiner Meinung nach noch besser ist: "je suis celui qui s'appelle: je suis.", zu deutsch: "Ich bin, der sich nennt: Ich bin."

153 P.JoüoN, Grammaire \$158n. Ex 20,2 lautet z.B. wörtlich: "Ich bin Jahwe, dein Gott, der ich dich herausgeführt habe".

154 "Ich bin, der ist." So z.B. MCCARTHY, Ex 3:14 S.317, der sich dabei auch auf Schild und Lindblom stützt. In "normal grammar" (vgl. 1 Chr 21,17) müBte unser Satz lauten: אני הרא אישר אהיה. - Es fällt auf, dab diese übersetzung der Septuaginta sehr nahe steht. Vgl. M.ALLARD, Note. 
ero." 155 Auch wenn die imperfektische Bedeutung von nicht gänzlich ausgeschlossen werden kann, so kommt sie doch sonst nirgends in dessen absoluter verwendung vor ${ }^{156}$.

Die genannten Schwierigkeiten bei den anderen übersetzungen führen dazu, eine Wiedergabe von Ex $3,14 a$ mit "Ich werde sein, wer immer ich sein werde" als die naheliegendste und wahrscheinlichste anzunehmen . Das soll kein übersetzungsmonopol bedeuten, im Gegenteil: Gerade der Inhalt von v14a, nämlich das freie Sein Gottes, übersteigt jede einseitige Festlegung des göttlichen Seins durch den Menschen. So gesehen bringen auch die anderen Übersetzungen korrekte Aspekte im Bild dieses Gottes.

c) Jahwes Antwort ist eine Aussage über sich selbst. Er sagt von sich zukünftige, freie Existenz aus. Das Besondere an der ÄuBerung Gottes ist dabei die Konstruktion, die seine Aussage zugleich als Betonung seines Seins und als offenlassen des "Wie?"

155 NICCACCI, Esodo 3,14a 11 (Übersetzung: "Ich werde sein, der ich war"). Die von ihm erwähnte äyptische Parallele aus der "Reise des Wenamon" steht allerdings in der 3.P., ist als Fragesatz formuliert und verwendet überdies im Hauptsatz Präsens.

Nach der von Alt gefundenen, von der späteren Diskussion dann aber abgelehnten "Parallele" in der "Lehre für Merikare" ist also auch der Vorschlag Niccaccis wenig überzeugend. Eine dritte ägyptische Parallele hat allerdings in der exegetischen Diskussion bisher kaum Beachtung gefunden. Es ist die stelle in der neuen Übersetzung des ägyptischen "Mythos von der Himmelskuh" von E. HORNUNG, 43, zeile 183: "Ich bin, der ich bin."

Die diesbezügliche Korrespondenz von H.Quecke (Rom), J.Osing (Bonn) und N.Lohfink (Frankfurt), in die mir freundlicherweise Einsicht gewährt wurde, stellt jedoch fest, daß das zugrundeliegende Original jw.j. jm.j sich zunächst nur als

a) "ich bin in mir" (so schon G.ROEDER, Urkunden 146, 2.11), oder b) "ich bestehe aus/in mir" übersetzen läßt.

Damit scheint auch diese stelle als vermeintliche Parallele zu Ex 3,14 fragwürdig.

156 Vgl. zuvor oben Anm.144, wo אהיה in der Bedeutung von "ich war" immer mit einer Selbstbezeichnung verbunden war und nur aufgrund des Kontextes seinen Sinn als Imperfekt annahm.

Die von Niccacci in Ex 3,14a gesuchte Verbindung des Gottes, der sein wird (=Jahwe), mit dem, der war (=der Gott der väter), und ihre Identität wird in 3,15 ausgesprochen; es wäre unter Umständen möglich, von dort aus rückblickend v14a zu lesen als "Ich werde sein, der ich war".

157 Dies gilt unter der voraussetzung, daB der Sprachgebrauch der hier verwendeten Ausdrücke und Konstruktionen innerhalb der Bibel konsistent ist und daB Ex $3,14 a$ sich darin einfügt. 
verstehen 1 läBt ${ }^{158}$.

Die stellung von v14a gibt zusammen mit seinem Inhalt einen Hinweis auf seine Funktion. Die Frage der Israeliten in 3,13 war doppeldeutig: "Was ist sein Name?" (Wie heiBt er?) und "Was bedeutet sein Name?" zu den zwei Ebenen der Doppeldeutigkeit gesellt sich eine dritte Ebene dadurch, daB die Frage durch Mose präsentiert wird. V14a ist als erste Antwort auf diese Frage auf der dritten Ebene $z u$ verstehen als eine dem Mose gegebene Information über das Wesen Gottes. Damit stimmt überein, daB die Redeeinleitung ausdrücklich Mose als Adressaten nennt (zwar auch in v15a), Gott jedoch nicht (wie in v14b.15a) den Auftrag erteilt, dies den Israeliten auszurichten. Der mit diesem exklusiven zusatzwissen ausgestattete Mose (und mit ihm der Leser) versteht mehr von Gott, als er weitersagen soll. Dieses "Mehr" besteht in Gottes Selbstaussage über sein freies, zukünftiges, nicht festzumachendes Sein. Es bewahrt Mose davor, den Namen magisch zu verstehen; er erhält damit "eine Art 'Gebrauchsanweisung' für den rechten Umgang mit dem in der gleichen szene mitgeteilten Jahwenamen" 159 .

158 Die Diskussion darüber, ob Ex 3,14a Enthüllung oder Verweigerung, Offenbarung oder verhüllung (M.Saeb $\phi$ ) des Namens Gottes sei, findet so mehrere Antworten:

1) v14a ist nicht explizit Antwort Gottes an die Israeliten auf die Frage nach seinem Namen in v13.

2) Insofern Gott eine Aussage über sich selbst macht, gibt er Mose eine Antwort, die nicht nur als Verweigerung, Verhüllung anzusehen ist. Es handelt sich um wirkliche Kundgabe seines Wesens.

3) Da aber v14a noch nicht alles zum Gottesnamen sagt (auch nicht sagen kann), muB seine Funktion im ProzeB der offenbarung erfaBt werden.

über die lautliche Ähnlichkeit zu v12a.14b hinaus, die dieselbe Wortform אהיח verwenden und somit für eine Konstanz im Wesen Gottes stehen, besagt v14a als erste Antwort auf die Frage nach dem Namen auch dadurch etwas, daB es keinen Namen nennt. Dieser Sachverhalt ist mit den Worten "Verweigerung" oder "Verhüllung" nur unzutreffend erfaßt, denn zum einen gibt Jahwe ja gleich darauf seinen Namen. Und zum anderen enthält v14a auch schon eine offenbarung.

Für das Offenlassen des "wie?" spricht auch die oft zum Vergleich mit Ex 3,14 herangezogene stelle Hos 1,9: (Und er sagte:) "Nenn seinen Namen 'Nicht-mein-Volk', denn ihr seid nicht mein volk, und ich bin 'Nicht-ich-werde-sein' für euch." In der Verweigerung wird dieses offenlassen des zukünftigen Seins Gottes auf die Spitze getrieben.

\section{R.BARTELMUS, HYH 233.}


Die Bedeutung von 3,14a liegt auch darin, die erste stufe im ProzeB der auf Gottes Aussprechen seines Namens Jahwe zulaufenden offenbarung $z u$ sein und dabei den als Selbstaussage ("Ich werde sein") zu verstehenden Namen 'Eh"yeh besser verstehen zu lassen. Mose ist der, dem anvertraut ist, auch hinter der die Bedeutung nennenden Selbstaussage ('Eh"yeh = der "Ich-werde-sein" in v14b) und dem von Gott gegebenen Namen (Jahwe = der "Er-wird-sein" in v15a) deren Verbindung zur freien Existenz Gottes zu sehen. Durch v14a bewahrt Jahwe seine Freiheit ${ }^{161}$.

(Ende des Exkurses)

\subsection{Ex 3,16-22: Jahwes Plan}

Die Beziehungen zum vorigen Bild sind hier beim übergang v15-16 deutlicher als sonst. Das Sprechen Gottes geht ohne erneute Redeeinleitung weiter ${ }^{162}$, die Schlüsselverben הל הלח verbinden mit den versen zuvor ebenso wie אמm im Reden Gottes und das Suffix der 2.P.Pl. Doch haben wir v15 vorhin auch als eine Art AbschluB erkannt; zu Beginn von v16 wird auBerdem Mose angeredet und damit vorausgesetzt, daB die in v15 den Israeliten auszurichtende Botschaft beendet ist.

Ex 3,16: "Geh und versammle die Ältesten Israels und sag zu ihnen: >Jahwe, der Gott eurer väter, ist mir erschienen, der Gott Abrahams, Isaaks und Jakobs, und hat gesagt:/ > > GewiB habe ich euch und das, was euch in Ägypten angetan worden ist, überprüft, (v17)...

ל "Geh!" Dieser Imperativ erneuert den Auftrag an Mose. Wie die anderen Aufforderungen zum Gehen $(3,10 ; 4,12)$ steht er hier nicht am Anfang des Redens Gottes, sondern folgt auf bereits Gesprochenes. In diesem Fall wird die Verbindung mit der unmittelbar zuvor ergehenden offenbarung Gottes zur Triebfeder seines Gehens. Dieses Gehen des Mose in v16 ist der Beginn einer Serie

160 Diesen Wechsel machen M.BUBER und F.ROSENZWEIG in der Übersetzung deutlich (siehe Anm.122).

161 J.J.O'ROURKE, MOses 51.

162 Noch einmal wiederholte Redeeinleitung (siehe Exkurs 1) hätte den Schwerpunkt auf v16 und das Folgende (statt auf den Namen Jahwe) gelegt. 
von Handlungen, die zum Auszug des Volkes führen, es ${ }_{16}{ }_{3}$ st (auf der menschlichen Seite) der Ausgangspunkt der Befreiung ${ }^{163}$.

V16 stellt grobteils eine verändernde Wiederholung von früher gebrauchten Ausdrücken unserer Erzählung dar. Durch die Veränderungen entstehen enge Beziehungen zu den folgenden Teilen des Buches Exodus - eine Eigenart, die wir für das ganze vierte Bild und teilweise auch für Ex 4,1-17 feststellen können. Im einzelnen:

a) "und versammle die Ältesten Israels". Aus der Reihe der בניריטראל, die in $3,15 \mathrm{zu}$ Ende ging, wird Israel aufgenommen und mit יקנ "die Ältesten" kombiniert". Die wörtliche Ausführung dieses Auftrages wird in Ex 4,29 berichtet.

b) "und sag zu ihnen": Es leitet ähnlich wie in v14b.15 innerhalb des Redens Gottes die wörtlich auszurichtende Botschaft ein. Wir begeben uns damit auf eine zweite zitatebene: Der Erzähler zitiert Gott (erste Ebene), und Gott zitiert, was er den Ältesten ausgerichtet haben möchte (zweite Ebene).

c) "Jahwe, der Gott eurer väter ist mir erschienen, der Gott Abrahams, Isaaks und Jakobs": Der große Name Gottes von v15 wird ganz aufgenommen, doch doppelt gewandelt. zum einen wird er auseinandergebrochen durch das "ist mir erschienen", das einen Rückbezug zum ersten Bild darstellt und die Erscheinung als Begründung des Folgenden heraushebt. Zum anderen wird vor Isaak und Jakob "Gott" weggelassen, was die Formel nicht mehr so feierlich macht, dafür aber unterstreicht, daB es ein Gott war, der den Patriarchen begegnete und den sie verehrten.

d) "sagend, und hat gesagt" wird zur Einführung direkter Rede verwendet. Es bezeichnet hier den übergang zur dritten zitatebene: Innerhalb seines Redens wechselt Gott vom Sprechen über sich (in der 3.P.Sg.; er/mir - Beziehung, sie entspricht der Sicht des Mose; 2. Ebene) zum eigenen, direkten Anreden (in der 1.P.Sg.; ich/euch - Beziehung; 3. Ebene). Das Folgende ist somit als persönliche Mitteilung Gottes an das Volk aufzufassen.

163 Das ist besonders deutlich im vergleich mit 3,10 und 4,12, die jeweils den letzten Vers des Redens Gottes darstellen. Hier aber folgen noch sieben Verse.

164 Es ist das erste Vorkommen der "Ältesten Israels" für den, der den Pentateuch von seinem Beginn in Gen 1 an liest. - Der zweite Teil des Ausdrucks בגיריטיאל wird am Ende des vierten Bildes, in "eure Söhne und eure Töchter" doppelt aufgenommen. 
e) "Gewis habe ich ... überprüft": Der absolute Infinitiv ist eine wiederholung der in 3,7 mit האר verwendeten Konstruktion, der die Intensität von Gottes Tun aussagt. Der Wechsel bei den Verben (von ראה 2 (פקד) bedeutet eine steigerung: Gottes Wahrnehmen ist weitergegangen zum Einsatz ${ }^{165}$. Diese überprüfung ("Heimsuchung") durch Gott stellt die Erfüllung der Vorhersage Josefs in Gen 50,24 dar, die in Ex 13,19 wörtlich (nur אלהים ist ans Ende gestellt) zitiert wird. Dazu besteht eine Verbindung mit Ex 4,31. Dort hören und akzeptieren die Israeliten diese Botschaft von Jahwes Heimsuchung an ihnen.

f) "euch und das, was euch in Ägypten angetan worden ist": פ wird mit doppeltem objekt verwendet, wobei das erste (euch) eine überprüfung im positiven Sinn (Hilfe, Nähe), das zweite eine im negativen Sinn (Gericht) erfordert ${ }^{166}$. Das zweite Objekt ist gegenüber der Darstellung der Not in 3,7-9 bemerkenswert neutral; dazu trägt das Verb עש "tun" (zusammenfassend für die Vergangenheit = Ex 1-2) und die lokale Verwendung von מצר "Ägypten" (zum ersten Mal wieder, nachdem es in v13-15 fehlte) bei. "Euch" (3x Suffix in unserem Vers) ist Fortführung der in v13 begonnenen Anrede an die Israeliten; zugleich wird durch es die spannung zwischen den schon im zweiten Bild einander gegenüberstehenden Gruppen aufgenommen: Waren es dort "mein Volk, die Israeliten" und Ägypten, so stehen sich hier im vierten Bild "ihr" und Ägypten gegenüber.

Ex 3,16 enthüllt im Voranschreiten zu zweiter und dritter zitatebene den Wunsch Jahwes, die Israeliten mit seiner eigenen Mitteilung anzureden. Die Ältesten stehen in Vertretung für sie. Diese Botschaft Gottes ist kohärent mit der bisherigen Erzählung, fast deren wesentliche Aussagen (Jahwes Erscheinen und sein Engagement für sein Volk) kurz zusammen und steht überdies in Beziehung zu Ex 4,29-31.

165 W.SCHOTTROFF, פקד 476, versteht in theologischer Verwendung (wie hier) als "aufmerksam sehen nach, achten bzw. schauen auf, sich jemandes annehmen". Damit wird mehr ausgesagt als bei 1 ikf (obwohl auch dieses Verb nicht folgenloses Wahrnehmen ausdrückt).

166 Die von G.ANDRE, Determining, erarbeitete Grundbedeutung von 7 D, , to determine the destiny", wahrt diese Doppeldeutigkeit. 


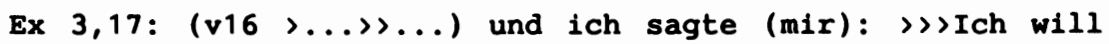
euch hinaufführen aus dem Elend Ägyptens in das Land des Kanaaniters, Hetiters, Amoriters, Perisiters, Hiwiters und Jebusiters,/ in ein Land flieBend von Milch und Honig. $\ll<<<$

Dieser Vers wiederholt zum großen Teil Ausdrücke aus v8. Einige durch den Vergleich hervortretende Änderungen tragen Bedeutung. - Die Liste der völker ${ }^{167}$ ist vor die traditionelle Beschreibung des Landes gestellt. Dieses Phänomen wird verschieden interpretiert $^{168}$. In der Anrede an die Ältesten stellt die völkerliste eine präzise ortsbestimmung dar: Die objektiven Fakten und der Bezug zur Tradition kommen vor der Attraktion durch gute Qualitäten. AuBerdem ergibt sich so ein "süBes Ende" 169 das Wort "Honig" ist das letzte wort des die Israeliten direkt ansprechenden Redens Gottes. - "Aus dem Elend Ägyptens" ist stärker als das in 88 parallel stehende "aus der Hand/Gewalt Ägyptens". פ" פ"Elend, Not" greift auf v7 zurück und stellt auch gegenüber der neutralen Benennung von v16 eine steigerung dar. - Der wichtigste Unterschied liegt im ersten wort sagte (mir)". Der damit eingeleitete Monolog Jahwes 170 führt gleichsam ins Innerste Gottes. Er gibt uns ungeschützt preis, was Gottes Absicht ist: "ich will euch hinaufführen ...".

167 Die Liste ist identisch mit der in 3,8 (siehe auch Anm.81). Von den 20 bei Frensdorff aufgezählten Listen sind nur zweimal drei gleich in bezug auf Anzahl und Reihung der Namen: Ex $3,8=\operatorname{Ex} 3,17=\operatorname{Ri} 3,5 ;$ Dtn $20,17=\operatorname{Jos} 9,1=\operatorname{Jos} 12,8$. - DaB selbst bei knapp aufeinanderfolgenden Texten die Listen verschieden sein können, siehe Ex $23,23.28$.

168 J.MAGONET, Bush 307-308, nimmt an, bei den Israeliten habe eine überlieferung von ihrem Land bestanden, und sieht in der Umstellung eine Bezugnahme auf diese bekannte überlieferung (die bei Mose in 3,8 nicht vorausgesetzt werden konnte). Gott setzte so jeweils bei dem ein, was den/die Betreffenden mehr anspricht.

- M.GREENBERG, Understanding 102, sieht in der Umstellung von v8 in $v 17$ "an inversion characteristic of resumptive repetitions".

169 Wie in 3,8 läßt sich auch hier eine Bewegung מן "von, her" - אל "hin, zu" $(2 x)$ feststellen.

170 Außerhalb der Urgeschichte gibt es nur vier Gottesmonologe im Pentateuch: Gen 18,17-19; Ex 3,17; 13,17; Dtn 32, 20-27. Siehe dazu C.J.LABUSCHAGNE, Wege 155. Ex 3,17 hebt sich von den anderen stellen dadurch $a b$, dab nur hier der Monolog im Dialog geschieht; es handelt sich also um einen zitierten Monolog. 
Ex 3,17 führt die Stufung der zitatebenen von 3,16 weiter. Das einleitende Wort "und ich dachte" vollzieht den übergang von der dritten zur vierten zitatebene (von der zu zitierenden direkten Anrede Jahwes an die Israeliten $z u$ seinem darin zu zitierenden Denken, das sein innerstes wollen enthüllt). Von der erzähltechnischen Gestaltung ${ }^{17}$ her gesehen ist es die offenbarung: So offen ist Gottes Denken bisher nie gestanden.

Ex 3,18: Und sie werden auf deine stimme hören./ Und du sollst mit den Ältesten Israels zum König Ägyptens kommen, und ihr sollt ihm sagen: >Jahwe, der cott der Hebräer, ist uns begegnet. Und nun wollen wir drei Tagreisen in die wüste gehen und Jahwe, unserem Gott, opfern.<

Die durch die verschiedenen zitate unterbrochene Mitteilung des Planes Gottes geht $\operatorname{mit}_{172}$ der Anrede an Mose (2.P.Sg.) weiter. Gehör finden, zum Pharao ${ }^{172}$ gehen und $z u$ ihm sprechen sind die nächsten Stufen im göttlichen Plan. Jede stufe kennzeichnet einen Schritt weiter in der Annäherung zwischen Mose und seinem Volk, repräsentiert durch die Ältesten. "Sie werden auf deine stimme hören" ist der Ausgangspunkt; die Adressaten nehmen die Botschaft des Mose positiv auf. Darauf folgt, daB Mose "mit" den Ältesten zum König Ägyptens geht. Das stellt bereits ein gemeinsames Tun

171 zitate im Reden finden sich häufiger, z.B. in Gen 18,$13 ; 20,13 ; 24,3.37-44 \ldots$ und oft in der Josefsgeschichte. Doch wird die vierte zitatebene für den von Gen 1 herkommenden Leser zum ersten Mal hier erreicht.

Im weiteren Verlauf von Ex finden wir ähnliches Vorgehen gleich zweimal. In Ex 4,21-23 wird für die entscheidende, an Pharao auszurichtende Botschaft "Entsende meinen Sohn ...!" die vierte zitatebene verwendet. Auch in Ex 7,14-17 (erste Plage) findet sich gestuftes zitieren. Die letzte (vierte) Stufe in $\mathbf{v 1 7}$ ist dabei jedoch der dritten (in v16 ab רמאל) sehr ähnlich, insofern es sich auch um eine an Pharao auszurichtende Mitteilung Gottes handelt. Ex 3,17 bedeutet demgegenüber mit der Enthüllung des innersten Denkens und Wollens Gottes einen Schritt weiter in der offenbarung.

172 "Hören auf die stimme" verbindet mit dem vierten Bild. - Der "König Ägyptens" ist mit dem Pharao von 3,10-11 identisch. Die andere Benennung scheint stilistisch und inhaltich bedingt zu sein: Sie führt die Reihe von "Ägypten" weiter und stellt den Repräsentanten eines Volkes (Älteste und Mose) den eines anderen Volkes bzw. Landes entgegen (während in v10-11 Mose und Pharao einander als einzelne gegenüberstanden). 
dar, wobei die Führung noch klar bei Mose liegt. Dann redet "und ihr sollt ihm sagen" bereits von einer Einheit, die Mose und die Repräsentanten des volkes umgreift ${ }^{173}$. Den Höhepunkt findet die zusammenschliebende Bewegung darin, daB diese Einheit in vierfachem "wir/unser" ${ }^{174}$ vor dem fremden Herrscher bekannt wird. Die in v12 insinuierte Identifizierung Moses mit seinem Volk wird hier von Gott erneut suggeriert.

Der längste Vers unserer Erzählung bietet noch andere Auffälligkeiten.

a) Vor dem König Ägyptens bezeichnet Jahwe sich als "Gott der Hebräer"175. Indirekt, auf dem Weg über die Gottesbezeichnung, wird also eine Identität der in v13-16 mit "euch" angeredeten Gruppe mit den Hebräern angenommen. Damit besteht nun auch für das Volk (wie für Jahwe in v15) eine dreigliedrige semantische Gleichung: "mein Volk = die Israeliten = die Hebräer".

b) "ist uns begegnet" legt die Erscheinung (האר Ni) an Mose und seine folgende Vermittlung der Botschaft Gottes an die Israeliten als Gottesbegegnung (אר Ni) aus. Es markiert damit neben

173 Damit wird das letzte Mal אמר im Reden verwendet; die Reihe von v13-18 geht zu Ende.

- Zum "ihr" siehe Textanmerkung a zu v18 in der BHS, wo zwei Manuskripte, die LXX und die vulgata durch das Beharren auf der 2.P.Sg. diese Entwicklung verlorengehen lassen, und die Analysen zum Gebrauch der Personen oben in v11-13.

174 Dem Gebrauch der 1.P.Pl. in der Bibel ist bisher wenig Aufmerksamkeit geschenkt worden. Das trifft jedoch nicht zu für die Verwendung des "wir" durch Gott in Gen 1,26; 3,22; 11, 7; siehe dazu P.MILLER, Genesis 9-26. Auch ist diesbezüglich unlängst eine studie zu den Psalmen erschienen: J.SCHARBERT, Das "Wir" in den Psalmen auf dem Hintergrund altorientalischen Betens.

Wohl aber gilt es für die Verwendung des "wir" in erzählenden Texten durch Menschen. Die 1.P.Pl. ist oft der pointierte Ausdruck einer Gemeinschaft, die angefochten wird (z.B. Gen $26,20 ; 31,14-16)$ oder erst noch definiert werden muB (z.B. Gen $34,14-16 ; 37,7-10)$. Die Häufung des "wir" in der Josefsgeschichte ist dabei bemerkenswert.

kontrahiert.

175 Nach P.JOüON $\S 90$ b, wird der Plural םי? meist zu םי-

Ex 3,18 ist das erste Vorkommen von "Gott der Hebräer" und das einzige von עבריים (also der nicht kontrahierten Form) in der Bibel. - O.LORETz, Habiru 181-182, rechnet alle Belege von עבר in die nachexilische zeit: "Mit "פבר wird ein Angehöriger der nachexilischen jüdischen Gemeinschaft bezeichnet." Doch hat H.ENGEL in seiner Rezension dieses Ergebnis in Frage gestellt. Siehe dazu auch D.N.FREEDMAN, B.E.WILLOUGHBY, עברי 1039-1056, und darin besonders den zusatz von H.-J.FABRY auf S.1055. 
der Gemeinsamkeit auch einen Unterschied zwischen Mose und Volk in bezug auf die Gottesbeziehung.

c) Der letzte Teil von v18 bringt ein doppeltes Verlangen zum Ausdruck: drei Tagereisen in die wüste gehen und Jahwe opfern. Diese Bitte um die Opferreise wird ein wichtiger Punkt in der Auseinandersetzung mit dem Pharao werden. Die zeitspanne von drei Tagen hat dabei eine symbolische Bedeutung . Die Verehrung Jahwes wird hier wie in v12 der Faktor, der die verschiedenen an ihn Glaubenden vereint. Diese Bewegung kulminiert in der letzten neuen Gottesbezeichnung "Jahwe, unser Gott" 177 .

Diese Formel "Jahwe unser Gott" begegnet hier zum ersten

176 Für die Symbolik von drei Tagen im AT siehe C.BARTH, Theophanie: Dem dritten Tag kommt eine besondere Bedeutung als Wende- und Höhepunkt, als neuer Anfang im Bund mit Jahwe zu (532). Vgl. auch $B$. de MARGERIE, Le troisième jour.

Verfolgt man das Thema der drei Tage bis Ex 15, so taucht es wieder auf in 5,$3 ; 8,23$. Mit ihm wird das schon beobachtete vorgehen einer Wissensdifferenz weitergeführt, wobei dieses Mal der Pharao derjenige ist, der weniger weib als Mose und der Leser. Für die israelitische Seite ist es klar, daB es sich um einen definitiven Aufbruch und anschlieBendes Hineinziehen in das Land handelt. (Für eine Interpretation in diesem sinn siehe weiter unten die Analyse von 3,21-22.) Dem pharao gegenüber wird aber nur von einer dreitägigen Opferreise gesprochen. Handelt es sich um bewuste Täuschung, mit der Konsequenz, Gott anzusehen "as working within the framework of human frailty" (M.GREENBERG, Understanding 85)?

Ein Ausweg bietet sich vielleicht durch die rabbinische Lösung an, wenn man die Orts- und zeitangaben für den Auszug der Israeliten studiert. Dreimal brechen die Israeliten auf $(12,37$; $13,20 ; 14,15)$, womit drei Tage bezeichnet sein könnten. (Eine Schwierigkeit besteht jedoch darin, daB am zweiten Tag in 13,20; 14,2 ein zweimaliges Lagern geschildert wird. Das zweite Lager könnte aber mit einem Ausruhen vor dem bevorstehenden Nachtmarsch 14,19-22 erklärt werden.) Am dritten Tag, morgens (14,24.27), errettet Jahwe die Israeliten aus der Hand der Ägypter, die durch ihre Verfolgung nun keinen Anspruch darauf haben, daB die Israeliten ihnen gegenüber Wort halten, und (als Tote) keine Möglichkeit mehr haben, die Einlösung der verpflichtung zu fordern.

"Wüste/steppe" greift die Ortsbezeichnung von v1 auf und verbindet so mit der Erscheinung Gottes an Mose und (über "Berg") auch mit v12 und der dort erwähnten verehrung (עכר). Für die semantische Differenz zu בז siehe J.FLOSS, Dienen 201-202.

177 Alle hier genannten Besonderheiten (a-c) verbinden mit Ex 5,3, wo sie wörtlich wiederholt und die in ihnen enthaltenen Bitten abgelehnt werden. Ausnahmen davon bilden nur "Jahwe", das aber bereits in 5,1-2 genannt wird, und "und nun", das von Mose und Aaron dem Pharao gegenüber doch vielleicht als etwas zu forsch empfunden wurde und deshalb ausgelassen ist. 
Mal in der Endgestalt des Pentateuch ${ }^{18}$. Im Unterschied zu allen bisherigen Bezeichnungen drückt diese Benennung (durch die in ihr enthaltene 1.P.Pl.) die Beziehung zwischen Gott und den ihn Verehrenden direkt aus. Keine andere Formel in unserem Text bringt das wechselseitige Verhältnis zwischen Jahwe und der Gemeinschaft der an ihn Glaubenden besser zur Sprache. Diese Formel "Jahwe unser Gott" ist Bekenntnis der Ältesten und Moses vor Pharao, sie entspricht also der sicht der Israeliten. Vorerst aber besteht dieses Bekenntnis nur im Reden Gottes, d.h. er legitimiert und wünscht dieses Bekenntnis.

Nach den vielen von Gott für sich vorgebrachten Benennungen (3,6.14-15) schliebt diese letzte neue Bezeichnung nicht nur Gottes Reden von sich in Benennungen, sondern auch sein Anführen von zitaten in unserem Text ab. "Jahwe unser Gott" steht an diesem Ende als Programm: als von Gott selbst autorisierte zusammenfassung dessen, wie er genannt (und angerufen) werden kann; als von Gott gefordertes Bekenntnis vor dem Pharao; als von Gott intendierte Einheit all derer, die sich zu ihm bekennen.

Im Plan Gottes stellt uns 3,18 eine Einheit von Mose und Volk in Tun und Denken vor, die diese vom Pharao eine dreitägige Opferreise zu Ehren des gemeinsamen Gottes Jahwe erbitten läBt. Die Selbstbezeichnung Jahwes als Gott der Hebräer und die Entwicklung von einem mit zunächst individueller Rolle versehenen Mose zu seinem zusammenschluB mit dem volk setzen darin besondere Akzente. Betonter, programmatischer schluBpunkt ist das erste Vorkommen von "Jahwe unser Gott".

178 "Jahwe unser Gott" kommt Insgesamt 101x in der hebräischen Bibel vor. Für die Belege siehe die Konkordanz von A.EVEN-SHOSHAN; dabei sind zu den von ihm genannten Vorkommen (Nummern 2220-2310) auch die Belege unter den Nummern 2163-2168, $2183,2185,2322$ (Esr 9,8) und 2336 (2 Chr 20,12) dazuzuzählen. Daneben gibt es noch Formulierungen wie "Jahwe zebaoth unser Gott" (Jer 23,36) oder solche, in denen "Jahwe" und "unser Gott" parallel verwendet werden (Ps 18,32). Die Verteilung im Pentateuch ist auffällig: "Jahwe unser Gott" kommt nur in Ex $(3,18$; $5,3 ; 8,6.22-23 ; 10,25-26)$ und Dtn (23x; aber nux im "Rahmen" Dtn 1-6 und 29) vor. $2 u$ erwähnen sind auch die vielen vorkommen in Jer $(19 x)$ und den Chrontkbüchern (15x). 
Ex 3,19: "Ich aber weiB, daB der König Ägyptens euch nicht gehen lassen wird,/ es sei denn, wegen einer starken Hand."

In adversativem Sinn $z u$ deutendes - $"$ "(ich) aber" leitet einen neuen Abschnitt ein, der vom Widerstand des Königs Ägyptens und von seiner überwindung berichtet (v19-22). Hatte bisher der Plan auszurichtende bzw. zu erfüllende Aufträge an Mose enthalten (v16-18), so entfaltet sich jetzt Gottes Vorherwissen in die Ergebnisse hinein.

"Nicht gehen lassen" wird die Antwort des Pharao auf die Bitte der Israeliten in 18 sein. Diese Aussage nimmt seine Ablehnung von Ex 5-11 vorweg, die dort allerdings, parallel zu Ex 4,21, mit של $\mathrm{Pi}^{179}$ verbunden ist. Der Widerstand wird überwunden werden durch die "starke Hand", ein seltsam offen bleibender Ausdruck $^{180}$. Damit entsteht eine Opposition zu Tr in v8: 2wei Gewalten stehen einander gegenüber.

179 Sonst steht של Pi "entsenden" verneint: Ex 4,21; 8,28; $9,7.35 ; 10,10.20 .27 ; 11,10$.

" הלף " Infinitiv vohen lassen" scheint innerhalb von Ex 3-11 hier das einzige Mal für die Weigerung zu stehen.

180 ביד חז ביד 32,11 (6x in Dtn; vgl. auch Ez 20,33-34). Zum selben semantischen Feld gehören auch die Ausdrücke יד "mit der Stärke der Hand" (Ex 13,3.14.16) sowie das Ausstrecken von Jahwes Arm/Hand (Ex $6,6 ; 7,5 ; 9,15 \ldots)$.

An den ersten drei stellen bleibt unklar, wessen Hand es ist; vielleicht handelt es sich, gerade in 6,1, sogar um bewubte Zweideutigkeit: Die Präposition - kann sowohl mit "mit" (dann wäre das Subjekt der Verben, nämlich der Pharao gemeint) als auch mit "wegen" (dann wäre Jahwe gemeint) übersetzt werden. Die letzten beiden stellen in $\mathrm{Ex}(13,9 ; 32,11)$ sind $k l a r$ auf Jahwe zu beziehen.

In dieselbe Richtung geht eine weitere Beobachtung: In Ex 115 ist 7 nie die Hand des Pharao (vgl. besonders 14,31). Im Zusammenhang der gesamten Erzählung (siehe hier auch 3,20) kann also nur Jahwes Hand gemeint sein.

J.K.HOFFMEIER, Arm 380-385, zieht eine Parallele zu dem in ägyptischen Texten wiederholt beschriebenen mächtigen Arm des Pharao, der als von der Kraft des höchsten Gottes erfüllt gedacht wurde. Die biblischen Schriftsteller setzen polemisch den Arm Jahwes dagegen (S.386), der im Sieg über den Pharao seine ubberlegenheit auch über die ägyptischen Götter beweist (S.387). 
Ex 3, 20: "So werde ich meine Hand ausstrecken und Ägypten mit all meinen Wundertaten schlagen, die ich in seiner Mitte tun werde./ und danach wird er euch entlassen."

Das offen gebliebene 7$\urcorner$ wird durch das Suffix der 1.P.Sg. geklärt: Es ist Gottes Hand/Macht, die er entsendet ${ }^{181}$. Der ganze erste Halbvers nimmt in Vokabular und Inhalt die Plagenerzählungen vorweg. Als Erklärung von v19b führt er die überwindung von Pharaos Widerstand breiter aus. Fünfmal (drei Verben und zwei Suffixe) redet Gott dabei von sich in der 1.P.Sg. Das unterstreicht sein machtvolles Eingreifen und entspricht in etwa v7 (drei Verben und ein Suffix der 1.P.Sg. für Gott). Das Tun Gottes steht nicht hinter seinem Wahrnehmen zurück.

Die engen Berührungen im Vokabular erstellen eine unbezweifelbare Beziehung zwischen v20a und den Plagenerzählungen. Doch scheint v20a eine Art zusammenfassung darzustellen, weil er einzelne charakteristische Ausdrücke in eigener Weise verwendet oder kombiniert. Im einzelnen:

a) "meine Hand ausstrecken" verbindet vor allem mit Ex 9,15 (7.Plage; Hagel) "denn nun strecke ich meine Hand aus und schlage dich und dein volk". Sonst verwenden Ex 7,4.5 noch "meine Hand" für Gott, und 9,3 redet von Jahwes Hand.

b) "ich schlage": נכה Hi wird öfter für Jahwe verwendet" ${ }^{183}$. Neben dem soeben erwähnten Ex 9,15 (und auch v25) wird es für das Schlagen von Menschen vor allem in Ex 12 bei der Tötung der Erstgeborenen gebraucht.

c) "Mit all meinen Wundertaten": Sicherlich sind die vielen Zeichen und Wunder Gottes (תix und מכת in 7,3) gemeint, die die Plagen darstellen. Das hier gebrauchte hebräische Wort jedoch findet sich nie in den Plagenerzählungen, und sonst nur noch einmal im Buch Exodus $(34,10)$, wo es sich auf zukünftige Wundertaten Gottes bezieht. Die besondere Note an diesem wort entsteht durch die Wurzel בלא, die überwiegend Gottes Rettungs-

181 Damit ist nachträglich auch für v19 79 als Jahwes Hand zu verstehen.

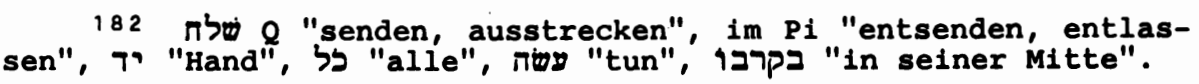

183 נכה Hi für Gott: Ex 9,15; 12,12-13.29. 
handeln bezeichnet" . כל "alle" weist auch auf den zusammenfassenden Charakter der Aussage hin" ${ }^{185}$.

d) "die ich in ihrer Mitte tun werde": Im Reden Gottes sind uns schon oft Relativsätze begegnet (v5.7.9.14). Das Verb עש "tun" kann Stufen im göttlichen Plan bezeichnen ${ }^{186}$; hier entsteht durch es eine Verbindung zu v16 ("was euch getan wurde"). Es gibt eine Beziehung zwischen dem Tun der Ägypter und Gottes. "In seiner Mitte" findet sich noch einmal in Ex 10,1 (achte Plage; Heuschrecken) und als "inmitten des Landes" in 8,18 bei der vierten Plage (Fliegen).

V20b schildert den erfolgreichen Ausgang. In einem Wortspiel mit אחריצין "danach" kommt innerhalb der Plagen nie vor. Einzig in der Ankündigung des Todes der Erstgeburt finden wir es zweimal: Ex 11,1. $8^{188}$.

Einige Entsprechungen prägen Ex 3,20: Die Intensität, mit der Gott sein zukünftiges Eingreifen beschreibt, entspricht der

184 R.ALBERTz, פל 418, zeigt zwei weitere Aspekte an dem mit der Wurzel פל bezeichneten Rettungshandeln auf: die dazugehörende staunende Reaktion des Menschen und den zusammenfassenden Charakter von פל פל. Ein so bezeichnetes Tun Gottes bleibt dem Menschen im letzten unerklärlich.

185 Das wird auch deutlich im Blick auf Ex 4,21; 11,10, die beide mit מפת "Wunder" verbunden sind und als äuBerer Rahmen die Plagenerzählung umspannen. - Dasselbe Nomen מפ verbindet sich auch zweimal mit רכה Hi "vielmachen", wodurch ein innerer Rahmen (Ex 7,$3 ; 11,9)$ entsteht.

Zur Verwendung von כל vgl. auch Ex 9,14 "alle Plagen" und den Ausdruck כל כלדרור (2x); $12,12.29(2 x)$.

186 J.L.SKA, Passage 44, bel der Interpretation von Ex $14,1-14$.

187 Siehe 2.2.2. חל wird zur tatsächlichen Entsendung verwendet in 12,$33 ; 13,17 ; 14,5$. - Weitere für die Entlassung der Israeliten verwendete Verben sind הל הל "gehen" $(3,19 ; 12,31-32)$, גרים 1 "vertreiben" $(6,1 ; 11,1 ; 12,39)$, "hinausgehen" $(11,8$; $12,31)$.

188 Darin geschieht ein weiterer Wechsel von Schlüsselverben: In $v 1$ steht noch $i$ b $P_{1}$ "entsenden", in v8 $\mathrm{ky} Q \mathrm{Q}$ gleich dreimal, das das freie Gehen/Verlassen herausstreicht.

Es scheint aufgrund dieses Befundes, daB v20b das Ende der Plagen ankündigt. Während v20a stärker mit den Plagen selbst verbunden ist, bestehen die Beziehungen bei v20b nur mit Ex 1114. 
Darstellung seiner Wahrnehmung in 3,7; die Ausdrücke stellen eine Opposition zwischen Jahwes Tun und dem der Ägypter $(3,8.16)$ her; dazu bringt das "Schlagen" der Ägypter ${ }^{189}$ eine inhaltiche Parallele zur Bedrückung der Israeliten in 3,7-9. DaB es sich hier jedoch nicht um eine Art Vergeltung handelt, wird aus der Begründung in v19 ersichtlich: Die Weigerung des ägyptischen Königs löst die Bestrafung aus. Die beiden folgenden Verse bestärken dies.

Die Entsprechungen von Ex 3,20 beziehen sich nicht nur auf unsere Erzählung; als Vorankündigungen geben sie dem Leser einen Blick in die zukunft. Diese Ausschau betrifft eher die Plagen als Ganzes denn einzelne Plagenerzählungen.

Ex 3,21: "Und ich werde diesem Volk in den Augen der Ägypter Gunst verschaffen,/ und es wird sein: Wenn ihr geht, geht ihr nicht leer."

Während beim ägyptischen König der Widerstand durch Bestrafung überwunden werden muB, wird das Volk (die Israeliten) bei den Ägyptern Gefallen finden ${ }^{190}$. Letzteres ist das Werk Jahwes; Jahwe bewirkt, daß die Ägypter den Israeliten gegenüber positiv eingestellt sind. Es bestehen wörtliche Verbindungen zu Ex 11,3 und 12,36. Damit geschieht bereits (wie in v20b) ein Schritt über die in v20a gesehenen Beziehungen zur Plagenerzählung hinaus. Im Plan Gottes stehen wir unmittelbar vor dem Auszug.

189 Ges.B.454 versteht unsere stelle im Sinne von "Volk" (die Ägypter). Da sich der Singular des Suffixes im Relativsatz darauf beziehen.

Vielleicht ist durch die Vermeidung des eindeutigen "die Ägypter" eine bewußte Zweideutigkeit erzielt worden, die eine Schwebe zwischen Land- und Volksbezeichnung erreicht und so mit wenigen Ausnahmen, wo die Schuldzuschreibung deutlich wird $(3,9.19)$, ם? 2 ?war als gegenüberstehende Macht, aber eher symbolisch, nicht moralisch wertend auffassen läBt.

190 In der Auslegung der folgenden zwei Verse stütze ich mich neben D.DAUBE, pattern 55-61, vor allem auf Y.T.RADDAY, Spoils 127-147.

נתן ist eine hebräische Redewendung und nach Radday "practically intranslatable"; in sei hier am besten mit "Charme" wiederzugeben. 
Ein Wortspiel mit dem zweiten Schlüsselverb des semantischen Feldes (הלק) beschreibt die Weise des Auszugs. Die Israeliten werden "nicht leer" gehen. Was ist darunter zu verstehen? Der Ausdruck ר kommt innerhalb der Auszugserzählung nicht mehr vor, obwohl er sich wegen des Verbs auf sie beziehen muB. So bietet sich ein inhaltliches verständnis von apr 7 im sinn des folgenden Verses $(3,22)$ an: Israel wird mit geschenkten Gegenständen aus Silber und Gold und mit Mänteln/Decken Ägypten verlassen $^{191}$. Das Wort apיר läBt dabei jedoch zwei übertöne mitschwingen. Im Buch Exodus kommt es noch zweimal vor, in 23,15 und 34,20. Die beiden Sätze sind identisch: "und niemand soll vor mir leer erscheinen" und besagen, daß man mit Gaben vor Gott kommen muB. Die beabsichtigte Opferreise der Israeliten sieht also auch ein solches Mitbringen von Gaben voraus. Der zweite überton ergibt sich durch das Gesetz der Sklavenbefreiung in Dtn 15,13, wo auch dieses Wort "leer" verwendet ist. Ähnlich darf Israel, das als Sklave im Dienst Ägyptens gearbeitet hat, von diesem nicht leer entlassen werden.

Ex 3,22: "Und es soll jede von ihrer Nachbarin und von ihrer Hausgenossin Gegenstände aus Silber und Gegenstände aus Gold und Mäntel erbitten, / und ihr werdet sie euren Söhnen und euren Töchtern anlegen. So werdet ihr Ägypten frei machen."

Der letzte Vers des vierten Bildes ist in sich nicht schwer verständlich. Doch hat die Auslegung des letzten Satzes, der so-

191 DaB "Israeliten" nicht leer aus Ägypten ausziehen, hat in der Abrahamsgeschichte eine Parallele (Gen 12,10-20) und eine Vorankündigung (Gen 15,14). D.DAUBE, Pattern 57-60, spricht sich für die Verbindung mit dem Sklavinnen- und Scheidungsrecht aus.

"Mantel, Obergewand, Kleidung" ist in seiner genauen Bedeutung hier schwierig zu bestimmen; es taucht noch zweimal im größeren Erzählzusammenhang auf (Ex 12,34.35). Letztere stelle ließe eher an eine Art Tuch denken, mit denen die BackgefäBe eingewickelt wurden; nachdem die Israeliten ihre eigenen (v34) dafür verwendet hatten, werden sie (v35) von den Ägyptern mit zusätzlichen versorgt. - In Ex 19,10-14 sind mit הini jedoch eindeutig die Kleider gemeint. Der letzte Beleg für שמלת in Ex $(22,25)$ verbindet beide Bedeutungen, da der folgende Vers zeigt, daB Kleidung/Mantel als Decke verwendet werden. שמלח scheint so einen Mantel ohne Ärmel, ein großes Gewand zu bezeichnen, in dem man etwas tragen kann. 
genannten "Beraubung" der Ägypter, immer wieder Schwierigkeiten bereitet.

Was die zeitliche Abfolge betrifft, so war bereits am Ende von v21 vom Auszug die Rede. Das Fragen/Bitten der Nachbarinnen von $\mathbf{2 2}$ bedeutet demgegenüber einen Schritt zurück. Eine ähnliche zeitliche Umkehr stellten wir schon einmal am Ende eines Bildes fest (in v6 kommt das Gesichtverbergen vor dem zeitlich vorausliegenden Fürchten); sie unterbricht im Erzählen die normale zeitliche Abfolge entsprechend dem Geschehen. Der Rückgriff auf eine Handlung zuvor bewirkt ein Innehalten in der Erzählbewegung $^{\text {. }}$.

In den letzten beiden Versen hatten wir Doppelungen der beiden Schlüsselverben gefunden. Hier nun werden dreimal in der Bedeutung ähnliche Nomina gedoppelt: ihre Nachbarin und ihre Hausgenossin $^{193}$; Gegenstände aus Silber und Gegenstände aus Gold; eure Söhne und eure Töchter.

Wie das "Gefallen finden" von v21 verbinden 194 ללי שאל mit Ex 11,2-3 und 12,35-36. Die letzte stelle macht durch deutlich, daß die Ägypter selbst sie geradezu drängten, etwas zu erbitten. שמלה "Kleid/Mantel/Decke" stellt eine lockere Verbindung zum Auszug und zur Sinaitheophanie ${ }^{195}$ her.

192 Viermal 2.P.Pl., die nachher mit Ausnahme von 4,15 nicht mehr in unserer Erzählung vorkommt, verstärkt diesen AbschluB.

193 RASCHI, Kommentar zur stelle, nimmt an, daB die Israeliten in Ägypten keine eigenen Häuser hatten. Deswegen hätten die israelitischen Frauen bei den (ägyptischen) Frauen, in deren Häusern sie wohnten, um diese Gegenstände gefragt.

194 Y.T.RADDAY, Spoils 136, möchte unter כל hier kleine Kunstgegenstände, Souvenirs verstehen (vgl. Gen 24,53). Die Deutung als Souvenir paste gut zum friedlichen Abschiednehmen.

- D.DAUBE, Pattern 57, weist darauf hin, daB eine übersetzung von לש mit "ausleihen" wegen des Kontextes hier nicht möglich ist.

Es ist verlockend zu fragen, ob eine Beziehung zur Erzählung vom Goldenen Kalb (Ex 32 ) besteht. Doch sind die dafür verwendeten Gegenstände als "Goldringe" (נזמי הזהב) bezeichnet.

195 Vgl. zuvor Anm. 191. 
Die vorhin genannten Ausdrücke wie auch die Tatssache ihrer Doppelungen weisen auf ein friedliches Abschiednehmen ${ }^{196}$ hin. Die meist gebräuchliche übersetzung für ben" schafft dazu einen starken Kontrast. Doch ist sie nicht zwingend $^{197}$, im Gegenteil, von der semantischen Valenz von נצ', von der Parallele in Ez 14,14 und von der Einfügung in den Kontext legt sich ein Verständnis von "und ihr werdet Ägypten retten/befreien" 198 nahe. Gottes Vision des Auszugs der Israeliten sieht in ihrer Befreiung auch eine Errettung der Ägypter.

Das hier vorgeschlagene Verständnis sieht in Ex 3,22 ein friedliches, freundschaftliches Auseinandergehen und ist so sowohl innerhalb des Verses (Bitte um Geschenke) als auch mit v21 (Gnade) kohärent. Die Art der Schilderung (Souvenirs, Gehen mit allen Kindern) läßt darin einen endgültigen Abschied erkennen.

196 Y.T.RADDAY, Spoils 139, spricht sogar von "pilgrimage", zu der die Israeliten von den Ägyptern verabschiedet werden.

197 Die anderen drei Stellen für נצ Pi sind Ex 12,36; Ez 14,14 und 2 Chr 20,25. B.S.CHILDS, Exodus 175-177, Exkurs II "The Despoiling of the Egyptians", sieht darin, das die Israeliten "leave Egypt as victors from a battle". Seine Deutung stützt sich jedoch auf die Chronikstelle, wo aber die, die beraubt werden, mit der Präposition $-\zeta$ eingeführt werden. Anders dagegen in Ez 14,14, wo נצ Pi "retten" bedeutet und das Objekt (נפטם "ihr Leben") ohne Präposition genannt wird. Für diese Interpretation von gצ $\mathrm{Pi}$ im Sinn von retten siehe Y.T.RADDAY, Spoils 142-144.

- Die Bedeutungen von $\mathrm{Pi}$ und $\mathrm{Hi}$ (in unserem Text in 3,8) kommen dadurch einander sehr nahe.

Tatsächlich ist die Chronikstelle eher eine stütze für die von Radday vorgeschlagene Bedeutung denn für "berauben": EÜ, NBE, RSV und TOB übersetzen mit "sie nahmen für sich (bis sie es nicht mehr tragen konnten)"; die eigentliche plünderung dagegen wird im selben Vers zweimal mit בזו wiedergegeben.

198 Y.T.RADDAY, Spoils 145, plädiert für ein zweifaches Verstehen als $\mathrm{Pi}$ und $\mathrm{Ni}$ : a) "you shall redeem Egypt"; b) "you shall be redeemed with (N) Egypt". - Die vielen Doppeldeutigkeiten bisher in unserem Text würden so um eine vermehrt werden.

Die Schwäche dieser übersetzung mit "retten/befreien" besteht darin, daB sie das sonst diesem Wort לy innewohnende Moment "mit Gewalt (gegen den Willen des Gegners) herausreiBen" nur unzulänglich wiedergibt und auch nicht deutlich macht, worin die Rettung für Ägypten besteht. Für Letzteres könnte jedoch evtl. Ex 12,29-33 eine Lösung bieten: Der Auszug der Israeliten bewahrt die Ägypter vor weiterem Unheil oder Tod. Das gilt aber nicht für die, welche verfolgend nachsetzen (Ex 14). 


\section{Rückblick auf den Plan Jahwes}

Im vierten Bild unserer Erzählung macht Gott Mose in zwei Stufen mit der zukunft vertraut. Zuerst, bis v18, erhält Mose einige Aufträge, die ihm die konkreten schritte zur Verwirklichung seiner Sendung zeigen sollen und sich an die erneute Aufforderung $z u$ gehen anschließen. Dann, ab v19, folgen Vorhersagen über das Verhalten des Pharao und seiner Untergebenen gegenüber den Israeliten und dem für sie sich einsetzenden Gott.

Das vierte Bild entfaltet sich in zwei entgegengesetzte Richtungen. Zum einen nimmt es (in v16-18) Elemente aus allen drei vorangehenden Bildern auf: ראה Ni aus dem ersten Bild; viele Ausdrücke in v16-17 greifen auf das Anliegen Gottes (2.Bild) zurück; die Gottesbezeichnungen und Gottes Reden von sich selbst verbinden mit dem dritten Bild. zum anderen kündet es (in v1622) an, was in Ex 4-12 folgen wird. Diese Ansage der zukunft enthält mehrere Momente. - Darin, daB Gott die kommenden Ereignisse so genau vorhersagen kann, geschieht eine Bestätigung des durch die Deutung אהיה v14b gegebenen Aspektes im Gottesbild. Jahwe ist einer, der die zukunft in Händen hält. Geschichte kommt so der Verwirklichung seines willens gleich. - Mose erscheint als der Vertraute Gottes. Er erhält Einblick in den göttlichen Plan (vgl. Am 3,7). Er weiB um das ziel und den Ablauf des göttlichen Rettungshandelns. - wo es um die zukunft geht, hat der Mensch nichts zu sagen: Mose bleibt völlig stumm.

Die Art und Weise, wie diese Zukunftsansagen sich auf die folgenden Ereignisse beziehen, verdient nähere Aufmerksamkeit. Es ist verständlich, $\mathrm{daB}$ auch die beiden folgenden Bilder (Jahwes Machterweis in 4,1-9 und die Mitbestellung Aarons in 4,10-17) die Durchführung beeinflussen. Doch finden, mit dieser Einschränkung, fast alle die zukunft ansagenden Ausdrücke wenigstens einmal in 
Ex 4,29-13,9 wörtlich Verwendung ${ }^{199}$. Die Untersuchung dieser Verbindungen $z u$ den nachfolgenden Erzählungen zeigt mehreres:

- Die Beziehungen bestehen nicht so sehr mit den einzelnen Plagenerzählungen $^{200}$ als vielmehr mit ihrem Rahmen bzw. der zwar variierten, doch in vielen Plagen $z u$ findenden Entlabforderung und ihrer Ablehnung durch den Pharao. - Besondere Beziehungen bestehen zur Rahmung der Plage der Erstgeburt und dem ihr folgenden Abschied Ex 12. - Ein Durchgang durch Ex 4-15 läBt neben dem stärkeren Eingehen auf die einzelnen Plagen folgende fehlenden Elemente erkennen: Aus c5 fehlt der widerstand des Volkes (er wird in 4,1-9 gebracht); die Theologie von Ex 6,2-8 ("ich bin Jahwe"; das Thema der Erkenntnis Jahwes, das auch in einzelnen Plagen wieder aufgenommen wird) scheint in Ex 3-4 zu fehlen (doch liefert die offenbarung des Jahwenamens dafür die Voraussetzung); ebenso findet sich keine Anspielung auf das Pascha oder auf die Schilfmeererzählung. - So zeigen sich insgesamt enge Beziehungen von Ex 3,16-22 zu Ex 4,29-5,3, zu Ex 11 und zu Ex 12,29-36. Diese Verbindungen mit dem übergreifenden Rahmen der Plagenerzählungen lassen uns zusammen mit dem Fehlen bestimmter Ausdrücke aus ${ }_{201}^{\text {Ex }}$ 6,2-8, aus einzelnen Plagen und aus der Schilfmeererzählung besser die Art des zukunftsbildes erkennen, das Ex 3,16-22 entwirft. Das vierte Bild spricht von den folgenden Ereignissen in groben zügen und eher optimistisch. Mit Ausnahme des Widerstandes

199 Die Verbindungen sind:

3,16 mit 4,29-31: die Altesten versammeln und ihnen Gottes Wort ausrichten; $3,18 \mathrm{mit} 5,3$ : zum Pharao gehen und ihm sagen ...; 3,19a mit (der Ablehnung in) c5: der Pharao wird euch nicht entlassen; $3,19 \mathrm{~b}$ mit 6,$1 ; 13,9$ : die starke Hand; 3,20 mit 7,5; 9,3.15: die Hand (senden); 3,20 mit $11,5.10 ; 12,12.29$ : "alle"; 3,20 mit 6,$6 ; 7,3.9 ; 11,9-10$ : die Wunder (allerdings wird dabei statt מפלאות das Werwendet); 3,20 mit 8,$18 ; 10,1$ : in seiner Mitte; 3,20 mit 11,8: danach; 3,20 mit 12,31-33: er wird euch entlassen (diesbezüglich finden sich viele Ankündigungen, Aufforderungen und Absichtserklärungen dazwischen); 3,21 mit 11,3; 12,36: Gnade finden; 3,22 mit 11,2; 12,35.36: Gegenstände, "befreien".

200 Vielleicht mit Ausnahme einer Formulierung der siebten Plage in 9,15 .

201 Natürlich kann aus dem Fehlen von Ausdrücken nicht viel geschlossen werden. Doch sind die obigen Beobachtungen vielleicht mit der von D.MCCARTHY, Plagues 155, geäuBerten Ansicht zu vergleichen, daB Ex 7,8-10,27 mit c5 und c14 zusammengehören, während $\mathrm{Ex} 6,2-7,7$ eher mit $c 11-12$ (13) zu verknüpfen ist. Siehe dazu auch S.Ö.STEINGRIMSSON, Vom Zeichen zur Geschichte. 
des ägyptischen Königs, der aber durch Gottes Eingreifen überwunden wird, geht alles glatt.

In diesem vierten Bild konnten wir den Gebrauch zweier Erzähltechniken beobachten, die Entscheidendes darlegen. Das stufenweise zurückschreiten in den zitatebenen führte zu einer offenlegung des innersten Denkens Gottes. Der Kern seines Planes besteht in der Hinaufführung in dieses prächtige Land der sechs völker. Die andere Technik bestand in der zunehmenden Identifizierung Moses mit seinem Volk innerhalb des Redens Gottes, die bis zum Bekennen dieser Einheit im Gebrauch der 1.P.Pl. vor Pharao geht.

Der Plan Gottes präsentiert uns ein fast neutrales Bild von Ägypten. Obwohl es in jedem Vers von 3,16-22 vorkommt, ist nie als Grund eines den Israeliten angetanen Bösen genannt (wie z.B. in 3,9$)$. Auf diesem Hintergrund hebt sich das Geschehen der Verse 3,19-20 ab; in 3,19 leistet der ägyptische König dem Plan Gottes Widerstand, und in v20 schlägt Gott Ägypten. Doch lassen gerade die beiden Schlubverse erkennen, daB die Beziehung zwischen den beiden Größen Ägypten und Israel freundschaftlicher wird.

\subsection{Ex 4,1-9: Jahwes Machterweis}

Sprecherwechsel und verändertes Vokabular signalisieren den Übergang zum fünften Bild. "Wird Gottes Botschaft Glauben finden?" ist nun das neue Thema. Die Initiative geht wie beim dritten Bild von Mose aus.

Ex 4,1: Und Mose antwortete und sagte: "Aber wenn sie mir nicht glauben und nicht auf meine stimme hören,/ sondern sagen: >Nicht ist dir Jahwe erschienen. " ?"

Zum ersten und einzigen Mal in unserer Erzählung werden für die Redeeinleitung des Mose zwei Verben verwendet. עמה "antworten" könnte dabei auch den stärkeren Sinn von "erwidern, entgegnen" haben und hier ein intensiveres Eingehen auf das von Gott zuvor Gesagte andeuten. 
wie schon oben (2.2.3) bei der Analyse des dritten semantischen Feldes gezeigt, nimmt Mose in seinem Einwand Ausdrücke von Gottes Reden aus v16.18 auf. Er stellt die Aussagen Gottes geschickt in Frage, indem er sie in einen Bedingungssatz ${ }^{202}$ stellt und verneint. Davor setzt er noch eine Art überschrift "wenn sie mir nicht glauben", das parallel zum Hören auf die stimme zu verstehen 1st und das neue Schlüsselverb אמן Hi einführt.

Am Einwand des Mose ist mehreres bemerkenswert. - Mose greift Gottes Reden auf, aber er setzt dort ein, wo noch nicht von seiner Einheit mit dem volk die Rede ist. Würde er einen später verwendeten Ausdruck ( $a b$ v18b) aufnehmen, so müBte er von "wir" reden. Damit hätte der Einwand keinen Sinn mehr. - Mose wendet sich nicht gegen Jahwes Plan, sondern gegen die zuversicht, mit der Jahwe die Aufnahme seiner Botschaft schildert ${ }^{203}$. - Der Einwand in 4,1 ist ähnlich wie in 3,13 formuliert und legt den widerstand auf die Israeliten, die direkt zitiert werden. Von sprachlicher Gewandtheit zeugt auch der unvollständige Bedingungssatz: Eine gewisse Ratlosigkeit läßt sich mit solch einem offenen Ende ausdrücken.

Der Einwand des Mose in Ex 4,1 beginnt das neue Thema der Glaubwürdigkeit von Jahwes Botschaft. Stilistisch (vgl. 3,13) und inhaltlich (siehe die Distanz Moses seinem Volk gegenüber) zeigen sich Berührungspunkte mit vorher beobachteten Eigenheiten an Mose.

Ex 4,2: Und es fragte ihn Jahwe: "Was ist das in deiner Hand?"/ Und er sagte: "Ein Stab".

Der kürzeste Vers unserer Erzählung bringt den "Gegenangriff" Gottes. Er beginnt nun zu fragen. Damit wird der Fragen-

202 Siehe die Erläuterung $A$ zur Übersetzung von 4,1.

203 Beide werden Recht erhalten, Jahwe noch im selben Kapitel $(4,31)$, Mose durch den weiteren Gang der Ereignisse, in dem Israel sich immer wieder als ungläubig erweist (siehe auch Anm.95 in c2). 
Mit der Frage Gottes beginnt ein Umschlagen. Hatte Mose vorher Gott dreimal mit Einwänden geantwortet, so stellt die gefügige Antwort "ein Stab" einen wechsel dar. Moses Antwort entspricht den Erwartungen. Wie in 3,4 reagiert Mose korrekt auf das Sprechen Gottes. Auch der Stil zeigt Veränderungen. Für Frage und Antwort genügen drei wörter ${ }^{205}$. Durch die kurzen sätze und den schnellen Sprecherwechsel kommt Bewegung ins Gespräch.

Ex 4,3: Und er sagte: "wirf ihn zur Erdel" Und er warf ihn zur Erde, und er wurde zu einer Schlange./ Da fuhr Mose vor ihr zurück.

Der knappe stil vom vers zuvor geht weiter. Fünf sätze in zehn wörtern bringen nach der Redeeinleitung zuerst einen Befehl Gottes und dann zum ersten Mal nach 3,6 wieder ausführlicher die Stimme des Erzählers ${ }^{206}$. Das erneute Auftauchen des Erzählers führt beim Hörer/Leser zu einer größeren Distanz gegenüber der Erzählung. Während die Reden der Gesprächspartner unmittelbar ansprechen, kommt nun durch den notwendigen Wechsel vom Dialog zur Beschreibung ein vermittelndes Element hinein, das eine "Au-

204 Mose hat bisher auBer seinem Monolog 3,3 und seiner Antwort in 3,4 nur gefragt:

3,11: "Wer bin ich ....?"

3,13: "... Was soll ich ihnen sagen?"

Auch der unvollständige Bedingungssatz in 4,1 kann als offene Frage angesehen werden: "Aber wenn ... ?"

205 Gott verwendet den singulären Ausdruck מק, zusammengezogen aus מהזr "Was ist das?". Neben der Kürzung könnte dabei auch die lautliche Ähnlichkeit zu מח "stab" eine Rolle gespielt haben. Zu משה in Ex 4,2 siehe H.SIMIAN-YOFRE, משה 820 - Vgl. auch die Kontraktion von להבה לב 3,2 .

206 Von 3,7 bis 4,2 hatte sich der Erzähler auf die Redeeinleitungen beschränkt. F.K.STANzEL, Theorie 243, schreibt dazu: "Die Dialogregie durch verba dicendi und andere Inquitformeln ist eine Aufgabe des Erzählers, die fast nur funktionalen Charakter hat und die daher vom Leser in der Regel gar nicht als ÄuBerung einer Erzählerfigur registriert wird." Durch eine solche Dialogregie geschieht ein zurücktreten des (auktorialen) Erzählers. 
Bensicht" 207 des Geschehens präsentiert. Signifikant dafür ist die Verwendung der 3.P., die hier sprunghaft zunimmt.

In drei Narrativen berichtet der Erzähler, was auf den Befehl Gottes folgt. Zuerst kommt die wörtliche Ausführung ${ }^{208}$, dann die Überraschung, eingeleitet mit 9 'ר, und schlieblich die Reaktion des Mose. Die Verwandlung des Stabs in eine Schlange und das zurückschrecken des Mose vor ihr kommen unerwartet und erhöhen die Spannung.

Ex 4,4: Und Jahwe sagte zu Mose: "Streck deine Hand aus und erfasse ihren Schwanzl"/ Und er streckte seine Hand aus und ergriff ihn, und sie wurde zum stab in seiner Hand.

Redeeinleitung für Gott und sein Sprechen werden länger (jeweils vier wörter), so beruhigt sich das Tempo der Erzählung etwas. Gott gibt dabei zwei Befehle; der erste greift mit "senden" ein Schlüsselverb des zweiten semantischen Feldes auf, der zweite präzisiert ihn ${ }^{2}$.

207 "AuBensicht" und die ihr zugrundeliegende "AuBenperspektive" schildern die Vorgänge von einem von den Personen der Erzählung distanzierten standpunkt. Damit wird die auktoriale Erzählsituation wieder deutlicher greifbar. Hier beschreibt der Erzähler sachlich, ohne Kommentare zu geben oder Gefühle (wie z.B. Moses Angst in 3,6 ) zu erwähnen. Vgl. dazu F.K.STANzEL, Theorie 70-89.

208 Die übereinstimmung mit Gottes Gebot ist perfekt und ist nur durch den Wechsel von Imperativ zu Narrativ von jenem verschieden. Das von Gott gebrauchte "של "werfen" klingt dem Schlüsselwort ${ }^{2}$ w sehr ähnlich.

209 Ex 4,30; 7,8-13.15 nehmen auf dieses zeichen bezug.

210 BA 40 (1977) 5, zählt sechs im sinai und Negev heimische giftige Schlangenarten auf.

Jeder, der mit Schlangen umzugehen versteht, weiB, daB er sie niemals am Schwanz, sondern nur dicht hinter dem Kopf ergreifen darf, weil sie sich sonst blitzschnell zurückwenden und in die Hand beissen. Gottes Aufforderung, die Schlange am Schwanz zu fassen, verlangt also entweder von Mose noch mehr Mut, oder sie zeigt die völlige Beherrschung dieser gefährlichen Macht: Wenn Mose die Schlange sogar an der ungeeignetsten stelle packen kann, ohne Schaden zu nehmen, heiBt das, das sie gänzlich unter seiner Macht steht. (Nach einer mündlichen Mitteilung von P. Proulx wäre es allerdings auch möglich, die Schlange am Schwanz zu fassen, weil sie damit ihren orientierungspunkt verliert.) 
Wie im Vers zuvor berichtet der Erzähler deren genaue Ausführung durch Mose und fügt ihr wie dort das überraschende Resultat an: Die Schlange wird in der Handfläche zurückverwandelt in einen Stab. Für Mose und den Hörer/Leser ist alles wieder wie vorher. Innerhalb weniger Augenblicke entstand eine lebensgefährliche Situation und verschwand wieder spurlos.

Ex 4,5: " Damit sie glauben, dab dir erschienen ist Jahwe, der Gott ihrer väter,/ der Gott Abrahams, der Gott Isaaks und der Gott Jakobs."

Unvorbereitet wird der Hörer/Leser mit dem Sprechen Gottes konfrontiert. Die fehlende Redeeinleitung ${ }^{212}$ verstärkt die Wirkung des Sprechens Gottes: Es bricht herein, ohne daB man sich darauf einstellen kann. So wird der zusammenhang mit dem vorhin von Gott angeordneten Tun noch intensiver, und auch die Beziehung zum Einwand des Mose wächst. Wie im Einwand des Mose der Hauptsatz des Bedingungssatzes fehlte, so fehlt hier der Hauptsatz des Absichtssatzes. Die soeben geschehene Verwandlung des stabs in eine Schlange und zurück spricht eine hinreichend deutliche sprache. Sie ersetzt den Hauptsatz. Gott erspart sich damit das Reden von seiner Macht ${ }^{213}$.

E.J.HAMLIN, Ordeal 37, arbeitet die symbolische Bedeutung mancher in Ex 4,1-9 verwendeter Begriffe heraus. Die Hand steht so für eine Person in ihrem Handeln; die Schlange ist Symbol für das Chaos oder für Ägypten. Auch beim "am Schwanz fassen" spricht er von symbolischer Bedeutung; es wird aber nicht klar, wie er es meint.

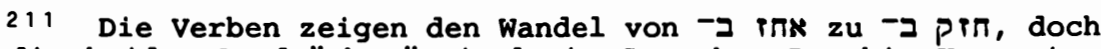
sind die beiden Ausdrücke äquivalent. So schon Raschi, Kommentar zur stelle.

212 Andere Beispiele (aus H.-J.STIPP, Elischa 237): Jos $24,22-23 ; 2$ Sam $18,22-23 ; 2$ Kön 10,15 . Für weitere Beispiele und Literatur siehe C.CONROY, Absalom $70 \mathrm{mit}$ Anm.109.

213 Gottes Reden geht genau auf Moses Einwand in 4,1 ein. Dadurch herrscht ein sachlicher Ton. Das Sprechen ist gegenüber den kurzatmigen Befehlen zuvor länger und ruhiger; der Rhythmus des vierfachen, durch je ein Wort unterbrochenen אלהים verstärkt diesen Eindruck. 
Wie wir gesehen haben (im dritten semantischen Feld), greift Gott das Reden des Mose in 4,1 auf und wendet es zum Positiven. Die Veränderungen gegenüber v1 sind: - Deutlicher als 'ל "mir" in $v 1$ bringt der mit ' der Glaube der Israeliten sich auf die Erscheinung Jahwes an Mose bezieht und so sein Fundament nicht in einem Menschen, sondern in einem Tun Gottes hat. - "Jahwe" von v1 wird hier ergänzt durch die aus $3,6.15$ bekannte vätergottformel ${ }^{214}$. Das gegenüber dem Kontext längere Reden und die viermalige rhythmische Wiederholung von "Gott" geben der Antwort Feierlichkeit und Ruhe. Auch verlagert die lange Gottesbezeichnung das Schwergewicht, das in $v 1$ auf אל "nicht (ist dir erschienen)" gelegen war, mehr auf Gott.

Wir haben bisher die mehrmalige ( 5 bzw. $6 x$ ) Wiederholung von אלהים als SchluBsignal kennengelernt. Hier bildet die viermalige wiederholung eine Art ScheinschluB, indem sie nicht das fünfte Bild, sondern nur dessen erstes Teilbild beendet. So wie Jahwe in 3,14-16 mehrere Antworten auf die Frage des Mose gegeben hat, so stellt Ex 4,(2-)5 nur eine zwischenantwort dar. Den letzten Teil dieser Antwort bildet unser v5.

Ex 4,6: Und Jahwe sagte ihm weiter: "Steck doch deine Hand in deinen Gewandbausch!" Und er steckte seine Hand in seinen Gewandbausch./ Und er zog sie heraus, und da: Seine Hand war aussätzig, wie Schnee.

Nach dem ScheinschluB im vorigen Vers folgt eine erneute, relativ ausführliche Redeeinleitung (vier wörter). Obwohl Jahwes Sprechen unmittelbar vorausgeht, wird sein Reden in v6 eigens eingeleitet. Wir haben im allgemeinen davon in Exkurs 1 gehandelt, doch liegt der Fall hier anders. Da in v5 die Redeeinleitung fehlte, kann nämlich nicht im eigentlichen sinn von einer doppelten Redeeinleitung gesprochen werden. Die Redeeinleitung hier in $v 6$ hat eher abgrenzende Funktion; das Reden führt mit dem Aufgreifen des Wortes T' "Hand" und der Befehlsform 4,4 weiter,

214 Doch erscheint sie leicht varilert: In der Anrede an Mose spricht Gott über die Israeliten. Deswegen steht das Suffix in der 3.P.PI. 
wodurch der in Vokabular und stil ohnehin schon isolierte v5 noch stärker abgehoben wird.

Der Befehl Gottes ergeht in vier Worten und ist mit der Prekativpartikel $\mathrm{kJ}$ - "bitte, doch" formuliert". Wie uns der Erzähler berichtet, kommt Mose der höflichen Aufforderung sofort genau nach und zieht anschließend die Hand heraus" והנה "und siehe" (vgl. 3,2) lenkt dabei die Aufmerksamkeit des Hörers/Lesers auf das folgende Resultat und streicht dessen überraschenden Charakter heraus. Das Partizip "aussätzig" und der Vergleich "wie Schnee" ${ }^{217}$ verstärken noch dieses Hinweisen des Erzählers.

zieht man die Schwere dieser Krankheit in Betracht ${ }^{218}$ und vergleicht überdies mit 4,3, wo Mose auf die Schlange noch zurückwich, so erstaunt einen hier, daB Mose keine Reaktion zeigt. Nach der aus einem Wort bestehenden Antwort in 4,2 ist Mose still geworden. Und seit dem Zurückschrecken in 4,3 tut Mose nur noch, was Gott ihm aufträgt.

215 Beim ersten zeichen enthielt einer der Befehle das Schlüsselwort $\pi$ ל Befehl ein zum selben semantischen Feld gehörendes, schon in 3,13.18 verwendetes Verb auf: בוא "kommen" (Hi bringen).

216 Das Herausziehen war nicht im Befehl enthalten. Doch wäre der Befehl kompliziert und eigenartig geworden, hätte Gott sowohl das Hineinstecken wie das Herausziehen befohlen.

217 צר "aussätzig", 20x im AT, davon 15x in einer form des Pualpartizips, wird nur fünfmal in Lev 13-14 (Gesetze zum Aussatz), dafür aber häufiger in erzählenden Texten verwendet: $6 x$ bei der Heilung des Syrers Naaman in 2 kön 5 , und $4 x$ für König Usija in 2 Chr 26.

26" "Schnee" findet sich auch $20 x$ im AT, davon $5 x$ als vergleich mit $\supset$ "wie". Von diesen 5 stellen sind zwei unserer ganz ähnlich: In Num 12,10 wird Mirjam aussätzig wie Schnee, und in 2 Kön 5,29 geschieht dasselbe dem Diener Elischas, Gehasi. Die Kombination "aussätzig wie Schnee" verwendet aus dem Vergleich die Farbe: Moses Hand ist weiblich geworden. - Interessanterweise wird in Lev 13-14 das Wort 2 לø nie erwähnt.

RASCHI, Kommentar zur Stelle, nimmt aufgrund des zusammenhangs mit Num 12 an, Mose werde hier für üble Nachrede bestraft (d.h. sein Einwand in 4,1 sei als falsches Reden von den Israeliten zu verstehen). Dieser überton mag mitschwingen, doch liegt das Hauptgewicht hier in 4,6-7 auf der Bevollmächtigung Moses.

218 In Lev 14,45-46 wird das Schicksal der Aussätzigen beschrieben: AusgestoBen aus der Gemeinschaft, müssen sie auBerhalb wohnen und sind zur Selbstisolation durch Schreien gezwungen. - Die Erzählung 2 Kön 7 ist ein Musterbeispiel dafür, wie verzweifelt die Lage solcher Aussätziger sein konnte und wie Ausgestoßene sogar der Gemeinde helfen können. 
Ex 4, 7: Und er sagte: "Steck deine Hand wieder in deinen Gewandbausch!" Und er steckte seine Hand wieder in seinen Gewandbausch./ Und er zog sie aus seinem Gewandbausch heraus, und da: Sie war wieder wie sein Fleisch.

Mit שוב Hi "wieder tun" gibt Gott den Befehl zur Wiederholung des Tuns von 4,6, den Mose auch genauso prompt erfüllt wie dort. Die mit dem vorigen Vers praktisch identische Satzstruk$\operatorname{tur}^{219}$ drückt stilistisch den Charakter als wiederholung aus. Vier den Ton tragende Suffixe auf 1- $^{-}$im Abstand von zwei bzw. drei Worten geben dem Sprechen des Erzählers Rhythmus.

Ex 4,7 wird bestimmt durch die je dreimalige Wiederholung von שוב und $p \pi^{220}$. Letzteres wird gegenüber v6, wo die Präposition zweimal verwendet wird, hier zweimal mit te Mal mit מ gebraucht; damit wird der AbschluB erreicht. Ersteres bildet ein Wortspiel: Nach zweimal Hi (wieder tun) wird das Verb zuletzt im Q (zurückkehren; wieder werden/sein) verwendet. So steht Mose wieder wie vorher ${ }^{21}$ da, nur um eine Erfahrung reicher. Diese Erfahrung besteht in der Konfrontation mit der Macht der Befehle Gottes und im Paradox, daß dasselbe Tun ${ }^{22}$ so völlig entgegengesetzte Wirkungen wie Krankheit und Heilung davon bewirken kann.

219 Der für 4,6 und 4,7 gemeinsame Versaufbau:

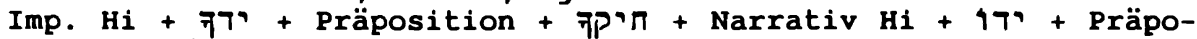

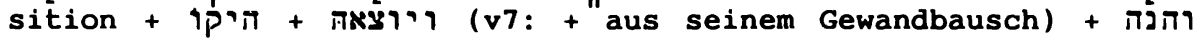
(v6: + seine Hand) + Partizip + Vergleich (-כ).

RASCHI, Kommentar zur Stelle, bemerkt als einzige Veränderung das zusätzliche "aus seinem Gewandbausch" beim Herausziehen. Doch dient es wohl als Gegengewicht zu dem in v6b gebrachten, hier in v7b aber fehlenden "T "seine Hand".

220 rommt in Ex nur diese fünf Male in 4,6-7 vor.

221 "Wie das Fleisch" verbindet vor allem mit 2 kön 5,14 (siehe auch Anm.217). In beiden Fällen meint es die völlige wiederherstellung. - Die anderen zwei stellen in der Bibel für diesen Ausdruck sind $\mathrm{Mi} 3,3$ und Neh 5,5.

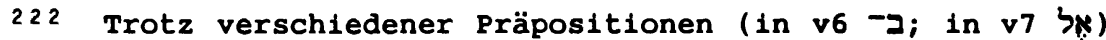
meinen beide Befehle Gottes wegen Damit heben sich 4,6-7 von 4,3-4 ab, wo von Mose zwei verschiedene Tätigkeiten gefordert wurden. 
Ex 4,8: " Und es wird sein: Wenn sie dir nicht glauben und nicht auf die Sprache des ersten zeichens hören, / werden sie der Sprache des anderen zeichens glauben.

Wie in 4,5 fehlt die Redeeinleitung. Das Sprechen kommt wieder überraschend und könnte so andeuten, daB Mose noch am Staunen ist über das, was vorgegangen ist. Die stimme Gottes, die die Wirkung ${ }^{23}$ der zeichen beschreibt, reiBt Mose wieder heraus.

Wie schon 4,5 nimmt auch 4,8(-9) auf 4,1 Bezug, mit einer entscheidenden Veränderung: Gott selbst greift die von Mose genannte Möglichkeit des Unglaubens auf. Hatte v5 durch "damit sie glauben" und die Betonung auf der Erscheinung vor allem v1b aufgenommen und einen scharfen Kontrast dazu erstellt, so geht Gott nun stärker auf Mose ein ${ }^{224}$ und nimmt selbst dessen Verneinung "nicht (glauben und hören)" ernst.

Ohne einen zu gesuchten Unterschied zwischen den einzelnen Ausdrücken konstruieren zu wollen, zeigt die Verwendung von אמן Hi "glauben" doch kleine Differenzen:

\section{Schema 7: אמן Hi und pמp in Ex 4,1-9}

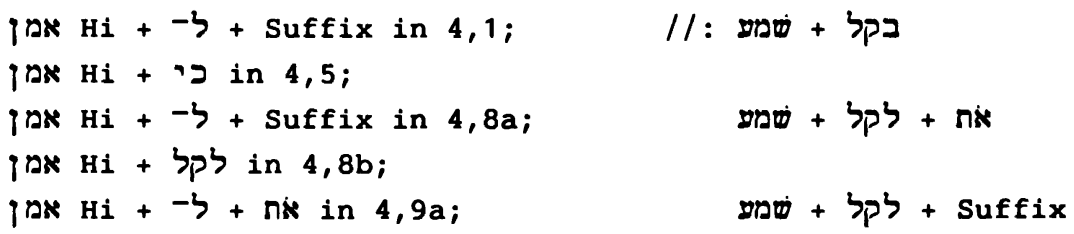

In $4,1.8 \mathrm{a}$ ist der Glaube mit Mose $_{2}$ in $4,8 \mathrm{~b} .9 \mathrm{a}$ mit zeichen verbunden. In beiden Fällen ist Unglaube 25 möglich, wie die Ver-

223 "und es wird sein" gibt an, daß das Folgende als zukünftig zu verstehen ist. - Gerade im letzten Teil unserer Erzählung wird es öfter verwendet: $4,8.9(3 \mathrm{x}) .16$.

224 Gottes Reden entspricht fast ganz dem des Mose in 4, 1a: "Aber wenn sie mir nicht glauben und nicht auf meine stimme hören ..." - v8a "Wenn sie dir nicht glauben und nicht auf die Sprache (= die stimme) des ersten zeichens hören ..."

225 Die Vordersätze zeigen dies. Ist ihre Redundanz, die in scharfem Kontrast $z u$ den kein überflüssiges Wort verwendenden Befehlen Gottes in 4,3-4.6-7 steht, zeichen einer "Rhetorik des Unglaubens", die in Wiederholungen und kleinen, wenig besagenden 
neinungen innerhalb der Bedingungssätze zeigen. In 4,5 dagegen bezieht sich der Glaube auf die Erscheinung Jahwes an Mose; dieser Glaube wird als ziel angegeben und nicht in Frage gestellt

In Ex 4,8 nimmt Gott Moses Bedenken von 4,1 auf und rechnet damit, das, wenn schon nicht das erste, so das zweite 227 zeichen Glauben finden wird.

Ex 4,9: Und es wird sein: Wenn sie auch diesen beiden zeichen nicht glauben und nicht auf deine stimme hören, so sollst du vom Wasser des Nil nehmen und auf das Trockene gieBen./ und es wird das Wasser, das du aus dem Nil nimmst, - es wird zu Blut auf dem Trockenen!"

In ganz ähnlicher Konstruktion wie im Vers zuvor ${ }^{228}$ erhält Mose den Auftrag zu einem weiteren Tun, falls die ersten beiden zeichen ihm nicht Glaubwürdigkeit verschaffen. Dabei ist der repetitive Charakter dieses neuen Auftrags auffällig. Sechs wörter (nehmen, von, Wasser, Nil, Trockenes, sein/werden) werden

Veränderungen das Ausweichen vor der Entscheidung für den vertrauenden Glauben darstellt?

Oder ist, wie unten am Ende des Rückblicks beschrieben, das Moment der exakten Wiederholung der Satzkonstruktionen stärker, sodaB es vor dieser Argumentation Gottes kein Ausweichen gibt?

226 למע 20 "damit ..". Die Erfüllungsnotiz in Ex 4,31 formuliert mit absolutem p $_{\text {Hi }}$ ohne Objekt.

zu beachten ist der Unterschied zwischen - אמן "etwas glauben, für wahr halten" und chen; siehe dazu J.L.SKA, Passage 143-144.

227 Die Verbindung von האחרון meint oft "erster" und "letzter": Jes 44,6; dann vor allem in $2 \mathrm{Chr}(9,29$ und weitere sechs Belege: die ersten und die letzten Taten eines Königs. So als Merismus verwendet, bezeichnet dieser Ausdruck die gesamte Geschichte des Königs). Doch weil es hier auf die zwei zeichen zu beziehen ist, darf (parallel zu Ru 3,10 ) auch verstanden und übersetzt werden: "erstes" und "zweites" zeichen.

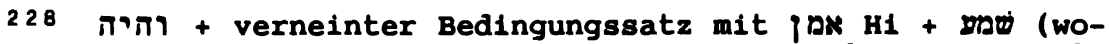
bei die objekte [Mose, die stimme und die zeichen] in der stellung vertauscht werden) + Afformativkonjugation nach - 7 . 
wiederholt $^{229}$ und erzeugen so den Eindruck des stehenbleibens.

Das Innehalten in der Erzählbewegung wird noch durch zwei andere Faktoren unterstrichen. - Die letzten beiden worte "Blut auf dem Trockenen" "230 beschreiben die Folge von Moses Tun. Wo Blut auf die Erde fliebt, da ist menschliches Leben in Gefahr. Der Ausdruck "Blut auf dem Trockenen" ${ }^{231}$ zeugt so von der Nähe des Todes; damit wird auch im sprechen eine Grenze erreicht. Anders als bisher wird die Reaktion der Israeliten nicht mehr beschrieben. Es wird offengelassen, wie sie dieses letzte Tun Moses aufnehmen werden. Dieser offene Ausgang läßt den Hörer/Leser im Ungewissen und bereitet ihn so auf das kommende Tun Moses in den Plagen vor.

\section{Rückblick auf Jahwes Machterweis}

In diesem fünften Bild ändert sich der Ton der Erzählung mehrfach. - Bisher hat Mose Fragen gestellt (bis 4,1), nun kommen die Fragen von Gott $(4,2.11)$. - Seit der Aufforderung Gottes zu gehen hat Mose bis 4,1 nur Einwände gebracht, ab 4,2 jedoch finden wir eine Antwort und genaues Ausführen der Befehle Gottes. - Bereits in 3,12 war von einem zeichen die Rede, das allerdings die zukunft betraf. Hier aber werden gleich mehrere zeichen in der Gegenwart gegeben. - Und schlieblich ist, zwar unaufdringlich, der Erzähler durch seine sachliche Beschreibung bedeutend mehr als vorher präsent.

229 Das wird u.a. ermöglicht durch einen Relativsatz, den wir schon öfter im Sprechen Gottes beobachten konnten. Vgl. 3,5. 7.9.14.20.

230 יבשת, ersetzt das sonst nur noch einmal in Ps 95,5 vorkommt. Der erste Ausdruck findet sich noch viermal in Ex im Zusammenhang mit dem Auszug: 14,16.22.29; 15,19 und evoziert schöpfungstheologische Hintergründe (Gen 1,9-10).

Die Verbindung von "Trockenem" mit Blut und Nil stellt allerdings die Frage, wohin unsere stelle zu beziehen ist, ob zu Ex 7,14-25 (erste Plage), wo zwar Blut und Nil, nicht aber das Trokkene erwähnt werden, oder zu Ex 14, wo zwar das Trockene mehrmals vorkommt, jedoch die anderen beiden Ausdrücke fehlen, oder aber zu beiden?

231 Diese Kombination von Blut und "Trockenem" kommt sonst in der Bibel nicht vor. Doch begegnet die verbindung von Blut und Erde öfter: Gen 4,10; Lev 17,13; Dtn 12,16 (auch Mt 23,25). An allen diesen stellen ist Blut auf der Erde die Konsequenz vorherigen Tötens. 
Es wäre falsch, dieses Umschlagen als radikalen Bruch innerhalb der Erzählung zu verstehen. Es gibt auch viele verbindende Elemente. - Der Dialog zwischen Gott und Mose geht weiter. Das Erscheinen Jahwes und das Hören auf die stimme aus dem dritten Bild werden aufgenommen. - Die Gestalt Moses ist kohärent mit der in Ex 3 gezeichneten, wobei sein Verstummen im dritten Bild hier in 4,3-9 besonders eindrucksvoll weitergeführt ist. Auch für die Israeliten ergibt sich eine durchgehende Linie, insofern nach der gütlichen Lösung des Konfliktes mit Ägypten nun sie selber und ihr Glaube zum Thema werden 232 .

Das fünfte Bild behandelt das Thema der zeichen. In ihnen zeigt sich gleichzeitig Jahwes Macht, die Autorität des Mose und die Glaubwürdigkeit der Botschaft. Es lohnt sich, die verschiedenen Aspekte dieser zeichen näher zu betrachten.

a) Jahwes Macht tritt deutlich hervor in der Weise seines Sprechens und in der Art der zeichen. Es genügen kurze Befehle, und Mose gehorcht. Die Ausführung des Befehles durch Mose führt dann zu einer Verwandlung, die Mose im ersten Fall erschrecken und im zweiten Fall reaktionslos macht. Gott erscheint dabei als absoluter Souverän: Ein Wort von ihm genügt, und etwas Machtvolles geschieht, ohne daB er selbst etwas dazu tut. Mit dieser Macht seines Wortes in den Befehlen korrespondieren seine völlig überraschenden, weil uneingeleiteten Redeeinsätze in 4,5.8, die neben der engen Verbindung des göttlichen Sprechens mit den von Mose ausgeführten zeichen den überwältigenden Charakter von Gottes Sprechen ausdrücken.

Auch die Art der zeichen spricht von Gottes Macht ${ }^{233}$. In der

232 Was auf der Ebene der Erzählung eine Weiterführung und Präzisierung ist, kann in der zeitlichen Abfolge einen Rückschritt bedeuten: zuerst kommt das Akzeptieren der Botschaft Moses $(4,1-9)$, dann erst das Ausziehen $(3,18-22)$. Diese Umkehrung der zeitlichen Abfolge wird durch Moses Rückgriff auf 3,16.18a eingeleitet.

233 E.J.HAMLIN, Ordeal 33, versteht die einzelnen zeichen als "ordeal" (Gottesurteil, Feuerprobe) für Mose und spricht von ihrem Eigenwert: Die zeichen sind nicht blos Vorankündigung.

Dann (s.35-39) weist ex ihnen die Bedeutungen Macht (1.2eichen), Tod (2.) und Blut auf dem Trockenen (letztes zeichen) zu. Diese zutellung vermag beim zweiten zeichen nicht zu überzeugen; Tod scheint eher mit dem Blut auf dem Trockenen gemeint zu sein (dort muB Hamlin auch wieder vom Tod reden). Die Bedeutung des zweiten 
Verwandlung von Stab, Hand und Wasser in Schlange, Aussatz und Blut zeigt sich Gott als Herr über menschliches Leben bestimmende Kräfte $^{234}$. Dabei deutet das letzte zeichen des wassers, das zu Blut wird und bei dem als einzigem keine Rückverwandlung stattfindet, an, das damit eine Grenze erreicht ist. Der Mensch, der dieses zeichen sieht, weiB, daB er bei etwas angekommen ist, von dem es kein zurück mehr gibt. Er steht an der Grenze des Todes. Nicht nur Mose $(4,2-7)$ kann dieser verwandelnden Kraft Gottes nicht standhalten, vielmehr: Kein Mensch vermag es $(4,9)$, es sei denn, er nimmt den Tod in Kauf.

b) Mose gewinnt durch diese zeichen an Autorität. Die Israeliten werden ihm Glauben schenken, wenn er diese Verwandlungen vor ihnen ausführt. Entscheidend für ein solches Verständnis ist die Deutung der in 4,3-4.6-7 geschehenen Verwandlungen als zeichen in 4,8-9. Durch diese Interpretation erhält das, was Mose geschehen ist $_{235}$ seine Bedeutung als Beglaubigung für Mose vor den Israeli$\operatorname{ten}^{2}$. Das Geschehen von v3-4.6-7 ist in sich vieldeutig und verlangt deshalb nach einer Interpretation. Sie wird in 4,8-9 in dem Sinn gegeben, daß die Bedingungssätze zweimal von der Autorität ("dir glauben" und "auf deine stimme hören") des Mose in Verbindung mit den zeichen sprechen.

Ein zug an dieser Autorität des Mose darf nicht übersehen werden. Er kommt in der achtmaligen Verwendung von "Thand" und in fünfmaligem חיק "Gewandbausch" zum Ausdruck, die zusammen mit anderen wörtern den greifbaren, materiellen Aspekt dieser zeichen betonen. Auch streichen sie heraus, daB Mose persönlich betroffen ist. Die beiden Ausdrücke werden nämlich immer mit Suffixen gebraucht, die sich auf Mose beziehen. "Hand" und "Gewandbausch" stehen so für Moses Betroffenheit, die bis zur Gefährdung und Minderung seines eigenen Lebens reicht.

Zeichens liegt eher in der Bedrohung der Lebenskraft durch Krankheit und in ihren gesellschaftlichen Folgen.

234 Die vorige Anmerkung aufgreifend, ergäbe sich die Linie: Macht - Leben - Tod.

235 In diesem Sinn wird in 4,17.30 darauf Bezug genommen. Mose kann nun die zeichen ohne den Befehl Gottes ausführen und scheint so selbst mit Gottes Macht handeln zu können. 
c) Nach 4,5 ist die Glaubwürdigkeit der Botschaft das primäre ziel der zeichen. Das Wort allein scheint nicht zu genügen ${ }^{236}$, um für seine eigene Wahrheit zu sprechen. So fragt Mose nach einer weiteren Beglaubigung, ohne jedoch explizit um ein zeichen zu bitten . Normalerweise folgt auf so ein Ansuchen zuerst eine Bestätigung durch eine zusage, die dann mit einem zeichen bekräftigt wird (vgl, 3,12). Hier geht es genau umgekehrt: Anfangs steht das zeichen, nachher erfolgt die Deutung, wie es $z u$ verstehen ist. Die zeichen wirken so wuchtiger, als wenn sie nur zur nachträglichen Bekräftigung eines Wortes dienten.

Zum SchluB sei noch auf einige sprachliche Eigenheiten des fünften Bildes verwiesen. Der "sachlichen" Atmosphäre der zeichen entspricht ein nüchterner Ton: viele exakte wiederholungen, oft Verwendung der 3.P. (durch den Erzähler), völlige Abwesenheit der 1.P. in 4,2-9. Der stil trägt so zur objektiven überzeugungskraft der zeichen bei. Am deutlichsten wird dies am fast mathematischen Schema der Wiederholungen ${ }^{238}$ :

$$
\text { [ ( } a \text { : "b" b" } c+d) \times 2: \text { " } e \text { " ] } \times 2
$$

Dem Zwang dieser Abfolge in 4,3-9 kann man sich schwerlich entziehen.

\subsection{Ex 4,10-17: Mitbestellung Aarons}

Ex 4,9 bringt auf der Ebene der Glaubwürdigkeit ein Letztes, nicht aber auf der Ebene der ganzen Erzählung. Dort stellt es nur einen vorläufigen Endpunkt dar, nach dem (in v10) die Erzählung

236 R.J.BURNS, Exodus 52: "God's word of commission and command is enough neither for Moses nor for Pharaoh". Zu ergänzen wäre, daß dies auch für das Volk gilt.

Die Bestätigung einer Botschaft durch begleitende zeichen gelingt manchmal. Doch die Bibel weiB auch darum, daB selbst die zeichen keinen Glauben finden (siehe die Plagenerzählungen, ferner Num 14,11 und Joh 12,37).

237 Im Gegensatz z.B. zu Gideon ( $\mathrm{Ri} 6,17$ ).

238 Dabei bedeuten:

$a=$ Redeeinleitung für Gott

: = Übergang zur direkten Rede (" ")

b $=$ Befehl Gottes

$b^{\prime}=$ Ausführung des Befehls Gottes (Erzähler)

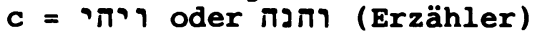

d = Resultat (Erzähler)

$e=$ (uneingeleitete) Deutung durch Gott

x2 = die vor der Klammer stehenden Teile werden wiederholt 
auf ein neues Thema springt. Der Übergang ist abrupt, in den Nomina und Verben gibt es keine Beziehung zwischen den genannten Versen . Mit dem Wechsel des Bildes geht der des semantischen Feldes überein, es handelt sich nun um das Reden.

Ex 4,10: Und Mose sagte zu Jahwe: "Bitte, mein Herr, kein Mann von Worten bin ich, weder seit gestern noch seit vorgestern noch seit du zu deinem knecht sprichst;/ ungeschickt mit dem Mund und ungeschickt mit der zunge bin ich."

Die Redeeinleitung für Mose erwähnt zum einzigen Mal in unserer Erzählung, daß er "zu Jahwe" spricht. Das entspricht der in 3,15 geschehenen Selbstvorstellung Gottes, an die sich auch der Erzähler hält. "zu Jahwe" wird aber in 4,10 durch einen interessanten zug weitergeführt: zum ersten Mal in unserer Erzählung redet Mose Gott direkt an. Er gebraucht dafür die Anrede "Bitte, mein Herr" und die 2.P.Sg. Die Anrede "Bitte, mein Herr" ${ }^{240}$ leitet das Sprechen des Mose ein und macht es zu einer Bitte. Das Bitten bedeutet gegenüber $3,11.13$; 4,1, wo wir die Einwände des Mose als Fragen verstanden haben, eine entscheidende Veränderung in der Beziehung zu Gott. Ihr entspricht die Selbstbezeichnung "dein Knecht" $"$ ".

Noch bezeichnender ist die Anrede Gottes mit der 2.P.Sg. "noch seit du zu deinem knecht sprichst". Bisher hat Mose immer nur über Gott geredet. Die Verwendung der 3.P.Sg. ermöglichte ihm diese Distanzierung. Hier in 4,10 gibt er diese Distanz zu Gott teilweise auf ${ }^{242}$.

239 Nur wörter ohne großes Gewicht $(j, y, k, a)$ verbinden 4,9-10.

240 Die Formel "Bitte, mein Herr!" begegnet in zwei Ausprägungen: 1) ברי (Ex 4,10.13; Jos 7,8; Ri 6,15; 13,8), immer an

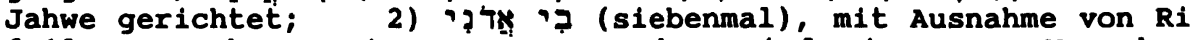
6,13, wo Jahwes Bote so angesprochen wird, immer an Menschen gerichtet.

241 Nachdem פבד als Verb schon öfter in Ex 1-2 verwendet worden ist, taucht es hier zum ersten Mal als Nomen auf.

Die Selbstbezeichnung wird von Jahwe zur Bezeichnung Moses übernommen: Num 12,7. - Beim Erzähler findet sie sich wieder in Ex 14,31 .

242 Die Distanz zu den Israeliten bleibt nach wie vor bestehen. Erst mit dem Ausdruck "meine Brüder" in 4,18 zeigt Mose, das er sich zu ihnen gehörig weis. 
Dem Fortschritt auf der persönlichen Ebene entspricht ein Rückschritt auf einer zeitlichen. Im fünften Bild ging es um die Aufnahme der Botschaft. Moses Einwand setzte bei 3,16.18 ein. Hier im sechsten Bild dagegen handelt es sich um die vorausliegende Vermittlung der Botschaft ${ }^{243}$, der Einwand des Mose bezieht sich also auf die Aufforderungen Jahwes in 3,14-16 (falls er sich überhaupt auf Gottes Sprechen und nicht nur auf sein eigenes Fühlen bezieht). In der Umkehrung der zeitlichen abfolge kommt die fortschreitende Erzählbewegung zum stillstand (wie in 3,6.2122).

Der vierte Einwand des Mose betrifft sein Unvermögen zu reden und hat einige über den unmittelbaren Textzusammenhang hinausweisende Aspekte, sodaB die Behandlung in einem Exkurs praktischer ist.

\section{Exkurs 5: Moses Unfähigkeit zu sprechen}

Um den Einwand des Mose besser zu verstehen, wollen wir vor die Deutung (d) drei Untersuchungsschritte stellen. Zuerst (a) soll allgemein das Sprechen Moses im näheren Kontext studiert werden. Darauf folgt ein Vergleich mit. den Parallelstellen Ex $6,12.30$ (b), bevor wir genauer auf unseren vers 4,10 (c) eingehen.

a) Moses Vermögen zu sprechen: Innerhalb unserer Erzählung war das Sprechen des Mose immer präzise und klar. Kein Anzeichen deutete auf eine Unfähigkeit in diesem Bereich hin, im Gegenteil, Mose ist in seinen Antworten sehr versiert. Sie können kurz sein wie in 3,4; 4,2; genau auf Gottes Reden eingehen wie 3,11; das Reden der Israeliten zitieren wie in 3,$13 ; 4,1$. Auch stilistisch ist Moses Reden beachtenswert. Doppelter Volitiv und Wortspiel mit der Wurzel ראה in 3,3, Parallelismus in 3,11, dreifach verschiedene Verwendung von אמר in 3,13, offene Frage von 4,1 und konsequentes Vermeiden der eigenen Identifikation lassen Mose als sehr guten Sprecher erscheinen. Ein genaueres Studium der Formulierung von 4,10 bestätigt diesen Eindruck.

243 Unter diesem Gesichtspunkt sind die sonst zu unterscheidenden Verben אמר und דבר hier gleichwertig. 
Auf die höfliche Anrede folgt die Aussage "kein Mann von Worten bin ich". אנכי "ich" steht zuletzt, ähnlich wie "dein Knecht" in der nachfolgenden dreifachen zeitlichen Bestimmung und nochmals "ich" in der mit כ eingeleiteten Begründung, die durch doppeltes כבר "schwer" zwei parallele Ausdrücke aufweist.

Ex 4,10 verwendet eine zeitliche Formel, die eine Beziehung zu einem früheren zeitpunkt herstellt. Das AT gebraucht $24 x$ die verbindung von תמול "gestern" und שלשם "vorgestern"

Die Formel hat verschiedene Ausprägungen. תמול kann allein stehen, oder mit כ (7x; "wie vordem"), oder mit מ- (8x; "seit vordem, seit längster zeit"). Mit Ausnahme unserer stelle aber wird של immer ohne Präposition angeschlossen. Ex 4,10 ist die einzige stelle im AT für משלשם.

Viermal erscheint die Formel mit doppeltem a "auch" verbunden: 2 Sam 3,17; 5,2; $1 \mathrm{Chr} 11,2$ und Ex 4,10. Das sind zugleich die einzigen Fälle, wo zwischen תמול und ein weiteres Wort tritt.

\section{Schema 8: Zeitformel mit mehrfachem a2}

$2 \operatorname{Sam} 3,17$

2 Sam 5,2

1 Chr 11,2 Ex 4,10
גם תמול גמ שלשם

גם אתמול גם שמל גמש שלשם גלים

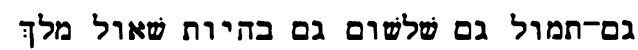

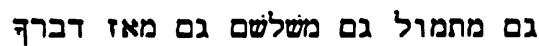

Besonders mit der Chronikstelle gibt es eine engere Verbindung, insofern sie nämlich neben Ex 4,10 die einzige dreigliedrige Formel ist: "Gestern und vorgestern und als Saul König war ..." Beide stellen verwenden dreimal a und drei zeitliche Bestimmungen , doch scheint Ex 4,10 stilistisch noch "abgerunde-

244 Ges.B.839 zu abb, übersetzt mit "gestern (u.) vorgestern, d.i. vordem". Das Buch Exodus hat mit sechs Vorkommen $(4,10 ; 5,7.8 .14 ; 21,29.36)$ die größte Häufigkeit aufzuweisen. Es folgen 1 Sam mit 5 und Dtn und Jos mit 3 Vorkommen.

$245 \mathrm{Da \beta}$ es auch anders möglich wäre, ist an der Parallelstelle zu $1 \mathrm{Chr} 11,2$ in 2 Sam 5,2 zu sehen.

Eine andere Stelle mit dreifachem $ם 2$ ist Jes 48,8 ; allerdings wird es dort mit drei Verben (hören, erkennen, verstehen) verbunden. 
ter", weil es zusätzlich dreimal parallel mit - מ" "von, seit" konstruiert ist. Ex 4,10 mag so als die längste und am besten symmetrisch ausgefeilte Formel dieser Art gelten.

Hier tritt ein Gegensatz zwischen stilistisch geschickter Formulierung und inhaltlich behauptetem Nicht-reden-Können des Mose zutage. Mose bringt seine Unfähigkeit zu sprechen in sprachlich bestechender Form zum Ausdruck ${ }^{246}$.

Auch auBerhalb von Ex 3,1-4,17 läBt nichts darauf schließen, daB Mose als Sprecher ungeeignet sei. In Ex 2,13 stellt er eine berechtigte Frage, im Vers darauf wird (ähnlich wie in 3,3) sein Denken berichtet. In 2,22 ist die Namensgebung seines Sohnes Gerschom mit einer Volksetymologie verbunden. 4,18 zeigt Mose (in groBer Ähnlichkeit mit 3,3 ) als entschiedenen, in seinem Reden klaren und höflichen Menschen. In 4,28 verkündet Mose dem Aaron alle Worte Jahwes, und dieser gibt sie dann (v30) an das Volk weiter. Ex 5,1-3 berichten dann, ebenso wie einzelne Plagenerzählungen, von einem gemeinsamen Auftreten und Sprechen von Mose und Aaron vor Pharao, doch selbst darin ist Mose oft der einzige Sprecher $(7,16.26 ; 8,1.12 .16 ; 9,1 \ldots)$. Nicht einmal die in unserem Bild vorgenommene (und in 4,28.30 eingehaltene) Aufgabenteilung, daß Aaron für Mose zum Volk spricht, wird durchgehalten (siehe z.B. Ex 13,3).

Insgesamt läßt sich sagen, daß Mose gut reden kann und es auch tut. Es gibt keine Anzeichen für eine objektive Unfähigkeit des Mose zu sprechen ${ }^{247}$. Selbst als ihm Aaron als Sprecher zugeteilt wird, redet er selbst noch häufig, ja er singt sogar (Ex $15,1)$.

246 Diese Diskrepanz lieBe sich allerdings dann verstehen, wenn Mose mit seinem Einwand die Fähigkeit meint, öffentlich, vor einer großen Versammlung zu sprechen. - Andere Aspekte an dieser Aussage des Mose: H.L.ELLISON, Fathers 94, sieht darin eine Beleidigung Gottes. Ähnlich versteht M.GREENBERG, Understanding 89, Ex 4,10 als Anklage gegenüber Gott.

247 Höchstens ließe sich sagen, daß sein Reden bisher immer sehr kurz war, gerade im Vergleich mit Gottes Sprechen. Vor diesem Hintergrund nähme Moses Aussage die Bedeutung an von "kein Mann der vielen Worte bin ich". - Auch der in der vorigen Anmerkung angedeutete Unterschied zwischen privatem und öffentlichem Sprechen bleibt als Deutemöglichkeit offen. 
b) Ein Vergleich mit Ex 6,12.30: Ex 4,10 erhält eine besondere Note dadurch, daB Moses Sprechunfähigkeit später noch zweimal unter der Verbindung ערל שפתים "unbeschnitten an den Lippen" (Ex 6,12.30) angesprochen wird. Die vielen inhaltlichen Parallelen zwischen 6,12 und 6,30 lassen sogar fragen, ob es sich an letzterer stelle evtl. nur um die wiederaufnahme von v12 handelt ${ }^{248}$ und somit beide stellen zusammen als eine zu nehmen wären. Doch geben der jeweils verschiedene Kontext und die veränderungen in den Formulierungen bei den stellen unterschiedliche Bedeutungsnuancen.

In 6,9 ist Moses Reden zum zweiten Mal auf Ablehnung gestoBen. Nach dem MiBerfolg beim Pharao (Ex 5) schenkt nun auch das Volk seinen Worten kein Gehör mehr. Auf Jahwes Aufforderung an Mose, zum Pharao zu gehen, antwortet dieser: "Siehe: Die Israeliten hören nicht auf mich. Wie soll der Pharao mich anhören, wo ich unbeschnitten an den Lippen bin?" ${ }^{249}$. Durch eine Petucha getrennt, berichtet 6,13 von einem Auftrag Jahwes an Mose und Aaron. Darauf folgt eine Genealogie von Aaron und Mose 250 .

In 6, 28-29 erteilt Jahwe dem Mose erneut den Auftrag, zum Pharao zu sprechen. Mose antwortet in 6,30 "Siehe: Ich bin unbeschnitten an den Lippen. Wie soll der Pharao auf mich hören?" Jahwe antwortet in Ex 7 mit einer ähnlichen Rollenverteilung wie in $4,14-16^{251}$.

Doch ist 6,30 von $v 12$ insofern verschieden, als der Kontext des MiBerfolges bei den Israeliten ausfällt. Das Nicht-Hören der

248 G.FOHRER, Überlieferung 49, deutet (im AnschluB an C.Kuhl) v30 als Wiederaufnahme. In diesem Fall wäre für die deutsche übersetzung wohl Vorvergangenheit gefordert.

249 הן "siehe" könnte auch hier (wie in 4,1) als Einleitung für einen Relativsatz mit "wenn" übersetzt werden. Der Einwand spielt mit שמע, das einmal mit am Verb konstruiert ist.

250 In dieser Reihenfolge (Aaron vor Mose) werden die beiden Brüder nur sechsmal genannt: Ex $6,20.26$; Num 3,$1 ; 26,59$; 1 Chr 5,29; 23,13. Alle diese stellen stehen ausschlieblich im Zusammenhang mit der Geburt oder mit Genealogien.

251 Die Unterschiede von Ex 7 gegenüber 4,14-16 sind beachtlich: Mose wird "Gott" für Pharao; Aaron wird zum Propheten; Mose muB wieder sprechen und der Pharao wird trotz alldem nicht hören. 
Israeliten, in 6,12 noch der durch $\pi$ eingeführte Hauptgrund, wird in 6,30 weggelassen, und der Nebengrund von 6,12 wird in v30 zum (einzigen) Hauptgrund für Moses Bedenken gegenüber Jahwes Auftrag. Dementsprechend geht die Antwort Jahwes in Ex 7,2b speziell darauf ein.

Von den 35 Verwendungen des Adjektivs לר sind 27 materiell, fleischlich zu nehmen. Sie bezeichnen jemanden mit Vorhaut, besonders die Philister, aber auch andere Nichtisraeliten. In Ez 32,19-32 wird der Ausdruck achtmal verwendet; dabei wird betont, daß der Pharao und Ägypten zu den Unbeschnittenen ins Grab hinab müssen. Daneben stehen acht Vorkommen mit übertragenem Gebrauch, davon einmal von Bäumen (Lev 19,23) und siebenmal von menschlichen Organen .

Jer 6,10 "siehe, unbeschnitten ist ihr Ohr, sie können nicht aufmerken" scheint davon die nächste Parallele zu Ex 6,12.30 zu sein, insofern das Ohr das Ergänzungsorgan zu den Lippen ist. Der Parallelismus "sie können nicht" verdeutlicht, daB es sich um eine Unfähigkeit handelt. "Unbeschnitten an den Lippen" würde dann gleichbedeutend sein mit "nicht sprechen können"

c) Die besondere Aussage von Ex 4,10-12: Auf dem Hintergrund von 6,12.30 heben sich die beiden Aussagen "kein Mann von Worten bin ich" und "ungeschickt mit dem Mund und ungeschickt mit der zunge bin ich" ab. Die Ausdrücke אבריש דברים "Mann der Worte" und "ungeschickt mit dem Mund" sind singulär im AT. Ersterer läвt sich aufgrund ähnlicher Konstruktionen verstehen im sinn von "einer, dem etwas eigen, habituell ist" 254 : Mose sieht sich selber nicht als einen, der gut reden kann oder zu reden gewohnt ist.

252 Ex 6,12.30; Lev 26,41; Jer 6,10;9,25; Ez 44,7.9.

253 Wie stark der Ausdruck bרy ist, mögen die folgenden Stellen zeigen, wo damit ein Ausschlub ausgedrückt wird: Die so Bezeichneten werden in Gen 17,14 von der zugehörigkeit zu Israel, in Ex 12,43 von der Teilnahme am Paschafest und in Ez 44,9 vom Betreten des Tempels ausgeschlossen. In dieser religiös-kultischen Note von gegenüber 4,10 .

254 Ges.B.8 unter 8 (x). 
Der zweite Ausdruck "ungeschickt mit dem Mund" ist wohl im Zusammenhang mit seinem parallelen Ausdruck "ungeschickt mit der zunge" zu verstehen, der noch zweimal in der Berufungsvision des Ezechiel (3,5-6) vorkommt, dort im Plural und in Parallele mit (wörtlich) "tief in bezug auf die Lippe". Diese einzige Entsprechung hilft ein wenig weiter in der Bestimmung von Moses Unfähigkeit. Bei Ezechiel ist mit diesem Ausdruck (hypothetisch) ein fremdes volk mit einer anderen sprache bezeichnet, und die Folge eines solchen Sprechens ist in Ez 3,6 als Nicht-Verstehen beschrieben ("deren Worte du nicht verstehen kannst"). Auch steht der Kontext (daB Israel nicht hört) dem von Ex 4,1-9; 6,9-12 recht nahe.

Sollte Ex 4,10 "ungeschickt mit der zunge" von der Ez-Stelle her zu erklären sein, würde es das Sprechen des Mose als unverständlich qualifizieren. Doch ist bei nur einer anderen stelle Vorsicht beim Vergleichen geboten. Sicher aber läßt sich sagen, daß die von Mose behauptete doppelte Ungeschicklichkeit (mit Mund und zunge) in keinem Verhältnis zu seinem tatsächlichen Redenkönnen steht.

Vom Kontext von Ex 6,9-12 und Ez 3,5-7 ausgehend, wo beide Male die Israeliten nicht hören, erscheint der übergang von Ex 4,1-9 zu v10 nicht mehr so abrupt wie der erste Blick es vermuten lieB. Nicht-hören- und Nicht-sprechen-Können sind zwei einander ergänzende Aspekte für das Ankommen von Gottes Wort, wobei sowohl die Vermittlung (das Sprechen) wie das Aufnehmen (Hören) gestört sein können.

In Ex 6 hatten wir gesehen, wie Moses Unfähigkeit beide Male zur Mitbestellung Aarons führt. Hier aber, in Ex 4, erhält Mose, wenigstens zunächst, eine andere Antwort. Der Verweis auf Jahwes Schöpfermacht $(4,11)$ und die Zusagen der Belehrung und des Beistands mit dem "Instrument" seiner Unfähigkeit verlagern den Blick von Moses Unvermögen auf dessen Geschaffen- und Getragensein durch Jahwe selbst.

d) Deutung: Es gibt offensichtlich ein MiBverhältnis zwischen dem, was Mose in Ex 4,10 von sich selbst sagt, und dem, was er ist. Wahrscheinlich ist diese Diskrepanz als Fehleinschätzung des Mose in bezug auf seine tatsächlichen sprachlichen Fählgkeiten 
oder aus der Angst vor öffentlichem Auftreten heraus zu deuten. Mose unterschätzt seine Begabung.

Der von Mose vorgebrachte Einwand erhält durch Gottes Antwort in 4,11-12 noch einen zusätzlichen Aspekt. Die Bitte des Mose in 4,10 zeugt nicht nur von seiner Fehleinschätzung, sondern auch (ähnlich wie in 3,11) von seinem zu engen Auf-sich-selberSchauen, dem Jahwe sein "Ich" (zweimal (אנכ) und Mitsein entgegenhält. So entsteht eine neue Nuance: Das bloBe Organ und auch die entsprechende Fähigkeit genügen nicht zur Sendung; Gott muB zu ihnen auch noch ihren rechten Gebrauch schenken

Ein Blick auf Jer 1,6 enthüllt dabei noch einen weiteren wichtigen Gesichtspunkt. Wie Mose erhält Jeremia den Auftrag, für Gott zu sprechen. Es handelt sich also nicht um ein beliebiges Sprechen, sondern um die Verkündigung des Wortes Gottes. Wenn es um das Weitersagen einer göttlichen Botschaft geht, wird das zurückschrecken und der Einwand der Berufenen verständlich.

(Ende des Exkurses)

Mose kommt in seinem vierten Einwand Gott wesentlich näher durch Bitte und Anrede mit "du". Zugleich enthüllt sein Bedenken bezüglich seiner rednerischen Fähigkeiten keine gute Selbsteinschätzung. Ex 4,10 steht zwar nicht in wörtlicher, wohl aber inhaltlich komplementärer Verbindung zum vorhergehenden Bild: Die vermittlung des wortes Gottes ist die Kehrseite zu dessen glaubender Annahme.

Ex 4,11: Und Jahwe sagte zu ihm: "Wer hat dem Menschen einen Mund gemacht? Oder wer macht stumm? Oder taub, oder sehend, oder blind?/ Nicht ich, Jahwe?"

Die Redeeinleitung zeigt Sprecherwechsel zu Jahwe an. Die am Ende stehende rhetorische Frage (v11b: "Nicht ich, Jahwe?") gibt

255 Die Unterscheidung von mit dem Organ gegebener Fähigkeit und deren rechtem bzw. verkehrten Gebrauch ist Standardthema prophetischer Verkündigung: Jes $6,9-10 ; 42,7.18 .20 ; 43,8 ; 50,4-$ $5 ; 52,15$ und die beiden schon erwähnten stellen Jer 6,10 und Ez $3,5-7$. 
eine Antwort auf die vorhergehenden, mit מ "Wer?" eingeleiteten Fragen und läßt so auch diese als rhetorische Fragen auffassen. DaB Gott für das Sprechen von seiner erschaffenden und Leben bestimmenden Macht Fragen und nicht Aussagen verwendet, vermindert den Kontrast zum Bedenken des Mose zuvor in 4,10 und macht sein Reden angenehm. Die Formulierung ist die eines Disputationswortes und klingt an manche Wendungen bei Deuterojesaja oder in weisheitlicher Literatur an ${ }^{256}$.

Im Reden Gottes fallen die Wiederholung von פים "setzen, machen" und die vielen Defektivbildungen 257 auf. Im doppelten zeigen der Gegensatz der zeiten und die verschiedenen objekte ein zweifaches Tun Gottes: Sowohl hat Jahwe die Voraussetzungen (Mund, das Sinnesorgan zum Reden) geschaffen, wie er auch jetzt noch (Präformativkonjugation) die Fähigkeit (bzw. Un-) zu ihrer Benützung (stumm und die anderen Defektivbildungen) schenkt. Es handelt sich hier trotz ארם "Mensch" wohl nicht so sehr um allgemeine Schöpfungsaussagen, sondern eher um eine direkte Antwort auf Moses Bedenken bezüglich seines Unvermögens zu reden. Darauf erwidert Jahwe, daB von ihm sowohl das Organ zum Sprechen wie auch sein Gebrauch, und nicht nur auf der Ebene des Sprechens, sondern auch der des Hörens und Sehens kommen. Damit ermutigt Gott Mose über die ihm geschenkte "natürliche" Begabung hinaus mit dem Gedanken an seine Unterstützung in ihrem Gebrauch. zugleich wird klar, daß Mose bei einem eventuellen Erfolg seiner Sendung ihn in keiner Weise sich selbst zuschreiben kann ${ }^{258}$.

Die vielen Gegensätze in v11a malen das Bild eines Gottes, der über ihnen steht. Vergangenheit und Gegenwart (ai und ישום),

256 Siehe dazu, mit genauen stellenangaben, W.H.SCHMIDT, Exodus 201-202.

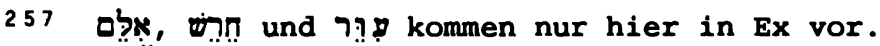

Einige möchten חִ פִ 11, S.249. Als Hinkender wäre Mose dann nicht geeignet, Opfer darzubringen (Dtn 15,21). Doch findet sich gerade in Ex noch einmal פִ̣ im Sinn von "geöffnet, sehend": Ex 23,8.

Bei "פקיָח "geöffnet" besteht ein Kontrast zwischen der grammatischen Form (Defektivbildung der Form לọp, vgl. P.JoüoN, Grammaire $\$ 88 \mathrm{Hb})$ und der inhaltlichen Aussage, die eine positive Eigenschaft beschreibt. Wir treffen dabei auf eine ähnliche Diskrepanz wie zuvor bei Mose in 4,10 bezüglich der stilistischen Formulierung seiner behaupteten Unfähigkeit zu reden. 
Erschaffung wie Ausübung (Mund und stumm), Erzeugung wie Wahrnehmung von Lauten (stumm und taub), öffnung wie Blindheit zum sehen (geöffnet und blind), alles ist von ihm gegeben.

Mit Fragen möchte Jahwe in Ex 4,11 Mose zur Einsicht bringen, daB er über menschlichen Gegensätzen und menschlichem Unvermögen steht und neben den Organen auch ihren Gebrauch schenkt.

Ex 4,12: "Und nun: Geh!/ Ich selbst werde mit deinem Mund sein und dich lehren, was du reden sollst."

Jahwes Sprechen von sich selbst $(4,11)$ mündet wieder (wie in 3,9-10.15-16) ein in die Aufforderung an Mose zu gehen. Zum dritten Mal wiederholt Gott diesen Imperativ, ihm geht wie in $3,10.18$ "und nun" voraus; ein Zeichen dafür, daB wir an einem Ende angelangt sind.

Laut Berufungsformular müBte auf die Aufforderung $z u$ gehen zuerst ein Einwand und dann die Beistandszusage kommen (vgl. unter 2.1.2). Hier aber folgt eine zusage des Beistands direkt auf die Sendung, wohl deshalb, weil es die dritte Aufforderung ist. Gottes Geduld ist angespannt; er rechnet mit sofortigem Gehen des Mose.

Hatte v11 nur allgemein und in Form von Fragen auf Moses vierten Einwand geantwortet, so gibt Jahwe nun zwei genaue und bestätigende Antworten. Zum einen wird die Beistandszusage von 3,12 spezialisiert ("mit dem Mund") und Gottes Ich, analog zu 3,12 und 4,11, durch Personalpronomen betont. zum anderen gibt Gott zusätzlich das Versprechen, Mose zu lehren, was er zu sagen hat .

259 ירה II Hi kommt noch fünfmal in Ex vor. Es wird aber auBer 4,15 nie dafür verwendet, daB Gott Mose lehrt, was er reden soll (Ex 15,25 berichtet davon, daB Jahwe Mose ein Holz "lehrt"). Auch sonst wird innerhalb des Pentateuch dieses Wort nie mehr für Moses Belehrung durch Gott gebraucht.

Vermutlich geht diese Zusage durch mit anderen wörtern eingeleitetes Reden Gottes in Erfüllung (vgl. Ex 12, wo zuerst Mose und Aaron von Jahwe angeredet werden und nachher Mose zu den Ältesten spricht). 
Was Moses Bedenken in 4,10 betrifft, so sichert Gott ihm hier in Ex 4,12 seinen Beistand zu.

Ex 4,13: Und er sagte: "Bitte, mein Herr,/ sende doch, wen du senden willst!"

Einfaches וריאמר genügt zum Andeuten des Sprecherwechsels. Die aus 4,10 wiederholte Bitte in der Anrede bestätigt, daB Mose spricht. Sein Reden ist genauso höflich eingeleitet wie in 4,10 und führt ebenso wie dort die Anrede an Gott in der 2.P.Sg. weiter, verstärkt diese persönliche Beziehung jedoch noch dadurch, daB es nicht nur zwei Suffixe sind (wie in 4,10), sondern zwei Verbformen, eine davon im Imperativ. Die Prekativpartikel "doch" macht (zusammen mit der Anrede v13a) deutlich, daB es sich nicht um eine "freche Antwort" " sondern um eine höfliche Bitte handelt.

Die Bitte ist in einer für unsere Erzählung typischen Weise formuliert, nämlich mit Doppelung des Verbs ${ }^{261}$. Sie bringt hier die Unbestimmtheit zum Ausdruck; Gott mag "irgend jemanden" senden. Mit dieser Bitte möchte Mose Gottes Sendung an ihn ablehnen. Eine solche Ablehnung ist singulär ${ }^{262}$, sie wird hier auch nicht weiter begründet. Es scheint, daß wir mit diesem fünften Einwand am Kern des Widerstandes des Mose gegenüber seiner Sendung durch Gott angekommen sind. Ein nicht zu begründendes Unbehagen/Nicht-

\section{H.L.ELLISON, Fathers 94.}

261 Das Verb של gehört zu den Schlüsselwörtern des zweiten semantischen Feldes. Für die Doppelungen siehe Anm.147 in Exkurs 4.

262 W.H.SCHMIDT, Exodus 202-203. - Für die Auslegung der Antwort Moses als Ablehnung: Ges.K. \$155 $\mathrm{n}$ ("sende Botschaft durch den, den du senden wirst, d.h. durch irgendeinen anderen") und die meisten Ausleger; auch der Kontext spricht mit der Entwicklung der Einwände seit 3,11 und dem folgenden zorn $(4,14)$ dafür.

Die Ablehnung dessen, was Gott von einem Menschen will, geschieht allerdings meist nicht in Worten und folgt nicht unmittelbar. Auch wird sie oft nicht so direkt beschrieben wie hier. Für eine Ablehnung im Tun mag das Verhalten Jonas (Jona 1) stehen. In alldem bleibt, daß Mose der einzige ist, der Gott gegenüber im Sprechen Widerstand bis zur Ablehnung zu leisten gewagt hat. 
wollen hat Moses Verhalten Gott gegenüber bisher bestimmt ${ }^{263}$. Dabei fällt auf, daB dieser innerste widerstand erst zuletzt und in der persönlichen Anrede an Gott geäuBert wird.

Ex 4,13 bringt mit dem als Bitte vorgetragenen fünten Einwand des Mose das eigentliche Problem in seinem widerstand. Es ist eine unbegründete Ablehnung gegenüber der Sendung durch Gott.

Ex 4,14: Da entbrannte der zorn Jahwes gegen Mose und er sagte: "Ist da nicht Aaron, dein Bruder, der Levit? Ich weiB, daB er sehr gut reden kann./ AuBerdem, siehe, er zieht gerade heraus, dir entgegen: Wenn er dich sieht, wird er sich von Herzen freuen."

Nach 4,7 meldet sich zum ersten Mal wieder und zum letzten Mal in unserer Erzählung der Erzähler zu Wort und berichtet die einzige Reaktion Gottes während des Gesprächs: "Da entbrannte der zorn Jahwes gegen Mose". Die Konsequenzen sind merkwürdig schwach $^{264}$.

263 R.J.BURNS, Exodus 54. - Der irrationale Charakter von Moses letztem Einwand zeigt sich auch an der sprachlichen Formulierung: Bisher hatte Mose in seinem Reden zu Gott immer etwas aufgegriffen, was Gott zuvor erwähnt hatte $(3,11$ nimmt 3,10 auf; 3,13 greift auf $3,6.12$ zurück; 4,1 auf $3,16.18$; selbst 4,10

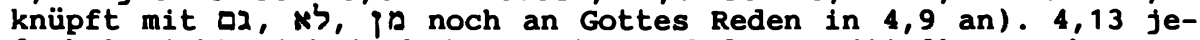
doch bezieht sich in keiner Weise auf das unmittelbar vorher von Gott Gesagte, sondern geht mit חל zurück auf $3,10.12$ ).

264 Wenn Gottes zorn entbrennt, sind die Folgen meist schwerwiegend. Sie reichen von Bestrafung bis zu Tod und Vernichtung. Hier aber ist keine Folge für Mose zu erkennen, auBer, daB sein widerstand gebrochen wird.

RASCHI, Kommentar zur stelle, nennt als Prinzip, das auf Gottes zorn immer eine Strafe erfolge, und zitiert für eine Lösung unserer stelle R.Jehoshua, nach dem hier die einzige stelle ohne strafe sei, und R.José, nach dem die strafe darin besteht, dab Aaron als Priester in zukunft über Mose steht. - Unter Umständen wäre es aber auch möglich, in Ex 4,24-26 eine Folge von Gottes zorn zu sehen.

Jahwes Erzürnen ist die Reaktion auf das Verhalten des Mose. offenbar ist Mose in seinem Reden zu weit gegangen. Wo er, wenn auch höflich (als Bitte), Gott Befehle (Imperativ) gibt, da verdreht er die Beziehung, die zwischen ihm und Gott besteht. Diesbezüglich schreibt G.SAUER, T $^{224}$, der göttliche zorn mache deutlich, "daB hier nicht gleichberechtigte Partner einander gegenüberstehen, sondern der Schöpfer seinem Geschöpf, der Gesetzgeber den ihm zum Gehorsam Verpflichteten, der Herr seinen 
Eine rhetorische Frage führt mit den Angaben von Name (Aaron), Beziehung (Bruder) und Beruf ("der Levit"" ${ }^{265}$ ) eine neue Person ein. Damit ist die Bestellung eines Helfers für Moses Sendung verbunden . Die Einführung einer neuen, dem Mose nahestehenden Person wird von Gott sehr positiv gezeichnet: Aaron geht Mose bereits entgegen. Das Partizip xy" "hinausgehend", noch verstärkt durch die beiden Partikeln lenkt den Blick betont darauf, daB Aaron schon unterwegs ist. Die letzten beiden wörter des Verses sind gleichzeitig die letzten beiden neu verwendeten wörter unserer Erzählung und stellen die besondere Freude beim zusammentreffen der beiden Brüder vor Augen. Dazu schreibt Gottes Vorstellung Aarons ihm sehr gute Fähigkeit zu reden und einen Beruf ${ }^{268} \mathrm{zu}$, die eine ideale Ergänzung zu der von Mose im vierten Einwand erwähnten eigenen Schwäche sind.

Ex 4,14 zeigt eine starke gefühlsmäßige Reaktion Gottes. Trotzdem geht Gott wenigstens teilweise auf Moses Ablehnung von v13 ein, indem er seinen Bruder in die Sendung einbezieht. Mit all dem führt 4,14 Neues in der Bibel ein.

Untergebenen". - Ex 4,14 ist das erste Vorkommen (nicht zeitlich zu verstehen) für den zorn Gottes in der Bibel.

In den Gutturalen der ersten vier wörter läßt sich vielleicht ein lautlicher Ausdruck des göttlichen Ärgers hören: הלא

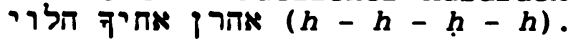

265 Für eine andere übersetzung siehe in c1 Erläuterung $K$ zur Stelle (O.LORET2, Aharon 454; W.GROSS, Pendenskonstruktion 118). - - הלר findet sich viermal in Ex: 4,$14 ; 6,19.25 ; 38,21$. Unsere stelle ist die erste für "Levit" in der Bibel. - In den drei Angaben (Name, Beziehung, Beruf) ist die Vorstellung Aarons mit der Jitros in 3,1 identisch.

266 w.H.SCHMIDT, Exodus 203, schreibt, daß die Helferbestellung für das AT singulär ist.

267 Es ist das einzige Vorkommen von Ex. Die konkrete Erfüllung dieser Ansage wird in Ex 4,27 berichtet als "und er küBte ihn".

268 DaB Aaron reden kann, kommt im absoluten Infinitiv (vgl. 3,7.16) zum Ausdruck. Außerdem ist der Verweis Gottes auf sein Wissen (siehe auch 3,19 ) eine weitere Bestärkung dessen.

Mit "der Levit" ist hier wohl eine Berufsbezeichnung (und nicht die zugehörigkeit zum Stamm Levi) ausgedrückt. H.SCHMID, Mose 38, sieht in dieser Benennung die amtliche stellung als Priester; W.H.SCHMIDT, Exodus 203, faBt Levit als Bezeichnung eines (vorpriesterschriftlichen) Berufes auf, mit dem das Amt zu lehren verbunden sei. 
Ex 4,15: "Und du sollst zu ihm reden und die Worte in seinen Mund legen./ Ich selbst aber werde mit deinem Mund und mit seinem Mund sein und euch lehren, was ihr tun sollt."

Die beiden Wendungen des ersten Halbverses sind selten. "und du sollst zu ihm reden" findet sich viermal in der Bibel ${ }^{269}$ und wird auBer für Mose nur noch für Elia verwendet.

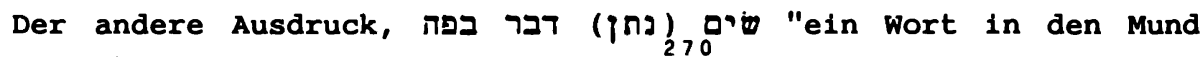
legen", ist ebenfalls nicht häufig und bezeichnet mit einer Ausnahme ( 2 Sam 14,3) immer das auf Gottes Auftrag erfolgende prophetische Sprechen, noch genauer das übergeben des zu Redenden durch Gott an den Propheten. Hier ist die Übergabe der Worte durch Mose vermittelt. Auch eine Untersuchung von הדברים "die Worte" in Ex bestätigt dieses Bild. Mit Ausnahme von Ex 18,19, wo es sich um "Angelegenheiten, Rechtsfälle" handelt, sind mit "den Worten" immer ein Reden Gottes, oft sogar seine Weisungen gemeint.

Während v15a das autoritative Sprechen von Jahwes wort (-en) in an prophetisches Auftreten anklingenden Ausdrücken beschreibt und damit die Weitergabe des Wortes Jahwes von Mose an Aaron kennzeichnet, erweitert der zweite Halbvers die Mose in 4,12 gegebene Zusage zweifach: Die Beistandszusage gilt auch dem Sprechen Aarons, das Lehren betrifft ebenfalls beide und umfaBt sogar ihr $\operatorname{Tun}^{271}$.

Ex 4,15 führt die Vorstellung Aarons vom Vers zuvor fort, indem es ihn zum Addressat des Redens Moses macht und Gottes Zusage von 4,12 auch auf ihn ausweitet.

269 Ex 4,15;9,1; 1 Kön 21,19 (2x).

270 Mir sind bekannt: Ex 4,15; Num 22,38; 23,5.12.16; Dtn 18,18 ; 2 Sam 14,3; Jes 51,$16 ; 59,21$; Jer 1,9. Die Stellen Dtn 18,18 und Jer 1,9 sind besonders wichtig, weil sie von der Ausstattung des Propheten durch Gott berichten (wohl am Beginn seines Wirkens; vgl. dazu auch Ez 3,1-2).

In Jer 5,14 wird dieselbe Konstruktion mit doppeltem objekt gebraucht (zusätzlich wộ); damit gewinnt es den Sinn von "zu Feuer machen".

271 Vom gemeinsamen Tun Moses und Aarons wird z.B. In Ex 7,10 gesprochen. 
4,16: "Und reden wird er für dich zum Volk/ und es wird sein: Er wird dir Mund sein, und du wirst ihm Gott sein."

Die Mitbestellung Aarons erfordert auch die Angabe seiner Aufgabe und die Abgrenzung der "Rollen" der beiden Brüder. An Aaron liegt es, für Mose zum Volk zu sprechen, was er z.B. in 4,30 tut" . Die Rollen werden mit "Mund" und "Gott" angegeben und mit redundantem ותיה "und es wird sein" leitet. Die Verwendung von אלהים für einen Menschen ist in der Bibel selten ${ }^{274}$. Mose ist der einzige, bei dem diese Bezeichnung in der Bibel für eine mit Namen festzumachende Person während der zeit ihres Lebens verwendet wird. Diese Auszeichnung ist freilich beschränkt, sie gilt hier gegenüber Aaron und in Ex 7,1 gegenüber dem Pharao, für die Mose an Gottes Stelle steht. Die Bezeichnung "Gott" für Mose ist möglich geworden und vorbereitet in unserer Erzählung durch die ersten drei Bilder, die Jahwe als Gottesnamen einführen. So kann das Wort אלהים "Gott", wenn allein (ohne Jahwe) verwendet, von der exklusiven Bindung an die Benennung Gottes frei werden dazu, auch Gott Nahekommendes zu bezeichnen. In dieser Nähe zu Gott liegt die Auszeichnung des Mose begründet.

4,17: "Diesen Stab aber nimm in deine Hand!/ Mit ihm sollst du die zeichen tun."

272 Dennoch bleibt Mose häufiger der Sprecher, auch zum Volk.

273 Für die beiden Rollen haben wir schon auf die Vergleichsstelle Ex 7,1-2 hingewiesen. - RASCHI, Kommentar zur stelle, interpretiert אלהים als "Meister, Chef" und פה als "Interpret, Sprecher".

Redundante Verwendung von היה fügt sich zweifach in den Sprachgebrauch unserer Erzählung ein. Zum einen wird dieses verb häufig verwendet (siehe auch $3,12.14 ; 4,8-9.12)$, zum anderen bildet es eine weitere Doppelung.

274 Sonst noch in Ex 7,1 (Mose ist Gott für Pharao); 1 Sam 28,13 (aber fraglich, weil das Partizip םיל im plural steht; gemeint ist durch den nachfolgenden vers der tote samuel, dessen Geist von der Beschwörerin gerufen wird); Ps 45,7 (der König wird als Gott angeredet); Ps 82,6 ("Götter seid ihr"). Von der Gottähnlichkeit aufgrund der Schöpfung ist in Gen 1 und Ps 8,6 die Rede. 
Aaron ist aus dem Blickfeld geschwunden, Gottes Weisung richtet sich nur mehr an Mose und nimmt früheres Sprechen (Ausdrücke aus den Versen 4,2.9.15; vgl. 1.2.1) auf. Der vollständig wiederholende Charakter dieses Verses entspricht so seiner Funktion: AbschluB und zusammenfassung für die gesamte Erzählung zu sein. Im Rückgriff auf Anfang und Ende des fünften Bildes ${ }^{2}$ zeigt Gott den ersten konkreten Schritt zur Ausführung der Sendung auf. Das Ergreifen des Stabes bedeutet für Mose den Beginn der Ausführung seiner Sendung, er beginnt damit, dem Auftrag Gottes zu gehen nachzukommen.

\section{Rückblick auf die Mitbestellung Aarons}

Das sechste Bild ist bestimmt durch das semantische Feld des Redens. In Ex 4,10-17 heben sich die Verse 13.17 fast als erratische Blöcke dadurch ab, daB sie weder פר enthalten und so eine ähnliche Sonderstellung einnehmen wie die Rahmenverse 4,5.8-9 im fünften Bild. Gleichzeitig markieren sie die letzten beiden Äußerungen unserer Dialogpartner. Moses Reden gipfelt in einer aus Unwillen oder Unbehagen kommenden Ablehnung, die von Gott in der zusätzlichen Entsendung des Bruders und im Aufzeigen des ersten kleinen Schrittes aufgefangen wird. Es scheint, als ob beide seiten wenigstens etwas nachgegeben hätten: Gottes Plan bestand wohl ursprünglich darin, Mose alleine zu senden. DaB Aaron nun teilhat an der Sendung, bedeutet demgegenüber eine Modifizierung oder Ergänzung. Auch Mose muB nachgeben, insofern sein Wunsch, Gott möge jemand anderen senden, in der Mitbestellung seines Bruders Aaron nur teilerfüllt wird.

In diesem sechsten Bild kommt die eigentliche Gestalt des Mose heraus. Im ersten Einwand $(3,11)$ hatte er zwar auch von sich geredet, aber in einer Frage und mit fast wörtlichem Aufgreifen des von Gott Gesagten. Seine beiden weiteren Einwände $(3,13 ; 4,1)$ waren weitestgehend durch die von ihm projektierte Reaktion der Israeliten bestimmt. Hier aber, in 4,10.13, redet er selbst:

275 Mit dem Stab kann Mose eigentlich nur ein zeichen tun. Der Rückgriff auf Anfang (Stab) und Ende (die zeichen) greift das Gesamt auf und ist wegen der sprachlichen Prägnanz geschehen; es wäre zu umständlich gewesen, hier am Ende die drei Zeichen noch einmal einzeln zu wiederholen. Deswegen entsteht die nicht ganz korrekte Verbindung des Stabes mit den Zeichen (im Plural). Mose wird von Gott so nochmals in der ihm gegebenen Macht bestärkt. 
bittend, Gott direkt mit "du" anredend, sein Unbehagen aussprechend. In ihren Widerständen tritt die Person des Mose offen zutage . Wenn dieser Mose am Ende doch gehen muB, dann geht er sicher nicht aus eigener Kraft oder eigenem willen. Seine Sendung basiert gänzlich, bis ins Letzte, auf seiner Befähigung durch Gott und auf Gottes Wollen.

Gott geht in beiden Fällen auf Moses Schwierigkeiten ein, auch wenn es ihn an den Rand seiner Geduld bringt. Der Fehleinschätzung des Mose bezüglich der Fähigkeiten seines Ich $(4,10)$ stellt Jahwe sein "Ich" entgegen (v11-12), der Wunsch nach Entsendung eines anderen wird durch die Mitbestellung Aarons beantwortet (v14-16). Die Helferrolle Aarons ist hier also nicht völlig (wie in 6,12.30) durch die Unfähigkeit des Mose, sondern durch seine Ablehnung nötig geworden ${ }^{277}$.

Am Ende ist Mose in seiner sendung nicht allein: Er hat mehrfache zusagen des Mitseins Gottes mit ihm. Er hält einen stab in Händen, der ihm durch die zeichen Glaubwürdigkeit verschafft. Und er hat einen Bruder, der ihm in seinem Auftrag hilft.

\subsection{Auswertung der Analyse}

a) Was die Untersuchungen von $c 2$ bereits ahnen lieBen, bestätigt sich hier vollends: Unsere Erzählung Ex 3,1-4,17 ist in bezug auf Form, Aufbau, Vokabular, gedankliche Entwicklung und inhaltliche zusammengehörigkeit in sich kohärent. Wir sind auf keine Spannungen gestoßen, die nicht innerhalb einer einheitlichen Erzählung zu erklären gewesen wären. Was von manchen als Spannung oder Doppelung (und damit als Grund für Quellenscheidung) angesehen wird, läßt sich mit ganz wenigen Annahmen erklären. Diese Annahmen sind: - Der Erzähler präsentiert Jahwe und

276 Was so bei Mose über die gesamte Erzählung hinweg, langsam und in Einwänden zutage tritt, bildet einen Kontrast zu Jahwes freier, zusammenhängender offenbarung seiner selbst in $3,14-15.16-18$.

277 Dennoch besteht eine wenigstens indirekte Beziehung zwischen vermeintlicher Unfähigkeit des Mose zu reden und der Bestellung Aarons, insofern in beiden Antworten Gottes das Wortfeld des Redens stark vertreten ist und er Aaron explizit diese Rolle zuspricht. 
Mose als zwei Personen mit verschiedenen Gesichtspunkten. - Die Sicht des Erzählers hebt sich von der Jahwes und Moses ab. Erzählung und Dialog können in ihrem Fortschreiten Aussagen weiterentwickeln.

Diese Annahmen gehen nicht über das hinaus, was von der Literaturtheorie für ein literarisches Werk als selbstverständlich vorausgesetzt wird. Die ersten beiden Punkte sind Ausdruck der notwendigen Gestaltung eines Werkes, insbesondere eines Dialogs, durch einen Erzähler; die dritte Annahme ist geradezu gefordert, soll eine Erzählung nicht in langweiliger wiederholung enden.

Zum selben Ergebnis der erzählerischen Einheitlichkeit unseres Textes kann man auch von einer anderen seite gelangen. Die Verbindungen innerhalb unserer Erzählung sind in der Aufnahme von Formulierungen aus anderen Teilen und in stilistischen Ähnlichkeiten so dicht, daß sie geradezu den gesamten Text als Auslegungseinheit fordern. Eine besondere Rolle kommt darin der in Moses Einwänden sich zeigenden Entwicklung bis 4,13 hin zu. Sie weisen einen solchen inneren zusammenhang und ein stufenweises Voranschreiten auf und sind überdies so eng mit Gottes Antworten verbunden, $d a \beta$ es nicht möglich ist, Teile davon abzutrennen, ohne die Logik der Erzählung zu zerstören.

Die zu Form und Aufbau gemachten Beobachtungen bestätigen dies, wobei allerdings eine Einschränkung zu machen ist: Es ist möglich, daß einmal 3,22 das Ende der Berufung Moses war. $2 u$ einem späteren zeitpunkt könnte in enger sprachlicher Annäherung 4,1-17 formuliert und angefügt worden sein. Dabei ist die Verbindung so gut gelungen, daß wir insgesamt eine einheitliche Erzählung vor uns haben. Es gibt kein wort in Ex 3,1-22 und in Ex 3,14,17, das nicht im Gesamt sinnvoll und für seine besondere Aussage erforderlich ist.

b) Die verwendeten Erzähltechniken legen zeugnis ab von der künstlerischen Qualität der uns vorliegenden Erzählung. Im besonderen ragen heraus das Arbeiten mit verschiedenen Gesichtspunkten, die nuancierten Redeeinleitungen (inklusive ihrer wiederholungen oder ihres Fehlens), das Verwenden doppeldeutiger Formulierungen, die stufenweisen Enthüllungs- bzw. Identifizierungs- 
prozesse, die vielen Doppelungen und die Präzision im Aufbau und in der Formulierung der Aussagen.

c) Wenn wir annehmen, das der Pentateuch eine Gesamtredaktion erfahren hat ${ }^{278}$, dann gewinnen neu auftretende Begriffe an Gewicht. Für einen, der von Gen 1 an fortlaufend zu lesen beginnt, sind in Ex 3,1-4,17 neu:

Berg Gottes, Horeb, das Gesicht verbergen, mein Volk (im Mund Gottes), Sendung durch Gott, der Gott eurer/ihrer väter, so sollst du sagen, der Gott Abrahams, Isaaks und Jakobs, Andenken, die Ältesten, der Gott der Hebräer, Jahwe unser Gott, die starke Hand, zorn Gottes, Aaron, der Levit, "Gott" für einen Menschen und Erzähltechniken wie vierte zitatebene oder fehlende Redeeinleitung ...

Bei den meisten dieser Ausdrücke erklärt ihre Verwendung hier ihre Bedeutung. Die Berufung des Mose wird so zum "wörterbuch", bei dem zur klärung entscheidender wörter des AT Immer wieder nachgeschlagen werden kann.

d) Wir sind in unserer Erzählung auch auf einige Ausdrücke gestoßen, die einzigartig für das AT sind. Wir fanden an singulären Ausdrücken: Kontraktion von לכת (+ nachfolgendes und מבע) die groBe Erscheinung, heiliger Boden, Gott anblicken Hi), gutes und weites Land, לרר דר, mein Andenken, die Langform עבריים, Blut auf dem Trockenen, seit vorgestern, Mann der Worte, ungeschickt mit dem Mund. Weiters kommen sonst in der Bibel nicht vor: brennender und nicht verbrennender Busch, Ablehnung in worten Gott gegenüber, Helferbestellung bei einer Berufung.

Die Verschiedenheit von Texten untereinander bedingt, daB in manchen von ihnen singuläre Ausdrücke vorkommen. Das ist also ein zu erwartender zug in einer Erzählung. Wir stehen in Ex 3-4 vor einem Text, der in den genannten Eigenheiten sprachlicher Reflex sonst im AT nicht beschriebener Erfahrungen ist.

e) Die Beziehungen zur Genesis und zum ersten Teil der Exoduserzählung sind sehr stark. Unser Text greift manche züge aus

278 Siehe dazu zuletzt die Position von R.N.WHYBRAY, Making 232-233, der den Pentateuch sogar als aus einer Hand stammend ansieht. 
den Patriarchenerzählungen auf und bringt sie zu einem AbschluB. So erreicht die vätergottformel hier ihre definitive Formulierung, und ebenso zeigt die Gestaltung der Theophanie in vielem letztmaliges Aufnehmen von zügen aus der Genesis.

Die Beziehungen zu den anderen Erzählungen in Exodus sind mehrfach. - Wir haben gesehen, daB Ex 3,1-4,17 sich harmonisch einfügt in Ex 1-5. Im Aufgreifen von Entwicklungen und Formulierungen aus Ex 1-2 bereitet unser Text teils wörtlich vor, was sich ab 4,18 ereignet. Die Übereinstimmung mit 4,18.27-31 und dem Anfang von Ex 5 ist so groB, daB diese Texte als zusammengehörig verstanden werden müssen. - Die Verbindungen $z u$ Ex 6,12.30; 7,1-3 und zu Teilen der Plagenerzählungen (im besonderen deren Rahmung und die Plage der Erstgeburt) sind auch deutlich geworden. Mehr als mit den einzelnen plagen und dem Durchzug durchs Schilfmeer scheint Ex 3-4 mit der allgemeinen Ausrichtung der Plagen insgesamt und damit der Vorbereitung des Auszugs verbunden zu sein. - $\mathrm{zu}$ den ersten beiden Punkten kommen noch vereinzelt Anspielungen an die Sinaitheophanie.

Diese beiden Aspekte von Ex 3-4, einerseits abschlieBende zusammenfassung für die Patriarchenerzählungen der Genesis, andererseits vorausschauende Ankündigung des Befreiungsgeschehens zu $\operatorname{sein}^{279}$, machen unseren Text zu einem Verdichtungspunkt. Die Berufung des Mose ist in manchem zusammenfassung des Patriarchengeschehens, Wendepunkt in der Gotteserkenntnis, Beginn der Volksgeschichte. Sie verdichtet diese Themen und strahlt aus bis zu Auszug, Landnahme und selbst darüberhinaus im bleibenden Verhältnis zu "Jahwe, unserem Gott".

279 Die Ankündigung scheint zwei Sichtweisen zu enthalten, eine für die nahe zukunft, in der die zeit bis zum Auszug recht genau geschildert wird (z.B. Bild 4), und eine, die den in weiter Ferne liegenden Einzug ins Land in den Blick nimmt $(3,8,17)$. 


\section{KAPITEL: KONVENTIONEN UND PERSONEN DER ERZÄHLUNG}

Die Fragerichtung der vorangegangenen Kapitel war eher analytisch. Es ging darum, die einzelnen Elemente des Textes in ihrem sinn, ihrer gegenseitigen zuordnung und ihres ortes in Aufbau oder Form zu befragen. Nun gilt es, die zusammenhänge der einzelnen Elemente unter dem Gesichtspunkt ihrer gemeinsamen Aussage sichtbar zu machen. Diese eher synthetische Fragerichtung verlangt nach einer Auswahl. Wir wollen uns im folgenden auf drei Themen beschränken, nämlich einmal die literarischen Konventionen', zum zweiten die Verbindungen mit Texten aus der Genesis und mit anderen Berufungen, und zum dritten die Art, wie unsere Erzählung die beiden Gesprächspartner schildert.

\subsection{LITERARISCHE KONVENTIONEN}

Bereits anläßlich der Form hatten wir uns mit schemen befaßt, die in Textgruppen zu finden sind und auch unsere Erzählung gliedern (2.1.2 und 2.1.3). Hier jedoch geht es nicht mehr um die Form, sondern um die Aussagen, die die literarischen Konventionen aufgrund der Beziehungen mit anderen Texten ermöglichen.

\subsubsection{Ex 3,15 - ein Einsetzungsbericht ${ }^{2}$}

1 Eine literarische Konvention ist ein sprachliches Schema, das mehreren Texten gemeinsam ist. Die suche nach literarischen Konventionen findet sich z.B. auch in den Untersuchungen von J.MAGONET, Bush, und D.MCCARTHY, Hero. Für die Abgrenzung zu "Gattung" siehe J.L.SKA, Passage 147, besonders Anm.1.

2 Im NT gibt es bei Paulus und den Synoptikern die Berichte von der Einsetzung des eucharistischen Mahles. Der Begriff "Einsetzungsbericht" stammt von den diesbezüglichen studien. zu erwähnen sind: J.JEREMIAS, Abendmahlsworte, H.SCHÜRMANN, Einsetzungsbericht, J.BETz, Eucharistie, H.FELD, Verständnis, R.PESCH, Abendmahl, X.LEON-DUFOUR, Partage.

Bei den zwei zuletzt genannten Autoren finden sich zusammenstellungen der im Einsetzungsbericht verwendeten Elemente. Pesch nennt in der synopse (S.22f) die materiellen zeichen Brot und Becher, weiters Deutewort ("dies"), Anamnesisbefehl und Todesprophetie bzw. sogenannter eschatologischer Ausblick. - Léon-Dufour zählt (in der deutschen übersetzung S.86-96) u.a. folgende Elemente auf: Dialogsituation, Geste/Wort, Mein Leib/ Mein Blut, Die Jünger/ Die Vielen, Eine neue Beziehung, Die künftige Situation. Gerade die Einzeluntersuchungen Léon-Dufours verweisen immer wieder auf das AT als Hintergrund. Doch bei keinem der angeführ- 
Öfter begegnen wir in der Bibel Texten, die von der Einsetzung eines zeichens berichten, das Ausdruck einer intensiveren Beziehung zwischen Gott und Mensch wird: Gen $9,8-17$; 17,9-14; Ex 3,$15 ; 12,14 ; 12,17 ; 31,12-17$; 1 Kor $11,23-26$.

Die diesen Texten gemeinsamen Elemente sind:

a) Gott will eine Beziehung verbessern oder stiften. Dabei redet Gott selbst, gebraucht meist die 1.P.Sg. "ich" und die 2.P.Pl. "ihr" und häufig das Wort ברית "Bund".

b) Diese neue/erneuerte Beziehung wird in einem faBbaren zeichen (wie z.B. Beschneidung, Mazzot; oft steht zusätzlich das wort תi "zeichen") konkretisiert. Auf zeichen oder Bund wird ausdrücklich mit Demonstrativpronomen hingewiesen.

c) Diese Festsetzung in einem zeichen verlangt (oft Jussiv oder Imperativ oder Erwähnung von "Gesetz") nach gedenken (Wurzel זכר) oder bewahren (שמר).

d) Die Einsetzung geschieht auf lange (דרת "Geschlechter") oder ewige (עלם) zeit.

ten Autoren war zu finden, daB das Schema des Einsetzungsberichtes als Ganzes auf das AT zurückzuführen sein könnte.

3 Wir beschränken uns hier auf die wichtigsten solchen Erzählungen in Gen und Ex und ergänzen diese durch den paulinischen Einsetzungsbericht aus dem NT.

Weitere Texte innerhalb von Ex, die diesen Einsetzungsberichten nahestehen, sind: Ex $12,2.24 .42 ; 13,9.16 ; 16,15-16.32$; 17,14. Mit Ausnahme der ersten und der letzten stelle spricht aber immer Mose oder der Erzähler.

In der Nähe dieser Einsetzungsberichte stehen auch jene Texte, die von Namensgebung oder zeugenfunktion berichten, z.B. Gen 28,17-19; $31,44.48 .51$, und jene, die vom Belehren der Söhne sprechen: Ex 10,$2 ; 12,26 ; 13,8.14$. In allen Fällen sind die gemeinsamen Elemente die Festsetzung und der Wunsch, sie möge auf längere zeit anhalten.

4 Es handelt sich trotz dieses Befundes nicht immer um direkte Anrede, weil die mit "ihr" gemeinten Personen nicht gegenwärtig sind: In Gen 17 wird nur Abraham, in Ex 3 und 31 nur Mose direkt angesprochen.

5 Verwendet werden הוא/היא זיז "er/sie" "dies" und "

In Gen $9 ; 17$ und Ex 3 stehen die Demonstrativpronomina am Beginn von Nominalsätzen; Ex 12,17 erreicht eine ähnliche Betonung durch zweimaliges $\pi r$ und zusätzliches "ִֶ̣ "genau, selbst". 
Schema 9: Einsetzungsberichte ${ }^{6}$

Gen9 Gen17 Ex3 Ex12,14 Ex12,17 Ex31 1 Kor11

a) Beziehung:

$\begin{array}{lrrrrrrr}\text { Gott redet } & \text { x } & \text { x } & \text { x } & \text { x } & \text { x } & \text { x } & \text { Jesus } \\ \text { "Bund" } & 9 & 9 & & & & 13 & 25 \\ \text { 1.P.Sg. } & 9 & 9 & \text { x } & & \text { x } & 13 & 24 \\ \text { 2.P.Pl. } & 9 & 10 & \text { x } & \text { x } & \text { x } & 13 & 24\end{array}$

b) Konkretisierung:

\begin{tabular}{lccccccr} 
Zeichen: & \multicolumn{3}{c}{ Beschnei- } & \multicolumn{3}{c}{ Mazzot/ } & Brot/ \\
& Bogen & -dung & Name & Tag & Tag & Sabbat & Becher \\
תi & 12 & 12 & & & & 13 & \\
"dies" & 12 & 10 & x & x & x & 13 & 24
\end{tabular}

c) Erinnerung, Bewahrung:

\begin{tabular}{|c|c|c|c|c|c|c|}
\hline ז כר & 15 & & $\mathbf{x}$ & $\mathbf{x}$ & & \\
\hline שמר & & 9 & & & $\mathbf{x}$ & 13 \\
\hline Befehl & & 9 & & $\mathbf{x}$ & $\mathbf{x}$ & 13 \\
\hline דר & 12 & 9 & $x$ & $x$ & $x$ & 3 \\
\hline ערלם & 12 & 13 & $x$ & $x$ & $x$ & 16 \\
\hline
\end{tabular}

d) Zeitdauer:

Trotz seiner Kürze von nur einem Vers enthält Ex 3,15 viele wesentliche und auch sonst $z u$ beobachtende Elemente der literarischen Konvention "Einsetzungsbericht". Die Worte für ${ }_{8}^{\text {Bund und }}$ zeichen $^{7}$ fehlen zwar, und desgleichen eine Befehlsform ${ }^{8}$. Gerade

6 Sind die Texte länger als ein Vers, gibt die zahl im Schema jeweils an, in welchem Vers der betreffende Ausdruck zum ersten Mal vorkommt.

Für 1 Kor 11 lauten die dem Hebräischen entsprechenden grie-

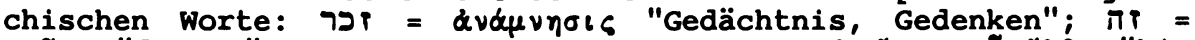

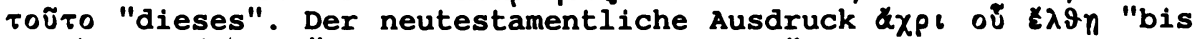
er (wieder)kommt", der sich auf das endgültige Kommen Jesu am Ende der zeiten bezieht, kann in einem weiten Sinn als Entsprechung zu עולם angesehen werden. Dazu fügt die katholische Liturgie in den Wandlungsworten über den Kelch dieses Wort "ewig" ein.

7 Doch findet sich nix "zeichen" in 3,12 für den zukünftigen Gottesdienst am Berg, und weiters mehrere Male in Ex 4 . Die rechte Verehrung Gottes am Sinai, auf die 3,12 anspielt, wird durch die Einsetzung des Namens hier ermöglicht. 
das erste Manko verbindet Ex 3 mit den beiden stellen in Ex 12, in denen auch die worte ברית und fehlen. So lassen sich bei den genannten Texten zwei Gruppen unterscheiden: eine Gruppe, die explizit von der stiftung eines Bundes redet und die auch erzählerisch länger ausgestaltet ist (wenigstens vier Verse), und eine andere Gruppe, aus nur einem Vers bestehend, die, ohne das Wort Bund zu verwenden, die Beziehung zu Gott in konkreten zeichen intensivieren möchte. Diese Vertiefung der Gottesbeziehung scheint der entscheidende und einende Faktor für die beiden Gruppen zu sein. Die Festsetzung eines Bundeszeichens (Regenbogen, Beschneidung, Sabbat, Brot/Becher) oder die Einsetzung anderer faBbarer zeichen (Name, Tag, Mazzot) kommen beide überein in ihrer Zielrichtung, nämlich die Beziehung zu Gott zu konkretisieren, und ebenso in ihrer Bestimmung für ewige zeit.

Die Kundgabe des Gottesnamens in Ex 3,15 ist also der Weise ähnlich, wie Gott auch sonst ewige Anordnungen stiftet. Im Namen möchte Gott die Beziehung der Menschen zu ihm intensivieren. An unserer Stelle wird diese Interpretation im Sinn einer Vertiefung der Beziehung unterstützt durch den Kontext der Verse 3,12.18, die beide auf den zukünftigen Gottesdienst der Israeliten zielen. In die Mitte dieser beiden Verse kommt mit 3,15 die offenbarung des Jahwenamens zu stehen, der eine zentrale Funktion im Gottesdienst Israels hat. Zweimal wird im Demonstrativpronomen i

8 Zu Versbeginn steht die Aufforderung an Mose, es den Israeliten zu sagen, doch bezieht sich diese nicht auf die Bewahrung des Namens.

9 G.V.RAD, Theologie I 196, bezeichnet den Jahwenamen als "Herz des israelitischen Kultes", der die stelle des in anderen Religionen verwendeten Kultbildes einnimmt.

Diese zentrale Funktion wird eher unterstrichen denn in Frage gestellt durch den Gebrauch, den Namen "Jahwe" nicht mehr auszusprechen. Diese Entwicklung bahnte sich bereits in hellenistischer zeit (Aussprechen des Namens nur noch bei der täglichen Segnung) an und wurde vermutlich spätestens mit dem Untergang des Tempels beendet, mit dem auch das einmalige Aussprechen des Jahwenamens durch den Hohenpriester am Versöhnungstag sein Ende fand (siehe dazu auch Anm. 128 in c3 und G.H.PARKE-TAYLOR, Yahweh 8586).

Das Nicht-Aussprechen erweist dem so "benannten" Gott noch höhere Ehre; der auBergewöhnliche Brauch des uneigentlichen Bezeichnens (nicht mit dem Jahwenamen, sondern mit dem Titel אר י "mein Herr") bestätigt durch die in ihm ausgedrückte vorsicht und Ehrfurcht die entscheidende Rolle des Gottesnamens.

Das Nicht-Aussprechen (und Nicht-Schreiben) mus aber nicht nur positiv gesehen werden. Einmal stellt es sich gegen die hier in Ex 3,15 geschilderte göttliche Anordnung. zum zweiten wird 
"dies" auf diesen Namen hingewiesen, zweimal richtet sich in den zeitbestimmungen der Blick von der Gegenwart hinweg auf kommende Generationen in die Ewigkeit.

Das fehlende Element der Aufforderung (in Jussiv/Imperativ oder "Gesetz") hat Ex 3 mit Gen 9 gemeinsam. Beide Fälle verwenden זכר "Andenken, Gedächtnis" zur Bezeichnung des Bewahrens. Implizit ist in der Erwähnung von כר jedoch auch schon die Aufforderung zur Bewahrung enthalten.

Das Besondere unseres Textes ist aber die Art des zeichens, in dem sich die vertiefte Beziehung konkretisiert. Regenbogen, Beschneidung und Mazzot haben sichtbare, materielle Gestalt. Die Zeichen von Ex 12 und 31 bestehen in der Beobachtung festgesetzter Tage. Ex 3 dagegen gehört mit dem Namen keiner dieser beiden Gruppen an. Es steht dazwischen. Mit Gen 9 und 17 verbindet es die Möglichkeit, den Namen - wenigstens in der Niederschrift sichtbar werden zu lassen, mit den übrigen Exodus-Texten die Beziehung zum Kult. Diese Sonderstellung des Namens als konkretisierendes zeichen wird noch durch einen anderen Vergleich deutlich. Es gibt sonst in der Bibel keine Erzählung, in der jemand sich selbst den Namen gibt. Dieses Privileg, sich selbst zu benennen, behält die Bibel nur Gott vor. Es drückt aus, das er seinen Ursprung in sich hat und nicht von anderen abhängig ist. zugleich wird dieser Name jenes zeichen, das am engsten mit Gott selbst verbindet ${ }^{10}$.

Die Untersuchung der Einsetzungsberichte hat groBe Ähnlichkeiten in bezug auf die Elemente mit den im allgemeinen $P$ zuge-

durch das Nicht-Aussprechen der eigentliche Name an den betreffenden stellen durch eine andere Bezeichnung ersetzt - wobei zu fragen bleibt, ob der Ersatzname geeigneter ist. Das hat J.SEVERINO CROATTO, "Yo soy" 159, in aller Schärfe benannt. Nach ihm ist es schade, das die jüdische und die christliche Tradition den Reichtum des Jahwenamens (von ihm verstanden als gegenwärtiger und beistehender Gott) verwässert hat mit dem majestätischen "Herr". - Aus den beiden genannten Gründen ziehe ich Schreiben und Aussprechen des Namens gegenüber der heute herrschenden Tendenz vor.

10 Der Name bezeichnet Gott selbst, während alle anderen zeichen nur indirekte Beziehungen zu ihm haben. In diesem Punkt steht Ex 3,15 der Stiftung des eucharistischen Mahles in 1 Kor 11 am nächsten. "Mein Leib, mein Blut" besagen ähnlich enge Verbindung mit dem stiftenden wie "mein Name". 
schriebenen Texten Gen 9; 17 und Ex 31 ergeben. Der Hauptunterschied gegenüber diesen Texten liegt in der Länge; hier steht Ex 3,15 in wesentlich größerer Nähe $z u$ Ex 12,14.17. Doch trotz der knappsten Formulierung (in nur sieben Worten) bietet Ex 3,15 alle wesentlichen Elemente, daB wir darin den Bericht von der Einsetzung des Jahwenamens sehen können.

\subsubsection{Die Erzählung vom Anfang}

P.Gibert hat sich in seinem Buch "Bible, mythes et récits de commencement" mit den Erzählungen vom Anfang beschäftigt. Auch wenn er dabei am Ende feststellt, daB es keine festgeprägte Gattung "Erzählung vom Anfang" gibt , so weisen nach ihm die Berufungserzählungen doch gewisse gemeinsame Merkmale auf, die sie zu recht als Erzählungen von einem Anfang ansehen lassen. Gibert widmet ihnen c16 und behandelt darin auch Ex 3-4. Er zählt folgende für Berufungserzählungen charakteristischen Merkmale ${ }^{12}$ auf: (a) eine Szene mit zwei Helden, einer menschlich, der andere übernatürlich

(b) Der übernatürliche Held hat die Initiative.

(c) Abwesenheit einer dritten Person (und damit eines zeugen)

(d) ein Auftrag, der die Fähigkeiten/Möglichkeiten des menschlichen Helden übersteigt

Wenn wir diese Merkmale als literarische Konvention für Berufungserzählungen ansehen, stellen wir mit Gibert fest, daB diese Konvention in Ex 3-4 eingehalten wird. (a) Die beiden Helden sind Gott/Jahwe und Mose. Dabei fällt auf, daB im Unterschied zu manchen sonstigen Berufungserzählungen die Rolle Gottes besonders ausgestaltet ist. (b) Die Initiative liegt bei Gott, sowohl was die Erscheinung wie das Reden wie auch das Einschreiten angesichts der Not betrifft. (c) Zwar berichtet - notwendigerweise - ein Erzähler, aber er tritt nicht als selbständige Gestalt in der Welt der erzählten Personen (Gott, Mose) auf. Sonst ist niemand anwesend am brennenden Dornbusch. (d) DaB der

\footnotetext{
11 P.GIBERT, Bible 274.

12 P.GIBERT, Bible 215.

13 Tatsächlich (mit Ausnahme von Apg 9, wo es der Herr ist) sind es an den von P.GIBERT, Bible 222-223, in der Tabelle F aufgeführten Stellen immer nur Jahwe oder sein Engel.
} 
Auftrag menschliche Kräfte überschreitet, unterstreichen die Einwände des Mose deutlich: Aus eigenem Vermögen ist er dieser Sendung nicht gewachsen. Auch zeigen Stellen wie Ex 5,22-23 und 14,15 (wo ein Schreien Moses zu Gott vorausgesetzt wird), daB die Ausführung des göttlichen Auftrags Mose immer wieder über die Grenzen seiner Fähigkeiten hinausführt.

Die vier von P.Gibert vorgeschlagenen Merkmale sind nicht die einzigen bei Berufungserzählungen. Zur literarischen Konvention scheinen noch folgende Elemente zu gehören:

(e) Die Erzählung berichtet das erste zusammentreffen der beiden Helden ${ }_{14}$ steht meist auch innerhalb des literarischen werkes am Anfang $^{14}$. Das erste zusammentreffen bedeutet zugleich den Beginn einer besonderen Beziehung zwischen Gott und dem von ihm Berufenen.

(f) Der Grund zu Gottes Intervention liegt immer, wie auch in manch anderen Erzählungen, in irgendeiner Not (siehe auch oben beim Berufungsschema unter 2.1.2). Gott beruft jemanden, weil er Menschen in Not helfen ([Gen 12], Ex 3, Ri 6) oder sie wieder auf den richtigen Weg zurückbringen möchte. Im letzteren Fall ist die Not die Blindheit, die das eigene Fehlverhalten nicht mehr sehen läßt ( 1 Sam 3, Jes 6, Jer 1, Apg 9).

(g) Der Auftrag erfolgt nicht (so sehr) um des Berufenen willen, sondern trägt Bedeutung für andere.

Auch diese zusätzlichen Merkmale treffen auf Ex 3-4 zu:

(e) Es schildert die erste Begegnung zwischen Gott und Mose und steht am Anfang der bis ans Ende von Dtn reichenden Darstellung des Mose. (f) Die Notsituation und ( $g$ ) die Bedeutung für andere ist mehrfach in der Analyse angesprochen worden; Moses Sendung hat den zweck, die Not der Israeliten zu wenden.

Neben der Einhaltung der literarischen Konvention in Ex 3-4 verdienen deren Elemente (c) und (e) spezielle Beachtung. Obwohl niemand zeuge des Dialogs zwischen Gott und Mose war und obwohl auch nicht Mose selbst davon berichtet (im Unterschied z.B. zu

14 Da Gibert's Buch von den Anfängen handelt, wird dieses Element von ihm vorausgesetzt. Bezüglich des literarischen ortes scheint Jes 6 die einzige Berufungserzählung zu sein, die nicht am Anfang steht.

Bei Mose erscheint eine Besonderheit, insofern in Ex 2,11-15 eine frühere erfolglose Tätigkeit berichtet wird. 
Jes 6, Jer 1, Ez 1, die alle in der "Ich-Form" erzählen), erfahren die Hörer/Leser unserer Erzählung diese unzugängliche Begegnung zwischen Gott und Mose bis in die Einzelheiten . Dazu kommt die Stellung am Anfang: Von diesem Beginn in der Begegnung mit Gott soll Moses weiteres Tun verstanden werden.

\subsubsection{Sichtbares Wort}

T.E.Fretheim hat in seiner Untersuchung von Theophanien ${ }^{16}$ auf jene Beziehung aufmerksam gemacht, die zwischen der Botschaft und den mit ihr verbundenen empirischen Phänomenen besteht. Letztere nennt er "visible words", weil durch sie das wort (als der eigentliche Kern der Theophanie) auf der vom Hören verschiedenen Ebene des Sehens noch einmal dargestellt wird. Die den Augen zugängliche Erscheinung bringt so ein zweites Mal zum Ausdruck, was der Inhalt von Gottes Mitteilung bei seinem Erscheinem ist. Tatsächlich läßt sich bei vielen Theophanien diese Beziehung zwischen wort und empirischem Phänomen beobachten, sodaB man darin wohl zu recht auch eine literarische Konvention sehen kann.

Beispiele für solche Verbindungen von wahrnehmbarem Phänomen und Botschaft Gottes sind: rauchender ofen und brennende Fackel beim BundesschluB mit Abram (Gen 15,17); die Leiter von der Erde zum Himmel in Jakobs Traum auf der Flucht (Gen 28,12); das gezückte Schwert des Heerführers Jahwes (Jos 5,13); bei Gideon Feuer aus dem Felsen, das die Mahlzeit verzehrt (Ri 6,21); das Brandopfer auf dem Felsen, als der Engel den Eltern Samsons erscheint ( $R i 13,19)$; die noch nicht erloschene Lampe Gottes in Samuels Berufung (1 Sam 3,3); Thron im Tempel und Glühkohle vom Altar bei der Berufung Jesaias (Jes 6,1.6); vier lebende Wesen, Feuer, Räder, Lichtglanz in der Vision Ezechiels (Ez 1 ).

15 Die Allwissenheit des Erzählers (D.GUTZEN, Einführung 22-23) ist die notwendige Voraussetzung einer solchen Darstellung.

16 T.E.FRETHEIM, Suffering, vor allem $c 6$ "God in human form"; für die folgenden Ausführungen siehe besonders S.84-88. Fretheim macht die von Westermann eingeführte Unterscheidung zwischen Theo- und Epiphanie (vgl. Anm.57 zu Beginn von Exkurs 3) nicht mit, sondern verwendet für beide "theophany".

In dem, was hier für Theophanien aufgezeigt wird, drückt sich ein auch sonst in Erzählungen $z u$ beobachtender $\mathrm{zug}$ aus. Oft spiegelt sich das Geschehen in den erwähnten Objekten wider (z.B. Josefs Kleid in Gen 37). 
Es ist nicht immer leicht, die genaue Beziehung zwischen empirischem Phänomen und göttlicher Botschaft an diesen (und anderen) Stellen aufzuzeigen, und noch weniger, sie zu beweisen. Doch gibt es eine innere Entsprechung, die die geschauten Dinge zu zeichen für Gottes Mitteilung macht. So kann man in der Leiter zwischen Himmel und Erde den Ausdruck der zusage des Mitseins Gottes an Jakob (Gen 28,15) sehen, das ihn seinen ganzen Weg begleiten wird. Das verzehrende Feuer bei Gideon kann als zeichen für Gottes Anwesenheit und dafür genommen werden, daB er die Midianiter schlagen wird (Ri 6,16). Jesajas Vision Jahwes auf dem Thron ist die sichtbare Übersetzung des dreifachen "Heilig" (Jes 6,3 ) und gibt ein Hauptthema seiner Verkündigung wieder (Jes 1,4; $5,19.24 ; 10,17.20)^{17}$.

Vielleicht darf man nach diesem kurzen überblick Folgendes festhalten: Auch wenn die genaue Bestimmung der Beziehung manchmal Schwierigkeiten bereitet, so gibt es doch die Konvention, bei manchen Theophanien oder Berufungsberichten das Wort durch ein ihm entsprechendes empirisches Phänomen sichtbar zu machen und so zu verstärken". Diese literarische Konvention können wir "sichtbares Wort" nennen.

Wenn wir in der Berufung des Mose nach solch einem sichtbaren wort suchen, bietet sich der brennende und nicht verbrennende Dornbusch an. In diesem Phänomen ist schon viel gesehen worden ${ }^{19}$.

17 Da die göttliche Botschaft meist eng mit dem zukünftigen Leben der betreffenden Person verbunden ist, wird in den geschauten Dingen auch ein charakteristischer zug des weiteren Lebens der Berufenen sichtbar.

18 T.E.FRETHEIM, Suffering 86 , spricht davon, daB solche "visible words" die ganze Person ansprechen und so die Intensität der Beziehung vergrößern. Zuvor (S.84) spricht er sogar von "sacramentalism".

19 M.GREENBERG, Understanding 71, weist auf die Verbindungen von Feuer/brennen zu Zorn (Est 1,12), Liebe (Hld 8,6), Reinheit (Num 31,23) und Leuchtkraft (Ex 13,21) hin. E.FOX, Names 23, erwähnt zwei weitere Aspekte an unserer Stelle: die Unauslöschlichkeit des Feuers und daß der Busch unvergänglich ist.

In der übertragenen Auslegung sind Busch und Feuer unserer Erzählung auf vielerlei Weise interpretiert worden: In der Kleinheit des Busches sah der Midrasch Gottes Hinwendung zum leidenden Israel in Ägypten (Midrasch Rabbah, Shemot II, 5). Gregor von Nyssa erblickte im brennenden Busch sowohl ein Bild für die Inkarnation (Mosè II 20) als auch für die jungfräuliche Mutterschaft Marias (Mosè II 21). 
Ohne die Bedeutung der Einzelelemente Busch und Feuer leugnen zu wollen, scheint uns die besondere Aussage unserer stelle in der Überwindung der Gegensätze "brennen - nicht verbrennen" zu liegen. Auf sie lenkt auch das Wortspiel בער $(3,2)$ - לא $(3,3)$ die Aufmerksamkeit. Das Besondere an Ex 3 ist die Aufhebung des negativen Aspektes des Feuers (seine vernichtende, zerstörende Kraft) bei gleichzeitiger Beibehaltung seiner gewaltigen, verwandelnden Macht. Ein Feuer aber, das trotz seiner verzehrenden Macht den von ihm ergriffenen Gegenstand unbeschadet läBt, ist menschlich gesehen etwas Unmögliches. In diesem menschlich Unmöglichen, in der Überwindung der Gegensätze "brennen und nicht verbrennen" zeigt sich der Gott, der hoch über allem Menschlichen steht $^{20}$.

Was hat das überwinden der Gegensätze mit dem Inhalt von Gottes Mitteilung in Ex 3-4 zu tun? Wir haben in der Analyse gesehen, daß verschiedene Ausformungen von Gegensätzen mit diesem Gott Jahwe in Verbindung zu bringen sind. Er, der in der vergangenheit Gott der väter war, ist zugleich Jahwe, der in zukunft mit den Israeliten sein wird. Jahwe ist auch der, der die Fähigkeit zum Sprechen gibt oder stumm macht, der, der sehend oder blind macht $(4,11)$. Auch bei den Menschen möchte Jahwe Gegensätze überwinden. Er hat den Wunsch, daß das ganze Volk (Mose, die Ältesten und die Israeliten) eins sei $(3,12.18)$, und er wird bewirken, daB die lange zeit feindselige Beziehung zwischen Ägypten und Israel, wenigstens für kurze zeit, in ein neutrales Verhältnis übergeht $(3,21-22)$.

20 Wie E.J.YounG, Call 133, bemerkt, gibt es zum brennenden Dornbusch keine Parallele. Doch ist eine Aussage aus Deuterojesaja beachtenswert, die etwas Ähnliches beschreibt: "Wenn du durchs Feuer gehst, wird du nicht versengt, und die Flamme verbrennt dich nicht" (Jes 43,2; für das letzte Verb wird auch רער verwendet).

Gegensätze zu überwinden ist in zeiten des Umbruchs besonders wichtig. In diesem Zusammenhang ist z.B. auch Nikolaus von Kues zu sehen, der öfters das zusammenfallen der Gegensätze im Unendlichen (coincidentia oppositorum) betont. G.DURAND, structures (Tabelle am Ende des Buches), hebt den harmonisierenden Charakter eines solchen Denkens und ihm entsprechender symbole hervor.

21 Ex 11,3 und 12,35-36 führen die Linie von 3,21-22 fort. Die letzte stelle ist jedoch im Kontext der Angst vor dem eigenen sterben (v33) zu lesen. Sie leitet so über zur nächsten im Erzählablauf geschilderten Handlung des Pharao und der Ägypter, nämlich ihrer Verfolgung der Israeliten in Ex 14 (besonders v5-9 und 23). 
Neben dieser Beziehung zwischen brennendem Busch und den Aussagen über Gott gibt es in unserem Text noch eine Reihe anderer Ausdrücke bzw. Phänomene, die mit Gegensätzen in Verbindung zu bringen sind. Die Ortsangaben wüste - Berg $(3,1)$ stehen für zwei einander gegenüberstehende Wirklichkeitsbereiche. Die Wüste ist traditionellerweise der ort lebensbedrohender Mächte ${ }^{22}$. Dem Bereich, in dem der Mensch von sich aus nicht leben kann, steht der Berg als ort der Gottesbegegnung, der sicherheit und des Heiles gegenüber ${ }^{23}$. Die doppelte ortsbestimmung in 3,1 , wüste/ Steppe und Gottesberg, die in der Erzählung nochmals aufgenommen wird $(3,12.18)$, könnte also schon zu Anfang Hinweis sein auf diesen Gott, der über den Gegensätzen steht.

Im fünften Bild werden Gegensätze besonders deutlich in den zeichen, die Jahwe Mose befiehlt. Sie beginnen mit dem Stab, der zur Schlange wird $(4,3-4)$. Der Stab ist fest, unbelebt und wird normalerweise aufrecht in der Hand getragen. Die Schlange ist beweglich, lebendig ${ }_{2}$ und kriecht am Boden. In der verwandlung des einen in das andere ${ }^{24}$ drückt sich eine Macht aus, die Gegensätzliches geradezu spielerisch im Griff hat. Das zweite zeichen besteht im Aussätzigwerden der zuvor gesunden Hand (4,6-7). Hier stehen einander Gesundheit und Krankheit gegenüber; Jahwe hat Macht über beide. Im letzten, nicht ausgeführten zeichen kommen die Gegensätze Wasser und Trockenes $(4,9)$ zusammen. DaB es dabei

22 M.LURKER, Wörterbuch 364; O.KEEL, Welt 66-67.

23 J.CHEVALIER, Dictionnaire 645-649; 0.KEEL, Welt 100-105; 158-162 (er weist auch auf den oft mit Berg synonymen Ausdruck "Fels" hin); F.RITZHAUPT, Weqzeichen 27-28.

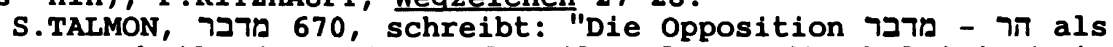
orte von Unheil einerseits und Heil andererseits kulminiert in der Konzeption des Zionsberges $(\mathrm{Ez} 34,26 ; 20,40)$ als Gegenpol der 'völkerwüste' ..." - Für die besondere, aber nicht ausschliebliche Verbindung des Gottes Israels mit den Bergen siehe u.a. Texte wie 1 Kön $20,23.28$ und Ps $121,1-2$.

Gottes Erscheinen am Berg oder auf dem zion zum Gericht (Ps 50,2-6; 76,3.8-10; zur Thematik siehe auch A.GAMPER, Gott als Richter 173) kann auch furchtbar sein. Wie die Sinaitheophanie zeigt, verlangt die Anwesenheit Gottes am Berg die Distanz des Volkes und führt $2 u$ Furcht $(E x 19,12 ; 20,18)$; doch ist in diesem Verhalten die angemessene Reaktion auf das Erscheinen Gottes zu sehen.

24 Der Gegensatz zwischen stab und Schlange wird weniger stark, wenn berücksichtigt wird, daß solch eine Verwandlung von Unbelebtem in Belebtes (und umgekehrt) sich in vielen Erzählungen findet. Vgl. dazu auch D.IRVIN, stories 194-196, und G.DURAND, Structures 368-369 (und 73). 
keine Rückverwandlung gibt, besagt Endgültigkeit ebenso wie die Tatsache, daB im Unterschied zu den ersten beiden zeichen die Gegensätze nicht zeitlich nacheinander kommen, sondern zusammenfallen: Kommen beim Menschen Gegensätze zusammen, so ist Leben in Gefahr. Bei Gott dagegen zeigt sich in den Gegensätzen und dem Umgehen mit ihnen gerade seine Macht. Er steht über ihnen, er kann über sie gebieten.

Die hier angeführten Beispiele ${ }^{25}$ weisen das überwinden von Gegensätzen in unserem Text als charakteristischen zug Gottes aus. In einer zeit des Umbruches klaffen Verschiedenheiten auf, Spaltungen oder Brüche werden spürbar, nicht nur in unterschiedlichen Benennungen. Das Bild eines Gottes, der über den Gegensätzen steht, kann in einer solchen zeit einende kraft auf die Gemeinschaft der ihn Anbetenden ausüben. Für diesen Gott ist der brennende und doch nicht verbrennende Dornbusch ein treffliches und eindringliches zeichen. Die literarische Konvention des sichtbaren Wortes verdeutlicht so im Phänomen des brennenden Busches einen zentralen zug im Gottesbild unseres Textes.

\subsection{DER KONTEXT VON GOTTESBILD UND BERUFUNG}

Die Darstellung der beiden Hauptfiguren unserer Erzählung nimmt breiten Raum ein und ist dadurch betont, daB sie selber fast durchgehend zu wort kommen. In zwei Punkten wollen wir Ex 3,1-4,17 mit anderen Texten konfrontieren:

1) in den Beziehungen zum Gottesbild der Genesis;

2) im Vergleich mit anderen Berufungsberichten.

\subsubsection{Jahwes Beziehung zum Vätergott}

D.Clines hat das Thema des Pentateuch als die Teilerfüllung des den Patriarchen gegebenen Segens/Versprechens bestimmt ${ }^{26}$. Dieses Versprechen faltet sich in drei konstituierenden Elementen aus: Nachkommen, Beziehung zu Gott, Land.

25 Weitere Beispiele wären: Das Erscheinen von Jahwes Boten ist zugleich das Auftreten Jahwes selbst. In 3,5 steht Mose bereits auf heiligem Boden und muB dennoch Distanz wahren.

26 D.CLINES, Theme 29 . 
Das erste Element geht mit Ex 1,1-7 in Erfüllung. Die Israeliten sind ein Volk (Ex 1,9) geworden. Das dritte Element findet seine Verwirklichung mit Einzug und Besitznahme im Land, die im Buch Josua berichtet wird. Unser Text erfüllt dabei eine wichtige Funktion. Es ist das erste Mal, daB Gott durch Mose hindurch sich mit dem Landversprechen nicht mehr an einzelne, sondern an eine Gruppe wendet $(\mathrm{Ex} 3,17)$. Von Gen 12,1 bis 46,4 richtete sich Gottes Sprechen immer an einen der Patriarchen, und das Versprechen betraf deren Nachkommen. In Ex 3 dagegen ist die Botschaft für jene bestimmt, die das Land in Besitz nehmen sollen.

Das zweite Element von Gottes Versprechen ist in bezug auf seine Erfüllung nicht so leicht zu fassen. Die Beziehung zu Gott besteht bereits, wenn nur der Erzähler sie aussagt (z.B. Gen $39,21)$, und sie ist auch noch da, wenn Gott über Menschen in zorn gerät $(z . B$. Ex 32,10$)$. Es ist deswegen notwendig, dieses Element genauer zu bestimmen. Wir wollen uns dabei besonders den Bezeichnungen für Gott und seinem Reden zuwenden und dies mit der Art vergleichen, in der in der Genesis von Gott geredet wird.

Wenn Gott mit den Patriarchen spricht, kann er sich auf verschiedene Weise vorstellen: als Jahwe (Gen 15,7; 28,13), als El Schaddai $(17,1)$, als Gott Abrahams $(26,24)$, als El und Gott deines Vaters $(46,3)$. Die unterschiedlichen Benennungen lassen fragen, wer Gott wirklich ist. Unsere Erzählung Ex 3,1-4,17 greift dieses Problem auf. Wir finden zwar verschiedene Benennungen, doch kommen hier alle in einer stelle und im Mund Gottes selber vor ${ }^{27}$. Damit erklärt Gott selbst diese Benennungen als für

27 Gott wird in unserer Erzählung insgesamt 43x mit Titel oder Namen angeredet/benannt. Die Vorkommen innerhalb einer stelle würden sich, wenn man mehrere Quellen annimmt, in verschiedene Schichten aufgliedern.

Bei den Ausdrücken, die Gott selbst verwendet, finden sich wiederholte Formeln wie "der Gott deines/eurer/ihrer väter" $(3,6.13 .15 .16 ; 4,5)$, und "Gott Abrahams, Gott Isaaks und Gott Jakobs" $(3,6.15 ; 4,5$; ohne dreimaliges "Gott" nochmals in 3,16$)$. $\mathrm{Ab} 3,15$ werden diese Formeln auBerdem immer mit Jahwe kombiniert. Bei all den vielen Kombinationen ist keine der anderen völlig gleich.

Dazu kommen noch die beiden in 3,18 verwendeten Gottesbezeichnungen "Gott der Hebräer" und "Jahwe unser Gott". Die letzte haben wir bereits eingehender bei der Analyse von 3,18 besprochen. Sie stammt aus der von Gott insinuierten sicht der Israeliten. Die erste dagegen entspricht der Sicht von AuBenstehenden und kommt in den Auseinandersetzungen der Plagen öfter vor (Ex $7,16 ; 9,1,13 ; 10,3)$. Besonders aufschluBreich ist Ex 5: In $v 1$ 
ihn zutreffend und ihn als einen bezeichnend. Von dieser mit Gottes Autorität ausgesprochenen Identität Jahwes mit dem vätergott hängt die Einheit der Bibel $a b^{28}$.

Es treten aber noch zwei Momente hinzu: Das eine ist der Wunsch nach zusammenfassung. Die Verbindung Gottes mit allen drei Patriarchen ungreift die bisherige Geschichte und schliebt sie $\mathrm{ab}^{29}$. Das zweite Moment ist die Festsetzung, die Gott an dieser Stelle vornimmt. In der Weise einer Einsetzung legt er seinen Namen auf "Jahwe" fest. In unserer Erzählung wird das deutlich durch den Unterschied in bezug auf die Benennung Gottes vor 3,15 und nachher. Bis 3,15 verwendet nur der Erzähler Jahwe als Gottesbezeichnung " während die beiden Gesprächspartner von "Gott", aber nie von Jahwe reden. Mit 3,15 ändert sich dies; sowohl Erzähler wie Gott wie Mose gebrauchen nur noch Jahwe, wenn sie Gott meinen, und verbinden diesen Namen mit weiteren Appositionen. "Gott" allein wird nicht mehr zur Bezeichnung Jahwes verwendet.

Unsere Erzählung behauptet die Identität Jahwes mit dem Gott der väter. Um die Identität dieser zwei zuerst einmal namentlich unterschiedenen Größen aussagen zu können, müssen in unserer Erzählung sie beide benennende Ausdrücke vorkommen. Die gleich-

reden Mose und Aaron von Jahwe, dem Gott Israels (eine Terminologie, die in Ex 3,1-4,17 nicht vorkommt). Auf die Frage des Pharao nach der Identität Jahwes (v2) antworten sie in v3 mit jener Bezeichnung, die ihrer Vorstellung nach die sicht (und die Sprechweise) des Pharao ist: "der Gott der Hebräer". Daraufhin "versteht" der Pharao und beginnt mit seinen vorwürfen und Anweisungen zur Unterdrückung.

28 F.ROSENZWEIG, Ewige 44, schreibt: "... von diesem Zusammenhang (er meint die Bindung des Namens an den namenoffenbarenden Moment) hängt die Einheit der Bibel ab".

Tatsächlich ist die von Jahwe selbst ausgesprochene Identität seiner selbst mit dem in den anderen Benennungen angerufenen Gott die beste (weil am höchsten autorisierte) Möglichkeit, die verschiedene Bezeichnungen verwendenden Erzählungen der Bibel unter dem Bild des einen Gottes zu vereinen.

w.H.SCHMIDT, Exodus 150, betont über die von den meisten Auslegern gesehene Identität hinaus auch noch den Aspekt der Wesensgleichheit. Siehe dazu weiter unten Anm.31.

29 Vergleiche Anm. 44 und 45 bei der Analyse von 3,6.

30 Neben "Gott" und "der Gott". Wir haben das oben (in 3.1) als zusatzinformation an den Hörer/Leser interpretiert, der so zeitweise mehr weiB als Mose. 


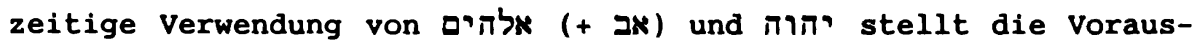
setzung dafür dar. Diese Doppelbenennung muB also nicht nur zufälliges Produkt unachtsamer Redaktionsarbeit sein, sondern ist die notwendige Bedingung für das Reden von der Einheit des alttestamentlichen Gottes. Ebenso ist gefordert, daB die verschieden benannten Größen - vereinfacht gesagt, stehen sie für jeweils unterschiedliche Erfahrungen - auch wiederum als nicht zu divergierend ${ }^{31}$ empfunden wurden.

Wenn unser Text die Identität Jahwes mit dem Gott der Väter behauptet, darf man fragen, ob das einfach eine "Taufe Gottes" (im Sinn einer Namensgebung) oder aber auch eine inhaltliche Aussage über sein Wesen sein soll. Ändert sich mit dem "neuen" Namen etwas an der Art, wie Gott ist oder handelt? Unsere Erzählung führt neu ein, daB dieser Gott in seiner Botschaft eine Gruppe von Menschen anredet $(3,16-17)$, sich als deren Gott ausgibt und als ihr Gott bekannt werden möchte ("Jahwe unser Gott" in 3,18 ). Doch ist diese Anrede im Plural die Konsequenz dessen, daB die Israeliten ein Volk geworden sind. Überdies sind sie die Nachkommen der Patriarchen, d.h. im Handeln Gottes gibt es Kontinuität.

Auch was den Inhalt von Gottes Botschaft betrifft, scheinen die darin angesprochenen Handlungen Gottes auf der Linie seines

31 Die von W.H.Schmidt erwähnte "Wesensgleichheit" und die Ausführungen von H.SEEBASS, Erzvater 76-85, gehen in diese Richtung.

Die Identität von vätergott und Jahwe verlangt auch nach einer ihr entsprechenden gesellschaftlichen wirklichkeit. Deren überaus komplexe Geschichte zu erheben, ist heute nur noch schwer möglich. Siehe dazu unter vielen anderen H.SEEBASS, Erzvater 49107; E.ZENGER, Das jahwistische Werk - ein Wegbereiter des jahwistischen Monotheismus?; die Ausführungen von H.P.MÜLLER, Gott (vor allem 114-115; 125-126 und 132-136), und F.STOL2, Monotheismus (besonders 155-174), in 0.KEEL (Hrsg.), Monotheismus; weiters H.DONNER, Geschichte I 79-84. Manches deutet auf zwei Gruppen hin, deren eine ursprünglich einen vätergott und deren andere Jahwe verehrt hat und die, als unser Text geschrieben wurde, bereits eine Einheit waren. Ex 3-4 ist zeugnis einer eine Einheit gewordenen Menschengruppe, die ihren Gott in dem Reichtum von aus zwei Traditionen stammenden Erfahrungen anbetet.

32 Die Frage, ob es bei Gott Veränderung gibt, wurde in letzter zeit Gegenstand der Diskussion durch die Vertreter der "ProzeBtheologie". Im deutschen Sprachraum ist diese Frage vor allem von E.JÜNGEL in seinem Buch Gott als Geheimnis der Welt aufgegriffen worden. Er überschreibt darin c13 "Gottes Einheit mit der Vergänglichkeit als Grund der Denkbarkeit Gottes". 
bisherigen Wirkens zu liegen: Gott hört (aw Gen 16,11; 21,17; $30,6.22$ ) und sieht (ראה 18,21;29,31-32) Not $(9,16,11 ; 29,32$; andere Worte in 35,$3 ; 41,51)$. Er ist mit den Patriarchen (היה[ ] व 26,$3 ; 28,15 ; 31,3.5 ; 35,3 ; 39,21$ [næ]; 46,4 [mit hinuntersteigen]; 48,21), er führt heraus (אצי 15,5.7.14; 31,13 ; mit שר "zurückbringen": 28,15 ; $31,3.13$; 48,21), hinauf (צל 35,$1 ; 46,4$ $[2 x] ; 50,24)$, er steigt herunter $(18,21 ; 46,4)$ und sucht heim (פקר 50,24[2x]). Gott redet mit doppeltem Namen an $(22,11$; $46,2)$, weiB selbst Verborgenes $(18,13-15)$, gibt Gnade in den Augen anderer $(39,21)$, ist machtvoll am Werk (הiש 41,$25 ; 42,28$ ) und mit Wunderbarem (Wurzel 18,14 ) zu verbinden. Sogar die Sendung durch Gott ( $\pi$ (W in 45,7-8) findet sich bereits ${ }^{33}$.

Doch gerade an diesem letzten wort "senden" wird bei aller Kontinuität auch der Hauptunterschied deutlich, der die Erzählungen der Genesis und ihre Darstellung Gottes von der in Ex 3,14,17 trennt. Josef hatte in Gen 45 im nachhinein sein Verkauftwerden nach Ägypten als Sendung durch Gott interpretiert. Hier aber steht die Sendung von Gott selbst ausgesprochen als Forderung am Beginn. Zudem wird sie unterstützt durch die zeichen des fünften und das Sprechen des sechsten Bildes. Ein Mensch wird so Gesandter Gottes.

Mit dieser Sendung beginnt eine neue Epoche: Gottes Interesse gilt nicht mehr so sehr einzelnen und ihrer vermehrung , sondern einem Volk und seiner Führung. Dafür erfüllt Gott auch ein Verlangen, das er in Gen 32,30 noch abgeschlagen hatte: Die Gewährung seines Namens ist zeichen einer neuen zeit. Ein Name ist weniger wichtig für einen einzelnen, der jemanden ihm Vertrauten anreden möchte, als vielmehr für eine Gemeinschaft, der er in der gemeinsamen Anrede zeichen der Einheit wird.

33 Die hier aufgezeigten Verbindungen zwischen den Aussagen über Gott in Ex 3-4 und in Gen wollen nicht besagen, daB Gottes Handeln völlig gleich bleibt. Auch wenn teils dieselben wörter verwendet werden, so gibt es doch eine Entwicklung, die Gottes Tun ab Ex 3 als einen Neubeginn ansehen läßt. Für die wichtigsten Veränderungen siehe die folgenden zwei Absätze.

34 Bezeichnenderweise endet die Liste der Versprechen der Nachkommenschaft bei D.CLINES, Theme 32-33, mit Gen 46,3.

Vgl. dazu auch die Häufigkeit der Wurzel ברק "Segen" bei den Patriarchen: Gen 12,2-3; 22,17-18; 26,3-4; 28,14; 32,30; 48,3; 49,25-26 und öfter, insgesamt $88 x$ in Gen, gegenüber nur $7 x$ in Ex). 


\subsubsection{Ex 3-4 im Vergleich mit anderen Berufungen}

Schon öfters sind wir im Verlauf unserer Untersuchung auf andere Berufungsberichte $z u$ sprechen gekommen. Unter 2.1 .2 stellten wir fest, daB unsere Erzählung die Form (in fünf Elementen) mit anderen Texten gemeinsam hat. Das erste Element - die vorausliegende Not - impliziert, daB Berufung eine Antwort auf sie ist. Die Entsendung des Mose ist Gottes Antwort auf das Schreien und die Unterdrückung der Israeliten. Im Element "Einwand" wurde deutlich, daß Berufung einen Widerstand im Berufenen überwinden muB. In diesem widerstand drückt sich sowohl Gottes überwältigende Macht als auch (indirekt) die Legitimation des Gesandten aus.

Was den Inhalt von Moses Sendung angeht, scheint er dem in 2.1.3 besprochenen Typ von Berichten näher zu stehen als den prophetischen Berufungen. Die Übereinstimmung mit dem Bericht von der Entsendung des Retters ist sehr groB. Tatsächlich ist die Hauptaufgabe des Mose die Herausführung aus Ägypten ${ }^{36}$. In Bild 6 tritt das Sprechen stärker hervor . Mose wird also mit einer Doppelaufgabe betraut: Er ist sowohl der Leiter des Volkes (im Sinn der Herausführung und Befreiung) als auch der Prophet (darin, daB er Gottes Wort ausrichtet). Mose scheint der einzige zu sein, der explizit diese Doppelaufgabe erhalten hat ${ }^{38}$.

Mit den anderen Berufungen gehört unser Text zu den Erzählungen vom Anfang (siehe 4.1.2). Im Anfang liegt der geheimnisvolle, von Gott her kommende Ursprung. Der Hörer/Leser erhält das Privileg, diese Herkunft und damit die innerste Ausrichtung

35 Für Jeremia und Ezechiel hat D.VIEWEGER, BERUFUNGSBERICHTE (vor allem 90-109), diesen Vergleich bereits geleistet.

36 Vor allem Bild 2 und 4; mit ihnen sind die Bilder 3 und 5 als Bestätigungen eng verbunden.

37 Doch auch 3,14-18 zeichnen Mose als Vermittler von Jahwes Wort.

38 Vgl. die Berufungen der großen Propheten: Ihr Auftrag betrifft die Mitteilung des Gotteswortes und nicht die Führung des Volkes. - In den anderen (nicht-prophetischen) Berufungen fehlt der Auftrag zu sprechen; dafür findet sich die Leitung des Volkes (z.B. Ri 6,14 "rette!"). 
alles Folgenden zu erfahren ${ }^{39}$. Wir erfahren in den Berufungen etwas, was sich allein zwischen Gott und dem Berufenen (also ohne dritten Anwesenden) abgespielt hat, und werden so zu Mitwissern solch vertrauter Begegnung. DaB diese am Anfang steht ${ }^{40}$, besagt eine Bindung der Sendung an diesen Moment der Beauftragung. Alles weitere Tun ist von dieser entscheidenden Begegnung mit Gott her zu verstehen. Bei Mose wird dies umso deutlicher, als er auBer Jesaja (siehe Anm. 14) der einzige ist, von dem eine längere Tätigkeit vor der Berufung, ohne unter Gottes Auftrag zu stehen (Ex 2,11-22), ausdrücklich geschildert wird.

In 4.1.3 waren wir auf die Beziehung der Botschaft mit einem sichtbaren Phänomen aufmerksam geworden ${ }^{41}$. Unser Text enthüllte dabei im Phänomen des brennenden und nicht verbrennenden Dornbusches das Bild eines über den Gegensätzen stehenden Gottes. Gerade in bezug auf die Präsentation Gottes bestehen große unterschiede zu den anderen Berufungen. In keiner der anderen Berufun-

39 Für den Hörer/Leser verstärkt sich so das Element der Legitimation (siehe 2.1.2). - F.D.HUBMANN, Bote 331, sieht in den Berufungen theologisch durchreflektierte zusammenfassungen. Auf diesen Charakter der Zusammenfasssung sind wir schon mehrfach gestoßen: in Exkurs 3, als uns die Fülle der im ersten Bild verwendeten Elemente nur so erklärbar schien; in der Benennung Jahwes als Gott Abrahams, Isaaks und Jakobs; in den fünf Einwänden, die das menschliche widerstreben vor Gottes Auftrag in sonst nicht erreichter vollständigkeit beschreibt; und in der unter 4.1.3 aufgezeigten Beziehung zwischen dem "sichtbaren Wort" und dem Leben des Berufenen. Unsere Erzählung scheint mehr als andere Berufungen als zusammenfassung ausgestaltet worden zu sein.

40 Wenn man die Tatsache der literarischen Komposition ernst nimmt, könnte man auch sagen "an den Anfang gestellt wurde".

41 Es scheint uns, daB unter dieser Rücksicht die von $\mathrm{zim}$ merli und Gouders vorgenommene Unterscheidung von visions- und wortbestimmtem Typ der Berufung nicht sehr glücklich ist (so auch B.0.LONG, Berufung 678). Tendenziell gibt sie zwar Richtiges wieder, doch sind bei Jes 6, Jer 1 (v11-19), Ez 1-3 und auch in Ex 3-4 Gesehenes und Gehörtes untrennbar verbunden.

F.D. HUBMANN, Bote 332-339, arbeitet für Jes 6 die Beziehung zwischen dem geschauten "Heiligen Gott" und der Botschaft Jesajas heraus. Das Sehen Jahwes in seiner Heiligkeit findet seine (entsprechende) Fortsetzung in dem an ihn ergehenden Auftrag, in Israel für diesen nicht mehr verstandenen heiligen Gott zu sprechen und so Ablehnung hervorzurufen. Ähnliche Beziehungen lassen sich auch für Jer 1 und Ez 1-3 aufzeigen. 
gen spricht Gott so lange und so viel über sich selbst ${ }^{4}$. Wir wollen uns dieser Besonderheit im nächsten Abschnitt (unter 4.3.2) zuwenden. Zuvor aber soll noch auf die Beziehung unserer Erzählung zu Ex 6,2-8 eingegangen werden.

Ex 6, 2-8 ist ein Text eigener Art ${ }^{43}$. Im Lauf unserer Erzählung haben wir mehrmals Formulierungen gefunden, die im großen Kontext teils nur noch in Ex 6 zu finden sind. Dazu zählen: "und Gott (אלהים) redete zu Mose und sagte" (Ex 3,14.15; 6,2); der Wechsel Gott/Jahwe zwischen Erzähler und sprechender Person; das Reden von "meinem Namen" $(3,15 ; 6,3)$ und dabei die Insistenz auf Jahwe (4x "Ich bin Jahwe" in 6,2-8; vgl. 4,11); die Erwähnung aller drei Patriarchen $(3,6 \ldots ; 6,2.8)$; der offen bleibende Ausdruck ביד חזקה "mit starker Hand" $(3,19 ; 2 x$ in 6,1); weiters die Verwendung von ראה $\mathrm{Ni}$ "erscheinen", Israeliten, "Hören" (des Schreiens), herausführen (אצי Hi), retten (נצ' Hi), usw...

J.Magonet zieht daraus den SchluB, daß die beiden Texte Ex 3-4 und Ex 6 in bewuBter Entsprechung zueinander komponiert worden seien ${ }^{44}$. Zwar kann die Absicht von Autor/Redaktion nicht mehr festgestellt werden, doch sind die Entsprechungen gewichtig. Vielleicht besteht eine ähnliche Beziehung wie zu Ex 4,18-23, das wir im AnschluB an B.Jacob als "Nachtrag" interpretiert haben. Ex 6,2-8 trägt einen in der Berufung des Mose ausgelassenen wichtigen Gottesnamen nach ("El Schaddai" 6,3) und vervollständigt so die dort verwendeten Gottesbezeichnungen. Dazu führt es die Linie von Ex 3,7; 4,23 weiter, indem es die persönliche, einer Aufnahme in die Familie gleichende Annahme durch Gott "und ich will euch

42 Wenn wir in den bekannten Berufungserzählungen nach Aussagen Gottes über sein Wesen, über sich selbst (und nicht das, was er tun wird) suchen, so finden sich nur ganz wenige stellen: In $\mathrm{Ri} 13$ geht v18 auf die Frage nach dem Namen ein; die Antwort besteht darin, daB er "wunderbar" (פל איאוא sei. In Jes 6 sagen die Gott nahestehenden Wesen, die Serafim (nicht aber Gott selbst), die Heiligkeit Jahwes aus. Aus der Berufung Jeremias kommen evtl. die Aussagen der Erwählung vor der Geburt und die Wachsamkeit über sein Wort (Jer 1,5.12) hinzu.

43 J.L.SKA, Place 541-543 und 548. - Die Verbindung mit unserer Erzählung wird auch behandelt von N.LOHFINK, Abwertung; J.MAGONET, Bush 311, u.a.

44 J.MAGONET, Bush 311. 
mir zum Volk nehmen" 45 durch Wechselseitigkeit "und ich werde euch Gott sein" (6,7; vgl. in 3,18 "Jahwe unser Gott") zur Bundesformel ergänzt. Trotz der Differenzen des Vokabulars (z.B. für die Not oder die Befreiung) besteht durch die aufgezeigten Ausdrücke und die in ihnen enthaltene gemeinsame Theologie eine enge Beziehung zwischen Ex 6,2-8 und unserem Text. Auf der Ebene der Erzählung und durch die Verwendung des Wortes "Bund" bedeutet Ex 6 jedoch einen Schritt weiter in der offenbarung des Gottesnamens (v2-3).

\subsection{JAHWE UND MOSE}

\subsubsection{Die Präsentation Gottes durch den Erzähler}

In der Darbietung durch den Erzähler ist die wechselnde Bezeichnung für Gott in Ex 3 auffallend: "Jahwe" $(3,4.7)$, "Gott" (3,4.14.15), "der Gott" (3,1.6.11.13).

was ist der inhaltliche Unterschied zwischen diesen Benennungen? Den besten Vergleich ermöglichen die Redeeinleitungen. Für die Einführung des Redens Gottes wird Gott ohne Artikel gebraucht: "und Gott (םיה) sprach zu Mose $(3,14.15 ; 3,4)$. Wenn Mose dagegen $z u$ Gott spricht, formuliert der Erzähler "und Mose sprach zu dem Gott" (האלהים in 3,11.13). Wenn der Mensch Gott anspricht, wird der Artikel verwendet (Blickrichtung vom Menschen $z u$ Gott). Geht Gott auf den Menschen $z u$, steht kein Artikel (Blickrichtung von Gott her auf den Menschen).

Versucht man den Sinn dieser vom Erzähler getroffenen Unter-

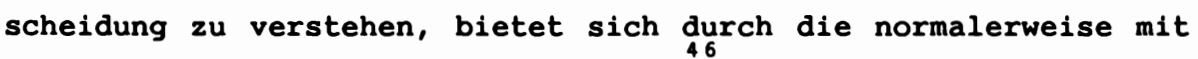
dem Artikel verbundene Determinierung ${ }^{46}$ als eine Möglichkeit an: Bestimmung durch den Artikel wird verwendet, wenn etwas/jemand bezeichnet wird. Meist handelt es sich bei dem mit Artikel verwendeten Nomen um einen Ausdruck, der wenigstens virtuell mehrere

$45 \pi p ל+$ objekt $+2 x-ל$ zur Einführung eines neuen Mitglieds in eine Familie: Gen 12,19; 25,20; 28,9 ... Zur Formel siehe A.TOSATO, Matrimonio 73-74.

46 Weil der Gebrauch des Artikels im Hebräischen aber recht schwankend ist (P.JOÜON, Grammaire $\$ 137 \mathrm{f})$, sind die folgenden Ausführungen nur vorsichtig tastende versuche. 
Dinge oder Personen benennen kann. האלחים "der Gott" bezeichnet (aus menschlicher sicht) den, der - innerhalb anderer (?) - der (eine, wahre) Gott $^{47}$ ist. Wird die Determinierung hier zur Kennzeichnung verwendet, entspräche dies einem monotheistischen Bekenntnis auf der Basis einer mit polytheistischen voraussetzungen gefüllten Sprache.

Auf der anderen Seite steht die Verwendung ohne Artikel, die, wenn sie bezeichnend sein soll (wie es hier durch die Verwendung für Jahwe geschieht), der eines Namens oder Titels gleichkommt. In diesem Fall ist אלהים "Gott" (bis 3,15) Benennung für den, der alleine Gott ist. Die Verwendung von אלהים für Jahwe entspricht so der sicht Gottes. Durch den Erzähler verwendet, wird sie hier Bekenntnis zum einen Gott. Die Verwendung des eine Pluralform darstellenden ${ }^{49}$ Gattungsnamens stellt uns also vor ein ähnliches Ergebnis wie zuvor bei האלהים: In den sprachlichen voraussetzungen zeigt sich noch polytheistisches Denken, die Verwendung von אלהים als Bezeichnung ist jedoch bereits deutliches zeichen eines Monotheismus in dem Sinn, daB Jahwe als einziger Gott für Israel angesehen wird ${ }^{50}$.

47 R.MEYER, Hebräische Grammatik III 27: "Der Artikel wird gebraucht ... bei Beschränkung von Allgemeinbegriffen auf Einzeldinge und -personen"; als Beispiele dafür nennt er "der (einzige) Gott" und רחị "der Strom" (="Euphrat").

Doch mübte der Artikel nach ihm ebenso bei Einmaligkeit der betreffenden Person oder Sache stehen (z.B. "dien Sonne"). So auch nach P.JOÜON, Grammaire $\$ 137$ h: Wenn eine Sache einzig ist, ist sie von selbst determiniert und nimmt den Artikel.

48 P.JoüON, Grammaire $\$ 137$ r: Bei den Bezeichnungen mit Titeln gibt es eine Tendenz, den Artikel wegzulassen.

49 พ.H.SCHMIDT, אלהים 153.

50 Die Diskussion über die Entstehung des Monotheismus in Israel spiegelt sich in drei Sammelbänden der letzten Jahre: 0.KEEL (Hrsg.), Monotheismus im alten Israel und seiner Umwelt (1980); B.LANG (Hrsg.), Der einzige Gott (1981); E. HAAG (Hrsg.), Gott, der einzige (1985).

Monotheistische Tendenzen lassen sich z.B. auch in Ägypten unter Echnaton und in der babylonischen Religion feststellen. Dort wird mit Hilfe der sogenannten "Gleichsetzungstheologie" eine Reduktion der übergroßen Anzahl der Götter vorgenommen, indem die kleineren Götter zu Aspekten oder Hypostasen der Hauptgötter gemacht werden. Siehe dazu W.von SODEN, Leistung und Grenze, besonders 443-448.

Im Zusammenhang mit Ex 3 interessante Beispiele für solche monotheistischen Tendenzen bieten "The Gula Hymn" (Hrsg.w.LAMBERT), der 10 verschiedene Namen für Gula und sechs (es hätte noch weit mehr gegeben) für Ninurta verwendet, und überdies die 
Nach dieser Klärung ist der Unterschied zwischen Jahwe und
$\operatorname{cott}^{51}$ ( $\operatorname{vor} 3,15$ ) immer noch offen. Die beiden Vorkommen von Jahwe in 3,4.7 weisen zwei Gemeinsamkeiten auf: Die Erwähnung Jahwes ist jeweils mit ראה "sehen" und mit nachfolgendem Reden verbunden. Es liegt nahe, unter "Jahwe" den Aspekt des die Not wahrnehmenden und in seinem Wort helfend einschreitenden Gottes bezeichnet zu sehen. Damit stimmte auch die Gesamtaussage unserer Erzählung überein, insofern sie die offenbarung des Jahwenamens mit dem zeitpunkt der Errettung des Volkes aus der Not Ägyptens verbindet.

\subsubsection{Gottes Reden über sich selbst}

Bisher haben wir geschildert, wie der Erzähler Gott präsentiert. Von den beiden Gesprächspartnern trifft Mose in unserer Erzählung keine Aussage über Gott.

In der offenbarung seiner selbst gibt Gott sich als Jahwe und als mit dem vätergott identisch zu erkennen. Die bloße Kenntnis des Jahwenamens und der Identität von Jahwe und vätergott hätte jedoch für sich genommen keinen großen Wert, wäre nicht eine Bedeutung damit verbunden. Erst im Bezug zu menschlichen Erfahrungen wird ein Name und auch der Gottesname bedeutsam 52 .

50 Namen Marduks im "Enuma Eliš" (R.LABAT, Poème, Tafel VI Z.148 bis Tafel VII Z.144. Die weiteren zeilen 145-148 sprechen vom Bewahren dieser Namen und von ihrer Weitergabe an die Nachkommen und weisen so eine beträchtliche Nähe zu den für Einsetzungsberichte typischen Elementen auf). In beiden Fällen sind die Aufzählungen der Namen Ausdruck theologischen Bemühens, ähnliche Gottheiten gleichzusetzen und so die vielzahl der Götter zu reduzieren. Die Unterschiede zu Ex 3 dürfen dabei nicht übersehen werden: In den babylonischen Texten handelt es sich um viele Namen und um ihre Präsentation in Lob (oder Selbstlob). Ex 3 dagegen kennt nur einen Namen und ist Dialog.

51 H.RINGGREN, 305, greift, wenigstens teilweise, die von U.Cassuto getroffene Unterscheidung auf. Danach würde "Jahwe" den Aspekt von Gottes Walten in der Geschichte Israels, "Gott" die eher abstrakte vorstellung vom universalen Gott und schöpfer der Welt bezeichnen.

52 In diesem zusammenhang sind auch die Ausführungen von H.USENER, Götternamen, aufzugreifen. Nach ihm wäre anzunehmen, daB Götter zuerst (a) durch Worte "adjectivischer Kraft" (z.B. "der Mächtige", "der Strahlende") bezeichnet werden. Diese Beinamen unterliegen einem sprachgeschichtlichen ProzeB: Im Lauf der Zeit geht ihre ursprüngliche Bedeutung verloren. Das ist die Voraussetzung dafür, daß sie (b) zu Eigennamen werden können. Als 
Welche menschlichen Erfahrungen mit dem Jahwenamen $z u$ verbinden sind, zeigt auch unsere Erzählung.

Die besondere Verbindung von "Jahwe" mit dem Wahrnehmen der Not und seinem helfenden Einschreiten in Wort $(3,4.7)$ und Tat $(3,8.10)$ ist gerade vorhin angesprochen worden. Mehrere andere Aspekte fügen sich dem an:

a) Gott steht auf der Seite der Israeliten, indem er sie als "mein Volk" bezeichnet $(3,7)$. Es ist auch sein Wunsch $(3,18)$, die Israeliten als Gemeinschaft, als ein "wir" und mit Mose zusammenzuschlieBen.

b) In 3,19-22 präsentiert sich Jahwe mehrfach als Herr der Geschichte: - Er weiB die zukunft voraus (v19). - Er ist so mächtig, daß er mit seinen Wundern große menschliche Mächte überwinden und zwingen kann zu tun, was er will (v20). - Er hat sogar die Fähigkeit, das Innere des Menschen, seine Einstellung zu verändern (v21). Im Letzten, im "Gnade geben in den Augen" zeigt sich übermenschliches Vermögen. Darin gipfelt Jahwes Sprechen von sich als dem Herrn der Geschichte, der sie nicht nur vorausplant oder -weiB (siehe seine Selbstbezeichnung in 3,14 "Ich-werde-

Eigenname wiederum kann der Gottesname in Mythos und Kult, Dichtung und Kunst gebraucht werden; dadurch wird er verbreitet und kann Gemeingut des ganzen Volkes werden. Auf dieser letzten stufe der Anerkennung eines mit Eigennamen angeredeten Gottes gibt es dann erneut (c) das Bedürfnis, den in seiner ursprünglichen Bedeutung nicht mehr verständlichen Namen $z u$ verstehen.

Auf Jahwe angewendet, heiBt dies: a) Wir können damit rechnen, daß "Jahwe" einmal Beiname gewesen ist. Um als eine Möglichkeit (für weitere siehe D.N.FREEDMAN, P.O'CONNOR, יהוח 543-549) die von E.A.KNAUF, Yahwe 468-470, durchzuspielen (vgl. auch in c3 Anm.139): Jahwe könnte aus einer Imperfektform von hwy entstanden sein, deren ursprüngliche (und später in Israel tabuisierte) Bedeutung "er weht" gewesen wäre. Das deutete auf einen Wettergott vom Hadad-Typ. - Nach einer mündlichen Mitteilung von R.Köbert ist die Grundbedeutung sogar noch intensiver: "heftig hinunterstürzen".

b) Im Lauf der Zeit und auch durch den Wandel in der Sprache ist dieser Beiname jahweh (?) = "er weht" nicht mehr verstanden worden. Er ist dadurch zum Eigennamen geworden und bezeichnete den Gott einer Gruppe von Israeliten. Diese Gruppe war innerhalb des Volkes offenbar so stark, daB sich ihre Gottesbezeichnung bei allen durchsetzen konnte.

c) Durch die allgemeine Verehrung entsteht auch der wunsch nach dem Verständnis dieses Namens. In der "Durchleuchtung des alten dunklen Namens" (F.ROSENZWEIG, Ewige 40) in Ex 3,14 wird dieses Anliegen aufgegriffen. Die neue Deutung in der Verbindung mit "Ich werde sein, wer immer ich sein werde" und "Ich-werde-sein" entspricht so kaum der historischen Entstehung des Jahwenamens, gibt aber für das Bedürfnis ihrer zeit eine Erklärung. 
sein", weiters $3,16-18$ und 4,14-16), sondern auch eingreifend bestimmt.

c) In 4,11 spielt Jahwe auf seine Schöpfermacht an, die sich in der Erschaffung und Befähigung/Verhinderung menschlicher Vermögen zeigt. Die Formulierung als rhetorische Frage kommt einer Aussage gleich. In aller Kürze scheint das Bild des Schöpfers durch.

Das Bild, das unser Text von Jahwe zeichnet, ist umfassend. Jahwe wendet sich einem Volk $(3,7-22)$, aber auch einzelnen $(3,4$. $10 ; 4,14)$ zu. Er ist der Herr der Geschichte und bestimmt über die zukunft $(3,16-22)$. Er ist Herr der Natur $(4,3-9)$ und Schöpfer des Menschen $(4,11)$. Er steht jenseits aller Gegensätze und damit hoch über dem Menschen. Unsere Erzählung verbindet alle diese Züge im Sprechen Gottes selbst zu einem Gottesbild. In dessen Hintergrund ${ }_{53}$ steht die Auffassung von Jahwe als dem einen, universalen Gott ${ }^{53}$. Unser Text zeugt so wiederum für Monotheismus im Glauben Israels.

\subsubsection{Die Einwände des Mose}

Mose redet im Verhältnis zu Gott kurz und wenig ${ }^{54}$. Während Gott bejahend von sich spricht, finden sich nach 3,4 bei Mose nur noch Fragen oder negative Aussagen über sich selbst. Wir wollen diesen Einwänden des Mose etwas genauer nachgehen.

Das Bemühen, eine "Logik" dieser Einwände zu entdecken, hat

53 Der Unterschied zu anderen, vergleichbaren Aussagen über Jahwe (z.B. bei Deuterojesaja) liegt vor allem darin, das der polemische Kontext fehlt. Während die Behauptung der Einzigkeit und Universalität Jahwes sonst oft mit der Leugnung der Existenz anderer Götter verbunden ist, wird sie hier durchgehend positiv, d.h. in Aussagen von Jahwe über sich selbst aufgezeigt.

Für die Universalität spielt der Gegensatz Ägypten - Israeliten eine große Rolle. Wir haben gesehen (Anm.189 zu 3,20), daB "Ägypten" dabei eine Art Symbolwert zukommt. Jahwe ist auch Herr über die anderen völker.

54 Doch absolut gesehen, was nämlich die zahl der wörter betrifft, ist Mose immer noch der, der in Berufungen (bei weitem) am meisten redet: 73 wörter (dazu noch 11 wörter in 3,3 ).

zum vergleich: Jes $6,8.11$ hat 5 wörter (und in 6,5 noch 22 Worte im Selbstgespräch); Jer 1,6.11.13 bringt 21 wörter; Ez 1-3: kein einziges Wort des Propheten. 
bisher kaum greifbare Resultate gebracht ${ }^{55}$. Das wird verständlich, denn diese Einwände gehorchen zwei Anforderungen. Auf der einen Seite müssen sie Antworten auf das sein, was Gott zuvor sagt. Und auf der anderen seite sind sie Ausdruck dessen, was eine eigenständige Person, eben Mose, denkt und fühlt. Nur aufgrund dieser beiden Aspekte lassen sich die Einwände des Mose verstehen.

Was den ersten Aspekt, den Antwortcharakter der Einwände betrifft, so zeigt sich darin eine ganz deutliche Entwicklung von einem anfangs noch stärkeren Eingehen auf das von Gott Gesagte bis zur vollständigen Konfrontation in 4,13, in der kein wort unmittelbar zuvor von Gott Gesprochenes aufnimmt. Diese Entwicklung beginnt in 3,11 mit wörtlichem und fast vollständigem Aufgreifen des Sprechens Gottes. Nur genaue Detailanalyse wurde darin schon auf das Fehlen zweier signifikanter Ausdrücke auf-

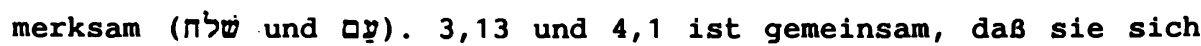
auf hypothetisches Verhalten der Israeliten in der zukunft beziehen und diese auch wörtlich zitiert werden. In beiden Fällen verwendet Mose noch zentrale Ausdrücke des Redens Gottes $(3,13$ : Gott der väter, senden; 4,1 greift, allerdings verneinend, auf $3,16.18$ zurück). In 4,10 ist die Beziehung zum vorigen Reden Gottes schon sehr schwach geworden: Nur לא "nicht", מן "von/seit" und "auch" verbinden noch mit den versen zuvor. 4,13 schlieblich enthält überhaupt keine Beziehung mehr zu Gottes Sprechen zuvor in 4,11-12. So gesehen vollzieht sich in den Einwänden eine Entwicklung zum Negativen. Mose, der anfangs noch ganz auf Gott

55 B.S.CHILDS, Exodus 71, bezeichnet den Fortschritt in den Gedanken mit "mehr gefühlsmäßig als rational".

56 Nachdem unser Text aber nicht nur die "private" Unterhaltung Jahwes mit Mose ist, sondern ein "öffentliches" Interesse enthält - was sich in überlieferung und Niederschrift zeigt -, tritt zu den zwei genannten ein dritter Aspekt hinzu: Ex 3,1-4,17 wird aus jahrhundertelanger Erfahrung mit von Gott gesandten Menschen heraus formuliert und spiegelt in den Einwänden gleichzeitig Probleme wider, denen diese Gesandten Gottes bei der Verkündigung ihrer Botschaft begegnet sind. Die fünf Einwände (sonst nicht in der Bibel) werden so zur summe und zum Reflex grundsätzlicher Schwierigkeiten bei der Weitergabe von Gottes Botschaft.

57 Ihr liegt das sonstige Verhalten des Mose gegenüber Gott voraus: bei der Erscheinung Reaktion des Abweichens und Hingehens, auf den Namensanruf korrekte Antwort mit, $22 \pi$, Gehorsam und Ehrfurcht gegenüber Gottes Befehlen und Selbstvorstellung in 3,56 . 
eingeht, kapselt sich zusehends ihm gegenüber ab und will sich in seinem widerstand verschließen.

Unter dem zweiten Aspekt enthüllt sich ein anderes Bild. Die Entwicklung geht hier von einem vorsichtig einwendenden Mose zu einem, der immer offener und mutiger sagt, was er selbst denkt und fühlt. In der Analyse von 3,11 hatten wir gesehen, daB die Frage "Wer bin ich, daB ...?" einem Höhergestellten gegenüber die eigene Unwürdigkeit ausdrückt. Die Einwände 3,13 und 4,1 schweben zwischen Frage und Bedingungssatz. Mose verweist so auf sein mangelndes Wissen (Name) und seine fehlende Autorität bei Infragestellung seiner sendung. In 4,10 wandelt sich der Ton: Mose redet von sich, aber negativ. Zugleich beginnt er, Gott mit "du" und höflich ("bitte mein Herr") anzureden. 4,13 schlieblich setzt diese Linie mit an Gott gerichtetem Imperativ fort, in dem Mose seinen Wunsch nach Ablehnung der Sendung zum Ausdruck bringt. Von Mose her betrachtet zeigt sich in den Einwänden also eine Entwicklung, die ihn zu einem immer stärkeren, selbständigeren Partner Gottes macht.

\subsubsection{Die Verwandlung des Mose}

Die Veränderung, die in Moses Einwänden deutlich wird, ist Ausdruck einer tiefgehenden Verwandlung , die mit Mose während seiner Berufung geschieht. Sie läßt sich am deutlichsten an jenen Bezeichnungen ablesen, die für ihn zu Anfang und zu Ende unserer Erzählung verwendet werden. In 3,1 wird Mose als "Hirt" geschildert, ${ }_{59}^{\text {in }}$ 4,16 sagt Jahwe von ihm, er sei "Gott" für seinen Bruder Aaron $^{5}$. $\mathrm{Zu}$ Beginn unseres Textes ist Mose noch ein Flüchtling, der in der Fremde in den Diensten eines anderen steht. Am Ende ist Mose einer, der wie Gott höchste, unantastbare Autorität genieBt und mit menschlichen Maßstäben nicht zu messen ist.

58 W.J.O'ROURKE, Moses 52-53, spricht davon, daB von solcher Verwandlung ("transformation") her auch die Berufung der Propheten $z u$ verstehen sei. - Andere Stellen verwenden für diese verwandelnde Neuschöpfung das Verb הפך "wenden, umgestalten": 1 Sam 10,6.9; Zef 3,9 .

59 Zwischen diesen "objektiven" (von außen, nicht durch Mose geschehenden) Benennungen steht noch eine einzige weitere in 4,10. Dort bezeichnet Mose sich selbst Gott gegenüber als "dein Knecht". 
Gottes zugehen beginnt mit seinem Erscheinen in 3,2. Gott weiB, wie Moses Aufmerksamkeit zu erregen ist; Mose geht auf das sonderbare Phänomen zu. Die folgenden drei Anreden Gottes $(3,4-6)$ fangen Mose ein: persönlich angerufen, barfuB auf heiligem Boden, im Gegenüber zu Gott. Aus Interesse war Mose dem Phänomen eines brennenden Busches nachgegangen, am Ende steht er voll Furcht vor Gott selbst. Mose wird damit auf alle zukunft einer, dem Gott begegnet ist und der davon geprägt ist. Allein ${ }_{60}^{\text {in }}$ unserer Erzählung wird noch viermal darauf bezug genommen . Die Differenz zwischen ursprünglicher Intention des Mose und ihrem Ausgang berechtigt, von einem "Locken" Gottes zu sprechen. Dieses Locken besteht in der Art seiner Erscheinung, die Mose anzuziehen imstande ist, ohne daB dieser sich bewubt wird, worauf er sich einläßt - es ist ja seine erste Begegnung mit Gott.

Die Befehle Gottes in 3,5 leiten die erste stufe der Verwandlung ein. Durch das verbot näherzukommen wird Mose in seiner Bewegungsfreiheit eingeschränkt und muB Distanz wahren. Im Ausziehen der Sandalen gibt er einen weiteren Teil seiner Freiheit auf (siehe die Analyse zu 3,5 in c3). Er erkennt an, daB der ihn Ansprechende Herr über ihn ist und daB er auf fremdem Boden steht, was durch die Begründung (heiliger Boden) noch bestätigt und weitergeführt wird. Das Wort שרp "heilig" konnotiert dabei eine Verbindung mit Gott. Nach dem Sehenwollen in 3,3 bildet die Angst $z u$ sehen in 3,6 den markanten AbschluB zu dieser ersten Stufe der Verwandlung. Mose ist wie festgenagelt an diesem heiligen Ort. Er kann nicht gehen und nicht sehen und ist so zum zuhörer dessen geworden, was Gott sagen möchte.

Hatte Moses Sehen in 3,6 aufgehört, findet es ab 3,7 seine Verlängerung im Sehen (ראה), Hören (שמע) und Kennen (ידמי) Gottes. Gottes Wahrnehmung setzt die des Mose fort. Was Gott damit anstrebt, ist, daß Mose sich seinen, Gottes plan zu eigen macht. So wie er selbst, Gott, betroffen ist von der Not, gegen sie einschreitet und das Volk geeint sehen möchte, so soll auch Mose betroffen sein von der Not seiner Landsleute, gegen diese Not angehen und sich mit dem volk vereinen. Deutlich wird diese über-

$603,16.18 ; 4,1.5$.

$61 \mathrm{~N}$ "sich fürchten" ist die angemessene Reaktion auf das Erscheinen Gottes. Vgl. dazu in Exkurs 3 Element XXVI. 
nahme von Gottes Plan durch Mose auch in den Aufträgen zu sprechen (אמר "sagen" in der direkten Rede von 3,14-18). Was Mose den Israeliten zu sagen hat, ist Gottes Wort. Mose wird so zum überbringer göttlicher Mitteilung. zusätzlich zeichnet Gott in 3,7-22 Mose noch mit zusage, zeichen und besonderem Wissen aus. Der Einwand in 4,1 zeigt jedoch, daB der widerstand des Mose noch nicht überwunden ist. Mose will oder kann noch nicht Gottes Plan für sich übernehmen.

In 4,3-9 wird Mose zum Objekt: Er sagt kein Wort mehr. Alles, was er tut, geschieht im Auftrag Gottes und ist dessen genaue Ausführung. Mose zeigt nicht die geringste Eigeninitiative. Wie sehr diese vorgänge auf Mose hereinbrechen, wird u.a. auch durch die beiden fehlenden Redeeinleitungen in 4,5.8 angedeutet: Das hier in 4,3-9 Geschehende ist so überwältigend, daß Mose den Wechsel von Geschehen und Sprechen nicht mehr mitbekommt; beides geht ineinander über und verstärkt noch den Eindruck des überrumpeltseins des Mose. Mit 4,10 zeigt Mose neues Gesprächsverhalten.

Neben diese Lehre für Mose tritt in 4,3-9 das Moment der Ausstattung mit göttlicher Macht. 4,8-9 berichten, daB die zuvor ausgeführten zeichen von Mose eigenmächtig (ohne weiteren Befehl Gottes) vor den Israeliten vollzogen werden können. Die zeichen stehen für verschiedene Machtbereiche.

a) Der stab ist unter den Menschen Sinnbild von Macht und Autorität $^{62}$. Die Schlange ist ein altes und wegen ihrer Ambivalenz schwer zu deutendes symbol . Im zusammenhang mit dem stab

62 M.LURKER, wörterbuch 299-300: Stab/zepter dient beim Herrschenden als zeichen der würde und der Macht, beim Richter als Bild für die Wahrheit des Richterspruchs und für die Gewalt über Leben und Tod. - Nach H.SIMIAN-YOFRE, מש 820, konnotiert der stab an unserer stelle "eine besondere JHWH zuzuschreibende Macht".

In Ex $7-10 ; 14$ ist der stab in der Hand Moses (oder Aarons) zeichen für die Beherrschung der Kräfte der Natur.

63 J.CHEVALIER, Dictionnaire 867-879. Nach ihm unterscheidet sich die Schlange wie der Mensch, aber im Gegensatz zu ihm, von allen übrigen Lebewesen; die Schlange steht am Anfang, der Mensch am Ende einer langen genetischen Entwicklung.

M.LURKER, Wörterbuch 268, hebt die verbindung der Schlange sowohl mit der Unterwelt (durch Lebensweise, todbringendes Gift und Umschlingung) als auch mit der Sonne (als Böses überwindende Kraft) und mit dem Mond (wegen der Fähigkeit zur Regeneration) hervor. - Derselbe Autor geht auf diese Beziehungen ausführlicher 
als dem Symbol für menschliche Macht läßt sich die Schlange vielleicht als symbol für die Macht über Erde und Natur verstehen. Die doppelte Verwandlung (vom stab in die Schlange und wieder zurück) könnte in additivem Sinn ausgelegt werden: Mose erhält $\operatorname{Mach}_{64}$ sowohl über den menschlichen Bereich wie über den der Natur.

b) Das zweite zeichen betrifft einen Aspekt des menschlichen Lebens. Die Hand ist Symbol für den handelnden Menschen, ${ }_{6}{ }_{5}$ wird sie zurückgezogen, bedeutet das Verzicht auf eigenes Tun . Dieser Verzicht wird noch unterstrichen durch ein Anzeichen der Krankheit, die den AusschluB aus der Gemeinschaft fordert. Die wiederherstellung zeugt von Gottes Macht über Krankheit und Gesundheit und damit auch über die zugehörigkeit $z u$ einer Gemeinschaft oder den Ausschlus aus ihr.

c) Das dritte zeichen stellt an die Grenze des menschlichen Lebens. Wo Blut auf die Erde fliebt, fängt der Bereich des Todes an. Mose erhält die Macht, solche Endgültigkeit, aus der es kein zurück gibt, zu verdeutlichen.

Insgesamt gesehen erhält Mose von Gott Macht über Kräfte der Natur und (bestimmte Aspekte) des menschlichen Lebens. Diese Macht erhält er zu dem zweck, Glauben in den Israeliten zu wekken. Unglaube muB mit der Konsequenz des Todes rechnen.

Der mit solcher Macht ausgestattete Mose kann sich im nächsten Einwand $(4,10)$ schon als "dein Knecht" bezeichnen. Seiner Redeunfähigkeit kommt Gott zu Hilfe mit den speziellen zusagen des Beistandes mit seinem Mund (פ) und der Belehrung. Auf den erneuten und letzten widerstand des Mose $(4,13)$ hin werden diese Zusagen verdoppelt und auch auf den mitbestellten Bruder Aaron ausgedehnt $(4,15)$; im Sprechen von Mose und Aaron ist Gott gegenwärtig. Zuvor muBte Mose aber die Erfahrung von Jahwes zorn machen $(4,14)$. Offenbar ist erst sie imstande, Mose zum Gehen zu

ein in seinem Buch "Adler und Schlange" (Tübingen 1983).

Eine Beziehung der Schlange zu Mose bezeugen zwei andere biblische Berichte: Num 21,4-9 und 2 Kön 18,4.

64 Durch den zusammenhang mit der Plagen- und Auszugserzählung scheint jedoch der Aspekt, Macht über die Natur zu erhalten, stärker betont.

65 E.J.HAMLIN, Ordeal 38, schlieBt aus der Parallelstelle Ps 74,11 auf die Bedeutung "voluntary renunciation of power". 
bewegen. Doch wenn er nun geht, so als "Gott" und damit dem ähnlich, der ihn sendet und mit dem er gesprochen hat.

Berufung bedeutet Verwandeltwerden, ${ }_{6}$ Mose ist nicht mehr derselbe, der er am Anfang war. Im Feuer ${ }_{67}^{66}$ der Begegnung mit Gott wird Mose ${ }^{67}$ verwandelt $z u$ Jahwes Gesandtem. War in Ex 2,11-15 sein Tun und sein Leben von zwei Seiten in Frage gestellt worden, so hat Mose nun von Gott neue Autorität und Identität erhalten. Die Frage von 2,14 "Wer hat dich zum Befehlshaber und Richter über uns gemacht?", von einem Israeliten gestellt, findet eine Antwort durch Gottes Auftrag zur Herausführung der Israeliten. Das Bestreben des Pharao, Mose zu töten $(2,15)$, wird aufgefangen durch Gottes Plan und Beistand. Die Sendung durch Jahwe rechtfertigt Moses Tun und schützt sein Leben. Was Mose in zukunft unternimmt, macht er für Gott.

66 Das Feuer als beliebtes Bild für Gott ist hier in seiner Erscheinungsweise im Busch auch typisch für das, was mit Mose geschieht. Durch das Brennen ist der reinigende, läuternde, durchdringende Aspekt bejaht und durch das "nicht verbrennen" der negative, zerstörende, vernichtende Aspekt ausgeschlossen.

67 Im allgemeinen (z.B. G.WIDENGREN, Moses 28; A.GELIN, Moïse 33; S.HERRMANN, MOse 49; H.DONNER, Geschichte Bd.1, 109) wird sein Name - anders als in der Volksetymologie von Ex 2,10von ägyptischem msj "erzeugen, gebären" hergeleitet. Dabei handelte es sich um eine verkürzte Form eines ursprünglich theophoren Namens, der uns in Herrschernamen wie Tutmoses, Ahmoses begegnet. Das zugrundeliegende Muster lautet jeweils: " $x$ (Name eines Gottes) hat geboren". Sein Name würde so ansagen, was Mose am Ende der Berufung geworden ist. 


\section{ABKÜRZUNGSVERZEICHNIS}

\begin{tabular}{|c|c|c|c|}
\hline abs. & absolutus & NBE & Nueva Biblia Española \\
\hline Anm. & Anmerkung & $\mathbf{N i}$ & Nifal \\
\hline Bd. & Band & $\mathbf{P}$ & Priesterschrift \\
\hline BEB & $\begin{array}{l}\text { Berufungs- und Theopha- } \\
\text { nieberichte }\end{array}$ & $\begin{array}{l}\mathbf{P} \\
\mathbf{P}^{\mathbf{G}}\end{array}$ & $\begin{array}{l}\text { Person } \\
\text { priesterliche Grund- }\end{array}$ \\
\hline BHS & $\begin{array}{l}\text { Biblia Hebraica Stuttgar- } \\
\text { tensis }\end{array}$ & $\mathbf{P i}$ & $\begin{array}{l}\text { schrift } \\
\text { Piel }\end{array}$ \\
\hline $\begin{array}{l}\text { bzw. } \\
\text { c }\end{array}$ & $\begin{array}{l}\text { beziehungsweise } \\
\text { Kapitel }\end{array}$ & PIB & $\begin{array}{l}\text { Pontificium Institutum } \\
\text { Biblicum }\end{array}$ \\
\hline constr. & constructus & Pl. & Plural \\
\hline d.h. & das heiBt & $\mathbf{Q}$ & Qal \\
\hline $\begin{array}{l}\text { dtr } \\
\text { E }\end{array}$ & $\begin{array}{l}\text { deuteronomistisch } \\
\text { Elohist }\end{array}$ & $\mathbf{R}^{\mathbf{P}}$ & $\begin{array}{l}\text { Redaktion der Priester- } \\
\text { schrift }\end{array}$ \\
\hline EU் & Einheitsübersetzung & RSV & Revised Standard Version \\
\hline evtl. & eventuell & s. & Seite \\
\hline exkl. & exklusiv & sem. & semantisch \\
\hline$f(f)$ & folgend (e) & Sg. & Singular \\
\hline FS & Festschrift & Stat. & Status \\
\hline Ges.B. & Gesenius-Buhl & TOB & Traduction Oecuménique de \\
\hline Ges.K. & Gesenius-Kautzsch & & la Bible \\
\hline Hi & Hifil & typ. & typisch \\
\hline Ho & Hofal & u.a. & unter anderem, und \\
\hline Hrsg. & Herausgeber & & andere \\
\hline $\mathbf{J}$ & Jahwist & usw. & und so weiter \\
\hline Je & Jehowist & $\mathbf{v}$ & Vers \\
\hline JPS & Jewish Publication Society & vgl. & vergleiche \\
\hline K. & Kuyunjik & Vok. & Vokabular \\
\hline KB & Köhler-Baumgartner & Vorl & Vorlage \\
\hline mask. & maskulin & z.B. & zum Beispiel \\
\hline
\end{tabular}




\section{LITERATURVERZEICHNIS}

Die folgende Liste enthält wichtigere zitierte oder konsultierte Literatur, die mir bis Dezember 1987 am PIB in Rom zugänglich war. Die Abkürzungen (ausgenommen die des Abkürzungsverzeichnisses S.235) entsprechen denen der zeitschrift Biblica.

M.H. ABRAMS, A Glossary of Literary Terms, New York 1981.

G.w. AHLSTRÖM, who were the Israelites, Winona Lake 1986.

R. ALBERTZ, פל, THAT II 413-420.

M. ALLARD, Note sur la formule "ehyeh aser ehyeh", RSR 45 (1957) 79-86.

L. ALONSO SCHÖKEL, Nota estilística sobre la particula hinneh, Bib 37 (1956) 74-80.

L. ALONSO SCHÖKEL, Salvación y Liberación (Cuadernos Bíblicos

5), Valencia 1980 .

A. ALT, Der Gott der Väter, in: Kleine Schriften I 1-78.

A. Alt, Jesaia 8,23-9,6. Befreiungsnacht und Krönungstag, in:

Kleine Schriften II 206-225.

R. ALTER, The Art of Biblical Narrative, New York 1985 .

E. ANATI, Has Mt. Sinai been found?, Biblical Archaeology Review

11 (1985) 42-57.

E. ANATI, The mountain of God, New York 1986.

G. ANDRE, Determining the Destiny. POD in the old Testament (CBOT

16), Uppsala 1980 .

ARISTOTELES, Poetik (Hrsg. I.BECKER, Berlin 1831).

E. AUERBACH, Moses, Amsterdam 1953.

G. AUzOU, De la servitude au service, Paris ${ }^{2} 1964$.

B. BAENTSCH, Exodus - Leviticus - Numeri (Handkommentar zum AT

2), Göttingen 1903.

S.E. BALENTINE, The Hidden God, Oxford 21984 .

S. BARNET, A Dictionary of Literary Terms, London 1964, 21971.

J. BARR, Why? In Biblical Hebrew, JTS 36 (1985) 1-33.

R. BARTELMUS, HYH. Bedeutung und Funktion eines hebräischen "Al-

lerweltswortes" (ATS 17) st.ottilien 1982.

C. BARTH, Theophanie, BundschlieBung und neuer Anfang am dritten

Tage, EvT 28 (1968) 521-533.

P. BEAUChAMP, Création et séparation, Paris 1969. 
J. BECKER, Gottesfurcht im Alten Testament (AnBib 25), Rom 1965. M.A. BEEK, Der Dornbusch als Wohnsitz Gottes (Deut XXXIII 16), OTS 14 (1965) 155-161.

G. BEER, Exodus, Tübingen 1939.

A. BERLIN, Poetics and Interpretation of Biblical Narrative (Bible and Literature Series 9), Sheffield 1983.

A.M. BESNARD, Le Mystère du Nom (LD 35), Paris 1962.

O.F. BEST, Handbuch literarischer Grundbegriffe, Frankfurt ${ }^{8} 1982$. A. BESTERS, L'expression "Fils d'Israel" en EX I-XIV, RB 74 (1967) 321-355.

J. BETZ, Die Eucharistie in der zeit der griechischen Väter Bd.1 und 2, Freiburg 1955-1961.

Die Bibel, Deutsche Ausgabe mit den Erläuterungen der Jerusalemer Bibel, Freiburg 121978.

Die Bibel, Einheitsübersetzung der Heiligen Schrift, Stuttgart 1980 .

The New Oxford Annotated Bible, Revised Standard Version, Oxford 1977 .

Traduction oecuménique de la Bible, Paris 1980.

La BIBLE de Jérusalem, Paris ${ }^{1} 1956$; 21974. Nueva Biblia Española, Madrid 21977.

Biblia Hebraica Stuttgartensis, stuttgart 1977.

J. BLAU, Adverbia als psychologische und grammatische Subjekte/

Praedikate im Bibelhebraeisch, VT 9 (1959), 130-137.

w.C. BOOTH, The Rhetoric of Fiction, Chicago 1961.

D. BOURG, La Critique de la "Métaphysique de l'Exode" par Hei-

degger et l'exégèse moderne, in: L'être et Dieu, Paris 1986.

J. BOURS, "Gesehen habe ich, gesehen das Elend meines Volkes".

Eine Meditation zu Ex 3,7, BibLeb 6 (1965) 299-303.

P. BOVATI, Ristabilire la giustizia (AnBib 110), Rom 1986.

G. BRAULIK, Rezension zu : B.LANG (Hrsg.), Der einzige Gott. Die

Geburt des biblischen Monotheismus, München 1981.

J. BRINKTRINE, Der Gottesname 'hyh im Alten Testament, TGl 42

(1952) 173-179.

W.H. BROWNLEE, The Ineffable Name of God, BASOR 226 (1977) 3946.

M. BUBER, Die fünf Bücher der Weisung, Köln 1954.

M. BUBER, Moses, Zürich 1948.

w. BÜHLMANN, Wenn Gott zu allen Menschen geht, Freiburg 1981 .

R.J. BURNS, Exodus, Leviticus, Numbers (OTM 3), Wilmington (Del) 1983. 
U. CASSUTO, A Commentary on the Book of Exodus, London 1967.

H. CAzelles, Moïse devant l'Histoire, Cahiers Sioniens 8 (1954) 11-27.

H. CAzELles, La titulature du roi David, in: FS André Robert (Travaux de l'Institut Catholique 4), Paris (1955?) 131-136.

J. CHEVALIER - A.GHEERBRANT, Dictionnaire des symboles, Paris 21982 (auch in vier Bänden).

B.S. CHILDS, Exodus (OTL), London 1974.

R.E. Clements, Exodus (Cambridge Bible Commentary), Cambridge 1972.

R.J. CLIFFORD, The Cosmic Mountain in Canaan and the old Testament (HSM 4), Cambridge (Mass) 1972.

D.J.A. CLINES, The Theme of the Pentateuch, Sheffield 1978.

G.W. COATS, The Moses Narratives as Heroic Saga, in: Saga, Legend, Tale, Novella, Fable; Narrative Forms in old Testament Literature (JSOTS 35), Sheffield 1985, 33-44.

G.w. COATS, Tale, in: Saga, Legend, ..., 63-70.

C. CONROY, Absalom, Absalom (AnBib 81), Rom 1978.

J.C. COOPER, Symbolism. The Universal Lanquage, Wellingborough 21984 .

B. COUROYER, L'Exode (BJ), Paris ${ }^{2} 1958$.

F.M. CROSS, Canaanite Myth and Hebrew Epic, Cambridge (Mass) 1973.

A.G. van DAALEN, De plaats waar JHWH Elohim zich aan Mozes liet zien. Een onderzoek naar de compositie van Exodus 3, in: Verkenningen in een stroomgebied Amsterdam 1974, 30-40.

M.K. DANZIGER, W. STACY JOHNSON, An Introduction to Literary Criticism, Boston 1961.

D. DAUBE, The Exodus Pattern in the Bible, London 1963.

G.H. DAVIES, Exodus (The Torah Bible Commentaries), London 1967.

H. DONNER, Geschichte des Volkes Israel und seiner Nachbarn in

Grundzügen Bd.1 und 2, Göttingen 1984-1986.

E. DREWERMANN, Tiefenpsychologie und Exegese Bd.1, olten 1985.

S.R. DRIVER, The Book of Exodus, Cambridge 1911.

S.R. DRIVER, Recent theories on the origin and nature of the Tetragrammaton, studia Biblica 1 (Oxford 1885), 1-20.

A.-M. DUBARLE, La révélation de Dieu à Moïse: VSp 119 (1968) 11 23.

G. DURAND, Les Structures Anthropologiques de l'Imaginaire, Poitiers 1969. 
E. EBELING, Dattelpalme, Dattelschnaps, in: Reallexikon der Assyriologie II 169.

W. EGGER, Methodenlehre zum NT: Einführung in linguistische und

historisch-kritische Methoden, Freiburg 1987.

H.L. ELLISON, Fathers of the Covenant, Exeter 1978.

H. ENGEL, Rezension zu O.LORETZ, Habiru-Hebräer, Bib 67

(1986) 287-291.

A. EVEN-SHOSHAN, A New Concordance of the Bible, Jerusalem 1980.

A. FALKENSTEIN, W. von SODEN, Sumerische und akkadische Hymnen und Gebete, zürich 1953.

H. FELD, Das Verständnis des Abendmahls (EdF 50) Darmstadt 1976.

J. FELIKS, Burning Bush, EncJud 4 (1971) 1528-1530.

M. FISHBANE, Text and Texture, New York 1979.

J.P. FLOSS, Jahwe dienen - Göttern dienen (BBB 45), Bonn 1975.

G. FOHRER, Überlieferung und Geschichte des Exodus (BZAW 91), Berlin 1964.

J.P. FOKKELMANN, Narrative Art in Genesis (studia Semitica Neerlandica 17), Assen 1975.

J.E. FOSSUM, The Name of God and the Angel of the Lord, Tuibingen 1985.

E. FOX, Now these are the names, New York 1986.

D.N. FREEDMAN, The Burning Bush, Bib 50 (1969) 382-384.

D.N. FREEDMAN, P. O'CONNOR, Tרדי TWAT III 533-554.

D.N. FREEDMAN, B.E.WILLOUGHBY, 9פע, TWAT V 1039-1056.

D.N. FREEDMAN, B.E. WILLOUGHBY, H.-J. FABRY, Tאל TWAT IV 887905.

S. FRENSDORFF, Ochlah W'Ochlah, Hannover 1864.

T.E. FRETHEIM, The Suffering of God. An OT Perspective (Ouvertures to Biblical Theology 14), Philadelphia 1984.

H. FREY, Das Buch der Heimsuchung und des Auszugs (Die Botschaft des AT 5), Stuttgart 1952.

T.S. FRYMER, L.I. RABINOWITZ, Honey, in: EncJud 8, 963.

T.S. FRYMER, Milk, in: EncJud 11, 1578.

H.F. FUHS, הלצ, TWAT V 84-105.

W. FUSS, Die deuteronomistische Pentateuchredaktion in Exodus 317 (BZAW 126), Berlin 1972 .

H. GALBIATI, La struttura letteraria dell'Esodo, Roma 1956.

A. GAMPER, Gott als Richter in Mesopotamien und im AT, Innsbruck 1966.

F. GARCIA LOPEZ, Election-Vocation d'Israël et de Jérémie: Deutéronome VII et Jérémie I, VT 35 (1985) 1-12. 
A. GELIN, Moïse dans l'AT, Cahiers Sioniens 8 (1954) 29-52.

S.A. GELLER, The struggle at the Jabbok: the uses of enigma in a biblical narrative, JANESCU 14 (1982) 37-60.

W. GESENIUS, F.BUHL, Hebräisches und Aramäisches Handwörterbuch über das AT, Berlin ${ }^{17} 1915$ (=1962).

w. GESENIUS, E.KAUTzSCH, Hebräische Grammatik, Leipzig ${ }^{28} 1909$.

P. GIBERT, Bible, mythes et récits de commencement, Paris 1986.

B. GLADIGOW, Gottesnamen, RAC 11 (1981) 1202-1238.

M. GÖRG, Aaron - von einem Titel zum Namen? BN 32 (1986) 11-17.

K. GOUDERS, $\mathrm{zu}$ einer Theologie der prophetischen Berufung (+ drei weitere Teile) BibLeb 12 (1971) 79-93; 162-186; und 13

(1972) 89-106; 172-184.

R. GRADWOHL, Bibelauslegung aus Jüdischen Quellen, stuttgart 1986.

M. GREENBERG, The Thematic Unity of Exodus III-XI, in: Fourth

World Congress of Jewish Studies $I$, Jerusalem 1967, 151-154.

M. GREENBERG, Understanding Exodus, New York 1969.

GREGOR von NYSSA, La Vita di Mosè (Hrsg. M.Simonetti), Mailand 1984 .

H. GRESSMANN, Mose und seine zeit, Göttingen 1913.

H.J. GRIMMELSMANN, The Book of Exodus, Cincinnati 1927 .

w. GROSS, Die Pendenskonstruktion im Biblischen Hebräisch (ATS 27), St. Ottilien 1987.

D. GUTZEN u.a. (Hrsg.), Einführung in die neuere deutsche Literaturwissenschaft, Berlin ${ }^{5} 1984$.

E. HAAG (Hrsg.), Gott, der einzige. Zur Entstehung des Monotheismus in Israel (QD 104), Freiburg 1985.

N. HABEL, The Form and Significance of the Call Narratives, ZAW 77 (1965) 297-323.

I. HAFEMANN, zum Problem der staatlichen Arbeitspflicht im alten

Ägypten I, Altorientalische Forschungen 12 (1985) 3-21.

J. HALBE, Das Privilegrecht Jahwes. Ex 34, 10-26 (FRLANT 114), Göttingen 1975.

E.J. HAMLIN, The Liberator's Ordeal. A Study of Exodus 4,1-9, in: Rhetorical Criticism (FS J.Muilenberg 1974) 33-42.

C. HARDMEIER, Texttheorie und biblische Exegese (BEvT 79), München 1978 .

P. HEINISCH, Das Buch Exodus (Die Heilige Schrift des AT I, 2), Bonn 1934.

A. HERMANN, Dornstrauch, RAC IV (1959) 189-197. 
S. HERRMANN, Geschichte Israels in alttestamentlicher zeit, München 21980 .

S. HERRMANN, Gesammelte Studien zur Theologie und Geschichte des AT, in: TBü AT 75 ( 3 Artikel: Mose; Der alttestamentliche Gottesname; Geschichtsbild und Gotteserkenntnis), München 1986.

J.K. HOFFMEIER, The Arm of God Versus the Arm of Pharaoh in the Exodus Narratives, Bib 67 (1986) 378-387.

H. HOLzINGER, Exodus (Kurzer Handcommentar zum AT II), Tübingen 1900 .

E. HORNuNG, Der ägyptische Mythos von der Himmelskuh (OBO 46), Freiburg 1982.

C. HOUTMAN, Exodus 4:24-26 and its Interpretation, JNWSemL 11

(1983) 81-105.

C. HOUTMAN, A Note on the LXX Version of Ex 4,6, ZAW 97 (1985) 253-254.

F.D. HUBMANN, Der Bote des Heiligen Gottes, TPO 135 (1987) 328339.

F. HUMMELAUER, Commentarius in Exodum et Leviticum, Paris 1897.

M. HUTTER, Das Werden des Monotheismus im Alten Israel, in: An-

fänge der Theologie (FS J.Bauer) Graz 1987, 25-39.

J.P. HYATT, Yahweh as "the God of My Father", VT 5 (1955) 130136.

D. IRVIN, The Joseph and Moses stories as narrative in the light of ancient Near Eastern narrative, in: J.H.HAYES, J.MAXWELL MILLER, Israelite and Judaean History (London 1977) 180-209.

C.D. ISBELL, The Divine Name אהיה As a Symbol of Presence in Israelite Tradition, HebAnR 2 (1978) 101-118.

C.D. ISBELL, Initial 'Aleph-Yod Interchange and Selected Biblical Passages, JNES 37 (1978) 227-236.

T. ISHIDA, The Structure and Historical Implications of the Lists of Pre-Israelite Nations, Bib 60 (1979) 461-490.

B. JACOB, Israel in Ägypten. Rückblick auf Ex 1-15, in: Jahrbuch für tüdische Geschichte und Literatur 31 (1938), Berlin, 8498.

B. JACOB, Mose am Dornbusch, MGWJ 66 (1922) 11-33; 116-138; 180200 .

J.G. JANzEN, What's in a Name? "Yahweh" in Exodus 3 and the Wider Biblical Context, Int 33 (1979) 227-239.

K. JAROS, Die stellung des Elohisten zur kanaanäischen Religion (ОВО 4), Freiburg 1974. 
E. JENNI, יחוה, THAT I 701-707.

J. JEREMIAS, Die Abendmahlsworte Jesu, Göttingen ${ }^{1} 1935,{ }^{4} 1967$.

J. JEREMIAS, Moses und Hammurabi, Leipzig ${ }^{2} 1903$.

J. JEREMIAS, Theophanie. Die Geschichte einer alttestamentlichen

Gattung (WMANT 10), Neukirchen 1965.

P. Joüon, Grammaire de l'Hébreu Biblique, Rom ${ }^{2} 1965$.

P. JoüoN, Notes de Syntaxe Hébraïque, Bib 2 (1921) 223-229.

E. JÜNGEL, Gott als Geheimnis der Welt, Tübingen 1977.

C. KAHRMANN (u.a.), Erzähltextanalyse Bd.1, Königstein ${ }^{2} 1981$.

M. KALISCH, Exodus, London 1855.

L. KAPLAN, "And the Lord Sought to Kill Him" (Exod 4:24): Yet

Once Again, HebAnR 5 (1981) 65-74.

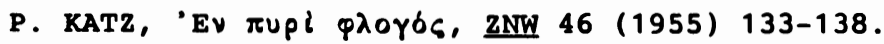

O. KEEL (Hrsg.), Monotheismus im Alten Israel und seiner Umwelt (BibB 14), Fribourg 1980.

O. KEEL u.a., Orte und Landschaften der Bibel Bd.1, zürich, Göttingen 1984.

O. KEEL, M. KüCHLER, Synoptische Texte aus der Genesis, Freiburg 1971 .

O. KEEL, Die Welt der altorientalischen Bildsymolik und das Alte Testament. Am Beispiel der Psalmen. zürich, Neukirchen 31984 .

C.F. KEIL, Das Zweite Buch Mose's, Exodus (Biblischer Commentar), Leipzig ${ }^{3} 1878$.

N. KILWING, Noch einmal zur Syntax von Ex 3,14, BN 10 (1979) 7079.

J. KINYONGO, origine et signification du nom divin Yahvé à la lumière de récents travaux (BBB 35), Bonn 1970.

K.S. KIYOSHI, Zusammenfassung von H. SADAKATA, "An Understanding of God in Exodus 3:13-15" (japanisch; in: The Bible and the Ancient Near Eastern World, Tokyo 1985, 57-80), old Testa ment Abstracts 9 (1986) 50 .

E.A. KNAUF, El Šaddai und der Gott Abrahams, BZ 29 (1985) 97-103. E.A. KNAUF, Yahwe, VT 34 (1984) 467-472.

L. KÖHLER, W.BAUMGARTNER, Hebräisches und aramäisches Lexikon zum AT, Leiden ${ }^{3} 1967$ - .

E. XöNIG, Historisch-comparative syntax der hebräischen Sprache, Leipzig 1897.

J. KOENIG, Le Site de Al-Jaw dans l'ancien pays de Madian, Paris 1971 . 
F. KOHATA, Jahwist und Priesterschrift in Ex 3-14 (BZAW 166), Berlin 1986.

F. KoHAtA, Verzicht auf die Quellenschriften im Pentateuch? Konsequenzen aus Textbeobachtungen in Ex 3-14, Annual of the Japanese Biblical Institute Tokyo 1986, 3-28.

S. KREUZER, Der lebendige Gott (BWANT 116), stuttgart 1983.

R. LABAT, Le poème Babylonien de la Création, Paris 1935.

C.J. LABUSCHAGNe, Neue Wege und Perspektiven in der Pentateuchforschung, VT 36 (1986) 146-162.

C.J. LABUSCHAGNE, לp, THAT II 629-634.

C.J. LABUSCHAGNE, Kר, THAT II 666-674.

S.T. LACHS, Exodus iv 11: evidence for an emendation, VT 26 (1976) 249-250.

W.G. LAMBERT, The "Gula Hymn" of Bulluțsa-Rabi, or 36 (1967) 105132.

E. LÄMMERT, Bauformen des Erzählens, stuttgart ${ }^{8} 1983$.

B. LANG (Hrsg.), Der einzige Gott. Die Geburt des biblischen Monotheismus, München 1981.

X. LEON-DUFOUR, Le partage du pain eucharistique selon le NT,

Paris 1982 (auf deutsch: Abendmahl und Abschiedsrede im NT, Stuttgart 1983).

C. LEVIN, Der Dekalog am Sinai, VT 35 (1985) 165-191.

A. de LIBERA, E.zUM BRUNN (Hrsg.), Celui qui est, Paris 1984.

J. LINDBLOM, Theophanies in Holy Places in Hebrew Religion, HUCA 32 (1961) 91-106.

F. LINDSTRÖM, God and the origin of Evil. A Contextual Analysis of Alleged Monistic Evidence in the old Testament (CBOT 21), Lund 1983.

S.E. LOEWENSTAMM, The Presence at Mount Sinai, Immanuel 5 (1975) 20-26.

N. LOHFINK, Die priesterschriftliche Abwertung der Tradition von der Offenbarung des Jahwenamens an Mose, Bib 49 (1968) 1-8.

N. LOHFINK, Beobachtungen zur Geschichte des Ausdrucks 'am yhwh, in: Probleme biblischer Theologie (FS G.von Rad; Hrsg. H.W. Wolff), München 1971, 275-305.

N. LOHFINK, Die deuteronomistische Darstellung des übergangs der Führung Israels von Moses auf Josue, Schol 37 (1962) 32-44.

N. LOHFINK, Die LandverheiBung als Eid (SBS 28), stuttgart 1967.

N. LOHFINK, Die Priesterschrift und die Geschichte, VTS 29

(1978) 189-225. 
N. LOHFINK, Die Ursünden in der priesterlichen Geschichtserzählung, in: Die Zeit Jesu (FS H.Schlier; Hrsg. G.Bornkamm, K.Rahner), Freiburg 1970, 38-57.

B.O. LONG, Berufung I. AT, in: TRE 5, 676-684.

O. LORETz, Aharon der Levit (Ex. 4,14), UF 8 (1976) 454 .

O. LORETZ, Habiru - Hebräer (BZAW 160), Berlin 1984 .

J. LOZA, Rezension zu W.H. SCHMIDT, Exodus (BK), und P. WEIMAR, Die Berufung des Mose, RB 94 (1987) 129-135.

M. LURKER, wörterbuch biblischer Bilder und Symbole, München 1973.

J. MAGONET, The bush that never burnt, HeyJ 16 (1975) 304-311.

B. de MARGERIE, Le troisième jour, RSR 74 (1986) 158-188.

C.M. MARTINI, Vita di Mosè-Vita di Gesù, Rom ${ }^{2} 1980$. (auf deutsch: Dein Stab hat mich geführt, Freiburg 1981).

H.G. MAY, The god of my father - a study of patriarchal religion, JBR 9 (1941) 155-158; 199-200.

G. MAYER, ריר, TWAT III 894-901.

D.J. MCCARTHY, Exod 3:14: History, Philology and Theology, CBO 40 (1978) 311-322.

D.J. MCCARTHY, Hero and Anti-Hero in 1 Sam 13,2-14,46, in: Institution and Narrative. Collected Essays (AnBib 108), Rom 1985.

D.J. MCCARTHY, Plagues and Sea of Reeds: Ex 5-14, JBL 85 (1966) 137-158 .

D.J. MCCARTHY, Treaty and Covenant (AnBib 21A), Rom 21978 .

D.J. MCCARTHY, The Uses of $w^{\circ}$ hinneh in Biblical Hebrew, Bib 61 (1980) 330-342.

S.E. McEvenue, The Narrative style of the Priestly Writer (AnBib 50), Rom 1971.

R. MEYER, Hebräische Grammatik Bd.I-IV, Berlin 1966-1972.

D. MIANBE BETOUdJI, El, le dieu Suprême et le Dieu des Patriarches (Religionswissenschaftliche Texte und studien 1) Hildesheim 1986.

F. MICHAELI, Le livre de l'Exode, Paris 1974.

J.D. MICHAELIS, Deutsche Uebersetzung des Alten Testaments mit Anmerkungen für Ungelehrte. Der dritte Theil, welcher das zweite und dritte Buch Mose enthält, Göttingen 1787.

P. MILLER, Genesis 1-11. Studies in structure and Theme (JSOTS 8), Sheffield 1978 .

H. MÖLLE, Das "Erscheinen" Gottes im Pentateuch. Ein literatur- 
wissenschaftlicher Beitrag zur alttestamentlichen Exegese (Europäische Hochschulschriften XXIII/18) Frankfurt 1973. R. MOSIS, כאב, TWAT IV 8-13.

J.A. MOTYER, The Revelation of the Divine Name. London 1959 ( 21970$)$.

H.-P. MÜLLER, Gott und die Götter in den Anfängen der biblischen Religion. Zur Vorgeschichte des Monotheismus, in: O.KEEL (Hrsg.), Monotheismus 99-142.

H.-P. MÜLleR, Der Jahwename und seine Deutung Ex 3,14 im Licht der Textpublikationen aus Ebla, Bib 62 (1981) 305-327.

T. MURAOKA, Emphatic Words and structures in Biblical Hebrew, Jerusalem 1985.

A. MURTONEN, A Philological and Literary Treatise on the old Testament Divine Names, Helsinki 1952.

E. NEUFELD, Apiculture in Ancient Palestine (Early and Middle Iron Age) within the framework of the Ancient Near East, UF 10 (1978) 219-247.

A. NICCACCI, Esodo 3,14a: "Io sarò quello che ero" e un parallelo egiziano, in: Liber annuus Studium Biblicum Franciscanum 35 (1985) 7-26.

A. NICCACCI, Sullo sfondo egiziano di Esodo 1-15*, in: Liber

Annuus Studium Biblicum Franciscanum 36 (1986), 7-43.

C. NOCE, Il nome di Dio. Origene e l'interpretazione dell'Es 3,14, Div 21 (1977) 23-50.

M. NOTH, Das Zweite Buch Moses. Exodus (ATD 5), Göttingen ${ }^{2} 1961$. J. OESCH, Petucha und Setuma (OBO 27), Freiburg 1979.

A. OHLMEYER, Der Erlösergott im brennenden Dornbusch, BK 12 (1957) 98-111.

G. del OLMO LETE, La vocación del lider en el antiquo Israel, Salamanca 1973.

J. van OORSCHOT, Gott als Grenze (BZAW 170) Berlin 1987.

J.J. O'ROURKE, Moses and the Prophetic Vocation, Scr 15 (1963) 44-64.

G.H. PARKE-TAYLOR, Yahweh: The Divine Name in the Bible, Waterloo 1975.

A. PEREVOLOTSKY, I. FINKELSTEIN, The Southern Sinat Exodus Route in Ecological Perspective, Biblical Archaeology Review 11 (1985) 26-41.

R. PESCH, Das Abendmahl und Jesu Todesverständnis (QD 80) Freiburg 1978 . 
J. PLASTARAS, The God of Exodus, Milwaukee 1966 (italienisch: Il Dio dell'Esodo).

H.D. PREUSS, "... ich will mit dir sein!", ZAW 80 (1968) 139-173.

H.D. PREUSS, KY, TWAT III 795-822.

P. PROULX, L.ALONSO SCHÖKEL, Las Sandalias del Mesías Esposo, Bib 59 (1978) 1-37.

R. de PURY, Der Exodus (französisches Original: Le libérateur) Neukirchen 1961.

G. von RAD, Die offenbarung des Jahwenamens, in: Theologie des

Alten Testaments I 193-200, München 1962.

Y.T. RADDAY, The Spoils of Egypt, ASTI 12 (1983) 127-147.

Y.T. RADDAY, "Wie ist sein Name?" (Ex 3:13), Linguistica Biblica 58 (1986) 87-104.

H. RAND, Moses at the Inn, Dor le Dor 14 (1985) 31-38.

RASCHI, Le Pentateuque II - L'Exode, Paris 1965.

B. RENAUD, La figure prophétique de Moïse en Exode 3,1-4,17, $\underline{\text { RB }}$ 93 (1986) 510-534.

H. RENCKENS, De Naam Jahweh als samenvatting van Israels Godsbesef, Bijdr 19 (1958) 117-136.

R. RENDTORFF, Offenbarung als Geschichte, KD (Beiheft 1) 21-41.

w. RESENHÖFFT, Die Quellenberichte im Josef-Sinai-Komplex (Europäische Hochschulschriften XXIII/199), Bern 1982 .

w. RICHTER, Die sogenannten vorprophetischen Berufungsberichte

(FRLANT 101), Göttingen 1970.

M. RIEBL, Dreimal: Berufung des Mose. Eine Bibelarbeit, BLit 53 (1980) 213-218.

H. RINGGREN, אלהים, TWAT I 285-305.

H. RINGGREN, נעל, TWAT IV 497-500.

F. RITZHAUPT, Weqzeichen. Bergsteigen und christliche Existenz, Bozen 1980 .

w. ROBERTSON SMITH, The Religion of the Semites Bd. 2, London

$$
\left.1901 \text { ( }{ }^{1} 1889 ;{ }^{3} 1927\right) \text {. }
$$

B.P. ROBINSON, Zipporah to the rescue: a contextual study of Exodus IV 24-26, VT 36 (1986) 447-461.

G. ROEDER, Urkunden zur Religion des alten Ägypten, Jena 1923.

M. ROSE, Jahwe (TS 122), zürich 1978 .

F. ROSENZWEIG, Der Ewige, in: Die Schrift, Königstein 1984, 3450 .

H. SADAKATA: Siehe K.S.KIYOSHI.

M. SAEB $\varnothing$, Offenbarung oder Verhüllung? Bemerkungen zum Charakter 
des Gottesnamens in Ex 3,13-15, in: Die Botschaft und die Boten (FS H.W.Wolff 1981) 43-55.

N.M. SARNA, Exploring Exodus, New York 1986.

N.M. SARNA, Understanding Genesis, New York 1966.

G. SAUER, ๆK, THAT I, 220-224.

J. SCHARBERT, Das "Wir" in den Psalmen auf dem Hintergrund altorientalischen Betens, in: Freude an der Weisung des Herrn (SBB 13; FS H.GROSS, HrSg. E.HAAG/F.-L.HOSSFELD) Stuttgart 1986, 297-324.

E. SCHILD, On Ex III 14 - "I am that I am", VT 4 (1954) 296-302. H.H. SCHMID, "Ich bin, der ich bin." Ein Beitrag des Alten Testaments zu unserer Frage nach Gott. TGl 60 (1970) 403-412.

H. SCHMID, Die Gestalt des Mose (EdF 237) Darmstadt 1986.

H. SCHMID, Mose (BZAW 110), Berlin 1968 .

R. SCHMID, Mit Gott auf dem Weg. Die Bücher Exodus, Levitikus,

Numeri. Stuttgart 1977.

W.H. SCHMIDT, אלהים, THAT I 153-167.

w.H. SCHMIDT, Exodus (BKAT II) Neukirchen-Vluyn ab 1974.

W.H. SCHMIDT, Exodus, Sinai und Mose (EdF 191), Darmstadt 1983.

w.H. SCHMIDT, Der Jahwename und Ex 3,14, TextgemäB (FS E.Würthwein) 1979, 123-138.

H. SCHNEIDER, Exodus (Echter Bibel 2), Würzburg 1952 .

W. SCHNEIDER, Grammatik des biblischen Hebräisch, München 1976.

F. SCHNUTENHAUS, Das Kommen und Erscheinen Gottes im AT, ZAW 76 (1964) 1-21.

A. SCHOTT, w.von SODEN, Das Gilgamesch-Epos, Stuttgart 1982.

w. SCHOTTROFF, פקר, THAT II 466-486.

H. SCHÜRMANN, Der Einsetzungsbericht Lk 22,7-38, Münster 1955.

H. SCHWEIZER, Metaphorische Grammatik (ATS 15), st.ottilien 1981.

H. SCHWEIZER, Biblische Texte verstehen, Stuttgart 1986.

S. SCHWERTNER, OI, THAT II, 47.50.

H. SEEBASS, Der Erzvater Israel (BZAW 98), Berlin 1966.

J. SEVERINO CROATTO, Yo soy él que estoy (contigo); la interpretación del nombre de "Yahvé" en Ex 3,13-14, in: El mistero de la palabra (FS L.Alonso Schökel; Hrsg. V.Collado, E.zurro) Madrid 1983, 147-159.

A. SHINAN, Rezension von A. WILDAvSKY, The Nursing Father: Moses as a Political Leader, Alabama 1984, und A.de GRAzIA, God's Fire: Moses and the Management of Exodus, Princeton 1983, in: Bible Review 2 (1986) 12-17.

H. SIMIAN-YOFRE, Exodo en Deuteroisaias, Bib 61 (1980) 530-553. 
H. SIMIAN-YOFRE, ממ, TWAT IV 818-826.

H. SIMIAN-YOFRE, פנים, TWAT VI 629-659.

H. SIMIAN-YOFRE, La teodicea del Deuteroisaia, Bib 62 (1981) 5572.

J.L. SKA, Moïse, Le monde de la Bible 41 (1985) 31-34.

J.L. SKA, Le Passage de la mer (AnBib 109), Rom 1986.

J.L. SKA, La place d'Ex 6,2-8 dans la narration de l'exode, ZAW 94 (1982) 530-548.

J.L. SKA, Rezension zu P.WEIMAR, Die Berufung des Mose, in: Bib 64 (1983) 136-138.

R. SMEND, Die Entstehung des Alten Testamentes, stuttgart 1978.

w. von SODEN, Leistung und Grenze sumerischer und babylonischer

wissenschaft, in: Die Welt als Geschichte" Bd.2, 411-464 und 509-557; Stuttgart 1936.

F. SONNEK, Die Einführung der direkten Rede in den epischen Texten, 吕 46 (1940) 225-235.

E.A. SPEISER, Genesis (AB 1), New York 1964.

F.K. STANzEL, Theorie des Erzählens, Göttingen ${ }^{3} 1985$.

O.H. STECK, Bemerkungen zu Jesaja 6, BZ 16 (1972) 188-206.

S.Ö. STEINGRIMSSON, Vom zeichen zur Geschichte (СвOT 14), Lund 1979.

H.-J. STIPP, Elischa - Propheten - Gottesmänner (ATS 24), st.ottilien 1987.

F. STOLz, Monotheismus in Israel, in: O.KEEL (Hrsg.), Monotheismus 143-189.

G. TE STROETE, Exodus (Commentar über den Pentateuch 2), Halle 1802 .

S. TALMON, מרכר, TWAT IV 660-695.

THEODORET, Quaestiones in Exodum (PG 80; Paris 1860).

R.C. THOMPSON, The Epic of Gilgamish, Oxford 1930.

J.H. TIGAY, "Heavy of Mouth" and "Heavy of Tongue": On Moses'

Speech Difficulty, BASOR 231 (1978) 57-67.

The Torah, The Five Books of Moses, Philadelphia 1962.

A. TOSATO, Il matrimonio israelitico (AnBib 100) Rom 1982.

R. TOURNAY, Le nom du "Buisson ardent", VT 7 (1957) 410-413.

H. USENER, Götternamen. Versuch einer Lehre von der religiösen

Begriffsbildung, Berlin 1896.

H. VALENTIN, Aaron. Eine Studie zur vor-priesterschriftlichen Aaron-überlieferung (OBO 18), Freiburg 1978.

A. VANHOYE, Homilie für haltbedürftige Christen. Struktur und Botschaft des Hebräerbriefs, Regensburg 1981. 
A. VANHOYE, La structure littéraire de l'Epître aux Hébreux, Paris 21976.

R. de VAUX, Les Institutions de L'AT Bd.2, Paris 1960.

R. de VAUX, The Revelation of the Divine Name YHWH, in: Proclamation and Presence (FS G.H.Davies), London 1970, 48-75.

D. VETTER, האר, THAT II 692-701.

D. VIEWEGER, Die Spezifik der Berufungsberichte Jeremias und

Ezechiels im Umfeld ähnlicher Einheiten des AT (Beiträge zur Erforschung des AT und des Antiken Judentums 6) Frankfurt 1986.

J. VOGT, Aspekte erzählender Prosa, Opladen ${ }^{6} 1986$.

D. VÖLLER, Wer war Mose? Eine religionsgeschichtliche Untersuchung, Leiden 1913.

H. VORLÄNDER, Mein Gott. Die Vorstellungen vom persönlichen Gott

im Alten Orient und im Alten Testament (AOAT 23), Neukirchen 1975.

S.Ph. de VRIES, Jüdische Riten und Symbole, Wiesbaden ${ }^{3} 1984$.

T.C. VRIEZEN, 'EHJE 'ASER 'EHJE, in: FS A. Bertholet, Tübingen $1950,489-512$.

B.N. WAMBACQ, L'épithète divine Jahvé $S^{\circ}$ ba'ôt, Paris 1947.

B.N. WAMBACQ, 'eh'yeh 'ǎer 'eh“yeh, Bib 59 (1978) 317-338.

P. WEIMAR, Die Berufung des Mose. Literaturwissenschaftliche

Analyse von Exodus 2,23-5,5 (OBO 32), Freiburg 1980.

P. WEIMAR, E. ZENGER, Exodus. Geschichten und Geschichte der

Befreiung Israels (SBS 75) stuttgart 1975, ${ }^{2} 1979$.

P. WEIMAR, Untersuchungen zur priesterschriftlichen Exodusge-

schichte (FzB 9), würzburg 1973.

J. WEISS, Das Buch Exodus, Graz 1911.

R. WELLEK, A.WARREN, Theorie der Literatur, Frankfurt 1972

(engl. Original: Theory of Literature, New York 1942,

2 1955).

J. WELlHAUSEN, Die Composition des Hexateuchs und der Historischen Bücher des Alten Testaments, Berlin ${ }^{4} 1963$ ( $\left.{ }^{1} 1876 / 7\right)$.

J. WELLHAUSEN, Israelitische und jüdische Geschichte, Berlin 1894, 91958 .

C. WESTERMANN, Lob und Klage in den Psalmen, Göttingen ${ }^{5} 1977$.

R.N. WHYBRAY, The Making of the Pentateuch (JSOTS 53), Sheffield 1987.

G. WIDENGREN, what do we know about Moses? in: Proclamation and

Presence (FS G.H.DAVIES), London 1970, 21-47. 
C. WIENER, La rencontre à L'Horeb, Le Livre de l'Exode (Cahiers Evangile 54) 15-17.

H. WILDBERGER, אמן, THAT I 187-193.

H. WILDBERGER, Jesaja (BK X/1) Neukirchen 1972.

N. WYATT, The Development of the Tradition in Exodus 3, ZAW 91

(1979) 437-442.

N. WYATT, The significance of the burning bush, VT 36 (1986) $361-$ 365 .

E.J. YOUNG, The Call of Moses, WTJ 29 (1967) 117-135; und 30 (1967/8) 1-23.

E. ZENGER, Das Buch Exodus (Geistliche Schriftlesung 7), Düsseldorf 1978 .

E. ZENGER, Der Gott des Exodus, BiKi 42 (1987) 98-103.

E. ZENGER, Israel am Sinai, Altenberge 1982 .

E. ZENGER, Das jahwistische Werk - ein Wegbereiter des jahwistischen Monotheismus?, in: E. HAAG (Hrsg.), Gott, der einzige (QD 104), Freiburg 1985.

W. ZIMMERLI, Ezechiel (BKAT XIII/1) Neukirchen-Vluyn 1969.

w. ZIMMERLI, Zum Problem der "Mitte des Alten Testamentes", EvT 35 (1975) 97-118. 


\section{VERZEICHNIS DER BIBELSTELLEN}

\section{Genesis}

1,26

3,1

3,9

3,22

4,1

4,10

6,5

$9,1.8 .12 .17$

9,8-17

11,5

11,7

12

12,1

$12,2 \mathrm{f}$

12,7

12,19

15,1

$15,2 f \quad 42 \mathrm{ff}, 118,120$

15,5

15,7

15,14

15,17

$15,19-21$

16,1

$16,6 f$

$16,9-11$ 42ff, $119 f$

$\begin{array}{rr}16,13 & 220 \\ 16,17 & 118 f\end{array}$

16,17

17

17,1

$17,3.9$

$17,9-14$

17,14

17,15

17,17

$18,1 \mathrm{f}$

18,13 ff $157 f, 220$

$18,2125,125,128$,

19,9

$20,9 f$

20,13

21 117, 119f, 122

21,1

21,14 ff 116,118

$21,17 \quad 104,118 \mathrm{ff}$

22 116f, 120,220

$22,1 \quad 104,120$

$22,1.11 \quad 13,69,108$

22,11 105f, 120, 220
$22,14107,110,118 f$

$22,17 f \quad 107,220$

24

24,1

24,3

24,12

$24,24 \mathrm{f}$

$24,37-44$

24,53

25,3

25,20

26,1

$26,3 f$

26,20

$26,24 f$

27,1

27,36

28,9

28,11

$28,12 \mathrm{f}$

28,14

28,15

28,16

28, 17ff

28,17

$28,20 f$

$29,31 \mathrm{f}$

$30,6.22$

31,3 ff

31,11

31,13

31,14 ff

$31,42.53$

$31,44.48 .51$

32

32, 22-33

32,30

$34,14-16$

$35,1.3$

$35,10 \mathrm{f}$

35,14

35,18

37

37, 7-10

$37,21 \mathrm{f}$

38,15

39,1

39,21

$41,39.41$

$41,25.51$

$42,1 \mathrm{f}$

42,28

42,35

43,1

167

132

224

116

220

159

110,112 ,

120,217

13,108

$42 f$

224

116

112,119 ,

212,217

220

213, 220

110

206

114,120

119,132

70,220

220

220

13,104 ,

$108,119 f$

119,220

159

112

206

$32,34,112$

32ff, 135

220

159

220

120

110

148

108,212

159

42ff

71

217, 222

$42 \mathrm{ff}$

220

$42 \mathrm{ff}$

220

69

22
43,23

44.30 .33

112

$45,4 \quad 138$

$45,5.8 \quad 73$

$45,7 f \quad 129,220$

45,9

46

$158 \quad 46,2 \mathrm{f} \quad 13,105 \mathrm{ff}$

$108,110,112$,

$120,217,220 \mathrm{f}$

$46,4107,217,220$

$47,3 f \quad 42 \mathrm{ff}$

48,3

220

$48,15 f \quad 112,119$

$48,21 \quad 220$

$49,25 f \quad 112,220$

$50 \quad 68,156$

$50,17 \quad 112,138$

$50,24112,156,220$

Exodus

$126 f, 29,55$, $99,119,124,127$, $156,185,204$

$1,1-2,22$

$1,1-7$

27

$1,1 \quad 22,27$

$1,6 \mathrm{ff}$

27,141

1,9

$14,27,124$,

$1,13 f$

217

1,15

27,128

$1,15 f$

27

1,17

$1,20 f$

$2 \quad 25-28,55,124$

$127,156,185,204$

$2,1-10$

$2,11-15 \quad 211,234$

$2,11-22 \quad 222$

$2,1121,69,103$,

$2,13 \quad 188$

$2,14 f 129,131,234$

$2,16-22$

2,18

2,22

28,71

148,188

2,23-25 21f, 27f,

$2,23 \quad 21,27,28$,

35,129

$2,24 f \quad 55,69,112$,

123,142

$2,2511,22 f, 26 f$, 
(Exodus)

24f, 27,37

$49,51,73,107$, $118,122,182$, 207-211, 214f, $217,221,227$

3,1-6 85ff, 99ff,

3,1-9 69ff

3,1 21ff, 25, 28 ,

$3,299 f, 215,230$

$3,2 \mathrm{f}$

3,3

3,4

3,5

3,6

$3,7-12$

3,7

3,8

$3,9 f$

3,9

$3,10-22$

3,10

3,11

3,12

3,13-15 208, 214f

$88 f, 134 f f$,

$3,13 \quad 134 \mathrm{ff}, \begin{array}{r}144 \mathrm{ff} \\ 229 \mathrm{f}\end{array}$

$3,14 \quad 41,137 f f$,

$147 f f, 227$

$3,1541,48,139 \mathrm{ff}$,

205ff, 218

3,16-22 83f, 89ff,

$154 \mathrm{ff}, 169 \mathrm{ff}$
$3,16 \quad 59,154 \mathrm{ff}$

$3,16 f$

3,17

3,18

214f, 217, 219

3,19

3,20

3,21

$3,21 \mathrm{f}$

3,22 24, 166ff, 202
$4,24 f, 28 f, 32,34$, $37,55,169 \mathrm{f}, 192$,

4,1-9 76ff, 84, $91 \mathrm{ff}$

$171 \mathrm{ff}, 181 \mathrm{ff}$
$4,1 \quad 171 \mathrm{f}, 229 \mathrm{f}$

$4,2 \quad 63,172 f$

4,3

$4,3 \mathrm{ff}$

4,4

4,5

4,6

$4,6 f$

$163 f f$

215,232

$174 f$

$175 f$

$41,176 f$

215
4,7

4,8

178

4,9

$179 f$

4,10-17 79ff, 84,

93f, 184ff, $200 f$

$4,10 \quad 81,185 f f$,

4,11 192ff, 214,

$4,12 \quad 59,194 f$

$4,1365,195 f, 202$,

$4,14 \quad 46,57,65$,

4,15

$196 f$

$4,15 f f$

198

4,16

$23 f$

4,17 23ff, $199 f$

4,18 23ff, 28f, 31

$35,48,50,58,61$ $63,103186,204$

$4,18 \mathrm{ff}$

29ff, 54

$4,18 \ldots 31$

23,156 ,

$174,180,183$

$188,204,223$

$\begin{array}{lll}4,19 & 34 f, 129\end{array}$

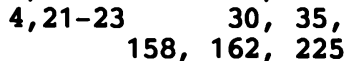

$4,24,35$

4,24-26 30, 32ff,

4,26

4,27

35,196

4,29

30,34

$4,29-13,9$

29,35

155

5 ff 54f, 162, 189

5,1 ff $160 f, 170$, 188,

$\begin{array}{ll}5,4 f & 204,218 \\ & 42 f f, 65\end{array}$

$5,7 f .14 \quad 187$

$5,22 f$

6,1
$6,2-8$

29

$29,162,223$

6,2

6,5

6,9

$170,223 f$

137,145

$6,12.30$

189,191

6,13

$6,19.25$

$18,189 \mathrm{ff}$,

201,204

$6,28 f$

189

$7 . .14 \quad 162-170,232$

7

7,1 ff

$\begin{array}{ll}7,14.19 & 42\end{array}$
$4,3123,172,204$

$145 \quad 189 \mathrm{f}$

7,16

188,217

7,18

8,1

$8,9.27$

188

$8,12.16$

34

8,23

188

9,1

9,3

$9,6.25$

$188,198,217$

9,13

10,2

$10,19.28$

160

10,3

163
34

34
217

$11164,167,170$

$11,3 \quad 165,213$

$11,4 f$

12

$34,109,124$, $146,163,168 \mathrm{ff}$,

195, 206f, 209f

$12,35 \mathrm{f} \quad 165 \mathrm{ff}, 214$

$12,37 f \quad 124,160$

12,41

12,43

19
190

13,3

188

13,5

126

13,8f.14.16 162, 206

$13,17 f \quad 145,157$

$13,19 f \quad 156,160$

$13,21 \quad 119,213$

$1427,160,211$,

$14 f \quad 181$

$14,19 \quad 119$

$14,3168,162,185$

$1599,160,170$,

188,195

$16,15 f .32 \quad 206$

$17,14 \quad 142,206$

$1828,119,204$

$18,19 \quad 198$

$19101,119 f, 125$ $133,138,166$

$19,12 \mathrm{f} 108,120,215$

20

20,2

20,18

29

20,22

$21,29.36$

22,25

23,8

23,15

23,21

$23,23,28$

$24,16 f \quad 103,120$

$25,1-30,10 \quad 46$

$25,1 \quad 42$

27,20

$28,1 \quad 22$

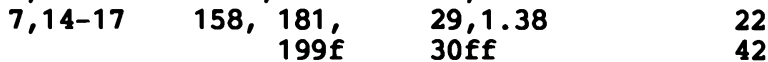

31,12-17 206, 209f 


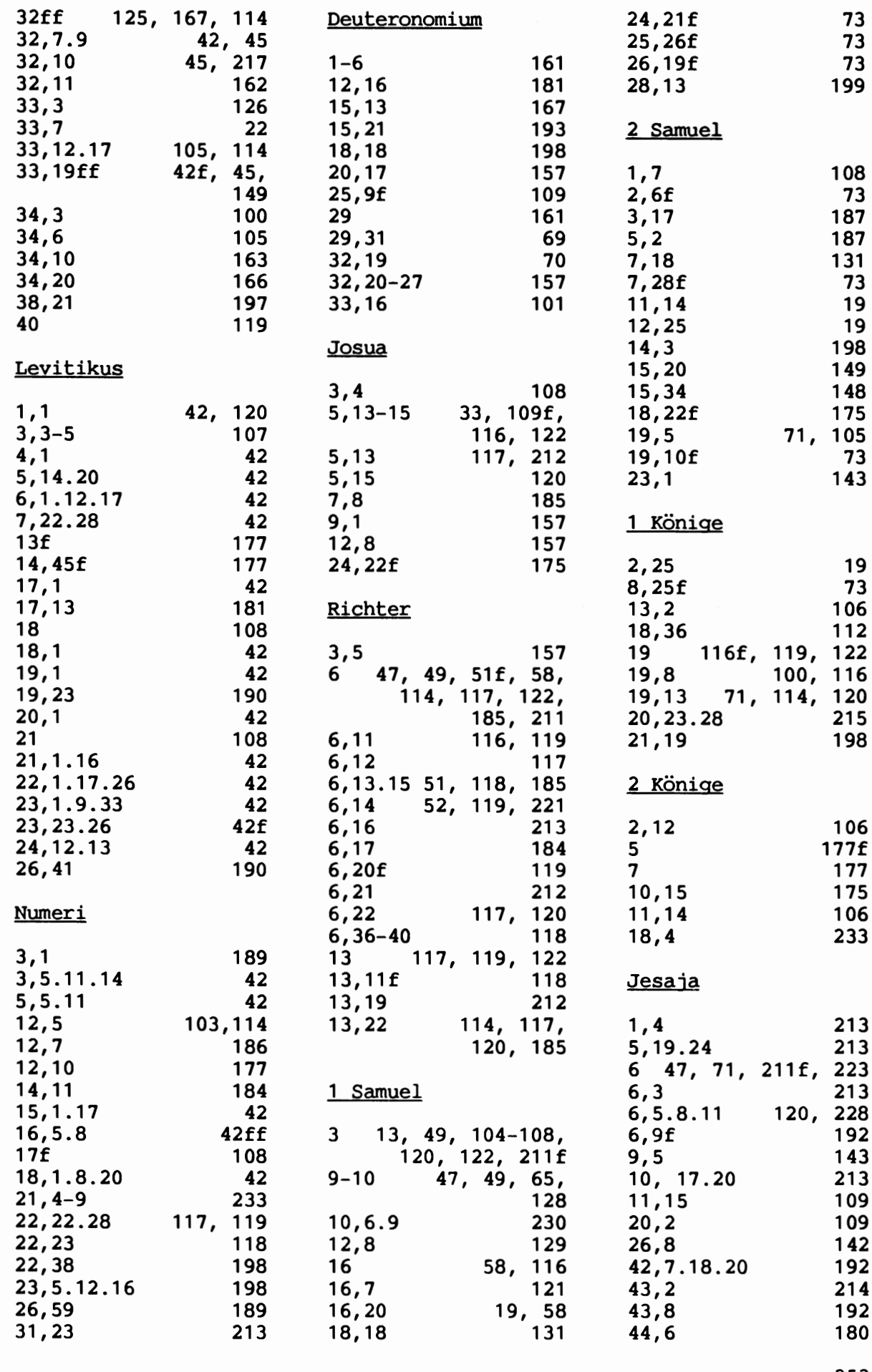




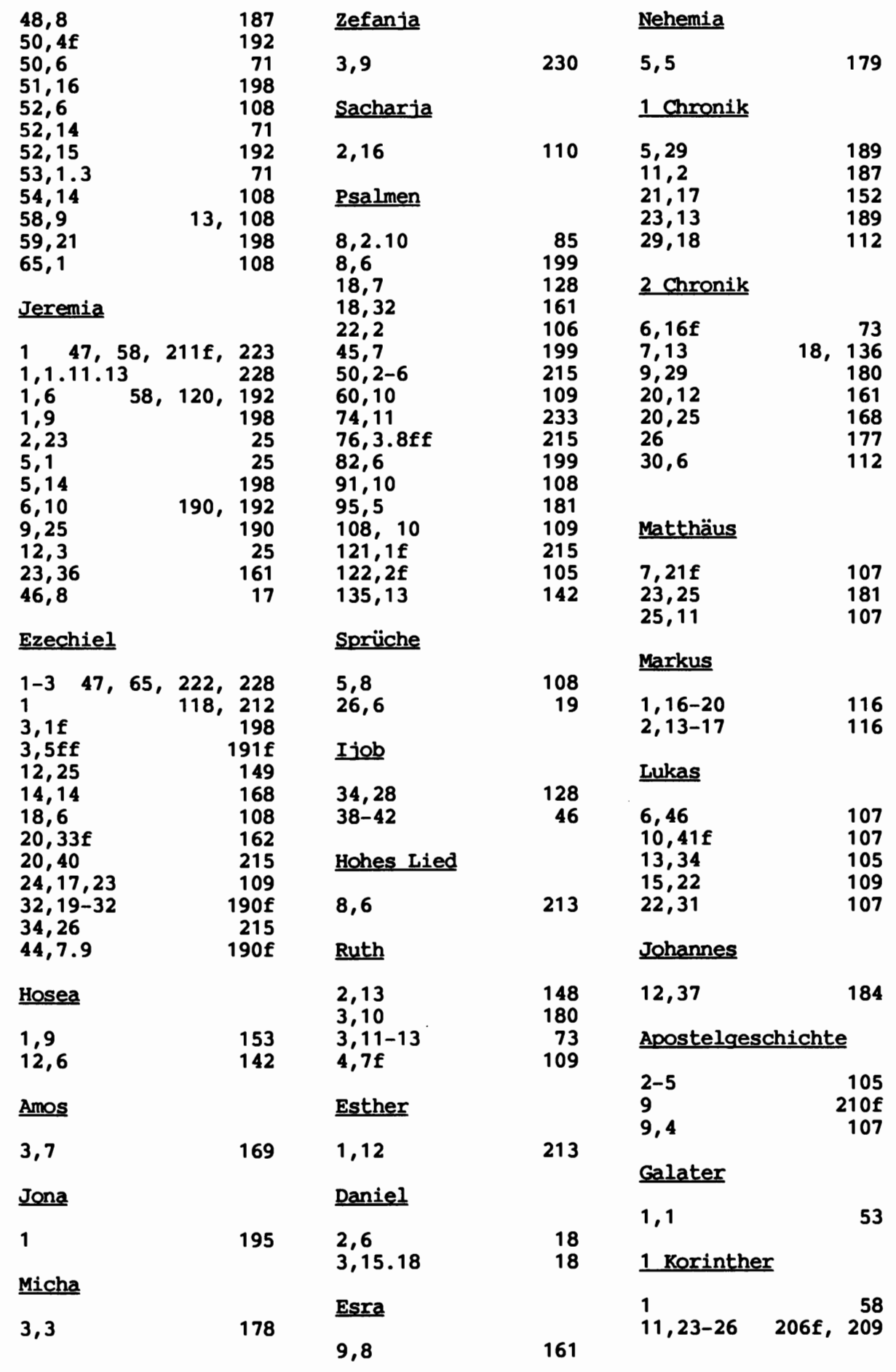


M.H. ABRAMS

R. ALBERTZ

M. ALLARD

151

L. ALONSO SCHÖKEL 70, 102, 109,

A. ALT

143

R. ALTER $38 f, 47$

G. ANDRE

ANGELUS SILESIUS

$16,75,156$

ARISTOTELES

G. AUZOU

B. BAENTSCH

S.E. BALENTINE

S. BARNET

R. BARTELMUS

$15,148,150,153$

C. BARTH

160

W. BAUMGARTNER

13

P. BEAUCHAMP

98

J. BECKER

M.A. BEEK

G. BEER

A. BERLIN

A.M. BESNARD

$21,23,133$

$21,23,104$

71

22

O.F. BEST

A. BESTERS

$117,127,133,137$

J. BETZ

205

J. BLAU

20

w.C. BOOTH

P. BOVATI

M. BUBER

F. BUHL

R.J. BURNS

38,46

$25,125,128$

$97,135,140,154$

$12,13,17,19,93$,

$110,165,187,190$

$21,23,147,184$,

196

U. CASSUTO 3, 21, 23, 135, 226

H. CAZELLES

143

J. CHEVALIER
B.S. CHILDS 3, 15, 18, 21, 23, $26 f, 66,68,100,132$, $135,140,146,168,229$

R.E. CLEMENTS

D.J.A. CLINES

$126,216,220$

G.W. COATS

$64,99,133$

C. CONROY

$5,41,113,175$

B. COSTACURTA

114

B. COUROYER

21

A.G. van DAALEN 104, 130, 136

M.K. DANZIGER

64

D. DAUBE

G.H. DAVIES

$129,165 f f$

H. DONNER

S.R. DRIVER

A. -M. DUBARLE

219,234

21,23

148

G. DURAND

$214 f$

E. EBELING

126

ECHNATON

225

W. EGGER

4

H.L. ELLISON

23, 188, 195

H. ENGET

159

A. EVEN-SHOSHAN $18,100,161$

H. -J. FABRY

159

H. FETD

205

J. FELIKS

101

M. FISHBANE $21,23,30,32,34$

J.P. FLOSS

160

G. FOHRER

189

J.P. FOKKELMANN

102,135

E. FOX

100,213

D.N. FREEDMAN

$13,119,140$,

159,227

S. FRENSDORFF

126,157

T.E. FRETHEIM

$212 f$

H. FREY

21

G. FREYTAG 
T.S. FRYMER

w. FUSS

A. GAMPER

H. GARTE

A. GELIN

S.A. GELLER

111,124

6,215

115

234

$30,34 f$

พ. GESENIUS 12-17, 19, 22, 93, $110,165,187,190,195$

P. GIBERT

$210 f$

B. GLADIGOW

105

K. GOUDERS

$37,47,115,222$

M. GREENBERG

$3,21,23,73$,

$100,105,109,113$,

$132 f, 135,145,151$,

$157,160,188,213$

GREGOR vOn NYSSA

213

H. GRESSMANN

$3,21,109$

H.J. GRIMMELSMANN

23

W. GROSS

20, 197

D. GUTZEN

4, 212

E. HAAG

225

N. HABEL

$24,37,47,53,99$

J. HALBE

125f, 128

E.J. HAMLIN

$18,175,182,233$

C. HARDMEIER

50

J.H. HAYES

37

P. HEINISCH

S. HERRMANN

21,23

234

J.K. HOFFMEIER

162

H. HOLZINGER

21

E. HORNUNG

152

C. HOUTMAN

F.D. HUBMANN

30,33

53,222

21,23

F. HUMMETLAUER

J.P. HYATT

D. IRVIN

$21,23,146$

T. ISHIDA

$37,53-58,215$

B. JACOB

126

$3,15,25,29,35$,

$105,114,126,129$,

$135,137 f, 150,223$

R. JACOBSON
G. JÄGER

J.G. JANZEN

$132,137,139$

K. JAROS

101

R. JEHOSHUA

196

JOachim JEREMIAS 205

JÖrg JEREMIAS 116

R. JOSE 196

P. JOÜON

12-15, 17-20, 22, $131,151,159,193,225$

E. JÜNGEL

219

C. KAHRMANN

38,46

E. KAUTZSCH

12, 14-16, 22, 195

O. KEEL

$6,126,143,215$, 219,225

C.F. KEIL

J. KINYONGO

135

E.A. KNAUF

146,227

R. KÖBERT

227

L. KÖHIERR

13

E. KÖNIG

12

F. KOHATA

$105,125,141$

C. KUHL

189

R. LABAT

226

C.J. LABUSCHAGNE

$18,119,157$

S.T. LACHS

193

W.G. LAMBERT

225

E. LÄMMERT

$4,22,34 f, 39$,

65,115

B. L.ANG

225

B. LAWTON

6

X. LEON-DUFOUR

205

C. LEVIN

28

J. LINDBLOM

151

F. LINDSTRÖM

$30,32-34$

N. LOHFINK

$6,69,124,126$,

$132,152,223$

B.O. LONG

222

O. LORETZ

$20,159,197$

M. LURKER 101, 109, 215, 232

J. MAGONET 73, 102, 115, 126, $130,143,157,205,223$ 
B. de MARGERIE 160

C.M. MARTINI

H.G. MAY

112,136

G. MAYER

125

W. MAYER

41

D.J. MCCARTHY $6,70,102,127$, $151,170,205$

J. MAXWELL MILLER

R. MEYER

$12,14,99,225$

F. MICHAELI

$21,23,151$

P. MILLER

159

R. MOSIS

J.A. MOTYER

124

G. MÜLLER

H. -P. MÜLLER

T. MURAOKA

A. MURTONEN

E. NEUFELD

A. NICCACCI

NIKOLAUS vOn KUES

M. NOTH

P. O'CONNOR

J. OESCH

A. OHIMEYER

G. del OLMO LETE

J. van OORSCHOT

J.J. O'ROURKE

J. OSING

G.H. PARKE-TAYLOR

R. PESCH

J. PLASTARAS

K. PLÖTZ

H.D. PREUSS

P. PROULX

R. de PURY

H. QUECKE

L.I. RABINOWITZ

G. von RAD

Y.T. RADDAY

H. RAND

$135,137,145$

22

219

123

146

126

149,152

214

21,23

140,227

$23 f$

109

$48,50,114$

46

154,230

152

142,208

205

125

84

129

109,174

21,23

152

126

26,208

$17,135,141$,

$165,167 \mathrm{f}$
RASCHI

$$
100 f, 141,167,175 \text {, }
$$
177f, 196, 199

D.B. REDFORD

26

B. RENAUD

98

R. RENDTORFF

117

W. RICHTER

$3 f, 37,47,49$,

129,132

H. RINGGREN

109,226

F. RITZHAUPT

215

G. ROEDER

152

M. ROSE

140

M. ROSENBAUM

129

F. ROSENZWEIG

$15,135,137$,
H. SADAKATA

$140,154,218,227$

M. SAEB $\varnothing$

N.M. SARNA

140,153

G. SAUER

J. SCHARBERT

E. SCHILD

H. SCHMID

R. SCHMID

พ.H. SCHMIDT

$19,21,23,25 f, 28,37$, $49,66,97,100,103-105$, $136 f, 140,193,195,197$,

218f, 225

H. SCHNEIDER

21,23

W. SCHNEIDER

14

F. SCHNUTENHAUS

116

A. SCHOTT

41

w. SCHOTTROFF

H. SCHÜRMANN

76,156

H. SCHWEIZER

205

H. SEEBASS

23

J. SEVERINO CROATTO

219

209

A.M. SILBERMANN

129

H. SIMIAN-YOFRE 6, 71, 173, 232

J.L. SKA $6,27,32,164,180$,

205,223

30

41,225 
F. SONNEK

E.A. SPEISER

148

. STACY JOHNSON

64

F.K. STANZEL

$4,38,65,173 f$

S.Ö. STEINGRIMSSON

170

H. -J. STIPP

175

K. STOCK

F. STOLZ

G. TE STROETE

S. TALMON

THEODORET

R.C. THOMPSON

J.H. TIGAY

A. TOSATO

H. USENER

H. VALENTIN

A. VANHOYE

R. de VAUX
D. VETTER

D. VIEWEGER

221

J. VOGT

$4,22,50,65$

S.Ph. de VRIES

83

B.N. WAMBACQ

137

P. WEIMAR $3,26 f, 41,49,56$, $66,97,111 \mathrm{f}$

\section{J. WEISS}

21,23

J. WELLHAUSEN

27, 104, 146

C. WESTERMANN

$26,116,212$

R.N. WHYBRAY

41,203

G. WIDENGREN

234

H. WILDBERGER

143

B.E.WILLOUGKBY

119,159

N. WYATT

$112,133,137$

E.J. YOUNG

105,214

E. ZENGER

$6,21,23,219$

พ. ZIMMERLI

\section{STICHWORTREGISTER}

Abfolge $49 f, 52,56 f, 67,81$, 167,184

Ablehnung $52,60,195 f, 201$, 222

Abstand $42 f, 45$

Abwesenheit (Gottes)

26

Alliteration 102, 113, 123, 138

Allwissenheit

asynetisch

16,113

Außenperspektive

174

174

Außensicht $38,57,68,81,83 f$, 97, $201 \mathrm{ff}, 205$

Aufbaumuster

60

Aussprechen (des Gottesnamens)

$$
142 \text {, 208f }
$$

Autor
Autorität $145,182 \mathrm{f}, 198,218$, $230,232,234$

Befähigung $\quad 58,129,228$ Begehren 58ff, 67

Beginn (der Einheit) 21ff, 230

Berufung $66 f, 116,216$, $221 \mathrm{ff}, 234$

Berufungsbericht $37 f, 51,65$, $115,121,216,221$ Berufungsschema 47-50, 53, 55f, $66 f, 205$

Betroffenheit, emotionale 43f, 127, 137f, 183

Bild $83 . .100$

biographisch 50

Blickpunkt 115,135

Blickrichtung 224

Blickwinkel 70,74 
$\begin{array}{lr}\text { Boden, heiliger } & \begin{array}{r}105,109 f, \\ 203,231\end{array} \\ \text { Bote (Engel) } & 116 f, 119,210, \\ & 212,216 \\ \text { Bruch 22, 26f, 40, 72, 182, } 216 \\ \text { Chiasmus } \\ \text { Crescendo } \\ \text { Defektivbildung } \\ \text { Demut } \\ \text { Deuteschlüssel }\end{array}$

Dialog 22, 25, 31, 35, 38f, $45 f f, 63,97,182$, $202,211,226$

Dialogregie

174

Distanz 110, 136, 172, 185, 231 Doppelaufgabe

221

Doppeldeutigkeit $35,135,142 \mathrm{f}$, $149,153,156,162$, $165,168,202,232$

vieldeutig

183

doppelt $\quad 70,75,89,105-108$, $144,150,155 f$

Doppelung 48, 115, 138, 167f, $195,199,201,203$

Verdoppelung $51,105,134$, 233

drei Tage $160 f$

Ebenen, zwei (oder mehr) 48, 102,153

des Begehrens 59-64, 67, 74 des Gesprächs 136

des Textverständnisses 146

der zitate 155f, 171, 203 Echo

Einheit (der Menschen) 132, $159,216,219 f, 227$

Einheit, literarische 3ff, 21 ,

$$
37,65,67,72 \text {, }
$$$$
84,94,96 f, 202
$$

Einheiten, drei

22,24
Einsetzungsbericht

142,145 , 205-210, 226

elliptisch

151

Ende (einer Einheit) 23ff, 97,

202, 230

Entwicklung

$38,70,73,74$, $77,80,114,147$, 202ff, 220, 229f

Epiphanie 116

Erwartung

$21,27,29,105$

Erwählen des Kleinen

58

Erzählbewegung

101,111 , 181,186

Erzähler 31, 38, 44, 63, 76, $89,99,113,134,173,175$, $177,181,202,212,224$

zurücktreten

46,173

Erzählfolge 102,111

Erzählsituation (auktoriale)

Erzähltechnik 26, 34, 99, 133, $158,171,202 \mathrm{f}$

Erzählung $36,38,53,65,68$, 101,202

Erzählungstyp 33, 53 Erzählzeit 22, 39 Etymologie $140,147 f, 188,234$ Familie 30f, $224 f$ Fehleinschätzung 191f, 201 Fehlen 49, 130f, 170, 229 Feld (semantisches) 67...83, $91,96,98 f, 115$, $129,172,177$

Figuren, erzählte 38, 65 Form 5, 37f, 50, 58, 67f, $98,201 f, 205$

Freiheit Gottes $\quad 154$ Gegenangriff 172

Gegensatz

$46,90,188,193$, 214ff, 222, 228

Gegensätze überwinden 214, 216 
Geschichte

$50,147,169$,

220,227

historisch

122

Gesichtspunkt

$48,81,84$,

$112,202 f$

Gewebetechnik

Gleichsetzungstheologie

225

Gleichung

$139,144,159$

Gliederung

$3,22,55 f, 68$,

$83,85,91,98$

"Gott" für Menschen 199, 230, 234

Gottesbild

216,228

Grenze

$88,96 f, 183$

Handlung

Handlungselement

$64,86,112$

$54 \mathrm{f}$

harmonisieren

104,214

Hinhaltetaktik

57

Höhepunkt 64f, 106, 143, $159 \mathrm{f}$ Hörer/Leser $\quad 66,69,86,102$, $123,134,144 f, 160,173,175$, $177,181,212,218,221$

Identifizierung 100f, 104, 124, $126 \mathrm{ff}, 130 \mathrm{f}, 140,146$, $150,159,171,186$

Identifizierungsproze $B \quad 134$, $202 f$

Identität $117,124,143,146$, 218f, 226, 234

Information

$24,99,129$

Informationswert

$23 f, 87$

zusatzinformation

218

Inhalt - Form

$42,67 f$

Inklusion

88,92

Inszenierung

$86 f, 114,123$

Szene

$91,115,122$

kohärent $3,156,168,182,201$

Kombination $90,112,117,130$,

$139,181,217$
Kommunikation

Kommunikationsniveau 38,46

Kontaktaufnahme $13,85,119$

Isolation

177

Komposition

$25,29,36,66$,

$84,94,96 f, 147,222 f$

Konflikt $\quad 38,58 f, 63,66 f$, $90 f, 125,128,182$

Konstruktion 22, 35, 71, 92, $95,99,112,128,134$, $137,145,148 f, 150$, $152,180,190,198$ Kontext 42ff, 71, 107, 109, $127,133,137,149,168$, $176,186,189,191$, $195,208,214,223$

Kontrast $87,102 \mathrm{ff}, 127,134$, 179f, 193, 201

Konvention (literarische) 5, 56, $142,205-210,213,216$ konzentrisch $98,130,134$ Kriterium 21f, 37, 42, 67f, $83 f, 97,104$

Lebensbedrohung $30,32 \mathrm{f}, 175$, $183,215,233$

Legitimierung $37,53,58,145 f$, $161,221 \mathrm{f}$

Locken (Gottes) 231

Merismus 180

Mittelbarkeit $\quad 65$

Monotheismus $\quad 5,56,155,219$, 225,228

Nachtrag 25, 29, 35, 223

Nähe zu Gott 45, 199, 206-209,

Name, doppelter 105-108

Name $\quad 75,88,104,108,117$, $120,135 \ldots 146,153,156$ 170, 199, 206-210, 218 $223,226,234$ 
neutral

$125,129,157,214$

offen $26,34,106,124,127$, $130,133,150,152 \mathrm{f}, 158$, $162 f, 172,181,223$

Ort 22, 24, 28, 32, 69, 85ff, $100 f, 104,109 f, 116,120$, $133,160,205,211,215$

Paradox

$13,57 f, 117 f$

Parallelismus

$90,102,141$

paronomastischer Relativsatz

15, 149ff

Perspektive 101

Doppelperspektive

117,146

Perspektivenwechsel

$102 \mathrm{f}$

Polytheismus

146,225

Programm

5,161

Projektion

146,200

Quellen

$3 f, 24,41,48 f, 65$,

97, 104, 201

Rahmen 76, 85, 87, 94, 170, 200

Randtexte

$36 f$

Redaktion

$3,28,36,41,84$, $97,104,111,203,219,223$

Redeanteil

39

Redeeinleitung 15, 39f, 69, 89, 115, 135ff, 142-145, $171,184 f, 203,224$ fehlende $\quad 40 f, 175 f, 179$, $182,203,232$

wiederholte $40-46,66,89$, $111,120,137,139,154,176$ redundant 199

Reihe

$85 \ldots 98$

Reihenfolge $52,54,56 f, 81$, 111,189

Reim 90,141

Rhetorik 179, 192f, 197, 228

Rhythmus

$13,28,99,143$, $175 f, 178$

Rückwendung

Rufen

$103 f, 119 f$
Sandalen ausziehen 108f, 120, 231

Schema 49ff, 57, 65, 184, 205

Schlußsignal

$83 . .97$

ScheinschluB

176

Schlüsselverben $72,74 \mathrm{ff}, 80$, $98,154,167,172,174$ Schlüsselwörter $73,80,82,88$, 93f, 115, 131, 134, 142, 177 Schweigen des Mose 45, 47, 169,182

Serie

$85 \ldots 98$

singulär $16,121,203$

Souveränität Gottes 34,182 , $227 f$

Spannung $3,21,31,34,59$, $64-67,74,100,103,127$, $156,174,201$

Aufbau der Spannung 21, 31,

Standpunkt 101

Stichwort 60

Stoff 50

Symbol

$160,175,228,232 f$

synchron

4

Tempo

$39,77,174$

Testament

145

Thema $43,73,79,81,97,135$, $160,171,192,204$

Theophanie 116, 133, 212f übergang $25,27 f, 35 f, 43,73$, $76,171,185$

Übergangsritus $32 f$ überraschung 106, 177 Überton 166, 177 Umstellung, Umkehrung 51f, 111 , $157,167,182,186$

Unfähigkeit (des Mose) 64, 80, $186-194,201,233$

Unwille 195f, $200 f$ Unwissenheit 110, 129, 134, 136 


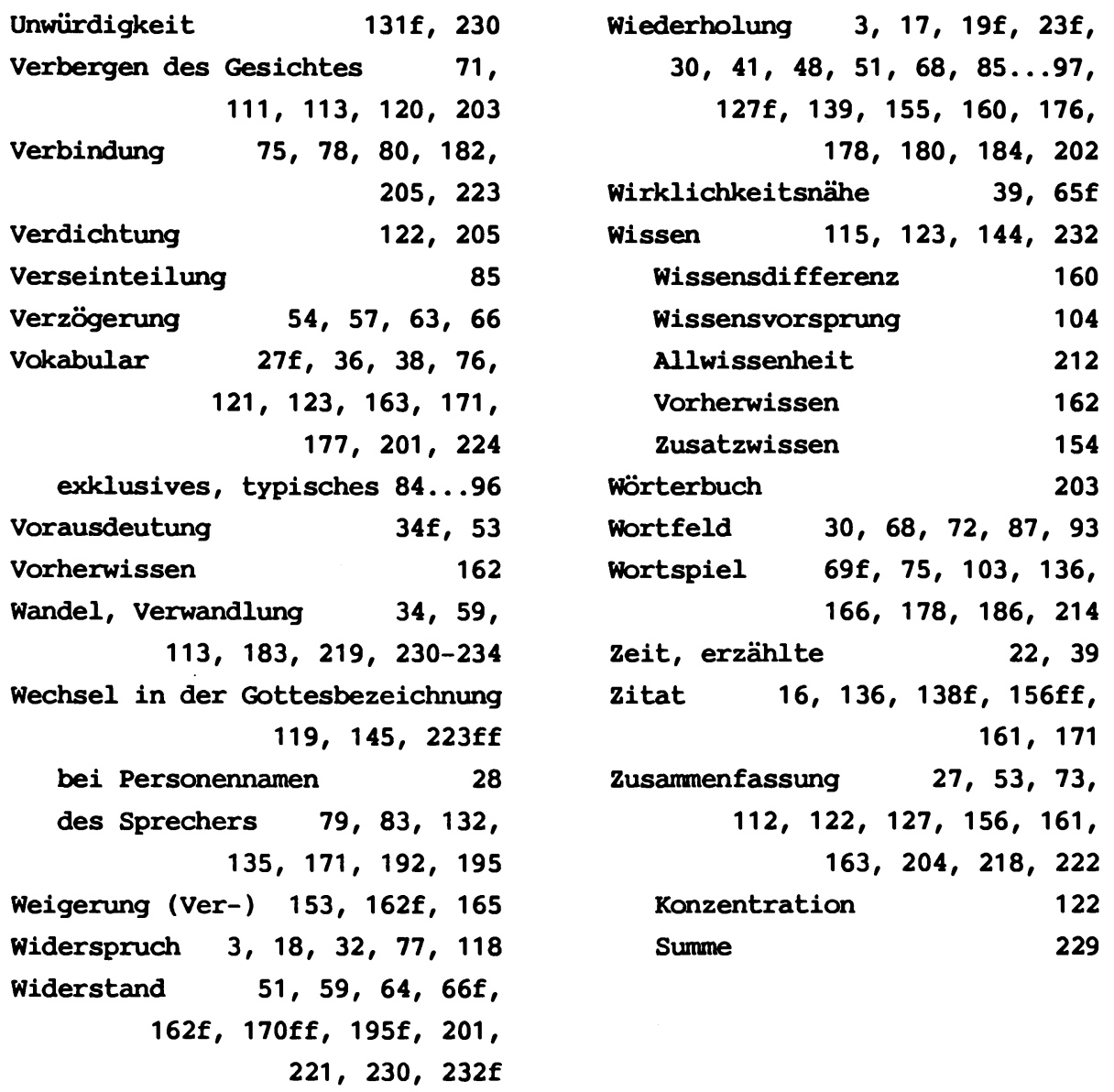


Bd. 1 OTTO RICKENBACHER: Weisheitsperikopen bei Ben Sira. X-214-15* Seiten. 1973. Vergriffen.

Bd. 2 FRANZ SCHNIDER: Jesus der Prophet. 298 Seiten. 1973. Vergriffen.

Bd. 3 PAUL ZINGG: Das Wachsen der Kirche. Beiträge zur Frage der lukanischen Redaktion und Theologic. 345 Seiten. 1974. Vergriffen.

Bd. 4 KARL JAROŠ: Die Stellung des Elobisten zur kanaanäischen Religion. 294 Seiten, 12 Abbildungen. 1982. 2. verbesserte und uberarbeitete Auflage.

Bd. 5 OTHMAR KEEL: Wirkmäcbtige Siegeszeichen im Alten Testament. Ikonographische Studien zu Jos 8, 18-26; Ex 17, 8-13; 2 Kön 13, 14-19 und 1 Kön 22, 11. 232 Seiten, 78 Abbildungen. 1974. Vergriffen.

Bd. 6 VITUS HUONDER: Israel Sobn Gottes. Zur Deutung eines alttestamentlichen Themas in der jüdischen Exegese des Mittelalters. 231 Seiten. 1975.

Bd. 7 RAINER SCHMITT: Exodus und Passa. Ibr Zusammenhang im Alten Testament. 124 Seiten. 1982. 2. neubearbeitete Auflage.

Bd. 8 ADRIAN SCHENKER: Hexaplarische Psalmenbruchstücke. Die hexaplarischen Psalmenfragmente der Handschriften Vaticanus graecus 752 und Canonicianus graecus 62. Einleitung, Ausgabe, Erläuterung. XXVIII-446 Seiten. 1975.

Bd. 9 BEAT ZUBER: Vier Studien zu den Ursprüngen Israels. Die Sinaifrage und Probleme der Volks- und Traditionsbildung. 152 Seiten. 1976. Vergriffen.

Bd. 10 EDUARDO ARENS: The $\mathrm{H} \Lambda \Theta O N$-Sayings in the Synoptic Tradition. A Historico-critical Investigation. 370 Seiten. 1976.

Bd. 11 KARL JAROŠ: Sichem. Eine archäologische und religionsgeschichtliche Studie, mit beson derer Berücksichtigung von Jos 24. 280 Seiten, 193 Abbildungen. 1976.

Bd. 11a KARL JAROŠ /BRIGITTE DECKERT: Studien zur Sichem-Area. 81 Seiten, 23 Abbildungen. 1977.

Bd. 12 WALTER BÜHLMANN: Vom recbten Reden und Schweigen. Studien zu Proverbien 10-31. 371 Seiten. 1976.

Bd. 13 IVO MEYER: Jeremia und die falschen Propheten. 155 Seiten. 1977. Vergriffen.

Bd. 14 OTHMAR KEEL: Vögel als Boten. Studien zu Ps 68, 12-14, Gen 8, 6-12, Koh 10, 20 und dem Aussenden von Botenvögeln in Ägypten. - Mit einem Beitrag von Urs Winter zu Ps 56, 1 und zur Ikonographie der Göttin mit der Taube. 164 Seiten, 44 Abbildungen. 1977.

Bd. 15 MARIE-LOUISE GUBLER: Die frübesten Deutungen des Todes Jesu. Eine motivgeschichtliche Darstellung aufgrund der neueren exegetischen Forschung. XVI-424 Seiten. 1977. Vergriffen.

Bd. 16 JEAN ZUMSTEIN: La condition du croyant dans l'Evangile selon Mattbieu. 467 pages. 1977. Epuisé.

Bd. 17 FRANZ SCHNIDER: Die verlorenen Söhne. Strukturanalytische und historisch-kritische Untersuchungen zu Lk 15. 105 Seiten. 1977.

Bd. 18 HEINRICH VALENTIN: Aaron. Eine Studie zur vor-priesterschriftlichen Aaron-Überlieferung. VIII-441 Seiten. 1978. 
Bd. 19 MASSÉO CALOZ: Etude sur la LXX origénienne du Psautier. Les relations entre les leçons des Psaumes du Manuscrit Coislin 44, les Fragments des Hexaples et le texte du Psautier Gallican. 480 pages. 1978.

Bd. 20 RAPHAEL GIVEON: The Impact of Egypt on Canaan. Iconographical and Related Studies. 156 Seiten, 73 Abbildungen. 1978.

Bd. 21 DOMINIQUE BARTHÉLEMY: Etudes d'bistoire du texte de l'Ancien Testament. XXV419 pages. 1978 . Vergriffen.

Bd. 22/1 CESLAS SPICQ: Notes de Lexicographie néo-testamentaire. Tome I: p. 1-524. 1978. Epuisé.

Bd. 22/2 CESLAS SPICQ: Notes de Lexicographie néo-testamentaire. Tome II: p. 525-980. 1978. Epuisé.

Bd. 22/3 CESLAS SPICQ: Notes de Lexicographie néo-testamentaire. Supplément. 698 pages. 1982.

Bd. 23 BRIAN M. NOLAN: The Royal Son of God. The Christology of Matthew 1-2 in the Setting of the Gospel. 282 Seiten. 1979.

Bd. 24 KLAUS KIESOW: Exodustexte im Jesajabuch. Literarkritische und motivgeschichtliche Analysen. 221 Seiten. 1979. Vergriffen.

Bd. 25/1 MICHAEL LATTKE: Die Oden Salomos in ibrer Bedeutung für Neues Testament und Gnosis. Band I. Ausführliche Handschriftenbeschreibung. Edition mit deutscher Parallel-Übersetzung. Hermeneutischer Anhang zur gnostischen Interpretation der Oden Salomos in der Pistis Sophia. XI-237 Seiten. 1979.

Bd. 25/1a MICHAEL LATTKE: Die Oden Salomos in ibrer Bedeutung für Neues Testament und Gnoisis. Band 1a. Der syrische Text der Edition in Estrangela Faksimile des griechischen Papyrus Bodmer XI. 68 Seiten. 1980.

Bd. 25/2 MICHAEL LATTKE: Die Oden Salomos in ibrer Bedeutung für Neues Testament und Gnosis. Band II. Vollständige Wortkonkordanz zur handschriftlichen, gxiechischen, koptischen, lateinischen und syrischen Überlieferung der Oden Salomos. Mit einem Faksimile des Kodex N. XVI-201 Seiten. 1979.

Bd. 25/3 MICHAEL LATTKE: Die Oden Salomos in ibrer Bedeutung für Neues Testament und Gnosis. Band III. XXXIV-478 Seiten. 1986.

Bd. 26 MAX KÜCHLER: Frübjüdische Weisheitstraditionen. Zum Fortgang weisheitlichen Denkens im Bereich des frühjüdischen Jahweglaubens. 703 Seiten. 1979. Vergriffen.

Bd. 27 JOSEF M. OESCH: Petucha und Setuma. Untersuchungen zu einer überlieferten Gliederung im hebräischen Text des Alten Testaments. XX-392-37* Seiten. 1979.

Bd. 28 ERIK HORNUNG/OTHMAR KEEL (Herausgeber): Studien zu altägyptiscben Lebenslebren. 394 Seiten. 1979.

Bd. 29 HERMANN ALEXANDER SCHLÖGL: Der Gott Tatenen. Nach Texten und Bildern des Neuen Reiches. 216 Seiten, 14 Abbildungen. 1980.

Bd. 30 JOHANN JAKOB STAMM: Beiträge zur Hebräischen und Altorientalischen Namenkunde. XVI264 Seiten. 1980.

Bd. 31 HELMUT UTZSCHNEIDER: Hosea - Prophet vor dem Ende. Zum Verhältnis von Geschichte und Institution in der alttestamentlichen Prophetie. 260 Seiten. 1980.

Bd. 32 PETER WEIMAR: Die Berufung des Mose. Literaturwissenschaftliche Analyse von Exodus 2, 23-5, 5. 402 Seiten. 1980. 
Bd. 33 OTHMAR KEEL: Das Böcklein in der Milch seiner Mutter und Verwandtes. Im Lichte eines altorientalischen Bildmotivs. 163 Seiten, 141 Abbildungen. 1980.

Bd. 34 PIERRE AUFFRET: Hymnes d'Egypte et d'Israël. Etudes de structures littéraires. 316 pages, 1 illustration. 1981.

Bd. 35 ARIE VAN DER KOOIJ : Die alten Textzeugen des Jesajabuches. Ein Beitrag zur Textgeschichte des Alten Testaments. 388 Seiten. 1981.

Bd. 36 CARMEL McCARTHY: The Tiqqune Sopherim and Otber Theological Corrections in the Masoretic Text of the Old Testament. 280 Seiten. 1981.

Bd. 37 BARBARA L. BEGELSBACHER-FISCHER: Untersuchungen zur Götterwelt des Alten Reiches im Spiegel der Privatgräber der IV. und V. Dynastie. 336 Seiten. 1981.

Bd. 38 MÉLANGES DOMINIQUE BARTHÉLEMY. Etudes bibliques offertes à l'occasion de son $60^{e}$ anniversaire. Edités par Pierre Casetti, Othmar Keel et Adrian Schenker. 724 pages, 31 illustrations. 1981.

Bd. 39 ANDRE LEMAIRE: Les écoles et la formation de la Bible dans l'ancien Israël. 142 pages, 14 illustrations. 1981 .

Bd. 40 JOSEPH HENNINGER: Arabica Sacra. Aufsätze zur Religionsgeschichte Arabiens und seiner Randgebiete. Contributions à l'histoire religieuse de l'Arabie et de ses régions limitrophes. 347 Seiten. 1981.

Bd. 41 DANIEL VON ALLMEN: La famille de Dieu. La symbolique familiale dans le paulinisme. LXVII-330 pages, 27 planches. 1981.

Bd. 42 ADRIAN SCHENKER: Der Mäcbtige im Scbmelzofen des Mitleids. Eine Interpretation von 2 Sam 24, 92 Seiten. 1982.

Bd. 43 PAUL DESELAERS: Das Bucb Tobit. Studien zu seiner Entstehung, Komposition und Theologie. 532 Seiten + Übersetzung 16 Seiten. 1982.

Bd. 44 PIERRE CASETTI: Gibt es ein Leben vor dem Tod? Eine Auslegung von Psalm 49. 315 Seiten. 1982.

Bd. 45 FRANK-LOTHAR HOSSFELD : Der Dekalog. Seine späten Fassungen, die originale Komposition und seine Vorstufen. 308 Seiten. 1982. Vergriffen.

Bd. 46 ERIK HORNUNG: Der ägyptische Mythos von der Himmelskuh. Eine Ätiologie des Unvollkommenen. Unter Mitarbeit von Andreas Brodbeck, Hermann Schlögl und Elisabeth Staehelin und mit einem Beitrag von Gerhard Fecht. XII-129 Seiten, 10 Abbildungen. 1982.

Bd, 47 PIERRE CHERIX: Le Concept de Notre Grande Puissance (CG VI, 4). Texte, remarques philologiques, traduction et notes. XIV-95 pages. 1982.

Bd. 48 JAN ASSMANN/WALTER BURKERT/FRITZ STOLZ: Funktionen und Leistungen des Mytbos. Drei altorientalische Beispiele. 118 Seiten, 17 Abbildungen. 1982. Vergriffen.

Bd. 49 PIERRE AUFFRET: La sagesse a bâti sa maison. Etudes de structures littéraires dans l'Ancien Testament et spécialement dans les psaumes. 580 pages. 1982.

Bd. 50/1 DOMINIQUE BARTHÉLEMY: Critique textuelle de l'Ancien Testament. 1. Josué, Juges, Ruth, Samuel, Rois, Chroniques, Esdras, Néhémie, Esther. Rapport final du Comité pour l'analyse textuelle de l'Ancien Testament hébreu institué par l'Alliance Biblique Universelle, établi en coopération avec Alexander R. Hulst $t$, Norbert Lohfink, William D. McHardy, H. Peter Rüger, coéditeur, James A. Sanders, coéditeur. 812 pages. 1982. 
Bd. 50/2 DOMINIQUE BARTHÉlEMY: Critique textuelle de l'Ancien Testament. 2. Isaïe, Jérémie, Lamentations. Rapport final du Comité pout l'analyse textuelle de l'Ancien Testament hébreu institué par l'Alliance Biblique Universelle, établi en coopération avec Alexander R. Hulst t, Norbert Lohfink, William D. McHardy, H. Peter Rüger, coéditeur, James A. Sanders, coéditeur. 1112 pages. 1986.

Bd. 51 JAN ASSMANN: Re und Amun. Die Krise des polytheistischen Weltbilds im Ägypten der 18.-20. Dynastie. XII-309 Seiten. 1983.

Bd. 52 MIRIAM LICHTHEIM: Late Egyptian Wisdom Literature in the International Context. A Study of Demotic Instructions. X-240 Seiten. 1983.

Bd. 53 URS WINTER: Frau und Göttin. Exegetische und ikonographische Studien zum weiblichen Gottesbild im Alten Israel und in dessen Umwelt. XVIII-928 Seiten, 520 Abbildungen. 1987. 2. Auflage. Mit einem Nachwort zur 2. Auflage.

Bd. 54 PAUL MAIBERGER: Topograpbische und bistorische Untersucbungen zum Sinaiproblem. Worauf beruht die Identifizierung des Gabal Müsä mit dem Sinai? 189 Seiten, 13 Tafeln. 1984.

Bd. 55 PETER FREI/KLAUS KOCH: Reichsidee und Reichsorganisation im Perserreich. 119 Seiten, 17 Abbildungen. 1984. Vergriffen.

Bd. 56 HANS-PETER MÜLLER: Vergleich und Metapher im Hohenlied. 59 Seiten. 1984.

Bd. 57 STEPHEN PISANO: Additions or Omissions in the Books of Samuel. The Significant Pluses and Minuses in the Massoretic, LXX and Qumran Texts. XIV-295 Seiten. 1984.

Bd. 58 ODO CAMPONOVO: Königtum, Königsherrscbaft und Reicb Gottes in den Frübjüdischen Scbriften. XVI-492 Seiten. 1984.

Bd. 59 JAMES KARL HOFFMEIER: Sacred in the Vocabulary of Ancient Egypt. The Term DSR, with Special Reference to Dynasties I-XX. XXIV-281 Seiten, 24 Figures. 1985.

Bd. 60 CHRISTIAN HERRMANN: Formen für ägyptische Fayencen. Katalog der Sammlung des Biblischen Instituts der Universität Freiburg Schweiz und einer Privatsammlung. XXVIII-199 Seiten. 1985.

Bd. 61 HELMUT ENGEL: Die Susanna-Erzäblung. Einleitung, Übersetzung und Kommentar zum Septuaginta-Text und zur Theodition-Bearbeitung. 205 Seiten + Anhang 11 Seiten. 1985.

Bd. 62 ERNST KUTSCH: Die chronologischen Daten des Ezecbielbuches. 82 Seiten. 1985.

Bd. 63 MANFRED HUTTER: Altorientalische Vorstellungen von der Untervelt. Literar- und religionsgeschichtliche Überlegungen zu "Nergal und Ereškigal». VIII-187 Seiten. 1985.

Bd. 64 HELGA WEIPPERT/KLAUS SEYBOLD/MANFRED WEIPPERT: Beiträge zur prophetischen Bildsprache in Israel und Assyrien. IX-93 Seiten. 1985.

Bd. 65 ABDEL-AZIZ FAHMY SADEK: Contribution à l'étude de l'Amdouat. Les variantes tardives du Livre de l'Amdouat dans les papyrus du Musée du Caire. XVI-400 pages, 175 illustrations. 1985.

Bd. 66 HANS-PETER STÄHLI: Solare Elemente im Jabweglauben des Alten Testamentes. X-60 Seiten. 1985.

Bd. 67 OTHMAR KEEL/SILVIA SCHROER: Studien $z u$ den Stempelsiegeln aus Palästina/lsrat. Band I. 115 Seiten, 103 Abbildungen. 1985.

Bd. 68 WALTER BEYERLIN: Weisheitliche Vergewisserung mit Bezug auf den Zionskult. Studien zum 125. Psalm. 96 Seiten. 1985. 
Bd. 69 RAPHAEL VENTURA: Living in a City of the Dead. A Selection of Topographical and Administrative Terms in the Documents of the Theban Necropolis. XII-232 Seiten. 1986.

Bd. 70 CLEMENS LOCHER: Die Ebre einer Frau in Israel. Exegetische und rechtsvergleichende Studien zu Dtn 22, 13-21. XVIII-464 Seiten. 1986.

Bd. 71 HANS-PETER MATHYS: Liebe deinen Nächsten wie dich selbst. Untersuchungen zum alttestamentlichen Gebot der Nächstenliebe (Lev 19, 18). XIV-196 Seiten. 1986.

Bd. 72 FRIEDRICH ABITZ: Ramses III. in den Gräbem seiner Söbne. 156 Seiten, 31 Abbildungen. 1986.

Bd. 73 DOMINIQUE BARTHÉLEMY/DAVID W. GOODING/JOHAN LUST/EMANUEL TOV: The Story of David and Goliath. 160 Seiten. 1986.

Bd. 74 SILVIA SCHROER: In Israel gab es Bilder. Nachrichten von darstellender Kunst im Alten Testament. XVI-553 Seiten, 146 Abbildungen. 1987.

Bd. 75 ALAN R. SCHULMAN: Ceremonial Execution and Public Rewards. Some Historical Scenes on New Kingdom Private Stelae. 296 Seiten. 41 Abbildungen. 1987.

Bd. 76 JOŽE KRAŠOVEC: La justice (S $S q$ ) de Dieu dans la Bible bébraïque et l'interprétation juive et cbrétienne. 456 pages. 1988.

Bd. 77 HELMUT UTZSCHNEIDER: Das Heiligtum und das Gesetz. Studien zur Bedeutung der sinaitischen Heiligtumstexte (Ez 25-40; Lev 8-9). XIV-326 Seiten. 1988.

Bd. 78 BERNARD GOSSE: Isaie 13,1-14,23. Dans la tradition littéraire du livre d'Isaîe et dans la tradition des oracles contre les nations. 308 pages. 1988.

Bd. 79 INKE W. SCHUMACHER: Der Gott Sopdu - Der Herr der Fremdländer. XVI-364 Seiten, 6 Abbildungen. 1988.

Bd. 80 HELLMUT BRUNNER: Das börende Herz. Kleine Schriften zur Religions- und Geistesgeschichte Ägyptens. Herausgegeben von Wolfgang Röllig. 449 Seiten, 55 Abbildungen. 1988.

Bd. 81 WALTER BEYERLIN: Bleilot, Brecheisen oder was sonst? Revision einer Amos-Vision. 68 Seiten. 1988.

Bd. 82 MANFRED HUTTER: Behexung, Entsübnung und Heilung. Das Ritual der Tunnawiya für ein Königspaar aus mittelhethitischer Zeit (KBo XXI 1 - KUB IX 34 - KBo XXI 6). 186 Seiten. 1988.

Bd. 83 RAPHAEL GIVEON: Scarabs from Recent Excavations in Israel. 114 Seiten, 9 Tafeln. 1988.

Bd. 84 MIRIAM LICHTHEIM : Ancient Egyptian Autobiographies chiefly of the Middle Kingdom. A Study and an Anthology. 200 Seiten, 10 Seiten Abbildungen. 1988.

Bd. 85 ECKART OTTO: Rechtsgeschicbte der Redaktionen im Kodex Ešnunna und im «Bundesbuch». Eine redaktionsgeschichtliche und rechtsvergleichende Studie zu altbabylonischen und altisraelitischen Rechtsüberlieferungen. 220 Seiten. 1989.

Bd. 86 ANDRZEJ NIWIŃSKI: Studies on the Illustrated Theban Funerary Papyri of the 11th and 10th Centuries B.C. 488 Seiten, 80 Seiten Tafeln. 1989.

Bd. 87 URSULA SEIDL: Die babylonischen Kudurru-Reliefs. Symbole mesopotamischer Gottheiten. 236 Seiten, 33 Tafeln und 2 Tabellen. 1989.

Bd. 88 OTHMAR KEEL/HILDI KEEL-LEU/SILVIA SCHROER : Studien zu den Stempelsiegeln aus Palästina/Israel. Band II. 364 Seiten, 652 Abbildungen. 1989.

Bd. 89 FRIEDRICH ABITZ: Baugeschicbte und Dekoration des Grabes Ramses' VI. 202 Seiten. 1989. 
Bd. 90 JOSEPH HENNINGER SVD: Arabica varia. Aufsätze zur Kulturgeschichte Arabiens und seiner Randgebiete. Contributions à l'histoire culturelle de l'Arabie et de ses régions limitrophes. 504 Seiten. 1989.

Bd. 91 GEORG FISCHER: Jabwe unser Gott. Sprache, Aufbau und Erzâhltechnik in der Berufung des Mose (Ex 3-4). 276 Seiten. 1989. 